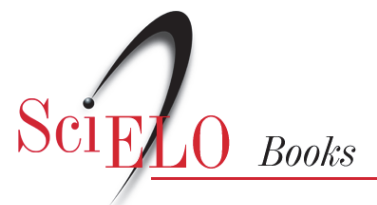

\title{
Uma escola para a saúde
}

\author{
Nísia Trindade Lima \\ Cristina M. O. Fonseca \\ Paulo Roberto Elian dos Santos \\ orgs.
}

LIMA, NT., FONSECA, CMO., and SANTOS, PRE., orgs. Uma escola para a saúde [online]. Rio de Janeiro: Editora FIOCRUZ, 2004. 268 p. ISBN 85-7541-047-4. Available from SciELO Books $<\underline{\text { http://books.scielo.org>. }}$

\section{(1) (1)(2)}

All the contents of this work, except where otherwise noted, is licensed under a Creative Commons Attribution-Non Commercial-ShareAlike 3.0 Unported.

Todo o conteúdo deste trabalho, exceto quando houver ressalva, é publicado sob a licença Creative Commons Atribuição Uso Não Comercial - Partilha nos Mesmos Termos 3.0 Não adaptada.

Todo el contenido de esta obra, excepto donde se indique lo contrario, está bajo licencia de la licencia Creative Commons Reconocimento-NoComercial-CompartirIgual 3.0 Unported. 
entendermos a nossa história e da para conhecermos näo somente a

Esco mas a moderna saúde coletiva brasileira, com a qual estamios
SND

Esta obra apresenta os caminhos percorridos na direção da profissionalização e da especialização em saúde pública no Brasil, refletindo as influências e iniciativas nacionais e internacionais na criação da Escola Nacional de Saude Pública (Ensp), no Rio de Janeiro em 1954. Nesse laboratório de idéias em que se constituiu a Escola, formularam-se propostas que contribuiram para as grandes conquistas da saúde pública brasileira e que subsidiaram o processo de Reforma Sanitária, cujos resultados se expressam na constituição e no fortalecimento do Sistema Unico de Saude.

A publicação de Uma escola para a saúde é um reconhecimento a todos os pensadores, cientistas e educadores da saude publica que construiram com os seus estorços e, especialmente, com seus idea uma das instituiçōes mais fortes da saúde pública latino-americana. Trata-se de uma homenagem a todos e, em particular, a Sergio Arouca cujo nome engrandece a Escola.

Horácio Toro Ocampo

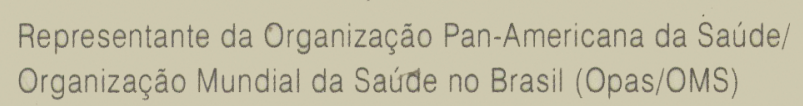
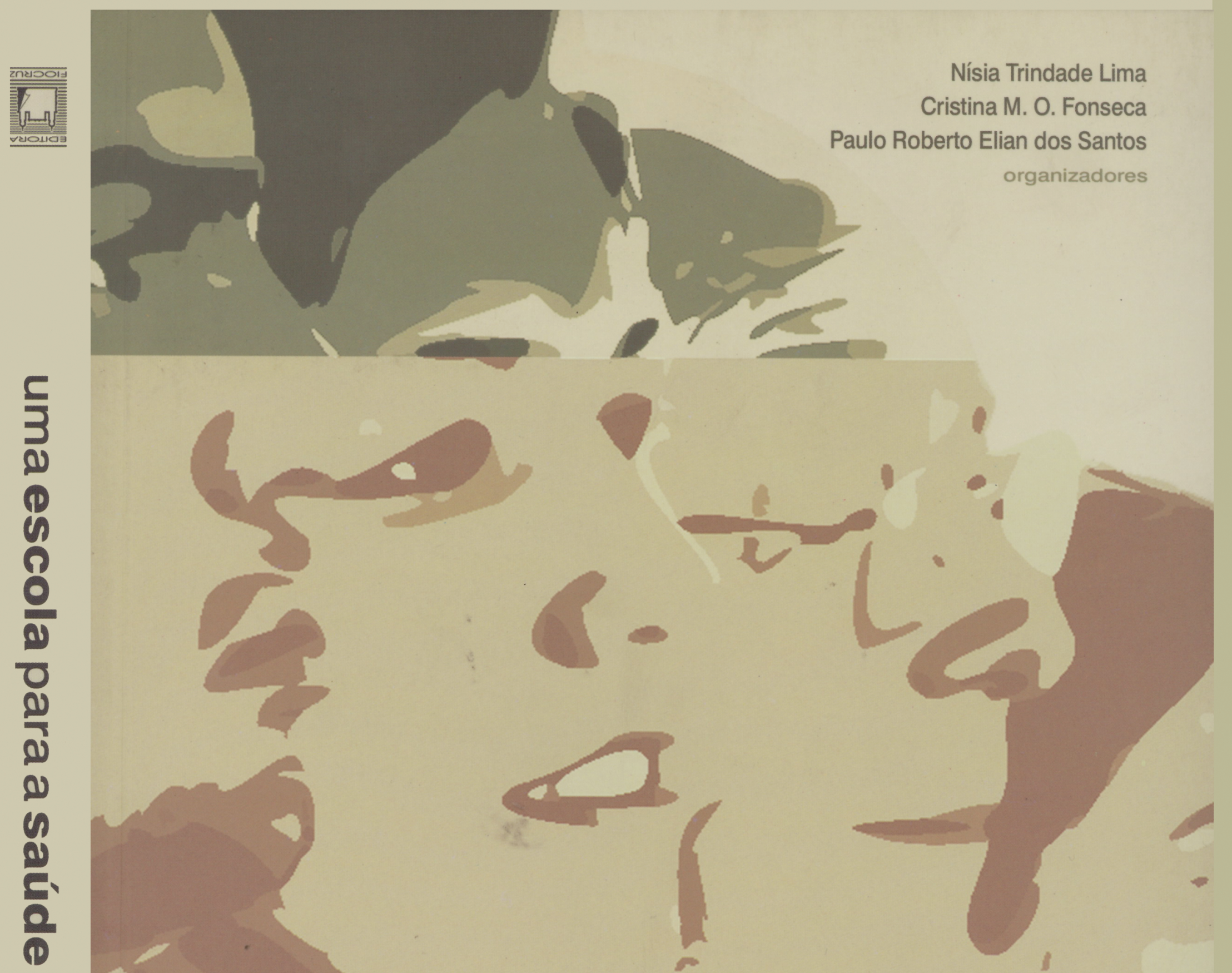

uma escola para a saúde

|i||iil|

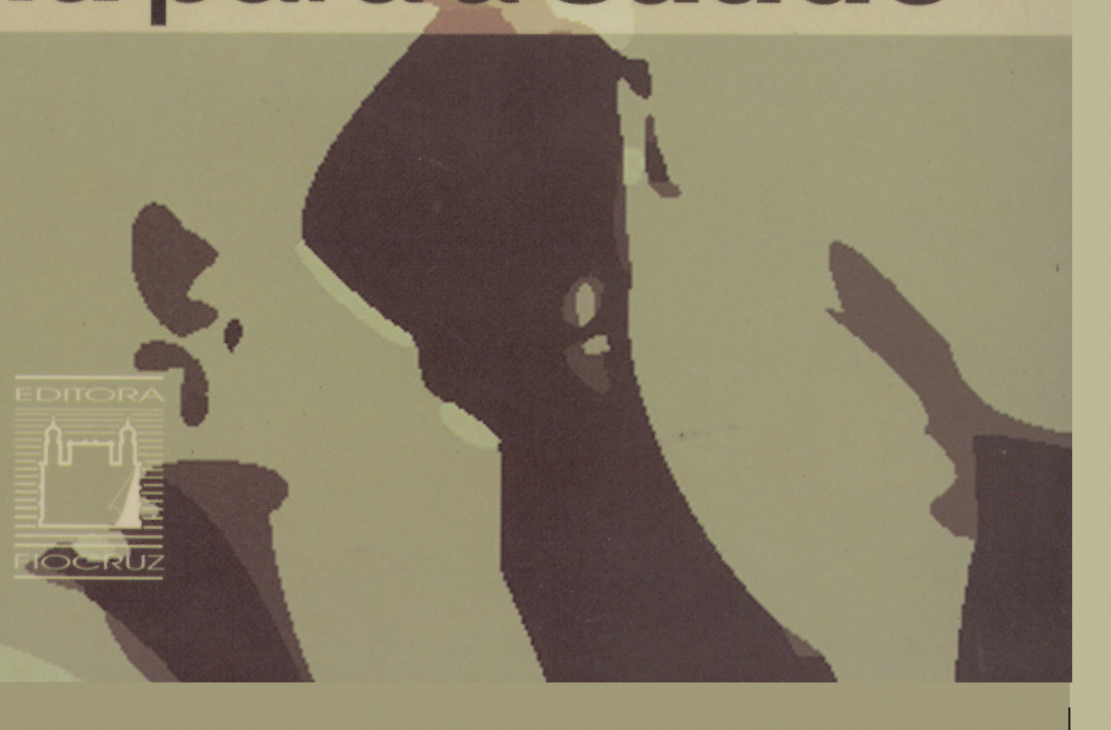

"A nossa Escola tem sido uma casa de pensamento e ação, com

Uname no nivel molecular ao social, com um objetivo prático claro: oferecer melhores condiçōes de saúde para a população ". Fernando Ferreira, contida em um do o escopo e o alcance da Escol Nacional de Saúde Pública Sergio Arouc Ensp). cuja história de 50 anos é qui retratada de modo felize oportuno.

rico acervo de documentos consultados e sistematizados, acrescido das narrativas pessoais, permite acompanhar a auto-reflexão oferecida sobre identidade e inscriçâa institucional da Ensp. A leitura dos textos reforça as claras evidências de sua importante e influente trajetória nos vários momentos da saúde pública na construção da moderna saúde oletiva brasileira. Sua presenca ranscende os limites da nossa fronteira e se faz repercutir nos países vizinhos da América Latina e Caribe.

Como ator institucional privilegiado, ao lado dos demais membros da comunidade da saúde coletiva representados pela nossa Associação. Brasileira de Pós-Graduação em Saúde 


\section{uma escola para a saúde}




\author{
FUNDAÇÃO OSWALDO CRUZ \\ Presidente \\ Paulo Marchiori Buss \\ Vice-Presidente de Desenvolvimento Institucional, \\ Informação e Comunicação \\ Paulo Gadelha \\ EDITORA FIOCRUZ \\ Coordenador \\ Paulo Gadelha \\ Conselho Editorial \\ Carla Macedo Martins \\ Carlos E. A. Coimbra Jr. \\ Carolina M. Bori \\ Charles Pessanha \\ Gilberto Hochman \\ Jaime L. Benchimol \\ José da Rocha Carvalheiro \\ José Rodrigues Coura \\ Luis David Castiel \\ Luiz Fernando Ferreira \\ Maria Cecília de Souza Minayo \\ Miriam Struchiner \\ Paulo Amarante \\ Vanize Macêdo \\ Coordenador Executivo \\ João Carlos Canossa P. Mendes
}


Nísia Trindade Lima

Cristina M. O. Fonseca

Paulo Roberto Elian dos Santos

organizadores

\section{uma escola para a saúde}


Copyright (C) 2004 dos autores

Todos os direitos desta edição reservados à

FUNDAÇ̃̃O OSWALDO CRUZ / EDITORA

ISBN: 85-7541-047-4

Capa: Carlos Fernando Reis (criação a partir da foto de Gutemberg Brito) Arte-final: Adriana Carvalho

Projeto Gráfico e Editoração Eletrônica: Carlota Rios

Revisão: Regina Celie Simões Marques

Supervisão Editorial: Janaina de Souza Silva

Catalogação na fonte

Centro de Informação Científica e Tecnológica

Biblioteca da Escola Nacional de Saúde Pública Sergio Arouca
L732u Lima, Nísia Trindade (Org.)
Uma escola para a saúde. / Organizado por Nísia Trindade Lima, Cristina M. O. Fonseca e Paulo Roberto Elian dos Santos. Rio de Janeiro: Editora Fiocruz, 2004.

268 p., ilus., tab., graf.

1. Escolas de saúde pública-história. 2. Saúde pública-educação. 3. Sistema de saúde-Brasil. 4. Educação de pós-graduação. I. Fonseca, Cristina M. O. (Org.). II. Santos, Paulo Roberto Elian dos (Org.). III. Título.

CDD - 20.ed. - 378.199

2004

EdITORa FIOCRUZ

Av. Brasil, 4036 - Térreo - sala 112 - Manguinhos

21041-361 - Rio de Janeiro - RJ

Tels: (21) 3882-9039 / 3882-9041

Telefax: (21) 3882-9006

e-mail: editora@fiocruz.br

http://www.fiocruz.br

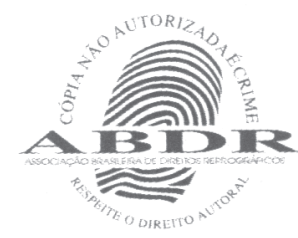




\section{Autores}

\section{André de Faria Pereira Neto}

Historiador, doutor em Saúde Coletiva, pesquisador da Casa de Oswaldo Cruz (COC/Fiocruz)

Carlos E. A. Coimbra Jr.

Antropólogo, Ph.D. em Antropologia, pesquisador da Escola Nacional de Saúde Pública

Sergio Arouca (Ensp/Fiocruz) e editor-chefe dos Cadernos de Saúde Pública

\section{Cristina M. O. Fonseca (Organizadora)}

Historiadora, mestre em História, pesquisadora do Departamento de Pesquisa da Casa de Oswaldo Cruz (COC/Fiocruz)

\section{Jorge Antonio Zepeda Bermudez}

Médico, doutor em Saúde Pública, pesquisador titular do Departamento de Ciências Biológicas e diretor da Escola Nacional de Saúde Pública Sergio Arouca (Ensp/Fiocruz)

\section{Luiz Fernando Rocha Ferreira da Silva}

Médico, doutor em Medicina, pesquisador emérito da Fundação Oswaldo Cruz (Fiocruz)

\section{Nísia Trindade Lima (Organizadora)}

Cientista social, doutora em Sociologia, pesquisadora e diretora da Casa de Oswaldo Cruz (COC/ Fiocruz) e professora de sociologia da Universidade do Estado do Rio de Janeiro (Uerj)

\section{Paulo Roberto Elian dos Santos (Organizador)}

Historiador, mestre em História Social, pesquisador do Departamento de Arquivo e Documentação da Casa de Oswaldo Cruz (COC/Fiocruz)

\section{Reinaldo Souza-Santos}

Epidemiologista, doutor em Saúde Pública, pesquisador da Escola Nacional de Saúde Pública Sergio Arouca (Ensp/Fiocruz) e editor-associado dos Cadernos de Saúde Pública 


\section{Ricardo Ventura Santos}

Antropólogo, Ph.D. em Antropologia, pesquisador da Escola Nacional de Saúde Pública Sergio Arouca/Fiocruz, professor do Departamento de Antropologia do Museu Nacional da Universidade Federal do Rio de Janeiro (UFRJ) e membro do conselho editorial dos Cadernos de Saúde Pública

\section{Tânia Celeste Matos Nunes}

Nutricionista, doutora em Saúde Pública, vice-presidente de Ensino e Recursos Humanos da Fundação Oswaldo Cruz (Fiocruz)

\section{Verônica Martins de Brito}

Bibliotecária, mestre em Ciência da Informação, coordenadora do Setor de Arquivo Institucional do Departamento de Arquivo e Documentação da Casa de Oswaldo Cruz (COC/Fiocruz)

\section{ENTREVISTADOS}

\section{Adauto José Gonçalves de Araújo}

Médico, doutor em Saúde Pública, ex-diretor da Escola Nacional de Saúde Pública Sergio Arouca (Ensp) e coordenador do programa de pós-graduação em Saúde Pública da Ensp

Entrevistadores: Cristina M. O. Fonseca e Paulo Roberto Elian dos Santos

LOCAL: Rio de Janeiro/RJ

DATA: 7 de abril 2004

(Fitas gravadas: 2)

\section{Arlindo Fábio Gómez de Sousa}

Sociólogo, ex-professor e ex-diretor Escola Nacional de Saúde Pública Sergio Arouca (Ensp), ex-presidente da Associação Brasileira de Pós-Graduação em Saúde Coletiva (Abrasco) e chefe de gabinete da presidência da Fiocruz

Entrevistador: André de Faria Pereira Neto

LOCAL: Rio de Janeiro/RJ

DATA: 14 de novembro e 18 de outubro de 2003

(Fitas gravadas: 6) 


\section{Luiz Fernando Rocha Ferreira da Silva}

Médico, professor titular da Escola Nacional de Saúde Pública Sergio Arouca (Ensp) e ex-vicepresidente da Fiocruz

ENTREVISTADOREs: Nara Azevedo e Wanda Hamilton

LOCAL: Rio de Janeiro/RJ

DATA: 7 e 9 de dezembro de 1999

(Fitas gravadas: 5)

Entrevistador: André de Faria Pereira Neto

LOCAL: Rio de Janeiro/RJ

DATA: 14 de novembro e 18 de outubro de 2003

(Fitas gravadas: 6)

\section{Eduardo de Azeredo Costa}

Médico, epidemiologista, Ph.D. em filosofia, assessor técnico da presidência da Fiocruz e exsecretário de Estado de Saúde do Rio de Janeiro (1983-1986)

Entrevistadores: Cristina M. O. Fonseca, Paulo Roberto Elian dos Santos e Lisabel Espellet Klein

LOCAL: Rio de Janeiro/RJ

DATA: 2, 8 e 16 de março; 27 de abril 2004

(Fitas gravadas: 10)

\section{Elsa Ramos Paim}

Enfermeira, especialização em Saúde Pública e em Planejamento do Setor Saúde e ex-professora da Ensp

Entrevistadores: Cristina M. O. Fonseca e Verônica Martins de Brito LOCAL: Rio de Janeiro/RJ

DAta: 26 e 30 de abril; 7 e 12 de maio; 17 de junho de 2004

(Fitas gravadas: 10)

\section{Fernando Leitão}

Médico, especialização em Planejamento de Saúde pela Escola Nacional de Saúde Pública Sergio Arouca (Ensp), professor honoris causa da Ensp e ex-assessor técnico da Escola Politécnica de Saúde Joaquim Venâncio

EntreVISTAdoras: Cristina M. O. Fonseca e Lisabel Espellet Klein

LOCAL: Rio de Janeiro/RJ

DATA: 17 de maio de 2004

(Fitas gravadas: 2)

\section{Hélio Wanderley Uchôa}

Cirurgião dentista, professor titular do Curso Básico de Saúde Pública e ex-coordenador dos cursos descentralizados de Saúde Pública

Entrevistadores: Cristina M. O. Fonseca, Paulo Roberto Elian dos Santos e Verônica Martins de Brito

LOCAL: Rio de Janeiro/RJ

DATA: 18 e 25 de novembro de 2003

(Fitas gravadas: 4) 


\section{Lenita Peixoto Vasconcelos}

Educadora em Saúde Pública e ex-professora da Escola Nacional de Saúde Pública Sergio Arouca (Ensp)

Entrevistadores: Cristina M. O. Fonseca, Paulo Roberto Elian dos Santos e

Verônica Martins de Brito

LOCAL: Rio de Janeiro/RJ

DATA: 9 e 16 de dezembro de 2003

(Fitas gravadas: 5)

\section{Maria do Carmo Leal}

Médica, doutora em Saúde Pública, ex-diretora da Escola Nacional de Saúde Pública Sergio Arouca (Ensp) e professora titular da Ensp

Entrevistadora: Cristina M. O. Fonseca

LOCAL: Rio de Janeiro/RJ

DATA: 2 de junho de 2004

(Fitas gravadas: 2)

\section{Paulo Marchiori Buss}

Médico, mestre em Medicina Social, pesquisador titular do Departamento de Administração do Serviço Público da Escola Nacional de Saúde Pública Sergio Arouca (Daps/Ensp), vice-diretor da Ensp (1985-1988), diretor da Ensp (1989-1992 e 1998-2000), vice-presidente da Fundação Oswaldo Cruz (Fiocruz - 1993-1996) e atual presidente da Fiocruz.

Entrevistadores: Nísia Trindade Lima, Cristina M. O. Fonseca, Paulo Roberto Elian dos Santos e Verônica Martins de Brito

LOCAL: Rio de Janeiro/RJ

DATA: 16 e 19 de fevereiro de 2004

(Fitas gravadas: 3 )

\section{Szachna Eliasz Cynamon}

Engenheiro sanitarista, doutor em Saúde Pública e professor titular da Escola Nacional de Saúde Pública Sergio Arouca (Ensp)

Entrevistadores: Cristina M. O. Fonseca, Paulo Roberto Elian dos Santos e Verônica Martins de Brito

LOCAL: Rio de Janeiro/RJ

Data: 3, 10 e 17 de fevereiro de 2004

(Fitas gravadas: 9) 


\section{SUMÁRIO}

PREFÁCIO

11

APRESENTAÇ̃̃o 17

PARTE I - HistóRIA: EXPERIÊNCIA E PERSPECTIVA

1. História da Especialização em Saúde Pública no Brasil: nota introdutória 25

Nísia Trindade Lima e Cristina M. O. Fonseca

2. A Criação da Ensp: integração e diversidade na formação em saúde pública

Cristina M. O. Fonseca

3. A Ensp e as Transformações na Sociedade e no Sistema de Saúde no Brasil: 1970 a 1985

Paulo Roberto Elian dos Santos, Verônica Martins de Brito, Nísia Trindade Lima e Cristina M. O. Fonseca

4. A Escola Nacional de Saúde Pública Sergio Arouca: um laboratório de idéias para a saúde 103

Paulo Roberto Elian dos Santos, Verônica Martins de Brito, Nísia Trindade Lima e Cristina M. O. Fonseca

Uma História de Vida na Saúde Pública

Entrevista com Ernani Braga 129 
Parte II - Uma Casa de Pensamento e Ação

5. Os Primeiros Tempos: Edmar Terra Blois e Sávio Antunes 159 Luiz Fernando Rocha Ferreira da Silva

6. A Valorização do 'Instituinte' na Construção do Modelo de Escola Nacional: a Ensp de 1970 a 1989

Tânia Celeste Matos Nunes

7. Cadernos de Saúde Pública: uma trajetória de 20 anos 203

Carlos E. A. Coimbra Jr., Reinaldo Souza-Santos e Ricardo Ventura Santos

8. O Perfil dos Egressos da Pós-Graduação Stricto Sensu da Ensp: hipóteses, tendências e proposta para uma avaliação institucional André de Faria Pereira Neto

9. Escola Nacional de Saúde Pública Sergio Arouca: uma reflexão pessoal

Jorge Antonio Zepeda Bermudez

MEMória FotogrÁficA 


\section{Prefácio}

Dos 50 anos da Escola Nacional de Saúde Pública (Ensp), vivi intensamente os últimos 30. Nela ingressei como auxiliar de ensino em março de 1976, depois de ter realizado um curso de administração e planejamento materno-infantil no segundo semestre de 1975, sob a coordenação de Mário Hamilton, Susana Badino e Célia Almeida, como complemento ao meu mestrado em medicina social que fazia na Universidade do Estado do Rio de Janeiro (Uerj). Logo depois, dona Elsa Paim convidou-me para colaborar na supervisão do trabalho de campo do curso de saúde pública de 1975, e daí tudo começou.

Quando lá cheguei havia uma efervescência absoluta na Escola. Pelas mãos de Arlindo Fábio e outros pioneiros, a Ensp começava a descentralizar seus cursos de saúde pública, numa das mais fascinantes experiências da saúde pública continental, pois decidia-se a suprir a necessidade de formação de recursos humanos em saúde pública de um país imenso, com realidades muito diferentes, a partir de uma Escola localizada na estrutura do Ministério da Saúde e sediada no Rio de Janeiro. Voltarei depois a este assunto!

$\mathrm{Na}$ outra ponta, a da pesquisa, iniciava-se uma experiência definitivamente transformadora para a Ensp e para a saúde pública brasileira: a Financiadora de Estudos e Projetos (Finep), no âmbito do I Plano Básico de Desenvolvimento Científico e Tecnológico (I PBDCT), criada no governo do 'déspota esclarecido', general Ernesto Geisel, passava a financiar o ressurgimento de Manguinhos, que se refletia na Ensp com a criação do Programa de Estudos Socioeconômicos em Saúde (Peses) e do Programa de Estudos Populacionais e Epidemiológicos (Peppe), sob a batuta de Eduardo Costa, Sergio Arouca e seu time, recém-chegados da Universidade Estadual de Campinas (Unicamp), de onde haviam sido 'expulsos'. 
A Ensp com que então entrei em contato era uma instituição cheia de promessas: uma interessante mistura de sanitaristas mais tradicionais, muitos deles oriundos da excepcional tradição do Serviço Especial de Saúde Pública (Sesp), com um grupo de vanguarda, academicamente bem titulado e originado de uma jovem universidade paulista. Arlindo Fábio, Elsa Paim, Eduardo Costa, Cynamon, Luíz Fernando, Arouca, Marília, Ana Tambelini, para citar apenas alguns, constituíam as referências para um grupo mais jovem, que chegava pelas mãos da Ensp ou do financiamento do Peses-Peppe.

E o contexto era, no mínimo, um primor de desafio: governo militar, recursos para pesquisa relativamente abundantes, a Escola espalhando-se pelo Brasil, um país que acelerava a industrialização e a urbanização. Era disso que a Ensp precisava tratar. E creio que o fez com galhardia e com refinada habilidade política e técnica.

Ao processo de descentralização dos cursos de saúde pública da Ensp, com a constituição de uma rede muito forte de núcleos em quase todos os estados brasileiros, seguiu-se a constituição de uma rede de residências em saúde pública e medicina preventiva e social, com o apoio do Instituto Nacional de Assistência Médica da Previdência Social (Inamps).

Herdeiros do Treinamento Avançado em Serviço (TAS), com o contexto favorável da valorização das residências médicas pelo Ministério da Educação e Cultura (MEC) - que constituíra a Comissão Nacional de Residência Médica - criamos a residência em saúde pública da Ensp, mas com características muito particulares: era multiprofissional e não apenas médica e desenvolvia-se em 'áreas de prática' concretas, isto é, no interior dos próprios serviços de saúde. Foram alunos deste programa docentes que hoje são referências no colegiado científico e técnico da Ensp e do mundo: Dora Schor, Pedro Barbosa, Marília Sá Carvalho, Sheila Lemos, Zulmira Hartz, Eduardo Levcovitz (Dadá), Luís Carlos Lima, Guido Palmeira, Evandro Coutinho, entre outros. Nildo Aguiar foi peça fundamental na constituição do programa de residência da Escola, como também do Programa de Apoio às Residências de medicina social, preventiva e saúde pública (PAR), como chamava-se a rede de residências. Francisco Campos, Jairnilson Paim e José Paranaguá Santana foram aqueles companheiros de todas as horas, que estiveram desde o início na formatação e, depois, no desenvolvimento do PAR.

Das duas redes mencionadas acima certamente nasceu a Associação Brasileira de Pós-Graduação em Saúde Coletiva (Abrasco), hoje uma poderosa associação de saúde coletiva, se levarmos em conta tanto o contexto continental quanto o contexto mundial. 
Não há dúvidas de que o pujante processo desenvolvido pela Ensp no último lustro da década de 1970 foi a base fundamental sobre a qual se erigiu a Abrasco, hoje um orgulho para todos nós. Fico envaidecido ao constatar que estive envolvido de corpo e alma nesses dois processos sucessivos - o da formação da rede de programas de residência EnspInamps e o do surgimento da Abrasco, dos quais fui, com um orgulho que não consigo disfarçar, o primeiro coordenador e secretário executivo, respectivamente.

Com a redemocratização do país, também recuperou-se um processo de maior autodeterminação da Fundação Oswaldo Cruz (Fiocruz), com a campanha que levou Sergio Arouca à presidência da instituição, em 1985, no advento da Nova República. O então ministro da Saúde, Carlos Santana, e os sanitaristas Fabíola Aguiar Nunes e Eleutério Rodriguez Neto foram importantes 'cúmplices' nesta 'conspiração'. Toda a Ensp empenhouse a fundo para que seu ilustre professor ascendesse ao cargo máximo da Fiocruz. Nesse contexto, fomos, Frederico Simões Barbosa e eu, promovidos a diretor e vice-diretor da Ensp.

Entre 1986 e 1989 implementamos duas iniciativas decisivas para a construção da Ensp de hoje: por um lado, reforçamos a instituição com um programa de pesquisadores visitantes doutores, financiado com recursos próprios, mas executado pelo Conselho Nacional de Desenvolvimento Científico e Tecnológico $(\mathrm{CNPq})$, que trouxe pouco mais de 30 doutores, fundamentais para o reforço ao programa de pesquisa e para a retomada do pós-graduação stricto sensu (reabriu-se o doutorado em 1990). Por outro, com o fantástico apoio de Hésio Cordeiro e José Gomes Temporão, respectivamente presidente e diretor de Planejamento do Inamps, firmamos um convênio de cooperação técnica, através do qual passamos a receber recursos regulares que permitiram expandir os cursos, financiar pesquisas e, sobretudo, contratar quadros qualificados, o que não se conseguia com recursos do Tesouro.

Como diretor da Escola (1989-1992), tratamos de finalizar o que tínhamos iniciado nos cinco últimos anos de 1970; qual seja, agregar à qualidade técnica e política da Ensp um status acadêmico. A (re)criação do doutorado, o reforço da estratégia dos pesquisadores visitantes e um importante programa de incentivo ao doutoramento junto aos quadros da instituição foram estratégias implementadas, simultaneamente, com muita persistência e denodo. Os resultados foram excelentes: o programa de pós-graduação prosperou enormemente, abriram-se inúmeras áreas de concentração as vagas multiplicaram-se, e as teses e dissertações da 
década de 1990 e dos primeiros anos deste século estão aí para testemunhar esta história.

Neste exame a vôo de pássaro dos meus 30 anos passados na Escola, gostaria de relembrar rapidamente os anos mais recentes, basicamente o meu segundo mandato (1998-2000). Ao retornar da vicepresidência da Fiocruz, durante um ano (1997) busquei construir uma nova área de conhecimento e prática, que considerava muito importante para a Escola e para a saúde pública brasileira: a promoção da saúde. Com o esforço iniciado nos dois anos anteriores, quando ainda estava na vicepresidência da Fiocruz, conseguimos, a partir de 1997, um apoio da Canadian International Development Agency (Cida) para o projeto conjunto da Escola e da Canadian Public Health Association (Ensp-CPHA), pelo qual creio que fincamos bases firmes para esta área antes não existente (ou não explicitada) no amplo universo de objetos de que trata a Ensp. José Roberto Ferreira foi fundamental, por todas as razões, para a construção desta empreitada.

Ao retornar à Ensp percebi o quanto ela se firmara na vida acadêmica, mas o quanto poderia e deveria agora se reaproximar do SUS. Era fazer o pêndulo institucional começar a voltar: de uma prioridade para o componente acadêmico tão importante intitulado, na nossa proposta de trabalho, 'gestão da diversidade', para a priorização da pesquisa e da formação para o SUS. Foi esta percepção simples e, obviamente, as condições objetivas que encontramos, que permitiram que emergisse a estratégia Escola de Governo em Saúde. O Programa de Educação a Distância, que iniciou na gestão de Adauto Araújo, era o ingrediente de ouro para que o reforço do compromisso da Escola com a pesquisa e a formação para o SUS passassem a vigorar.

Mais uma vez, a Escola movia-se: um grande debate se estabeleceu em torno da pós-graduação, da educação a distância, da estratégia Escola de Governo e do mestrado profissional. Outra vez a Ensp sai reforçada do debate e um conjunto muito significativo de novos programas de ensino, bem como o programa de pesquisa estratégica são desenhados e implementados pela comunidade científica da instituição.

Os desafios não cessam. Sem ser exaustivo e talvez com uma ponta de arrogância, permito-me pensar o que toca à Ensp nos próximos anos de sua caminhada, agora rumo ao centenário, depois de completar com brio e formosura os seus primeiros 50 anos.

Creio que precisamos reafirmar mais do que nunca o 'papel e o compromisso nacional' da Ensp. Isto significa que devemos procurar 
diminuir a distância que separa os sanitaristas que estão na academia daqueles em atuação nos serviços do grande território brasileiro. Nesse sentido, certamente o fortalecimento e a ampliação do Programa de Educação a Distância estão entre os nossos principais desafios (e obrigações) dos próximos anos. A constituição de uma Rede Escola de Governo em Saúde, reunindo as escolas e departamentos existentes no país, com o apoio da Abrasco, beneficiaria substantivamente o alcance das ofertas educativas da Ensp e de seus parceiros, nos diversos segmentos do hoje complexo campo da saúde pública. Não há dúvida de que a expansão dos mestrados profissionais é inevitável e de que sua oferta como parte da educação a distância é uma questão de tempo (esperamos que o menor possível).

A organização de um consistente núcleo federal da Ensp em Brasília, em cooperação com a Diretoria Regional de Brasília (Direb), teria grande valia na formação e capacitação dos profissionais do Ministério da Saúde e de ministérios afins, como os do Desenvolvimento Social, das Cidades, da Agricultura (em saúde animal, por exemplo) etc. Vejo nesta iniciativa uma missão essencial para o futuro imediato, que certamente corresponde a demandas que há muito já vêm sendo colocadas pelo Ministério da Saúde para a Ensp e para a Fiocruz como um todo.

$\mathrm{Da}$ mesma forma, a abrangência de nossos estudos e pesquisas deve aspirar ao alcance nacional, sempre que possível. A constituição de bases nacionais próprias e cooperativas, utilizando-se os recursos já existentes em instituições co-irmãs e nas unidades da Fiocruz de Manaus, Recife, Brasília, Salvador, Belo Horizonte e Curitiba, precisam ser acionadas para os estudos de base populacional de caráter nacional, assim como os estudos do sistema de saúde, ambos hoje mais necessários do que nunca. A proposta de uma plataforma nacional de pesquisa estável, com núcleos permanentes em diversas localidades do país, deveria ocupar nossa imaginação, pois diz respeito ao futuro da Ensp no campo da pesquisa.

Finalmente, afirmo que inexistem motivos para adiarmos nossa presença mais forte na América Latina - particularmente no Cone Sul - e nos países lusofônicos da África. É necessário, para tanto, não só superar a retórica como buscar bases de financiamento mais consistentes e permanentes. É claro que diversas parcerias são necessárias para alcançar estes objetivos, seja com os organismos internacionais, o próprio governo brasileiro, e também com as organizações não-governamentais e doadores privados interessados.

Evidentemente deixei escapar muitas coisas objetivas e subjetivas nesta curta reflexão sobre os últimos 30 anos da Escola, assim como do 
seu sonhado futuro. Ela expressa talvez apenas a visão particular de um apaixonado pela vida da nossa Ensp. Mas o restante do livro, com os artigos que abordam os diversos aspectos e sujeitos dessa história, organizados com muita competência pela equipe de pesquisa da Casa de Oswaldo Cruz (COC) e colaboradores, dá mais do que conta de um certo olhar para a vida complexa desta Escola tão querida. São olhares amorosos e, simultaneamente, plenos de sapiência e reflexão. As reflexões aqui contidas beneficiam a todos nós e certamente servirão de plataforma de lançamento para outras análises e visões que virão com o tempo. Mas este livro indiscutivelmente marcará uma base a ser sempre consultada.

Desde que ingressei na Ensp, com menos de 25 anos, dediquei o melhor do meu tempo e da minha paixão à saúde pública e a ela, muito particularmente. Alegro-me ao vê-la, cinqüentenária, cheia de vida e de sonhos, ainda espalhando paixão entre tantos que cruzam seus umbrais, na busca do conhecimento e do aperfeiçoamento da prática da saúde pública. Viva a Ensp, agora Sergio Arouca, por muitos e muitos anos!

Paulo Marchiori Buss

Professor Titular da Escola Nacional de Saúde Pública Sergio Arouca (Ensp) e Presidente da Fundação Oswaldo Cruz (Fiocruz) 


\title{
Apresentação
}

\begin{abstract}
A Escola Nacional de Saúde Pública Sergio Arouca da Fundação Oswaldo Cruz (Ensp/Fiocruz) completa 50 anos. O que nos leva a celebrar esse marco cronológico, como todos um tanto arbitrário, na história de uma instituição? Certamente, razões diferentes fazem com que nos unamos hoje. Para os atores que construíram a organização em seu cotidiano, sentimentos de orgulho e de 'fazer parte' do que está sendo narrado dão a marca da vivência e da afetividade. Para os pesquisadores da Casa de Oswaldo Cruz (COC), desafiados a refletir sobre documentos variados e narrativas pessoais, descobre-se, além do esforço de sistematização e análise, um caminho de auto-reflexão sobre nossa identidade e inscrição institucional, pois também a história da COC se confunde com o alargamento da concepção sobre saúde que teve na Ensp um dos atores institucionais privilegiados. Portanto, ao aceitarmos tal desafio, sabíamos que não se tratava simplesmente de contribuir com a tentativa de reconstituição histórica, protegida das dimensões afetivas que caracterizam a memória, o que seria, além de impossível, equivocado como atitude metodológica. Éramos também, de certo modo, parte do objeto sobre o qual nos debruçávamos.

Mas retomemos a pergunta: o que nos faz comemorar o aniversário de instituições? Há 20 anos, o historiador inglês Eric Hobsbawm tentou respondê-la em conferência na Universidade da Califórnia, por ocasião do $75^{\circ}$ aniversário daquela instituição, desenvolvendo instigante argumento sobre o papel da história nas sociedades contemporâneas. Entre outras contribuições desse texto, destacamos uma frase aparentemente singela, mas plena de significados: "Necessitamos e utilizamos a história mesmo quando não sabemos por quê".

Hobsbawm realizou interessante reflexão sobre a natureza histórico-cultural das comemorações, observando o quanto elas diferem, pois, nas sociedades tradicionais, as relações entre passado, presente e futuro
\end{abstract}


apresentam significados distintos dos que predominam hoje e caracterizam, em sua forma de representar, o tempo pela busca de modelos e ensinamentos nos momentos pretéritos: "uma utopia com sabor de nostalgia". Esta concepção ainda é bastante freqüente e, como a história recente de movimentos sociais e políticos o demonstra, encontra-se na origem de outro interessante fenômeno observado pelo historiador: a invenção das tradições. Tal concepção, com os possíveis riscos de tradicionalismo, convive com outros, entre elas a de um modelo de cientificismo que negligencia a experiência histórica. Por outro lado, de que modo é possível estabelecer um lugar para a história em sociedades caracterizadas por transformações rápidas, profundas, radicais e contínuas como as que ocorreram nas sociedades ocidentais a partir do final do século XVIII e, especialmente, a partir da metade do XX? Por fim, defende o historiador a combinação entre experiência e perspectiva históricas, esta última definida como o inventário de possibilidades e rumos alternativos no passado, presente e futuro.

Em instituições de pesquisa, ensino e ações de atenção à saúde como a Ensp, nas quais os modelos de cientificidade e a ênfase em temas como inovação parecem deslocar a experiência e a perspectiva históricas para o espaço restrito das comemorações oficiais, tornar estes 50 anos um momento de reflexão é algo da maior importância, quando se está diante de tratar também dos rumos futuros da instituição, em suma, de seu projeto. Para responder a tal desafio, nos propomos a tarefa de publicar este livro, organizado em duas partes. Na primeira, apresentamos um texto narrativo sucinto sobre a Ensp, desde a sua criação até os anos recentes, usando como fio condutor a idéia da presença de várias escolas/gerações que foram conformando a identidade institucional. O pluralismo institucional e o de perspectivas do conhecimento sobressaem como temas centrais. Recorremos a documentos que compõem hoje o Fundo Ensp, sob guarda da Casa de Oswaldo Cruz e cujo catálogo estará brevemente acessível ao público como parte das atividades comemorativas dos 50 anos.

$\mathrm{O}$ registro de depoimentos orais se constituiu em fonte imprescindível para esta a primeira aproximação com o nosso objeto. $\mathrm{Na}$ seleção dos depoentes, privilegiamos os atores que tiveram papel de destaque nos primeiros tempos e os que participaram da direção da Escola no em período mais recente. Certamente, pode-se dizer que esta escolha imprime um viés oficialista, dificultando uma reconstituição exaustiva de projetos e concepções, por vezes em disputa, ao longo desses cinqüenta 50 anos. Mas nossa opção foi tratar das grandes diretrizes e linhas imprimidas pelas sucessivas direções da Ensp, o que, se obviamente não esgota o tema, 
permite uma sistematização das macropolíticas institucionais. A expectativa é que este nosso esforço inicial tenha continuidade, sob a forma de um programa mais extenso de história oral e de recuperação e sistematização de informações encontradas na documentação escrita e iconográfica.

$\mathrm{Na}$ primeira parte do livro, buscamos combinar dois planos de análise, situando a experiência da Ensp em sua relação com processos históricos mais amplos e com as idéias e programas que foram sendo edificados no interior da instituição. A tentativa foi a de escapar a uma visão simplificada de contexto, enfatizando uma relação de mão dupla entre condicionamentos externos e iniciativas que surgiram na instituição, muitas delas com grande potencial de inovação.

Lidamos com algumas versões já cristalizadas sobre a trajetória institucional, e uma das contribuições deste esforço, ainda bastante preliminar, foi a descoberta de novos ângulos e mesmo informações que, eventualmente, permitam rever interpretações e até mesmo identificar semelhanças onde se percebem rupturas em relação aos primeiros tempos da instituição. Além disso, foi possível recuperar a gênese de algumas idéias que só puderam ser implementadas no período atual, o que não implica conceber a história da instituição como processo linear, mas observar as complexas relações entre idéias e práticas. É interessante ressaltar que resultados similares são encontrados em estudos sobre história de instituições que adotam perspectiva de análise em que se privilegiam o processo e a complexidade das interações sociais.

No que se refere à saúde pública, os estudos sobre sua institucionalização em diferentes contextos nacionais - nos quais se inclui, como fator essencial, a formação de recursos humanos - vêm contribuindo para uma visão mais rica sobre a construção desse campo de conhecimentos e de práticas.

A seguir, publicamos documento inédito de importante valor histórico: trecho de entrevista de Ernani Braga concedida a Sergio Arouca, Luiz Fernando Ferreira, Mabel Imbassahy e Lisabel Klein. A entrevista foi feita quando a Casa de Oswaldo Cruz era ainda um projeto, idealizado por Sergio Arouca, Luiz Fernando Ferreira e Arlindo Fábio Gómez de Sousa.

A segunda parte do livro desta obra contém artigos sobre temas relevantes para o entendimento da história da Ensp e de seu papel na saúde pública contemporânea. O primeiro artigo, de Luiz Fernando Ferreira, pesquisador emérito e responsável por importantes iniciativas relacionadas à ampliação e ao aprofundamento da missão institucional da Ensp, aborda, com a acuidade e gosto pela narrativa de cunho pessoal característicos 
do autor, os primeiros tempos e a contribuição de Edmar Terra Blois e Sávio Antunes.

Combinando análise e defesa de uma posição sobre o projeto Ensp, segue-se o texto de Tânia Celeste Nunes, que, já em sua tese de doutoramento voltara-se para a história da instituição, sobretudo a partir da experiência dos cursos descentralizados na década de 1970.

A contribuição dessa instituição para o periodismo científico e a difusão de textos de pesquisadores da Fiocruz e de outras instituições da área de saúde coletiva é analisada no artigo de Carlos Coimbra, editor dos Cadernos de Saúde Pública, Reinaldo Souza-Santos e Ricardo Ventura Santos, respectivamente editor-associado e membro do Conselho Editorial do periódico. Uma quarta contribuição é oferecida pelo artigo elaborado por André de Faria Pereira Neto, pesquisador da COC, em que se apresenta o estudo de perfil dos egressos da Ensp. Finalmente, o livro se encerra com a contribuição de Jorge Bermudez, atual diretor da Escola, que combina em seu texto uma análise sobre o papel da Ensp com um depoimento sobre sua vivência e trajetória nesse espaço da saúde pública.

Esperamos, ao reunir capítulos elaborados segundo perspectivas diversas - com inevitáveis mudanças de tom a alternar planos mais distanciados com da experiência cotidiana e da construção coletiva da Ensp com enfoques mais subjetivos, frutos da vivência dos atores que construíram parte significativa desta história - ampliar a compreensão sobre alguns processos e incentivar novas pesquisas e análises, sem que se perca, contudo, o encantamento.

Consideramos também que parte importante de nossa contribuição encontre-se em conferir significado e valorizar a expressividade de uma história junto aos que não freqüentam as salas de aula da Ensp, os pontos de encontro e sociabilidade, bem como aos que não compartilharam os momentos de unidade e de conflitos, que dão vida e sabor às histórias institucionais.

Valorizamos, desde o primeiro capítulo, a Ensp como projeto para a saúde, entendendo-a como algo que ultrapassou as fronteiras de Manguinhos e, mesmo - não seria ufanista afirmar - as fronteiras de uma saúde pública nacional, pois a Escola tem sido um celeiro de idéias, projetos e propostas de ampla repercussão, seja nos programas de cooperação, seja na presença de estudantes de vários continentes. Assim, muito mais do que poderia indicar o projeto de construção de uma 'escola nacional', trata-se de perseguir e implantar uma visão de saúde pública para a sociedade contemporânea. E esta é também a reflexão subjacente à elaboração deste livro. 
Para viabilizarmos as entrevistas e outras etapas deste projeto editorial, contamos com o apoio inestimável de diversas pessoas. De forma especial, agradecemos a Maria Inês Rodrigues Fernandes Mendes e Eduardo Maranhão, da Ensp; a Rose Olyveira e Maria Rachel F. da Fonseca, da COC; a José Roberto Ferreira, da presidência da Fiocruz, e aos assistentes de pesquisa Cláudio Arcoverde e Monica Curcio de Souza.

Gostaríamos de registrar nossos agradecimentos a Adauto J. Gonçalves Araújo, Arlindo Fábio Gómez de Sousa, Eduardo Costa, Elsa Paim, Fernando Leitão, Hélio Uchôa, Lenita Vasconcelos, Luiz Fernando Ferreira, Maria do Carmo Leal, Paulo Buss e Szachwa Cynamon, que compreenderam a importância do projeto e nos concederam entrevistas fundamentais para a reconstituição desta história.

Os Organizadores 
PARTE I

HISTÓRIA: EXPERIÊNCIA E PERSPECTIVA 


\section{História da Especialização em Saúde Pública no Brasil: nota INTRODUTÓRIA}

Nisia Trindade Lima

Cristina M. O. Fonseca

$\mathbf{E}_{\mathrm{m} \text { seu estudo sobre a criação da Escola de Higiene e Saúde }}$ Pública Johns Hopkins, a historiadora Elizabeth Fee (1987) oferece-nos uma agenda de problemas que podem servir como referência para a análise de outras experiências institucionais no campo da educação em saúde pública. Ressalta a autora as tensões constitutivas dessa área, com implicações importantes para o desenho dos projetos educacionais, desde as que se referem à relação entre saúde pública e medicina e entre abordagens sociais e biológicas, até a que contrapõe a importância da educação avançada e alta qualificação de uma elite profissional ao treinamento em serviço voltado para uma maioria de profissionais que atuam na prática da saúde pública. Relacionada a essa tensão, destaca-se o debate entre formação de perfil mais acadêmico, concentrado na pesquisa e em métodos de investigação, ou a aquisição de habilidades práticas com implicações mais imediatas para a gestão e o planejamento de ações de saúde pública.

Como observa a autora, os que defendem uma educação orientada para a pesquisa argumentam que as demandas de ordem prática mudam constantemente, o que torna uma educação voltada para o treinamento em métodos e habilidades específicas ultrapassada, enquanto uma educação orientada para a pesquisa oferece bases mais consistentes para o enfrentamento de questões abrangentes assim como para resolução de problemas específicos e de novos desafios. Por outro lado, os que advogam programas orientados para a prática observam que, a despeito da pesquisa científica ser importante, a principal orientação para a saúde pública deve estar na aquisição de competência organizacional e administrativa.

Ao traçar estas duas grandes linhas, naturalmente bem menos nítidas ao pesquisarmos casos concretos, Elizabeth Fee acentua que a 
corrente mais próxima de uma educação voltada para o treinamento na gestão de saúde aproxima-se do modelo britânico. Os defensores de um modelo orientado pela pesquisa identificar-se-iam, por seu turno, com os institutos alemães de higiene. De acordo com a autora, na experiência norteamericana de fins do século XIX e início do século XX, o termo saúde pública aproximava-se do modelo administrativo inglês, ao passo que 'higiene' era praticamente um sinônimo da orientação para a pesquisa, de inspiração germânica. O caso de Johns Hopkins seria um resultado de debate e negociação entre essas vertentes, como o próprio nome indica: escola de higiene e saúde pública.

Em concordância com a perspectiva e as observações da autora, vale acentuar que as tensões enunciadas, em particular a que se verifica entre orientação para a pesquisa e orientação para a gestão e o planejamento, tão marcante na história da educação em saúde pública, não apenas são identificadas em outros contextos institucionais e nacionais, como também serão sempre objeto de intensos debates e negociações. A história da Fundação Oswaldo Cruz (Fiocruz) e, em particular, da Escola Nacional de Saúde Pública (Ensp) pode oferecer, mais do que oposições, contribuições importantes para a análise sobre as relações entre esses modelos, o que parece indicar também outras possibilidades de comparação com experiências internacionais, além da que tem sido lembrada com mais freqüência - as proximidades da história institucional da Fiocruz com o modelo do Instituto Pasteur.

Cabe acentuar ainda que, na experiência norte-americana em fins do século XIX, o movimento em prol da profissionalização da saúde pública deu origem a propostas de criação de escolas especializadas. A primeira experiência ocorreria com a criação da Escola de Higiene e Saúde Pública na Universidade Johns Hopkins, em 1916, após intenso processo de competição de universidades norte-americanas pelos recursos oferecidos pela Fundação Rockefeller para apoio a essa iniciativa. Johns Hopkins serviu de modelo para instituições semelhantes, criadas com o apoio da Fundação Rockefeller, em Praga, Varsóvia, Londres, Toronto, Copenhague, Budapeste, Oslo, Belgrado, Zagreb, Madri, Cluj (Romênia), Ancara, Sofia, Roma, Tóquio, Atenas, Bucareste, Estocolmo, Calcutá, Manila e São Paulo (Marinho, 2001: 25). O modelo de escola de saúde pública, delineado a partir da experiência de Johns Hopkins, foi o que alcançou disseminação em escala mundial e esteve relacionado a mudanças importantes nos padrões que passaram a ser preconizados a respeito da formação especializada em saúde pública. 
No Brasil, a partir de 1920, a influência da Fundação Rockefeller na formação de recursos humanos não se restringiu à criação do Instituto de Higiene de São Paulo, experiência que também não pode ser vista como mera transposição de um modelo, envolvendo estratégias e ações complexas por parte da comunidade científica e de lideranças políticas daquele estado. ${ }^{1}$

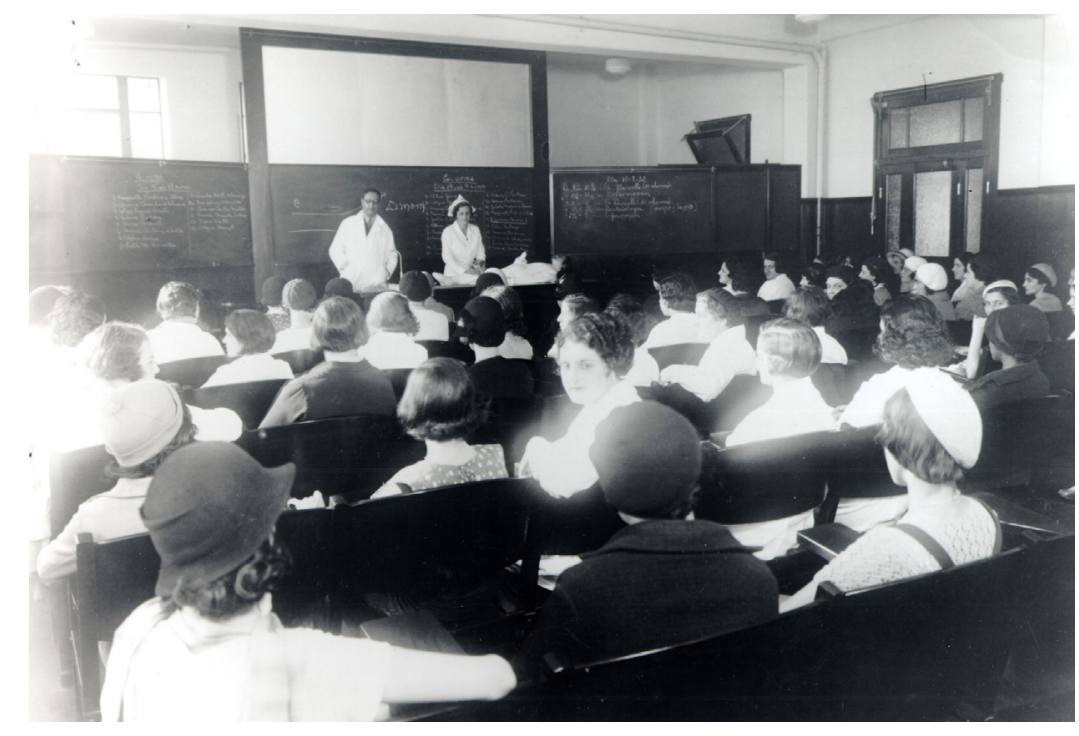

No que se refere aos marcos de criação das escolas de saúde pública, é possível também argumentar que, desde seus primórdios, o Instituto Oswaldo Cruz (IOC) dedicou-se à formação de recursos humanos altamente qualificados, por intermédio da criação, em 1908, do Curso de Aplicação, o que implicava a formação, a um só tempo, para a pesquisa biomédica e para a saúde pública. O curso tinha duração de dois anos em tempo integral e teria sido oferecido pela instituição até 1969.

A identificação da necessidade de uma formação mais específica esteve na origem de outra experiência institucional, definida a partir de uma ampla reforma do ensino, conduzida pelo ministro da Justiça João Luiz Alves e pelo diretor da Faculdade de Medicina Juvenil da Rocha Vaz em 1925.

A trajetória institucional do Instituto paulista apresenta a seguinte seqüência: Laboratório de Higiene da Faculdade de Medicina e Cirurgia de São Paulo (1918); Instituto de Higiene da Faculdade de Medicina e Cirurgia de São Paulo (1919); Instituto de Higiene de São Paulo (1925); Escola de Higiene e Saúde Pública (1931); Escola de Higiene e Saúde Pública da Universidade de São Paulo (1938); Faculdade de Higiene e Saúde Pública da Universidade de São Paulo (1945); Faculdade de Saúde Pública da Universidade de São Paulo (1969). Ver Laboratório de Higiene da Faculdade de Medicina e Cirurgia da São Paulo (2004).
Curso para enfermeiras de guerra que, juntamente com o curso de emergência para enfermeiras, foi ministrado durante a revolução de 1932, no Instituto de Higiene de São Paulo. Acervo Rockefeller. 
Oswaldo Cruz em sua última fotografia no encerramento do Curso de Aplicação do Instituto Oswaldo Cruz, Rio de Janeiro, 1916. Da esquerda para a direita, sentados: Osvino Penna, Adolpho Lutz, Oswaldo Cruz, Carlos Chagas, Walter Oswaldo Cruz. De pé, na primeira fila: Edgar da Costa Pereira, não identificado, Lauro Travassos, Ezequiel Dias e Álvaro Lobo. Na última fila, o segundo e terceiros são Raul Franco de Primio e João Vicente de Souza Martins. Acervo Coc.

Escola de enfermeiras Anna Nery inaugurada em 1923. Acervo Coc. Fundo Família Chagas.
Carlos Chagas, à época diretor do IOC e do Departamento Nacional de Saúde Pública (DNSP), almejava criar uma escola de saúde pública, mas não obteve acordo favorável junto à Fundação Rockefeller para implementá-la, optando, então, pela criação do curso de higiene e saúde pública, anexo à Faculdade de Medicina na Praia Vermelha. ${ }^{2}$
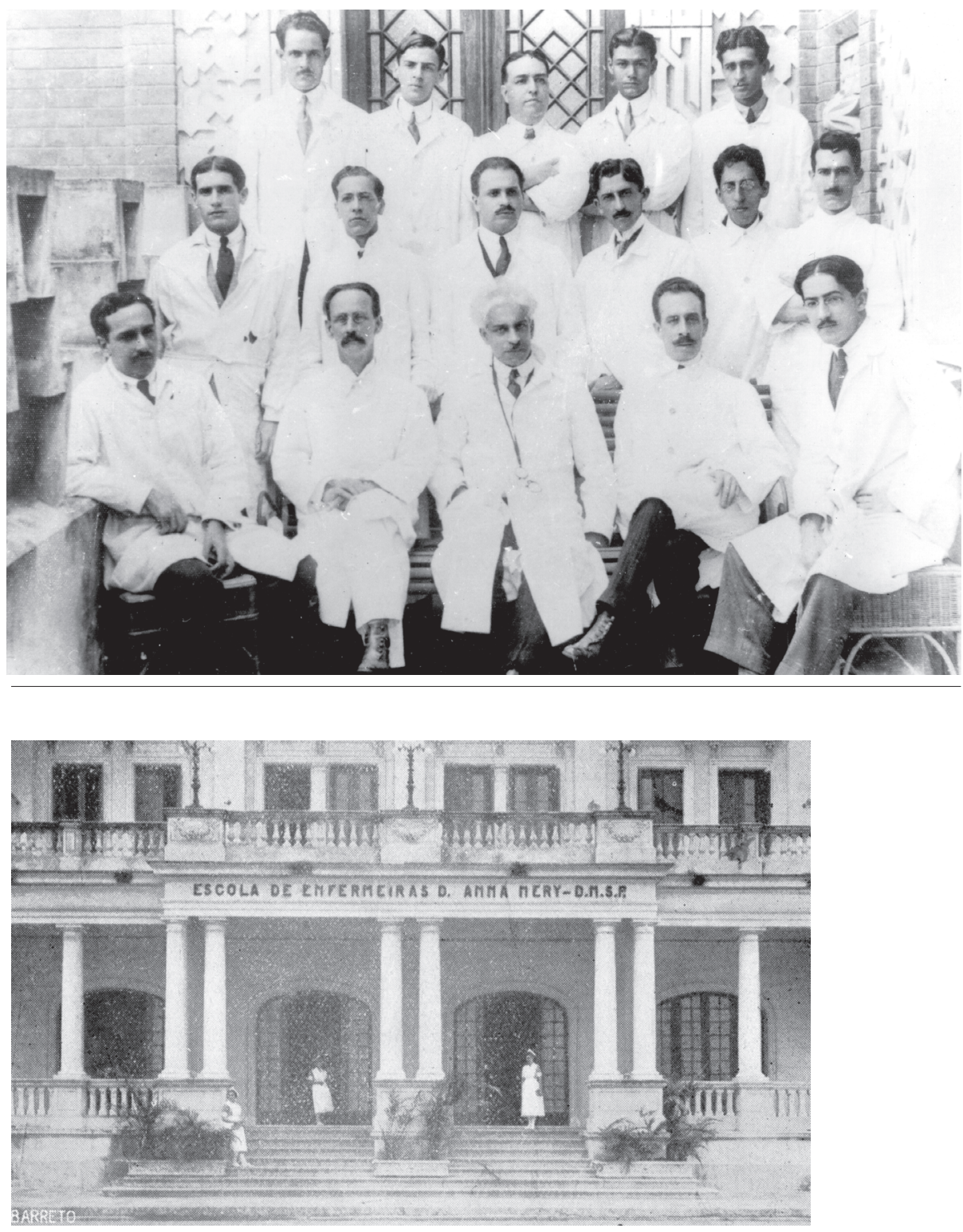

2 A Reforma Rocha Vaz foi implementada a partir do decreto 16.782-A, de 13 de janeiro de 1925. Cabe lembrar que também durante a gestão de Chagas foi criada a Escola de Enfermagem Anna Nery, em 1923, mais uma instituição vinculada à formação na área da saúde. 
Como observa Carlos Chagas Filho (1993: 175),

Esse curso, sem a menor dúvida, deu novo impulso à higiene em nosso país. Embora anexado à faculdade de medicina, com o objetivo de conferir-lhe um caráter universitário, tal curso era extremamente ligado ao Instituto Oswaldo Cruz. (...) Sem dúvida, o curso deu origem aos ensinamentos de saúde e higiene públicas que se fazem na Escola Nacional de Saúde Pública.

A legislação determinava que o curso ficasse sob direção do IOC, que constituiria uma especialização do ensino médico, habilitando os higienistas nele diplomados para a ocupação de cargos federais sem necessidade de realização de concurso. O programa seria formulado pelo próprio diretor do IOC para posterior aprovação do diretor da Faculdade de Medicina (Chagas Filho, 1993: 176). Carlos Chagas interferiu assim diretamente sobre o processo de formação profissional, reforçando a relação entre as duas instituições. Definiu um modelo de ensino que contribuiu para a institucionalização da especialização em saúde pública, vinculandoa ao ambiente universitário, sem, entretanto, retirá-la do campo da pesquisa científica. A subordinação à esfera universitária não foi mantida nas décadas seguintes, contudo, esse ponto seria sempre referência nos debates relativos à formalização do ensino da saúde pública.

O crescente interesse pela formação em saúde pública deve também ser observado em suas relações com as mudanças verificadas nos contextos nacional e internacional a partir de 1930. No plano nacional, a profissionalização em saúde pública constituiu um dos elementos do projeto político e ideológico do novo governo de Getúlio Vargas, adequando-se às condições específicas da realidade brasileira e aos interesses em jogo na área de atuação do Ministério da Educação e Saúde Pública. A partir dos anos de 1930, especialmente a partir de 1937, o governo realizou uma série de alterações na estrutura administrativa e institucional da saúde, reorganizando os serviços com o propósito de constituir e consolidar uma política de saúde de abrangência nacional.

Os temas e as diretrizes referentes à formação em saúde pública aproximavam-se em muitos aspectos de propostas, preconizadas e aplicadas em particular nos Estados Unidos, que vinham sendo debatidas em fóruns internacionais. Desse modo, foram incorporadas as prioridades definidas pelas agendas dos congressos e conferências patrocinados pela Oficina Sanitária Pan-Americana. Esse organismo (atual Organização PanAmericana da Saúde - Opas) realizou no período de 1930 a 1945 vários congressos, mantendo uma agenda regular de debates relativos à política 
de saúde, com o propósito de se consolidar como fórum de interação entre os diversos países latino-americanos.

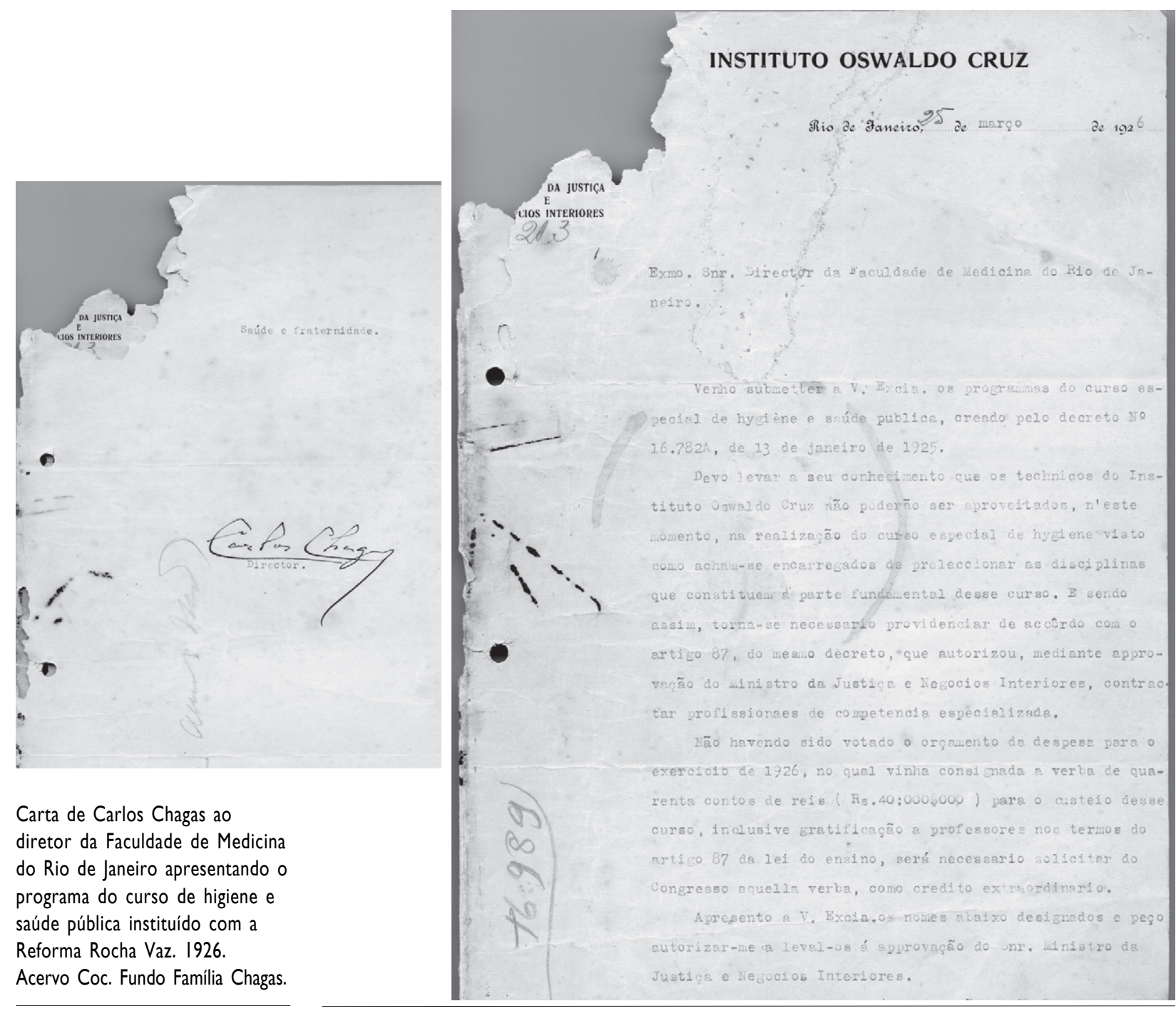

Particularmente a partir de 1939, sob o impacto do contexto de guerra, os problemas daí decorrentes passam a fazer parte dos debates de saúde pública e ganham crescente atenção de setores norte-americanos. ${ }^{3}$

3 Neste período, a Oficina Sanitária Pan-Americana patrocinou a realização da das $9^{\mathrm{a}}, 10^{\mathrm{a}}$ e $11^{\mathrm{a}}$ Conferências Sanitária Pan-Americanas, respectivamente em Lima, Bogotá e no Rio de Janeiro (1934, 1938 e 1942). Além disso, promoveu, nos anos intercalados a estes eventos, as $3^{\text {a }}, 4^{\text {a }}$ e $5^{\text {a }}$ Conferências Pan-Americanas de Diretores Nacionais de Saúde, respectivamente em 1936, 1940 e 1944, todas realizadas em Washington. 
As resoluções e recomendações aprovadas no decorrer desses diferentes fóruns internacionais incluíram entre suas proposições mais importantes a consolidação de uma organização sanitária nacional, que deveria se fazer mediante maior coordenação entre os serviços sanitários federais, estaduais e municipais; a formação de uma comissão encarregada de estabelecer as bases fundamentais de um código sanitário padrão a ser aplicado em todas as nações da América; e a instituição generalizada da carreira de sanitarista, condicionando o ingresso aos diplomados por escolas de higiene.

Como reforço dessas diretrizes recomendou-se a criação do maior número possível de bolsas de estudo para técnicos de repartições oficiais, que seriam concedidas por intermédio da Oficina Sanitária Pan-Americana (Barros Barreto, 1944). Tal intercâmbio, que se intensificou no decorrer dos anos seguintes, permitiu a freqüência de alunos brasileiros em seus cursos, muitas vezes financiados pela Fundação Rockefeller. Assim, estabeleceu-se um canal direto de influência sobre a formação dos profissionais que iriam conduzir as ações de saúde pública no Brasil. Desses cursos participaram funcionários do Departamento Nacional de Saúde (DNS) e do Serviço Especial de Saúde Pública (Sesp), como também houve atuação de técnicos americanos nos cursos realizados aqui no Brasil, nos serviços nacionais criados a partir de 1941 e nas campanhas que se implementaram e necessitavam de profissionais qualificados para as ações de combate e controle de doenças transmissíveis como a febre amarela e a malária. Ou seja, o modelo de ensino e formação profissional em saúde pública estabelecido no interior da Johns Hopkins constituiu referência central para a profissionalização da saúde pública no Brasil.

O que importa aqui destacar é que o crescente movimento de nacionalização das ações estatais de saúde, que se fortaleceu como diretriz para toda a América Latina, reforçou a necessidade de investimento em profissionais habilitados ao desempenho destas funções, demonstrando que deveria haver também maior atenção ao processo de formação e especialização das diversas categorias profissionais envolvidas com o trabalho de saúde pública. Essas medidas voltadas para questões objetivas e mais imediatas, associadas ao fortalecimento do intercâmbio entre os países da América Latina e à influência americana sobre o processo de reorganização institucional no campo da saúde pública, deixavam claro que as mudanças em curso no Brasil não constituíam um fator isolado do quadro sanitário mundial, apesar de respeitarem as especificidades do caso brasileiro. A adequação entre os interesses políticos internos e a agenda internacional definida para o setor da saúde orientou, 
principalmente a partir de 1930 , o processo de institucionalização da especialização em saúde.

Quando, no dia 13 de janeiro de 1937, entrou em vigor a nova lei que reorganizava a estrutura do Ministério da Educação e Saúde, delegando ao DNS a incumbência de administrar as atividades de saúde pública no Brasil, mais um passo estava sendo dado na direção desses objetivos. Medidas voltadas para a centralização e a normalização das ações públicas de saúde, que já se encontravam em andamento, se fortaleceram e se intensificaram, amparadas pela nova organização institucional. A partir daí iniciou-se um período de intenso trabalho normativo com elaboração de leis, regulamentos e códigos sanitários que objetivavam padronizar as atividades dos diversos serviços de saúde nos estados em seus mínimos detalhes, acompanhando tanto o processo de burocratização do Estado que se fortalecia como também as orientações internacionais já observadas anteriormente.

A intensa atividade regulatória destinada a conduzir o funcionamento dos serviços de saúde, tanto no âmbito federal como nos estados, acompanhada por detalhado projeto de formação dos técnicos dessa área, não era exclusividade do campo da saúde. É preciso não esquecer que houve, nesse período, uma política deliberada de reformas no serviço público destinada a todas as áreas de atuação do poder público, que se constituiu em um dos elementos do processo de burocratização do Estado e de formação de pessoal, obedecendo às diretrizes mais gerais delimitadas para a área administrativa e concretizadas com a criação do Departamento de Administração do Serviço Público (Dasp) em 1938.

A nacionalização das ações de saúde, fortalecida pela estrutura centralizadora adotada pelo ministério, efetivou-se mediante detalhada normalização dessas atividades, implementadas sob coordenação do governo federal e acompanhadas pelo investimento na formação e especialização de profissionais de saúde e pelo constante debate em torno da adequação entre saúde pública e assistência médica. A intenção de consolidar um amplo arcabouço institucional nessa área não se apresentou somente no plano regimental, mas também no que se refere à criação de infra-estrutura, com a construção de prédios como centros e postos de saúde, hospitais e dispensários, e com investimento expressivo em recursos humanos.

A preocupação em assegurar que as ações de saúde pública fossem comandadas por profissionais especializados está relacionada a uma das tensões constitutivas desse campo, já observadas por Elizabeth Fee (1987) 
- a definição e a preservação da especificidade da saúde pública em relação à assistência médica -, o que levou a uma política deliberada de investimento na especialização e profissionalização de técnicos em saúde pública. Considerava-se que a medicina clínica não deveria ser observada como uma ameaça à saúde pública e, portanto, era necessário consolidar essa última área de atuação, fortalecer seu campo e delimitá-lo segundo critérios de especialização técnica. Ou seja, todo o projeto delineado para a atuação do Estado na área da saúde pública dependia diretamente do fortalecimento desse campo profissional, que, por sua vez, seria consolidado a partir de áreas de conhecimento específicas.

Tendo em vista que a consolidação de uma estrutura nacional de saúde pública era uma das principais diretrizes que nortearam esse processo de reformulação institucional, compreende-se a importância que foi atribuída à formação e especialização em saúde pública. Era preciso formar profissionais especializados, orientá-los e direcioná-los para ocupar postoschave na estrutura administrativa do governo federal. Com essa orientação, iniciou-se, a partir de 1937, uma série de cursos de especialização e aperfeiçoamento em diversos estados, destinados à formação de técnicos atuantes nas diversas áreas de saúde pública, como médicos, enfermeiras, visitadoras sanitárias, engenheiros e guardas sanitários.

Amparado na decisão do governo federal de só admitir nos serviços de saúde pública médicos diplomados pelo curso de especialização da Faculdade Nacional de Medicina, e diante da impossibilidade de estender rapidamente a todos os médicos estaduais esta modalidade de especialização, João de Barros Barreto, diretor do DNS - ele também um ex-aluno da Johns Hopkins e da Escola de Saúde Pública da Universidade de Havard -, enviou um convite aos diretores de saúde estaduais, em fevereiro de 1937, apresentando as vantagens da indicação de pelo menos um médico do serviço para realizar o curso de 12 meses que seria oferecido a partir de abril. A resposta foi positiva e matricularam-se 29 médicos de 15 estados diferentes, indicando a expansão do processo de formação para outras regiões do país. Houve um grande número de participantes do Rio de Janeiro, por ser este o local de realização do curso, mas não se contou, apesar da proximidade, com a presença de nenhum representante dos estados de São Paulo e Minas Gerais. ${ }^{4}$

\footnotetext{
4 A distribuição de alunos por estado foi a seguinte: Amazonas (1), Pará (1), Maranhão (2), Rio Grande do Norte (2), Paraíba (1), Pernambuco (2), Alagoas (1), Sergipe (1), Bahia (1), Espirito Santo (1), Rio de Janeiro (12), Paraná (1), Santa Catarina (1), Rio Grande do Sul (1) e Goiás (1) (Barros Barreto, 1938a: 84).
} 
Curso de saúde pública do Departamento Nacional de Saúde Rio de Janeiro, 1946. Na primeira fila da esquerda para a direita: Lúcio Costa, Irineu Malagueta de Pontes, Messias do Carmo e Arce Reyeros. Na segunda fila em pé: Francisco Dulcetti, não identificado, José Carlos Falcão Neto, Aníbal da Silva Marques, Celso Arcoverde de Freitas, Álvaro Vieira da Melo, Roberto Abra e Alcides Pontes Vieira. $\mathrm{Na}$ terceira fila em pé: Lima Torres, Paulo Duran, Leão, Corson Teixeira Neto, Damasceno Costa e Aparício Silva. Acervo Celso Arcoverde/Coc.

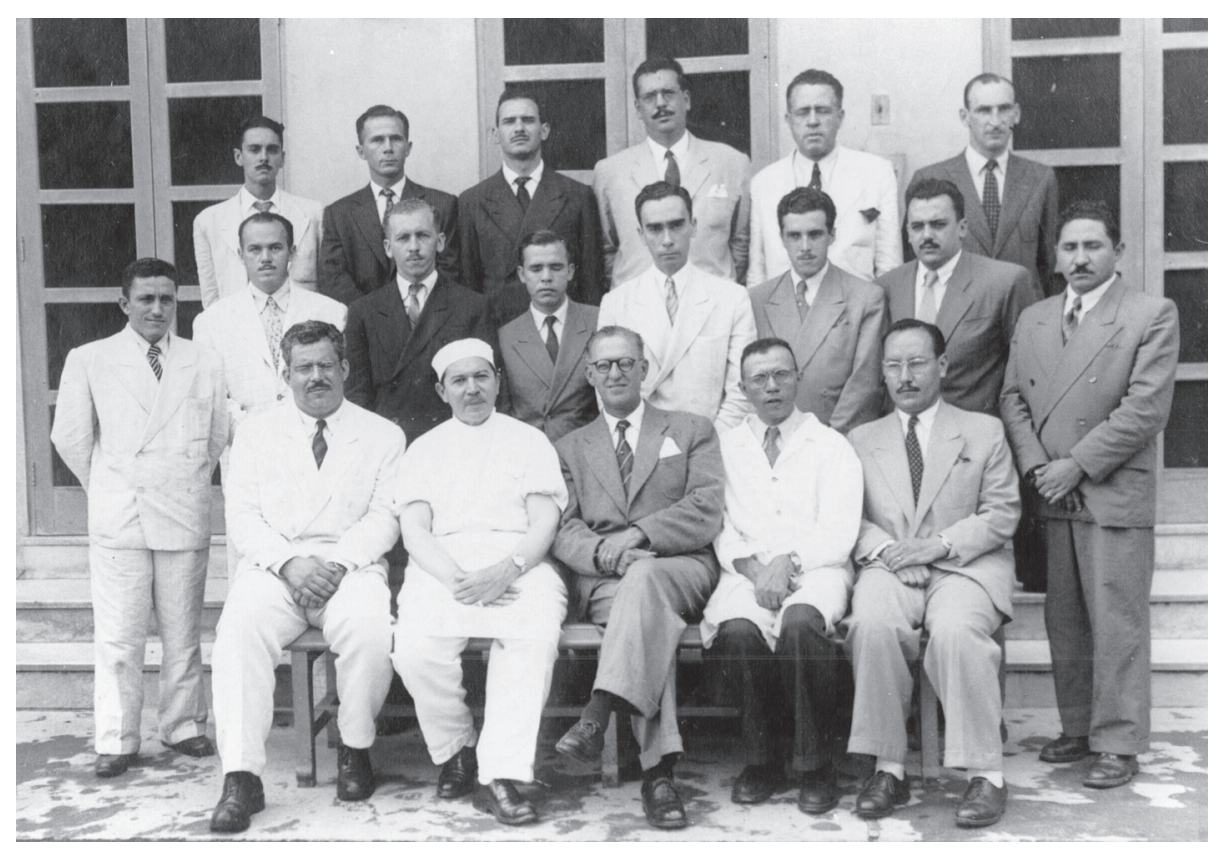

Levando em consideração a impossibilidade de, em curto espaço de tempo, atender a todos os médicos envolvidos com serviços de saúde estaduais, o DNS, em colaboração com o Departamento Estadual de Saúde e a Faculdade de Medicina de Pernambuco, deu início em 1938 a outra modalidade de curso de aperfeiçoamento. Este teria curta duração - quatro meses - e seria destinado aos profissionais com atividades no Nordeste, nos estados compreendidos entre Ceará e Sergipe. João de Barros Barreto via essa modalidade como a mais adequada para pequenas cidades e serviços do interior (Barros Barreto, 1938b: 292).

Além dos dois tipos de curso - de 12 e de quatro meses - destinados à formação e especialização de médicos sanitaristas, foram realizados, no decorrer dos anos de 1937 e 1938, cursos de especialização em tisiologia, malariologia, administração dos serviços de amparo à maternidade e à infância, tracoma, bioestatística e microbiologia e parasitologia aplicadas.

A formação profissional não se restringiu aos médicos. Na área de atuação das enfermeiras de saúde pública, por exemplo, foram instituídos cursos para visitadoras em vários estados e indicada a necessidade de se ampliar o número de escolas de enfermagem, instalando-se novas escolas em Belém, Recife, Salvador, São Paulo e Porto Alegre. Naquele momento, 12 enfermeiras de saúde pública exerciam atividades em diversos estados, chefiando e/ou organizando os serviços de visitadoras sanitárias nos estados 
do Pará, Maranhão, Ceará, Rio Grande do Norte, Paraíba, Pernambuco, Sergipe, Rio de Janeiro, Mato Grosso, Paraná, Santa Catarina e Rio Grande do Sul (Barros Barreto, 1938b: 294). Também os guardas sanitários, outra categoria profissional que foi alvo de cursos de especialização realizados em alguns estados, tiveram seu papel crescentemente valorizado como importante no auxílio dos médicos e engenheiros de saúde pública.

Todas essas modalidades de cursos seguiam as diretrizes estabelecidas pela direção do DNS e destinavam-se à formação de quadros para o desempenho das tarefas dos diversos órgãos que compunham o departamento. Alguns anos depois, em 1942, foi criado o Sesp, em convênio com o Instituto de Assuntos Inter-Americanos, que se constituiria, com o passar do tempo, em mais uma instituição a investir na especialização e no aprimoramento profissional em saúde pública, aproximando-se também das orientações adotadas em instituições de ensino norte-americanas.

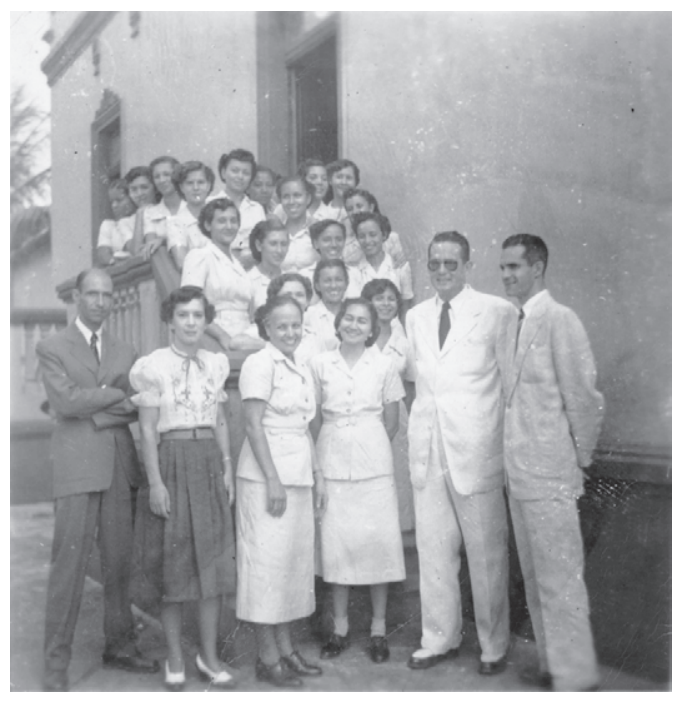

O processo de institucionalização da especialização em saúde pública no Brasil, que, pelo que foi exposto aqui, se intensificou a partir da década de 1920, acompanhou assim a gestação de um modelo de formação em saúde pública que se desenvolvia na área de ensino nos Estados Unidos, concretizada principalmente na Escola de Higiene e Saúde Pública Johns Hopkins. No contexto brasileiro, os interesses políticos em jogo, que indicavam a necessidade de reforçar a presença federal nos estados, amparados em um forte projeto ideológico de construção nacional,
Primeiro curso de visitadoras sanitárias do Sesp - 1949 - llhéus, Bahia. Na primeira fila, da esquerda para a direita: $d r$. Cajueiro (médico da Unidade), enfermeira paulista Nadir Moura, Elsa Paim, Aminto Bastos (diretor do Programa) e dr. Aluízio Sanches. Acervo Particular. 
imprimiram características peculiares ao desenvolvimento de políticas públicas destinadas à formação de recursos humanos para a saúde.

A necessidade de aparelhar as instituições que estavam sendo criadas para implementação das políticas de saúde infundiu uma orientação mais pragmática aos cursos de formação e especialização, abrindo novas especialidades diretamente vinculadas ao cotidiano do serviço público. $\mathrm{Ou}$ seja, as necessidades definidas pelas estratégias políticas adotadas naquele contexto privilegiavam a expansão do poder público para as diversas regiões do país, demandavam um perfil de formação mais pragmático, o que não significou a exclusão de uma linha de investimento em pesquisa, constituinte da área das ciências da saúde no Brasil. No decorrer dos anos seguintes, as diretrizes estabelecidas nesse momento específico da história da saúde pública brasileira permaneceriam orientando os debates e as proposições para este campo.

Quando foi realizada a $2^{\text {a }}$ Conferência Nacional de Saúde, de 27 de novembro a 2 de dezembro de 1950, o tema da formação de técnicos para a saúde pública recebeu especial atenção dos profissionais presentes. Cabe lembrar que a conferência foi considerada não como um congresso do ponto de vista científico, mas como um "conclave de técnicos de saúde pública ao qual compareceram delegados de todo o Brasil e diretores de diversos serviços nacionais" (Brasil, 1950: 9505) com o objetivo de debater os problemas ligados à saúde. Para isso, elegeram-se três temas em torno dos quais seriam realizados os trabalhos, constando entre eles, no grupo C, a 'formação de pessoal': médicos sanitaristas, engenheiros sanitaristas, enfermeiras, visitadores de saúde pública e outros auxiliares. ${ }^{5}$ Após os debates, foram aprovadas 18 recomendações relativas a esse tema, sendo que oito diziam respeito especificamente ao trabalho das visitadoras de saúde pública, demonstrando uma grande preocupação em se investir nesse tipo de especialização profissional.

Além disso, houve uma recomendação específica para que "se considere prematura a criação de uma Faculdade de Saúde Pública na Universidade do Brasil” (Brasil, 1950: 9505). Esta recomendação apontava para a existência de um ponto de divergência entre os profissionais envolvidos com a profissionalização em saúde pública, considerando que, no discurso que proferiu durante a conferência, o diretor do DNS, Heitor Praguér Fróes, havia proposto a criação de uma

5 Os outros dois temas diziam respeito a: 1) Organização sanitária nos estados e municípios;

2) Serviços básicos de saneamento rural (Brasil, 1950: 9505). 
escola nacional de saúde pública subordinada exatamente à universidade "onde se possa melhor prover a formação eficiente de sanitaristas, além de cursos de especialização, comandados por professores efetivos e atuando em regime de tempo integral, com vencimentos compensadores" (Brasil, 1950: 9505).

$\mathrm{Na}$ sessão de encerramento, Heitor Praguér Fróes voltaria a se pronunciar formalizando sua discordância em relação à recomendação que havia sido aprovada em plenário, lembrando que já havia encaminhado ao presidente da República proposta para criação da referida faculdade vinculada à universidade (Brasil, 1950).

Quatro anos depois, em 1954, foi criada a Escola Nacional de Saúde Pública, primeira escola federal destinada a formar quadros qualificados para todo país - não por acaso nos momentos iniciais do Ministério da Saúde -, assegurando a existência de uma instituição exclusivamente dedicada à formação de especialistas em saúde pública. Tal projeto pode ser compreendido como o resultado de um processo em que experiências anteriores de formação, intensificadas a partir da década de 1940, tiveram um peso significativo. A partir daquela década, ampliou-se também a abrangência da especialização de profissionais de saúde pública, valorizando-se profissionais com formação de nível superior em outros cursos, além do tradicional curso de medicina. Um pequeno trecho do depoimento de Elsa Ramos Paim ilustra esse processo de descobrimento e fascinação pela saúde pública que marcaria sua geração, fruto daquele momento em que a preocupação em formar novos quadros para a saúde atraiu jovens estudantes das mais diversas regiões do país.

A essa época, um dia deu no jornal, eu vi, um edital de concurso para fazer um curso de visitadora sanitária. Foi logo após a minha formatura, eu me formei em 1939, o curso de visitadora sanitária foi em 1940. Nessa época, as enfermeiras do Departamento Nacional de Saúde saíam por esse Brasil afora preparando pessoal para as secretarias de Saúde. Preparavam o pessoal, organizavam os serviços, depois iam para os outros estados. Esse curso eu fiz com dona Leontina Gomes, uma mulher extraordinária que conseguiu passar toda essa coisa, todo esse fascínio da saúde pública para gente.

O curso copiava um pouco o $4^{\circ}$ ano de enfermagem de saúde pública das escolas de enfermagem. A gente tinha, por exemplo: microbiologia, parasitologia, anatomia, fisiologia. $\mathrm{O}$ curso não era nem só a parte de saúde pública, era um curso de enfermagem. E depois tinha a parte técnica, que era muito boa. Ia gente do Rio de Janeiro, do departamento, para dar aula pra gente. 
O curso se destinava a preparar visitadoras mais ou menos como essa coisa do agente de saúde de hoje. Só que era muito mais profundo, dava muito mais base para gente. E eu me encantei com o curso. Fiquei assim deslumbrada e fiz o curso muito bem. Quando o curso terminava, a gente era lotada nos centros de saúde. A gente começava a trabalhar imediatamente.

Eu comecei a trabalhar. Mas aí aconteceu o seguinte, como eu tinha sido uma das melhores alunas do curso, ganhei uma bolsa para fazer enfermagem aqui no Rio de Janeiro. E devo ter trabalhado como visitadora uns dois anos. (Entrevista com Elsa Ramos Paim, 2004)

A atual Escola Nacional de Saúde Pública Sergio Arouca contou, em seu momento fundador, com a experiência acumulada nos anos que a antecederam, sobretudo pela participação direta de muitos profissionais formados no decorrer das décadas de 1920, 1930 e 1940. Eles trariam a experiência tanto da área de ensino como de pesquisa; seriam o elo entre aquele período, no qual se iniciou o processo de institucionalização desse campo de especialização profissional, e o novo momento da história do ensino da saúde pública que se iniciava com a inauguração da Ensp.

\section{REFERÊNCIAS BIBLIOGRÁFICAS}

BARROS BARRETO, J. de. Serviços federais de saúde em 1937. Arquivos de Higiene, VIII(1): 81, fev., 1938a.

BARROS BARRETO, J. de. Saúde pública no Brasil. Arquivos de Higiene, VIII(8): 289-304, nov., 1938b.

BARROS BARRETO, J. de. A $5{ }^{\text {a }}$ Conferência Pan-Americana dos Diretores Nacionais de Saúde. Arquivos de Higiene, XIV(3): 183-200, dez., 1944.

BRASIL. Diário do Congresso Nacional (DCN), 8 dez. 1952, Brasília.

CHAGAS FILHO, C. Meu Pai. Rio de Janeiro: Fiocruz/Casa de Oswaldo Cruz, 1993.

FEE, E. Disease of Discovery: a history of Johns Hopkins School of Hygiene and Public Health: 1916-1939. Baltimore: The Johns Hopkins University Press, 1987.

LABORATÓRIO DE HIGIENE DA FACULDADE DE MEDICINA E CIRURGIA DA SÃO PAULO. Dicionário Histórico-Biográfico das Ciências da Saúde no Brasil (1832-1930). Disponível em: <http://www.dichistoriasaúde.coc.fiocruz.br>. Acesso em: 15 jul. 2004.

MARINHO, M. G. S. M. C. Norte-Americanos no Brasil: uma história da Fundação Rockefeller na Universidade de São Paulo (1934-1952). Campinas/São Paulo: Editores Associados/Universidade São Francisco, 2001. 


\title{
2. A Criação da ENSP: \\ INTEGRAÇÃO E DIVERSIDADE NA FORMAÇÃO EM SAÚDE PÚBLICA
}

\section{INTRODUÇÃO}

\begin{abstract}
A Escola Nacional de Saúde Pública (Ensp) surge no cenário institucional brasileiro incorporada a uma abrangente legislação relativa à saúde, aprovada em setembro de 1954, menos de um mês após o suicídio de Vargas. ${ }^{1}$ Nesse contexto de transição e instabilidade política, as medidas destinadas a efetivar sua implementação e funcionamento só começariam a ser adotadas quatro anos depois, a partir de 1958, quando tem início a publicação de uma série de decretos definindo sua finalidade, estrutura, regulamento e regimento. ${ }^{2}$ Somente em novembro de 1959 começariam de fato os cursos daquela que seria a primeira escola brasileira de saúde pública de abrangência nacional.

Portanto, os primeiros anos de atividades da Escola se desenrolariam exatamente no decorrer da década de 1960, período de conturbada vida política, marcado pelos acontecimentos que desencadearam o golpe de 1964 e, posteriormente, pelos seus desdobramentos na direção de um regime autoritário.

A nova instituição destinada a formar profissionais para o campo da saúde pública - antiga aspiração daqueles que já atuavam nesta área conseguira, no decorrer dos anos de 1950, assegurar seu estatuto jurídico/ legal e necessitaria, a partir dos anos de 1960, implementar as atividades para as quais se destinava, consolidando sua função institucional. Ou seja, a nova Escola integrante do quadro do Ministério da Saúde teria de mostrar

1 Brasil (1954). O artigo $5^{\circ}$ da referida lei determinava que a "União manterá uma escola de saúde pública $(\ldots)$ ".

2 Brasil (1959a, 1959b).
\end{abstract}


a que veio no decorrer destes primeiros anos, o que tornava este período decisivo para consolidar seu papel no cenário institucional e burocrático da saúde. Neste projeto, tanto seus dirigentes como os profissionais envolvidos em suas atividades obtiveram sucesso.

Inicialmente funcionando em situação precária, sem sede própria para realizar seus cursos e centralizar a administração e tampouco com corpo docente definitivo, ao final década de 1960 a Ensp já estava instalada em Manguinhos, em uma ampla sede de nove andares e com um quadro de profissionais definido.

Para garantir este movimento, foi necessário, por um lado, estabelecer relações com as instituições que já vinham atuando na área da saúde pública, criando parcerias para definir suas estratégias de atuação e delimitando suas especificidades, através da colaboração dos profissionais desses órgãos. Por outro lado, foi preciso demarcar sua relação no âmbito político, procurando assegurar um mínimo de autonomia diante das alterações de poder nesse quadro. Além disso, era necessário obter verbas para a realização das atividades pretendidas, o que demandava acesso aos centros decisórios do poder.

As conquistas asseguradas no decorrer destes primeiros anos garantiriam a sobrevivência da instituição nos anos seguintes, quando, durante a primeira década de 1970, a Ensp passaria por radicais cortes em seu orçamento e pela redução drástica de seus funcionários. Diante de tais considerações, algumas questões despontam como orientadoras deste texto e estimulam o trabalho que aqui se inicia.

Como nos chama a atenção a ampla literatura que se dedica à análise de processos de criação e mudança institucional, alterações neste campo devem ser observadas em uma perspectiva de desenvolvimento histórico que se apóia na idéia de path dependency com a convicção de que as políticas públicas implementadas num determinado período não surgiram do nada; pelo contrário, apresentam algum vínculo com as instituições já existentes.

Com base nessa argumentação, as alterações na esfera institucional estariam envolvidas por um determinado contexto político e institucional que, influenciado pelos seus antecedentes, condicionaria suas estratégias e possibilidades de transformação (Hall \& Taylor, 1996; Pierson, 1995). Assim, ao analisar o processo de criação da Ensp - tanto em sua dimensão jurídica, a partir de 1954, como a partir de novembro de 1959, quando têm início suas atividades -, procuro identificar a confluência entre interesses políticos, herança institucional, atores participantes do processo e concepções sobre 
saúde pública, todos eles elementos que orientaram este movimento de mudança e a consolidação de um novo projeto institucional voltado para a formação em saúde pública.

Nesse sentido, as instituições que antecederam a Ensp e, portanto, já atuavam neste campo de formação profissional nas décadas anteriores, desempenharam papel relevante nos primeiros anos de constituição da Escola. Em torno deste projeto destinado a fortalecer a institucionalização do ensino especializado em saúde pública, envolveram-se experientes sanitaristas, comprometidos com trajetória da saúde no Brasil.

Foram principalmente os profissionais pertencentes ao quadro do Departamento Nacional de Saúde (DNS) e do Serviço Especial de Saúde Pública (Sesp) - órgãos que integravam o Ministério da Saúde - que inicialmente constituíram parte da equipe de professores da Escola, trazendo subsídios e contribuindo na definição das atividades necessárias à formação e especialização na área da saúde pública. A eles se juntaram especialistas de outros órgãos como o Laboratório de Águas do Estado da Guanabara, a Superintendência de Urbanização e Saneamento (Sursan), as faculdades de medicina e de farmácia, tanto do Rio de Janeiro como da Universidade Federal Fluminense e professores da Pontifícia Universidade Católica do Rio de Janeiro (PUC/Rio), entre outros. A colaboração desses médicos, engenheiros enfermeiras, odontólogos, professores etc. teve como ponto de partida a experiência dos anos anteriores em que se especializaram e desempenharam suas funções nos mais diversos setores da saúde pública. A lista dos professores colaboradores neste momento inicial da Ensp confirma a participação de nomes de reconhecida competência na área da saúde pública, como também demonstra origem institucional diversa. ${ }^{3}$

A Ensp nasceu, portanto, como um espaço de agregação, de interrelação entre profissionais de diversas instituições em torno de um objetivo comum - consolidar o processo de ensino e especialização em saúde pública. Esta marca de seu momento fundador, ou seja, uma escola aberta às mais diversas experiências e concepções, permaneceria como uma de suas mais importantes características ao longo das décadas seguintes.

A partir dessas observações, algumas questões merecerão atenção e orientarão a apresentação deste trabalho, norteando as informações e os questionamentos relativos à história da Ensp. Procurarei responder como

O Anexo 1, com a relação nominal dos professores da Ensp em 1961, dá uma idéia da diversidade institucional dos colaboradores da Escola neste seu processo de institucionalização. Ver Fundo Ensp/caixa 67, maço 2, Casa de Oswaldo Cruz/Fiocruz. 
Carteira do dr. Fernando Leitão curso básico de saúde pública para médicos, 1962. Acervo Particular. se desenrolou este processo de consolidação institucional no decorrer do período e quais foram seus principais agentes. Além disso, procuro identificar o diagnóstico sobre a saúde que orientava as diretrizes políticas para o setor e quais os temas eleitos, priorizados nos debates relativos à política de saúde e à formação profissional neste campo.

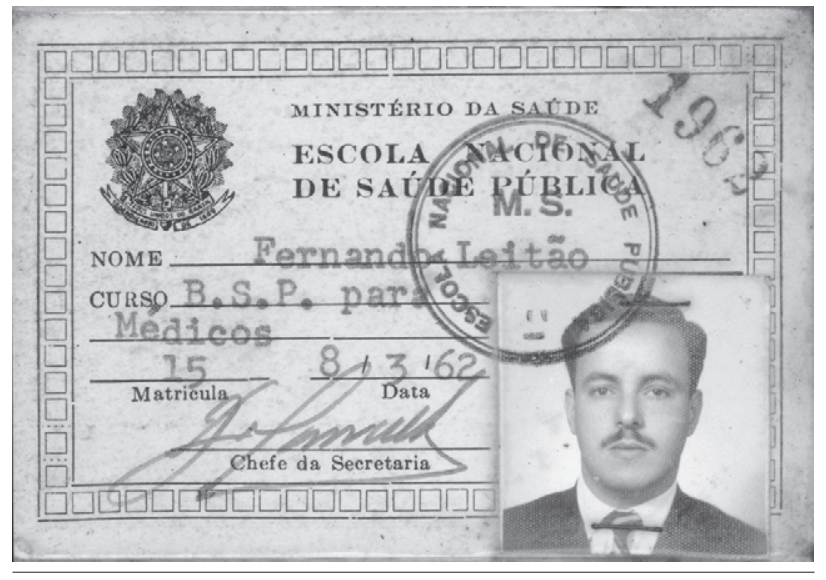

Para tanto, divido o trabalho em duas partes. Na primeira, recupero o contexto político e legislativo dos anos de 1950 durante o qual foram definidas as normas que orientariam a organização da instituição e assegurariam seu estatuto jurídico, também procurando identificar os princípios interpretativos que nortearam as regulamentações adotadas. $\mathrm{Na}$ segunda parte, detenho-me sobre as atividades implementadas na Ensp no decorrer dos anos de 1960, identificando as idéias, concepções e preocupações que inspiraram aqueles que se dedicaram a consolidar este projeto ambicioso, destinado a atrair profissionais das mais diversas regiões do país. 


\section{Diretrizes para a Saúde Pública nos Anos 1950: O PAPEL DA NOVA ESCOLA NACIONAL}

\begin{abstract}
Analisando o panorama sanitário brasileiro não perderemos de vista o conceito de que o nível de saúde de um povo é corolário do seu progresso econômico, e que somente a gradual ascensão dos quadros sociais e educativos da vida nacional e a melhoria do nível de bem-estar da população poderão efetivamente conduzir ao definitivo aperfeiçoamento dos índices sanitários. (...)

a saúde pública é incontestavelmente um problema de superestrutura que deverá de modo irrecorrível ajustar-se ao arcabouço econômico da Nação. (Getúlio Vargas, 1951)
\end{abstract}

Em sua primeira mensagem após seu retorno à presidência da República em 1951, Getúlio Vargas formalizava em discurso político a linha de interpretação que ganharia força, no decorrer dos anos seguintes, nas análises relativas aos problemas de saúde no Brasil, associando-os diretamente ao desenvolvimento econômico do país. Nacionalismo e desenvolvimentismo, palavras-chave para compreender o debate político dos anos de 1950/60, estariam presentes também nas análises relativas à saúde pública.

Ao longo de seu discurso, o presidente enfatizaria em diversas passagens a importância do desenvolvimento econômico para que fossem asseguradas melhores condições de saúde à população, pois

o baixo nível de saúde no Brasil é fiel reflexo da pobreza que grava a grande maioria do nosso povo. Este, na verdade, só é doente porque ainda não possui os meios para comprar sua saúde, sob a forma de alimentação adequada, ambiente higiênico, e sadio regime de trabalho. (Vargas, 1951: 1)

Relembrando e reforçando o que havia feito em sua gestão anterior na área da saúde pública, principalmente entre os anos 1935-1945, identificou o que considerava as principais lacunas no âmbito da saúde e apresentou os objetivos mais imediatos de seu novo governo, destacando os problemas que necessitavam atenção mais efetiva a partir daquele momento.

Com uma especial preocupação em relação aos habitantes da área rural, onde ainda predominavam grandes moléstias associadas às precárias condições sanitárias da maior parte do país, o presidente destacou entre as prioridades de ação pública no campo da saúde: combate à malária e às endemias rurais; luta contra a tuberculose; expansão dos serviços de assistência médica e hospitalar; plano de saneamento básico; política
Porque a nossa preocupação era muito em cima da parte epidemiológica e de odontologia preventiva. Porque na realidade, quando a gente está na faculdade aprende a curar, a tratar a parte clínica, mas a parte preventiva é muito fraca. Eu não sei hoje, pode ser que tenha melhorado. Então a gente dava muita ênfase à parte preventiva. Levava o pessoal pra visitar a Fundação Sesp que era 0 modelo, até para os cursos em São Paulo. E viajava para 0 interior; quer dizer, a gente tinha um programa de campo com esses alunos no interior - Aimorés e Baixo Guandu - e mais recentemente até aqui no estado do Rio (...).

(Entrevista com Hélio Uchôa, 2003 - sobre o curso de odontologia) 
Isso foi uma coisa fantástica, porque aqui, sempre, depois disso, sempre a gente inventou alguma coisa que tinha que fazer com a comunidade, sempre, pra poder manter um contato direto com a população, especialmente nós da Educação. Não tem sentido a gente ficar vendo Educação só do nível do pessoal que estava aqui nos cursos. A gente ia dizer o que pra eles? Coisas que a gente tinha feito há 10 anos atrás, só e acabou? Não, tinha que estar sempre renovando.

(Entrevista com Lenita Vasconcelos, 2003 - a respeito da experiência do teatro com a comunidade de Manguinhos) dirigida de alimentação; prosseguimento nas ações de assistência à maternidade e à infância; e educação sanitária.

Apontava com este discurso para a estreita relação entre desenvolvimento econômico e melhoria das condições de saúde da população, relação esta que iria conduzir grande parte das análises e propostas apresentadas para as políticas de saúde. Aliados ao lento desenvolvimento econômico estariam os problemas relativos à área rural, que não haviam alcançado os avanços obtidos nos centros urbanos. Este rápido diagnóstico apresentado pelo executivo no início de 1951 comungava com as análises e debates que já vinham sendo realizados no âmbito de organismos internacionais como a Organização Mundial da Saúde (OMS) e a Organização Pan-Americana da Saúde (Opas), que desempenhariam importante papel no fortalecimento das ações destinadas à institucionalização do ensino médico e ao incremento de uma política de formação de recursos humanos em saúde na América Latina.

No Brasil, tais questões estariam presentes na esfera política, no âmbito legislativo, como também nos fóruns tradicionais que agrupavam os profissionais de saúde. E a estas diretrizes orientadas pela preocupação em assegurar meios que favorecessem o desenvolvimento seriam incorporadas análises que destacavam a descentralização como atributo necessário ao fortalecimento das ações de saúde no país.

Aramis de Ataíde, primeiro ministro da Saúde após a crise que se sucedeu ao suicídio de Vargas - e, portanto, o titular que ocupava a pasta quando a Ensp foi criada em setembro de 1954 -, em vários discursos realizados ao longo de todo o ano de 1955 explicitou e desenvolveu os argumentos que subsidiavam essas propostas. Reafirmando preocupação com a excessiva centralização administrativa no setor, chamou a atenção para os municípios e para importância de lhes restituir seu papel na gestão dos serviços de saúde da qual haviam sido afastados no decorrer dos anos de 1930 e 40. Segundo Ataíde (1957: 16)

Entre nós, desde há algum tempo se observa uma tendência acentuada para a centralização administrativa, e não há mais municípios, a não ser os de algumas capitais estaduais, que mantenham sua própria organização sanitária, o que dá às comunas um sentido de irresponsabilidade em face de um dos mais importantes setores da administração local. Pensamos já ser tempo de reagir contra esta tendência, procurando fortalecer os nossos Municípios, que representando a célula fundamental do regime democrático e a base da organização política, precisam ter revigoradas suas administrações. 
Em outra palestra, realizada na Academia Brasileira de Medicina Militar seis meses depois, o ministro, após fazer referência a Gunnar Myrdal - que no decorrer dos anos seguintes influenciou com suas idéias diversas análises empreendidas por muitos sanitaristas e políticos vinculados aos projetos de saúde pública -, expôs:

A saúde pública está, assim, deixando de ser um problema que possa ser estudado apenas pelos médicos sanitaristas. Exige com crescente intensidade, que seus programas sejam integrados nos planos gerais de modernização da economia nacional, organizados pelos economistas, engenheiros, industriais, administradores, etc. (Ataíde, 1957: 51)

Com esta lógica de abordagem, o desenvolvimentismo e a descentralização constituíram dois eixos centrais na orientação e elaboração de políticas públicas ao longo dos anos de 1950 e 60, interferindo também sobre a área de saúde pública. Nesse sentido, o processo de criação e institucionalização do ensino e da especialização em saúde pública não pode ser observado como resultado de uma simples alteração legislativa. A criação da Escola Nacional de Saúde Pública em setembro de 1954 concretizava propostas que vinham sendo debatidas há alguns anos e se apresentava como uma das medidas destinadas a atender aos propósitos de desenvolvimento do país, contribuindo diretamente para o processo de descentralização das ações de saúde pública. A própria vinculação da escola ao projeto de desenvolvimento nacional já havia sido definida em 1947, quando ainda no governo de Eurico Gaspar Dutra foi elaborado o Plano Salte, ${ }^{4}$ em cujo item relativo à saúde constava uma verba destinada especificamente à criação de uma Escola Nacional de Saúde Pública. ${ }^{5}$

Três anos depois, em 1950, durante a realização da $2^{\text {a }}$ Conferência Nacional de Saúde, realizada de 27 de novembro a 2 de dezembro, a criação de uma Escola Nacional de Saúde Pública voltou a ser lembrada no decorrer dos debates. O discurso proferido pelo então diretor do DNS Heitor Praguer Fróes, no ato inaugural da conferência, indicava a proximidade de propósitos entre os técnicos da saúde pública e o poder executivo, demonstrando que as mudanças institucionais implementadas nos anos seguintes viriam ao

4 O Plano Salte foi um plano econômico aprovado no governo de Eurico Dutra e constituído na lei n. 1102, de 18 de maio de 1950. A nomenclatura indicava os quatro principais problemas que o plano se propunha resolver: saúde, alimentação, transporte e energia (Abreu et al., 2001).

5 Esta previsão de dotação orçamentária seria utilizada como argumento pela Comissão de Finanças para aprovar o projeto de lei do qual redundou a criação da Escola (Brasil, 1951b: 12034).

\section{A Escola contratou as} atendentes, as visitadoras. E aí a gente começou a sentir muita falta de laboratorista. Que é que a gente faz com laboratorista? Não tem laboratorista. E lá havia uns guardas antigos da malária que estavam desempregados. Aquela região havia tido muita malária, mas nessa época a malária estava mais ou menos controlada naquela área. Um deles, seu Antônio, me procurou e a gente conseguiu um cursinho de laboratorista para ele, para aquelas coisas práticas, as coisas mais simples. 0 seu Antônio fez o treinamento, voltou entusiasmadissimo e foi um excelente laboratorista naquele posto. E o que é muito interessante, isso é um parêntese, os filhos do seu Antônio, depois, eles todos vieram fazer curso de laboratorista e passaram a trabalhar na Fundação.

(Entrevista com Elsa Paim, 2004 - a respeito do trabalho no Posto Samuel Libânio em Jacarepaguá na década de 1960) 
Era um curso de um ano em que a gente estudava no Instituto Fernandes Figueira. Tinha aula de epidemiologia com o dr. Lincoln de Freitas, com o Aristides Celso Limaverde, o Bichat de Almeida Rodrigues e o Mário Magalhães da Silveira, que nos dava aula sobre fundamentos socioeconômicos. As aulas dele eram muito interessantes. Ele abriu uma perspectiva. Depois do curso a minha cabeça abriu, mudou a minha percepção de vida. A percepção de que as doenças não caem do céu, não são deterministas, elas são probabilísticas, dependem de uma porção de fatores (...).

(Entrevista com Fernando Leitão, 2004 - a respeito do curso básico de saúde pública feito na Ensp em 1962) encontro das propostas debatidas nos fóruns específicos do setor. ${ }^{6}$ Entre as principais medidas pleiteadas o diretor indicou: a) a criação de uma Escola Nacional de Saúde Pública, que deveria preferencialmente estar integrada à Universidade do Brasil; b) a criação de um Serviço Nacional de Endemias Rurais; c) a promulgação do Código Sanitário Nacional (Lei Orgânica da Saúde), cujo anteprojeto se encontrava no Congresso Nacional; d) a criação de um Ministério de Saúde e Assistência Social (Nogueira, 1950: 9506).

Três anos depois, estas propostas começaram a ser efetivadas. A primeira ocorreria em julho de 1953, com a separação do Ministério da Saúde da pasta da Educação, antiga aspiração dos sanitaristas que finalmente se concretizava. Em seguida, seriam criados em seu interior dois novos órgãos: a Escola Nacional de Saúde Pública em 1954 - não incluída na Universidade do Brasil, como era a proposta original - e o Departamento Nacional de Endemias Rurais (DNERu) em 1956. Tais alterações na área institucional da saúde pública, que a princípio podem ser observadas como meramente burocráticas, foram responsáveis em médio prazo pela consolidação das áreas de atuação pública neste campo. Elas implicaram mudanças efetivas nas políticas públicas de saúde sem, entretanto, significar um rompimento com as ações que vinham sendo desenvolvidas principalmente nas últimas décadas. Por um lado, apontam de imediato para as questões que se destacavam como prioritárias no processo de definição de políticas para a saúde. Ou seja, a autonomia para a saúde, com a conquista de um ministério separado da educação, as endemias rurais e a consolidação e o controle sobre o processo de formação profissional no campo específico da saúde pública. Por outro lado, demonstram que as diretrizes deveriam se ajustar aos interesses políticos em jogo naquele contexto, sendo inseridas nas negociações políticas atreladas a grupos de interesses específicos, como foi o caso, por exemplo, da criação do Ministério da Saúde e como seria também a aprovação do projeto de lei que resultaria na criação da Ensp. ${ }^{7}$

É com esta perspectiva - levando em consideração as diretrizes políticas definidas naquele contexto e os interesses em jogo - que a criação da Ensp não pode ser observada como um fato isolado, mas como mais uma medida integrante de um conjunto de proposições e concepções acerca

6 O senador Hamilton Nogueira, em discurso publicado no dia 8 de dezembro de 1950, refere-se ao conteúdo da apresentação do diretor do DNS como uma contribuição valiosa para a elaboração de leis no Congresso Federal (Nogueira, 1950: 9505).

7 Em trabalho anterior, em co-autoria com Wanda Hamilton, analisamos como a criação do Ministério da Saúde atendeu aos interesses eleitorais do PSD do Rio de Janeiro. 
da atuação pública na área da saúde, que imprimiu um sentido comum às três alterações institucionais.

\section{A TRAJETÓRIA LEGISLATIVA}

A própria trajetória legislativa que originou os projetos de lei referentes a cada uma das mudanças administrativas indica que estas caminharam paralelamente no decorrer do mesmo período, uma reforçando a outra.

O ponto de partida jurídico para a criação da Ensp pode ser encontrado no mês de fevereiro de 1948, quando o poder executivo enviou à Câmara o projeto de Lei Orgânica da Saúde. Na exposição de motivos que acompanhava a mensagem presidencial, expunha o ministro da Educação e Saúde da época, Clemente Mariani, que o anteprojeto havia sido organizado por uma comissão formada pelo diretor do DNS com a colaboração da Sociedade Brasileira de Higiene (SBH), a partir de um esboço apresentado ao ministro em 1945. Em setembro do mesmo ano, este projeto seria debatido na Comissão de Saúde Pública, quando o deputado Rui Santos (UDN/BA), relator da referida comissão, apresentaria parecer substituto fazendo uma série de alterações no projeto, entre elas a que incluía um novo artigo com a indicação de criação de uma Escola de Saúde Pública. ${ }^{8}$

No projeto original, as medidas referentes à formação profissional no campo da saúde pública, definidas no artigo de $\mathrm{n}$. 7 de forma concisa, estipulavam: "os órgãos federais competentes organizarão cursos de aperfeiçoamento para técnicos e auxiliares dos serviços de saúde, instituindo bolsas de auxílio para os candidatos" (Brasil, 1951c: 12.029). No substitutivo, apresentado por Rui Santos, constava uma proposição mais ambiciosa e detalhada com a seguinte redação:

para a formação do pessoal técnico especializado a se encarregar do trabalho previsto nos artigos anteriores, a União manterá uma Escola Nacional de Saúde Pública, à qual poderão ser equiparados outros

\footnotetext{
Em sua longa justificativa na qual expunha as alterações que havia realizado, Ruy Santos começava por questionar a nomenclatura de Lei Orgânica, citando estudo de Afonso Arinos a respeito do tema e argumentando que o mais coerente, tendo em vista os preceitos constitucionais em vigor, seria adotar a nomenclatura de Lei de Proteção e Defesa da Saúde. É interessante observar que Rui Santos também seria o responsável pelo projeto que originou a criação do Ministério da Saúde, indicando seu interesse direto por temas e decisões desta área do setor público.
}

$0 \mathrm{dr}$. Blois, realmente, teve bastante sabedoria para não querer ficar sozinho, ele trabalhou com todos os serviços: Secretaria de Saúde, escolas de enfermagem, Faculdade de Saúde Pública de São Paulo, Escola de Enfermagem de Ribeirão Preto (....). A Escola não teria crescido como ela cresceu sozinha.

(Entrevista com Elsa Paim, 2004) 
A minha visão era preparar alguém para as necessidades do país que eu, na época, conhecia bem, conhecia porque eu tinha morado em alguns lugares e tinha viajado, estava sempre viajando. Então, nosso objetivo era preparar a turma de um modo que eles saíssem sabendo a profissão (...).

(Entrevista com dr. Cynamon, 2004) existentes ou que venham a ser criados pelos Estados, ou pela iniciativa particular.

$\S 1$ Os diplomados nos estabelecimentos de ensino acima referidos bem como os habilitados em cursos especiais de saúde pública, têm preferência na nomeação para serviços sanitários.

$\S 2$ O Governo Federal concederá bolsas de estudos a técnicos indicados pelos governos estaduais e dos territórios, que completarão sua formação profissional na Escola Nacional de Saúde Pública, bem como a técnicos seus e dos estados, para a realização de estudos e observações no estrangeiro nos termos da regulamentação a ser baixada. (Brasil, 1951b: 12.033)

As alterações do deputado em relação à versão original do projeto propunham uma ampliação das funções do governo federal neste campo. Além de ministrar cursos de especialização com concessão de bolsas de estudo - ações que já vinham sendo realizadas há várias décadas - assumiria uma nova instituição de âmbito nacional com funções mais abrangentes neste setor. ${ }^{9}$ O projeto de Rui Santos seria aprovado na Comissão de Saúde Pública e encaminhado à Comissão de Finanças, onde permaneceria até o final daquela legislatura.

Em 3 de setembro de 1951, já sob o novo governo de Vargas, o deputado Rui Santos apresentaria o seu substitutivo através de um novo projeto de lei, que passaria por novas discussões no interior das comissões, sendo posteriormente levado para aprovação em plenário. Em seguida, seria encaminhado ao senado, onde permaneceria aguardando nova votação. ${ }^{10}$ A sua promulgação três anos depois, em 1954, seria resultado da articulação de um grupo de sanitaristas liderados pelo então diretor do DNS Ernani Braga, que, conhecendo a existência do projeto de lei de Rui Santos, engavetado no senado, mobilizou-se para votá-lo sem que passasse por novas alterações:

Nós conseguimos e eu fiz, pessoalmente, contatos com o presidente da Comissão de Saúde do senado, para que essa lei não fosse emendada no senado, pudesse ser aprovada sem voltar à Câmara. Ela viria, então, ao

9 Como já foi observado no artigo, até então os cursos de saúde pública destinados à formação de sanitaristas haviam sido realizados pelo Instituto Oswaldo Cruz, pela Escola de Saúde Pública de São Paulo e pelo Departamento Nacional de Saúde.

10 A justificativa para a mudança era de que o anteprojeto apresentado em 1948 não havia recebido número por ter sido apresentado pelo executivo através de mensagem presidencial. O projeto de lei passaria a ter o n. 1090 . 
Ministério da Saúde para se corrigir alguns elementos que estivessem confusos. (Entrevista com Ernani Braga, 1978)

E foi o que efetivamente aconteceu. $\mathrm{O}$ artigo referente à Ensp não sofreu nenhuma alteração no decorrer deste processo legislativo, e a redação definitiva que constava da lei após sua aprovação seria exatamente aquela que havia sido proposta por Rui Santos em 1948. Os ajustamentos necessários viriam com os decretos instituídos em 1958 e 1959, que definiriam com mais detalhes os objetivos e normas de funcionamento da escola.

Com isso, dava-se mais um passo na direção dos projetos delineados para o setor da saúde, adequando os interesses mais específicos dos sanitaristas atuantes na área da saúde pública às análises que os incorporavam em um programa abrangente de desenvolvimento para o país.

A definição do estatuto legal da Ensp deve, portanto, ser observada como resultado da combinação entre dois pontos. Por um lado, atendia ao novo contexto político e às novas estratégias e prioridades definidas para o setor, com base em propostas que focavam o desenvolvimento econômico e criticavam a excessiva centralização que havia sido imposta ao longo das décadas de 1930 e 40. Por outro lado, atendia aos propósitos dos profissionais diretamente vinculados a este campo de ação pública, que já pleiteavam a criação de uma Escola Nacional de Saúde Pública há algum tempo.

A criação da Ensp se apresenta, portanto, como resultado de uma articulação política conjuntural em resposta aos propósitos mais amplos e não imediatos que vinham sendo elaborados e amadurecidos nos fóruns políticos e acadêmicos. Neste quadro de diretrizes políticas, a Escola gradativamente definiria seu papel para o desempenho das metas e objetivos traçados, compatibilizando-os com uma estratégia política abrangente.

Cabe agora observar como a Escola Nacional de Saúde Pública desempenhou seu papel no cenário político nacional, contribuindo para o desenvolvimento de políticas públicas de saúde, ao mesmo tempo que se consolidava institucionalmente. Considerando que ela aparece num contexto de revisão das estratégias de ação pública, ela é um novo elemento, que espelha, em diferentes aspectos, este cenário de mudança.
0 grupo de ciências sociais não era um grupo de teóricos da sociologia, de política ou da antropologia e da psicologia não. As pessoas pegavam e aplicavam isso ao contexto de medicina (...).

(Entrevista com Arlindo Sousa, 2003) 


\title{
Saúde Pública como uma Nova Profissão Social: ENCONTRO DE PROPOSTAS E ANÁLISES
}

\begin{abstract}
O acervo comum de conhecimentos, que se superpõe aos das profissões básicas, constitui a essência da profissão de saúde pública, que não é simplesmente uma especialização, mas uma nova profissão social, como outras novas profissões justificadas e necessárias em vista da complexidade das realidades do mundo moderno. (David Tejada apud Blois, 1967: 124)
\end{abstract}

O processo de estruturação e consolidação institucional da Ensp, implementado a partir dos anos de 1960, acompanhou as diretrizes que vinham sendo debatidas e aplicadas em outros países da América Latina, destinadas ao fortalecimento do ensino das ciências da saúde. Este movimento foi patrocinado por organismos internacionais, como a OMS e a Opas, que dedicaram especial atenção ao investimento e à supervisão do desenvolvimento das atividades deste setor, com crescente prioridade para o tema da formação de recursos humanos e para a incorporação das ciências sociais em saúde.

Amparadas na constatação do constante aumento no número de escolas de medicina e na necessidade de intervenção sobre o processo de formação e especialização em saúde pública, estas diretrizes acabaram por eleger o tema dos recursos humanos como o objeto central dos debates no âmbito da saúde, no decorrer da década de 1960.

Diferentes eventos nacionais e internacionais contribuíram para o encontro entre profissionais da saúde pública, sistematizando diretrizes para este campo de ação que fortaleceriam princípios em elaboração desde a década anterior, como a questão do desenvolvimento e da descentralização. Entre eles, destaco a significativa instituição das Conferências de Diretores de Escolas de Saúde Pública da América Latina, planejadas pela Oficina Sanitária Pan-Americana. A primeira conferência seria realizada em 1959, no México; a segunda, em 1961, na Venezuela; e a terceira, em 1963, no Brasil (São Paulo), reforçando a participação brasileira neste processo. ${ }^{11}$

No âmbito nacional, foram realizadas duas Conferências Nacionais de Saúde, que apresentaram significativa repercussão sobre os rumos da

\footnotetext{
11 Carta de Abraham Horwitz enviada ao ministro da Saúde Paulo Pinheiro Chagas, em 7 de junho de 1963. Ver Fundo Ensp, caixa 98, maço 2, Casa de Oswaldo Cruz/Fiocruz.
} 
saúde pública no Brasil. A $3^{\text {a }}$ Conferência Nacional de Saúde (CNS) foi realizada no Rio de Janeiro, 13 anos após a realização da $2^{\text {a }}$ CNS, entre os dias 9 e 15 de dezembro de 1963. Convocada pelo então ministro da Saúde Wilson Fadul, aglutinou profissionais dos mais diversos organismos da saúde pública brasileira, sendo presidida pelo ministro e pelo diretor geral do DNS Arnaldo Beiró de Miranda, contando, ainda, com a colaboração de Mário Magalhães da Silveira, na época diretor da Divisão de Organização Sanitária (DOS) do DNS, como secretário geral do evento.

Segundo o próprio ministro indicaria alguns anos mais tarde, a $3^{\text {a }}$ CNS "se constituiu num marco importante da história do pensamento dos sanitaristas brasileiros. No processo de elaboração desse pensamento, sobretudo a partir de 1940, foi tomando corpo a idéia de que a saúde é inseparável do processo nacional de desenvolvimento" (Fadul, 1992). Sob esta perspectiva, os temas centrais da conferência se direcionaram para uma análise crítica da organização sanitária brasileira naquele período, buscando alternativas para os problemas identificados, entre eles a excessiva centralização. ${ }^{12} \mathrm{O}$ debate se concentrou, portanto, em torno de questões mais relacionadas com a organização institucional da saúde pública e sua forma gerencial de prestação de serviços, diversa da temática que se destacaria quatro anos depois na conferência seguinte.

A $4^{\text {a }}$ CNS foi realizada entre 30 de agosto e 4 de setembro de 1967 no Rio de Janeiro e representou um importante espaço para confluência das análises no campo da saúde pública nacional e internacional, além de ter estimulado debates através de seminários entre grupos de trabalho e a própria definição do papel da Ensp neste processo, tendo sido o local onde a conferência ocorreu.

Ao sediar um evento que apresentava como tema central "Recursos Humanos para as Atividades de Saúde" e que contou com cerca de 300 participantes de todo o país e do estrangeiro, a Escola fortalecia seu papel como referência no processo de formação de profissionais especializados em saúde pública. ${ }^{13}$

12 Os temas oficiais da conferência for: geral do problema; b) distribuição d municipal; c) municipalização dos s (Brasil/MS, 1992).

13 Na época, a Escola já havia se reestru de Saúde Pública (Fensp). Vários organização da conferência, como A sanitarista e professor, além do próp de secretário geral da conferência ( atividades médico-sanitárias nos níveis federal, estadual e rviços de saúde e d) fixação de um pla o nacional de saúde

turado transformando-se em Fundação 1 nsino Especializado nembros de seu corpo docente estiv ram envolvidos na chilles Scorzelli Junior, ex-diretor, e M anoel José Ferreira, io diretor na época, Edmar Terra Blois, que ocupou o cargo rasil/MS, 1967). n: a) situação sanitária da população brasileira e apreciação
E ele valorizava muito a Unidade. Porque, nessa época, a idéia era de que a Unidade era 0 laboratório do sanitarista! Era 0 campo de prática do sanitarista.

(Entrevista com Luiz Fernando Ferreira, 1999 - sobre Blois) 
4를 Conferência Nacional de Saúde. Da esquerda para a direita: Edmar Terra Blois (quinto), ministro da Saúde Leonel Miranda (sexto) e Ernani Braga (oitavo). Foto: Cid Fayão. Acervo Ensp.

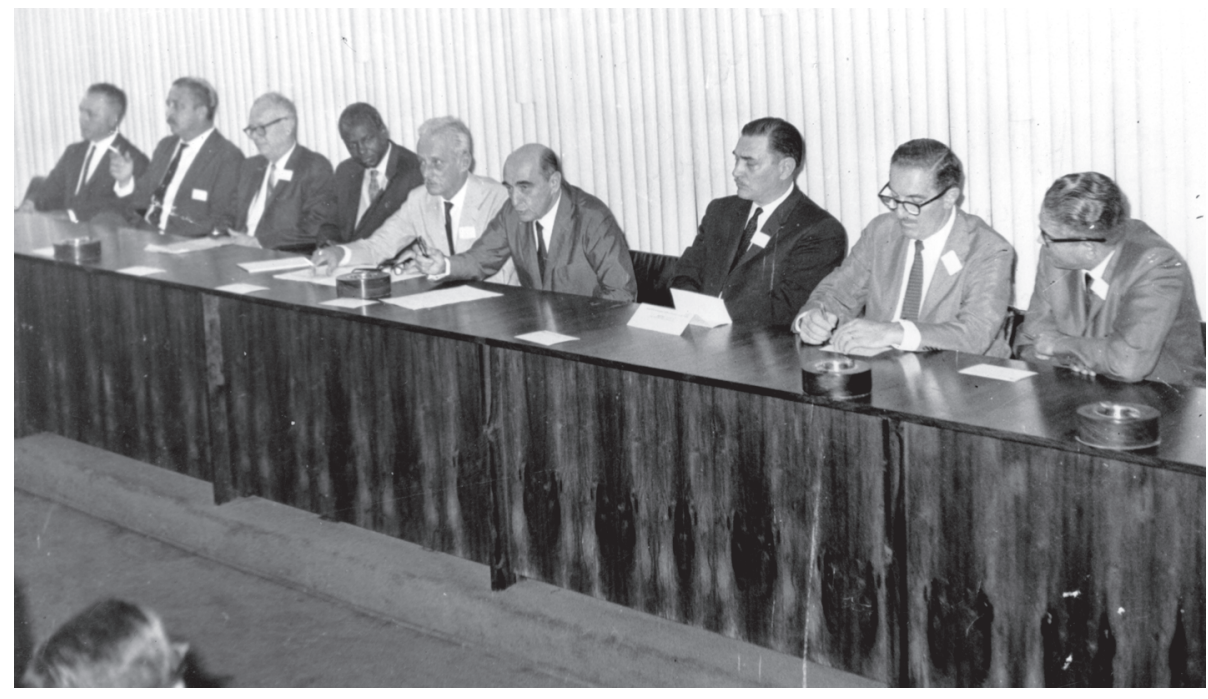

A conferência foi definida como um espaço de encontro entre diferentes categorias profissionais envolvidas com a área da saúde pública, como secretários de Saúde e reitores; sanitaristas e educadores. Entre os membros participantes, encontrava-se o chileno Abraham Horwitz, diretor da Opas. Na palestra que proferiu, ele acentuou o papel das escolas de saúde pública no processo de desenvolvimento, reforçando as intenções da organização que presidia de intervir neste campo e contribuir para a sistematização do conhecimento no setor.

Existem na América Latina 10 escolas de saúde pública e a todas elas nossa Organização presta assessoria. Cabe à especialidade redefinir seus propósitos, identificar seus métodos ou determiná-los através da investigação científica, para nortear o ensino acadêmico e prático no sentido de assegurar à saúde sua condição de componente indispensável do desenvolvimento. (Horwitz, 1967: 41)

Os trabalhos expostos no decorrer do evento apresentaram reflexões sobre os problemas relacionados à formação profissional na área da saúde pública e suas deficiências, bem como proposições para o desenvolvimento deste campo. Entre os palestrantes encontravam-se Achilles Scorzelli, Edmar Terra Blois, Sávio Antunes e Ernani Braga, este último ocupando o cargo de chefe da Divisão de Educação e Treinamento da OMS. Esta estreita colaboração apontava para a afinidade entre os dirigentes, os gestores deste processo de institucionalização do ensino e as proposições em destaque nos fóruns internacionais da área. 


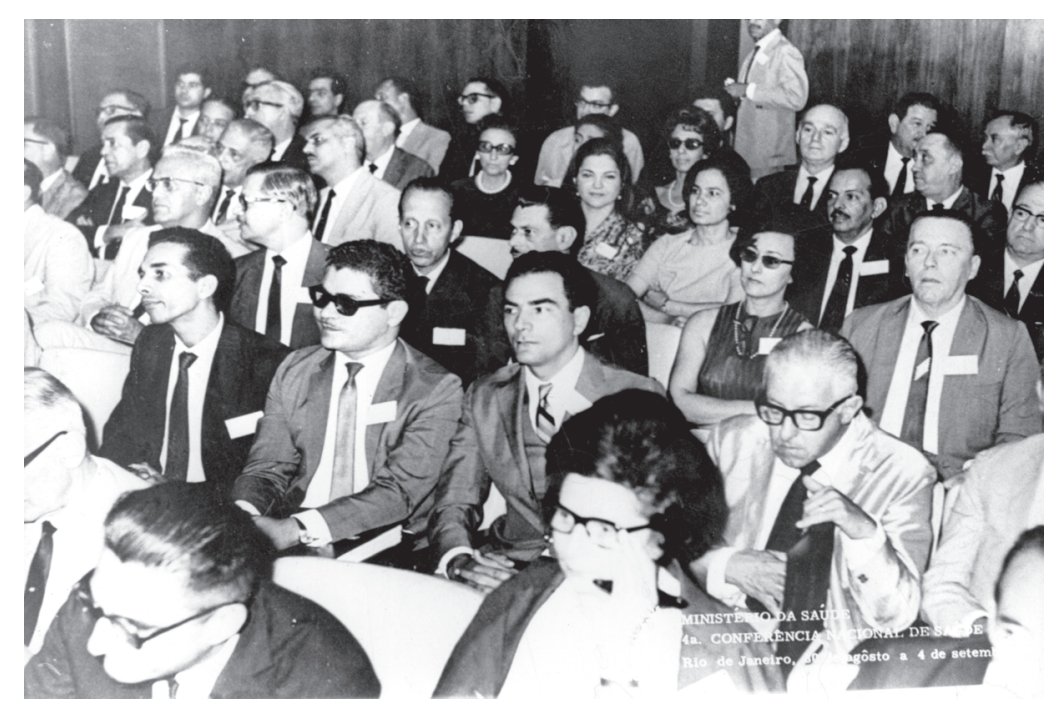

Entre os temas que se destacaram nas propostas norteadoras das para o trabalho na área de formação em saúde pública, percebe-se uma evidente preocupação com pessoal de nível médio e auxiliar, acentuandose a importância de investir em sua preparação para não haver concentração sobre o trabalho de profissionais de nível superior, cujas formação e habilitação para o mercado de trabalho eram mais longas e demoradas (Braga, 1967: 53). Outro aspecto acentuado pelos trabalhos dizia respeito à integração entre as escolas de saúde pública e as universidades, indicando a necessidade de estabelecer mecanismos que favorecessem uma harmonia entre as duas esferas de formação profissional no campo da saúde sem, entretanto, perder de vista as demandas e carências de pessoal no país (Blois, 1967: 136). Com este objetivo constatou-se a importância de expandir a capacidade de preparação e treinamento, a partir de estudo detalhado do mercado de trabalho sobre as necessidades de mão-de-obra para a saúde. Complementava tais diretrizes a indicação de que deveria o poder público procurar diversificar as atividades de preparação e treinamento do Ministério da Saúde, investindo em uma atuação descentralizada, através da cooperação com os estados. Achilles Scorzelli Júnior (1967: 118) acentuou esta questão da descentralização associando-a ao trabalho das escolas de saúde pública.

Tanto na formação de pessoal de nível médio, como auxiliar elementar, deve-se cuidar de dois objetivos: 1) a formação deve ser descentralizada, realizando-se em pontos estrategicamente situados, em função das necessidades regionais; 2) o recrutamento deve visar ao pessoal local.
4ํㅡㄹ Conferência Nacional de Saúde. Auditório. Foto: Cid Fayão. Acervo Ensp.
0 Arlindo costuma brincar, dizendo que aqui era tão progressista que, além de criar 0 Departamento de Ciências Sociais, este era chefiado por uma mulher e secretariado por um homem. 0 Abel era secretário assim que nem a Natalina. Então, esse foi 0 Departamento de Ciências Sociais. E era tão paparicado, porque era um grupo jovem. Então o Blois, um dia, pegou uns três automóveis, daquela Rural Willys que ele tinha na época e disse: "Vocês têm que conhecer 0 Brasil”. E eles saíram viajando pelo rio São Francisco para conhecer o Brasil. Foi ótimo! Foram até Recife onde houve uma série de seminários no Instituto Joaquim Nabuco.

(Entrevista com Luiz Fernando Ferreira, 1999) 
E mais adiante complementou:

Sem prejuízo da preparação centralizada, nas Escolas ou nas Faculdades de Saúde Pública, as quais devem existir em número estritamente necessário, é indispensável descentralizar a execução dos programas, com o fim de se estender a ação das mesmas mediante o aproveitamento, na forma e extensão indicadas, dos recursos institucionais ou não, regionalmente disponíveis, em âmbito macro ou microrregional.

As observações apresentadas procuraram reforçar também a importância de se investir na relação entre a área da saúde e o campo da educação, criando uma "Ponte Sólida entre Saúde e Educação" (Blois, 1967: 137). Essas questões, presentes nos debates e proposições da conferência, permitem identificar as diretrizes apontadas para a formulação de políticas de formação de recursos humanos para a saúde pública.

O tema eleito pelos fóruns e agências da área da saúde pública no decorrer da década de 1960 relaciona-se diretamente com a história institucional da escola, ou seja, ela inicia seu processo de consolidação institucional em um contexto nacional e internacional voltado para a área da atuação pública da saúde, onde este setor ganha destaque no campo das políticas públicas de saúde. Não seria apenas coincidência a alteração jurídica estabelecida em 1969 através do decreto-lei n. 904 de $1^{\circ}$ de outubro, alterando a nomenclatura da Fundação Ensino Especializado de Saúde Pública (Fensp) para Fundação de Recursos Humanos para a Saúde.

Cabe agora observar os principais pontos de atuação da Ensp no decorrer da década de 1960, identificando que atividades foram implementadas e as características que assumiu seu processo de institucionalização. Quais as ações priorizadas para consolidar o ensino da saúde pública em todo o Brasil? De que forma as questões debatidas nos fóruns nacionais e internacionais se aproximavam das atividades postas em prática na Escola?

\section{Ensino, Pesquisa e Relação com a Comunidade}

A história da Escola Nacional de Saúde Pública, na década de 1960, foi marcada principalmente pela gestão de Edmar Terra Blois, responsável pela instituição no período compreendido entre 1964-1969. Seus antecessores, Achilles Scorzelli Júnior e Lincoln de Freitas Filho, conduziram as atividades da Escola, respectivamente, entre 1959-1961 e de 1961 a 1964, tendo como ponto central para administração um espaço cedido na Avenida Rui Barbosa, na cidade do Rio de Janeiro, nas 
dependências do então Departamento Nacional da Criança, atualmente o prédio do Instituto Fernandes Figueiras (IFF), integrante da Fiocruz. ${ }^{14}$

A estrutura básica naquele momento seguia o que havia sido delimitado com os decretos de 1958 e 1959. No primeiro, foram definidas as finalidades da Escola e estabelecida sua primeira estrutura organizacional que a partir de então seria constituída de: Diretoria, Secretaria, Biblioteca, Conselho Consultivo, Setor de Ensino, Núcleo de Administração da Saúde Pública, Núcleo de Epidemiologia e Bioestatística, Núcleo de Parasitologia e Núcleo de Saneamento. Observa-se aqui a configuração das primeiras áreas de especialização, que, nos anos seguintes, incorporadas a outros setores do conhecimento e da prática em saúde pública, originariam os departamentos da Escola (Brasil, 1958).

As aulas eram ministradas em lugares diversos, em função do assunto/tema e do professor responsável pela disciplina. Ao mencionar as aulas e lembrar-se dos professores, Elsa Paim - que, antes de se tornar colaboradora da Escola e ingressar definitivamente como professora de seu quadro, foi aluna do primeiro curso de especialização em saúde pública para enfermeiras - nos aproxima do que era o dia-a-dia dos alunos.

A gente tinha aula, por exemplo, de microbiologia, lá na universidade, com Paulo de Góes. Tinha um professor de parasitologia, cujo nome não me lembro, mas que era excelente, também lá na faculdade de medicina. Nós tínhamos aula de educação sanitária... (rindo) com um professor chamado Délio Camarão, sabe onde? Em Niterói. A gente tinha que pegar a barca ir lá para Niterói.

A gente ia ter aula nos lugares onde estavam os professores, sabe (...) os alunos é que iam aos professores. (Entrevista com Elsa Ramos Paim, 2004)

A partir da gestão de Blois, em 1964, intensificaram-se as articulações para obtenção de uma sede definitiva para a Escola, projeto que conseguiu êxito a partir de um acordo entre Ministério da Saúde e o governo do estado, inaugurando-se as novas instalações em 1966. A partir deste momento, a Escola ganhou um novo status jurídico ao se constituir como Fundação Ensino Especializado de Saúde Pública (Fensp), passando por novas alterações em sua composição e estrutura interna.

14 Achilles Scorzelli Jr., médico sanitarista que havia feito curso de saúde pública no DNS na gestão de Barros Barreto, especializou-se em estatística e era assessor de Mario Pinotti, ministro da Saúde (1958-1960) que o indicou para ocupar o posto de diretor da Ensp (Depoimento de Celso Arcoverde de Freitas a Cristina M. O. Fonseca em 30/07/2004). 
Curso básico de saúde pública para enfermeiras, 1964. Hospital Artur Bernardes. Na primeira fila, da esquerda para a direita, a quinta é Elsa Paim. Acervo Particular.

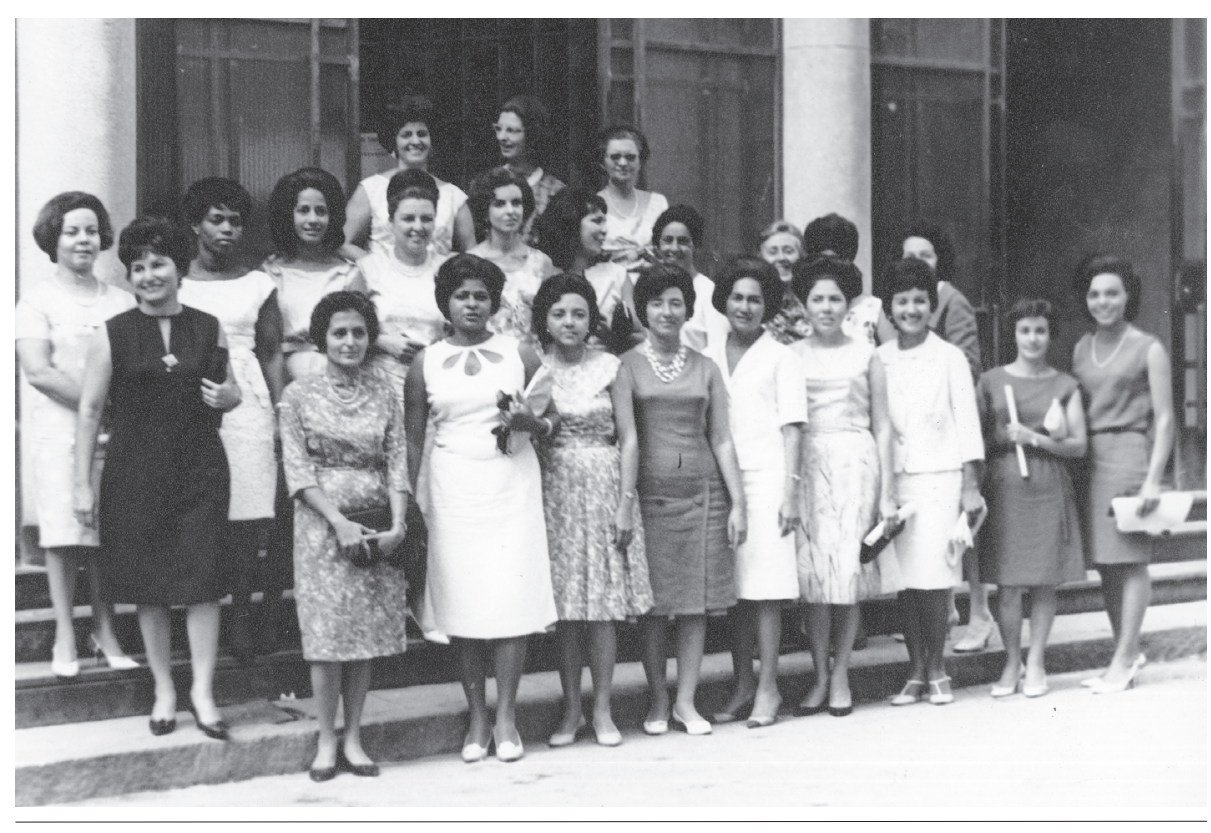

A nova proposta organizacional era ambiciosa e com ela instituíramse oito departamentos, ficando a Escola Nacional de Saúde Pública subordinada a um deles, o Departamento de Ensino. Os outros departamentos criados foram: Ciências Sociais; Ciências Biológicas; Estatística; Epidemiologia; Saneamento; Administração em Saúde e Metodologia do Planejamento. Com esta alteração, formalizou-se a incorporação de duas novas áreas de conhecimento: ciências sociais e planejamento. ${ }^{15}$

Entre as inovações, constava também a criação do Colégio Técnico, igualmente subordinado ao Departamento de Ensino, instituído, entre outras finalidades, com o objetivo de atender aos funcionários de nível médio permitindo-lhes qualificação adequada para posterior acesso à carreira de nível superior. Segundo Lenita Vasconcelos,

a idéia era fazer do Colégio Técnico o que é o atual Politécnico. A idéia inicial era fazer uma coisa assim, só que não chegou a se concretizar porque em 1968 o Blois saiu da escola e as coisas mudaram muito, começou a haver muita dificuldade de manter todo o grupo. (Entrevista com Lenita Peixoto Vasconcelos, 2004)

Para uma maior aproximação da lógica institucional que orientava tais mudanças, é necessário acompanhar o pensamento de Edmar T. Blois,

\footnotetext{
15 Ver Anexo 2 da lei n. 5.109, com organograma dos órgãos que compunham a Fensp (Brasil, 1966).
} 
expresso resumidamente no trecho a seguir, extraído de palestra que realizou durante a $4^{\mathrm{a}} \mathrm{CNS}$, em que expôs um pouco da sua percepção sobre os ideais que deveriam nortear a formação neste campo.

Tudo faz pressentir um processo mutacional, no entanto, a ferramenta por excelência para compreendê-lo - a política - continua engatinhando com pobreza lamentável de perspectiva e sobretudo de audácia.

Busquemos nas vertentes da fantasia, da imaginação criadora e nos recursos científicos as muletas tão necessárias a uma política tão carente.

Os elementos acima assinalados devem fecundar, além disso, a essência do processo desenvolvimentista, determinando que os modelos elaborados estejam intimamente ajustados à realidade através, também, do conhecimento histórico, das expressões artísticas e, principalmente, da percepção lúcida dos ambientes sociais, psicológicos e culturais. (...) A construção de modelos elegantes, matemáticos, para o desenvolvimento econômico-social, sem a seiva fecunda das asperezas do sacrifício, do sofrimento, e da vivência dos problemas que afligem entes humanos em áreas extensas do mundo, apenas tem utilidade como jogo de inteligência. Os fatores antes referidos devem guiar, a nosso ver, as ações do processo de desenvolvimento, quer nos países subdesenvolvidos, quer naqueles mal desenvolvidos. (Blois, 1967: 121)

Algumas das idéias aqui esboçadas, em particular a preocupação com o conhecimento da realidade nacional e com uma aproximação das condições de vida da população-alvo dos programas de saúde pública, seriam implementadas no cotidiano das atividades empreendidas na Escola e se manifestariam nas três principais áreas que estruturaram as ações realizadas: o ensino, a pesquisa e a relação com a comunidade. Nesse aspecto, estes propósitos encontravam afinidade com a experiência de trabalho incorporada pelos funcionários do Sesp, que tinham como prática profissional a implementação de atividades no interior do país, o que lhes permitiu maior contato com os problemas enfrentados pela população fora dos grandes centros urbanos.

Como já foi mencionado, a Escola iniciou suas atividades com a colaboração de profiłsionais das mais diversas instituições de ensino e pesquisa, que se dis puseram a colaborar como professores em cursos destinados a diferente categorias profissionais. As primeiras aulas tiveram início em novembro de 1959, com dois cursos: um para engenheiros, com 15 alunos, e outro para enfermeiros, com 23 alunos (Blois, 1967: 138). 
No decorrer dos anos seguintes, os cursos foram englobando progressivamente as diferentes profissões envolvidas com a saúde pública. Surgiram os cursos para médicos, odontólogos, veterinários e farmacêuticos, sempre separados por categorias profissionais, seguindo, nesse aspecto, o modelo dos cursos que até então vinham sendo oferecidos pelo DNS.

Alguns anos depois observou-se a necessidade de reformular este formato tradicional e procurou-se oferecer um curso com disciplinas comuns às diversas profissões, constituindo núcleos que integrassem os profissionais envolvidos em torno do tema comum da saúde pública. Esta mudança foi reconhecida como vantajosa:

Porque se tinha muito maior integração entre os vários profissionais. Eles aprendem o trabalho dos outros. Era muito interessante. Não tinha cabimento você ter um curso só para enfermeiras, afinal as disciplinas eram basicamente as mesmas, e a única coisa diferente era o estágio. Então, vinha o Paulo de Góes dar aula para a gente, depois ia dar para os médicos (...). Não estava certo (...) Era ruim estar repetindo! Eu acho que foi da maior importância a integração dos vários profissionais. Você começa a discutir os problemas em conjunto. Não é enfermagem discutindo enfermagem, o médico discutindo a parte médica. Havia discussão dos problemas de saúde pública na visão de todos os profissionais. Era muito, muito interessante, e tanto deu certo que nunca mexeram.

Você tinha um problema, vamos dizer, de desidratação. Isso era discutido pela enfermeira, pelo médico, pelo engenheiro, pelo dentista, por toda a equipe. Cada um via um aspecto. (Entrevista com Elsa Ramos Paim, 2004)

Curso básico de saúde pública. Ensp, 1968. Foto: Cid Fayão. Acervo Ensp.

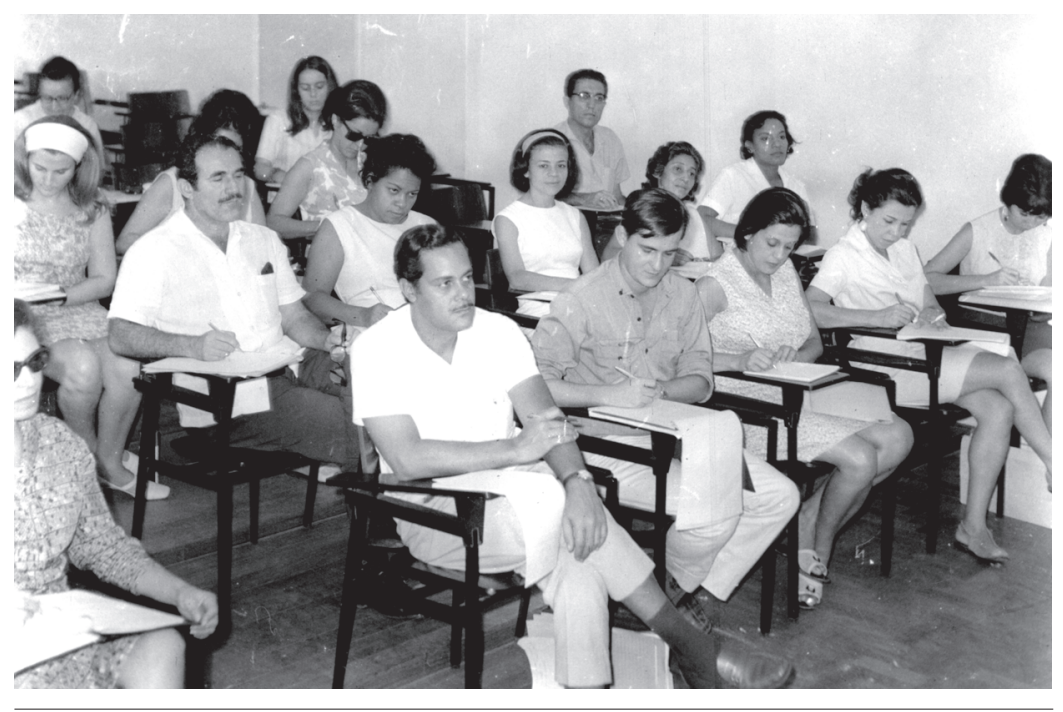


Esta integração não se restringiu somente aos alunos de diferentes grupos profissionais; também ocorreu entre os membros do corpo docente, quando professores de diferentes especialidades se reuniam para dar aulas em conjunto. Um trecho do depoimento de Arlindo Fábio Gómez de Sousa, que foi professor e diretor da Ensp, ilustra este ponto e nos permite visualizar a dinâmica em sala de aula:

Eu me lembro de uma aula que nós demos (...), Luiz, eu, Cynamon e Hermann, sobre a questão das migrações e doenças. Eu, muito mais acompanhando do que dando aula, porque não era da área. A escola estava muito pobre, não tinha mapa-múndi, e precisava de um. Aí não sei se o Luiz ou o Cynamon, um dos dois foi ao quadro-negro, um quadro grande e não desenhou a giz, mas só apontou: 'Suponha que aqui tem a Europa, aqui está a Península Ibérica, aqui está a África, aqui está o Oriente, aqui você tem a América (...)'E foi fazendo assim no quadro. Mas sem botar a mão nele, sabe, só para que se tivesse uma idéia de espaço, de distribuição espacial: 'E aí a tal corrente migratória (...) Porque os pássaros vêm de tal lugar (...) Após a chegada dos negros, que vieram de cá...' (...). E lá pelas tantas, um aluno saiu da carteira dele, foi até a frente do mapa que não existia, localizou o que queria e fez a pergunta: 'Pois é, mas aqui, quando do norte da África migra essa população, que migra para Europa (...)'. Não sei se consigo passar essa força [dessa cena]. Quando você e o aluno estão mesmo tão inteiramente jogados em uma proposta, (...) que enxergam o mapa onde ele não existe, entende? Aquilo era tão forte que as pessoas ficavam impactadas. (Entrevista com Arlindo Fábio Gómez de Sousa, 2004)

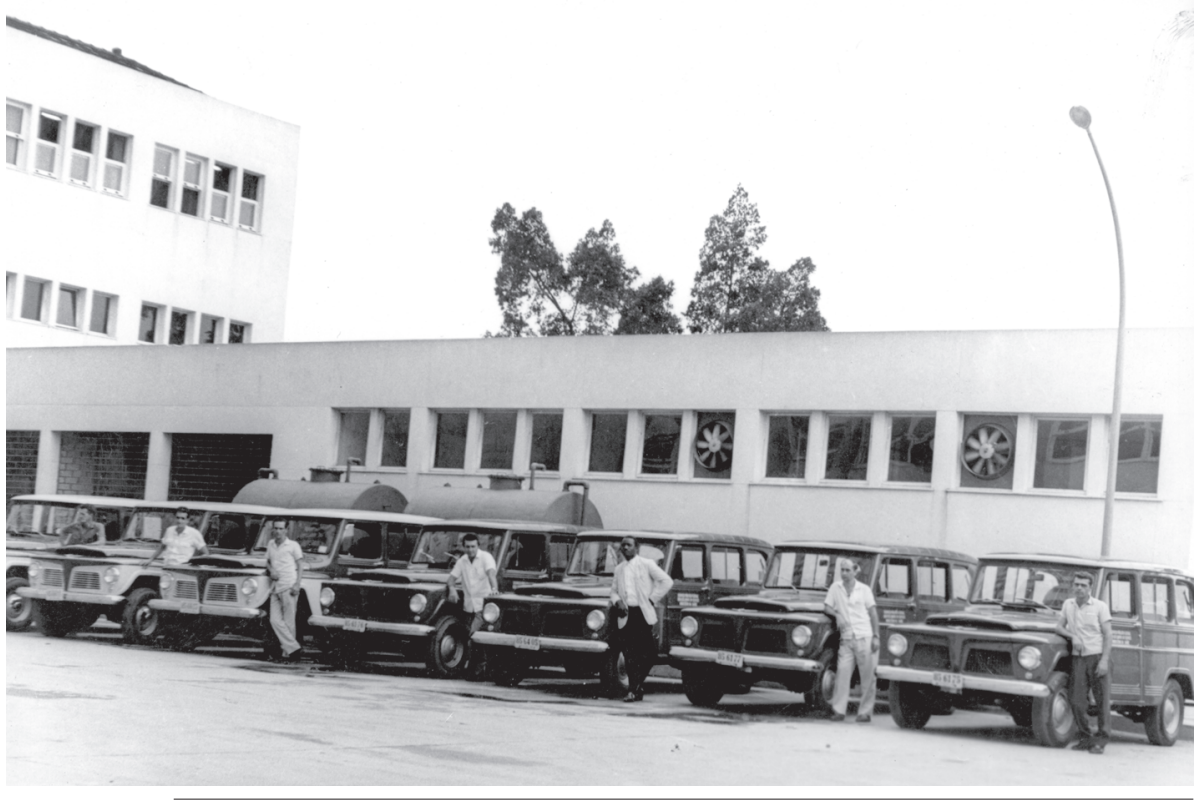

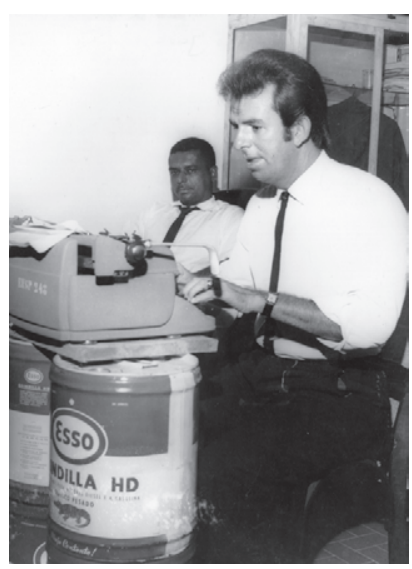

Escritório da garagem, Nelson e Juan, 1966.

Frota de carros. Ensp, 1967. Fotos: Cid Fayão. Acervo Ensp. 
I curso de planejamento - Ensp, 1967. Na primeira fila da direita para a esquerda: sentados - dr. Fernando Leitão, Ethevaldo de Miranda e Sólon Vianna. Em pé atrás, da direita para a esquerda: Darcy, não identificado, Gentille de Mello, Bismarck, Paiva, dois não identificados, Osvaldo Costa, Cora Ficherman. Atrás deles René de Brito, três não identificados, Reinaldo Ramos, não identificado e Mario Sayeg. Acervo Particular.
Com isso, os cursos gradativamente foram também se hierarquizando com outro formato, cujas distinções não mais eram estabelecidas por profissões, mas por cursos - atualização, básico e especialização -, chegando ao final dos anos 1960 à implementação da pós-graduação, com o início do mestrado em saúde pública. Toda esta estrutura era voltada especificamente para os profissionais de nível superior. Paralelamente, foram implementados os cursos destinados aos profissionais de nível médio, como atendente, inspetor de saneamento, laboratorista e visitadora sanitária.

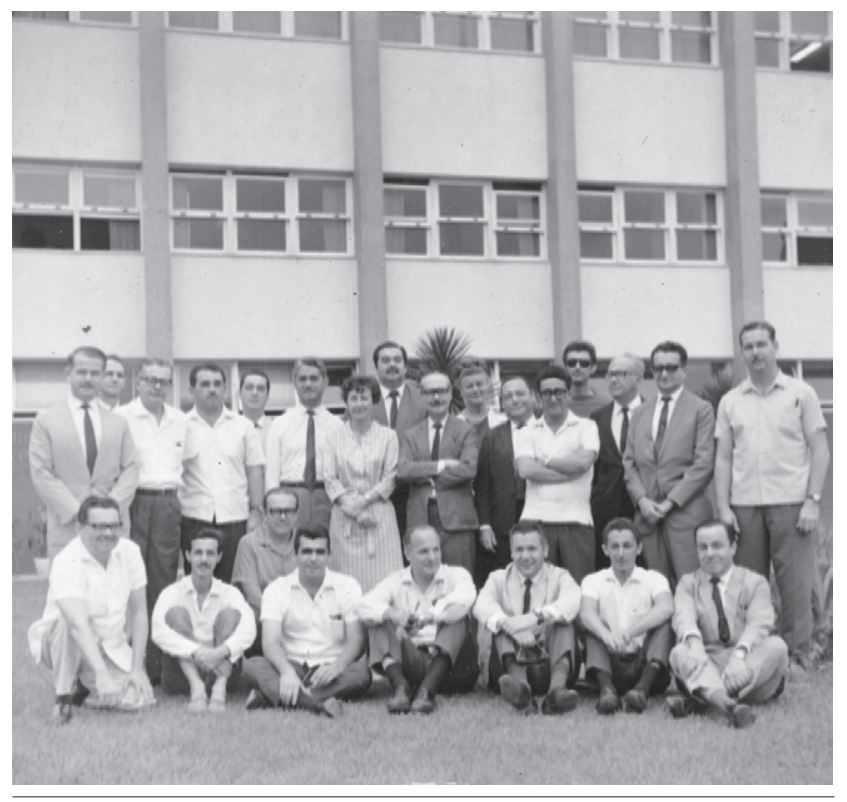

O número de alunos inscritos nas duas categorias de cursos foi se expandindo, mas manteve durante todo o período de 1959 até 1967 um grande predomínio de alunos de nível superior, com um total de 887 alunos para um correspondente de 212 de nível médio. Em 1967, por exemplo, iniciaram-se dois cursos de mestrado, um com 57 alunos e o segundo com 48 alunos. Estes dados contribuem para compreender a grande preocupação com a formação de pessoal de nível auxiliar evidenciada na $4{ }^{\text {a }} \mathrm{CNS}$, realizada exatamente neste ano de 1967 (Blois, 1967: 138).

Observa-se também o surgimento do primeiro curso de educação em saúde, uma área de conhecimento que gradativamente iria configurar-se como fundamental no processo de formação e especialização em saúde pública. Lenita Vasconcelos, professora da Ensp durante muitos anos, participou diretamente da organização dos cursos nesta área e explica sua 
inserção, chamando a atenção para a contribuição de ex-funcionários da Campanha da Malária, que passaram a cooperar com a Escola especificamente nestes cursos, trazendo sua experiência para as salas de aula.

(...) o Ministério da Saúde formou uma comissão de educadores para elaborar uma proposta de um projeto de um curso de educação e saúde para a Escola realizar. Aí me chamaram para integrar essa comissão. Fomos eu, Nilo Chaves de Brito Bastos, doutor Lincoln de Freitas Filho (...) Não sei se tinha mais alguém, não me lembro (...).

Era o primeiro curso dentro da escola daqui. Em São Paulo já tinha há algum tempo, e também em Porto Rico, na Costa Rica, no Chile, nos Estados Unidos. Mas aqui, no Rio [de Janeiro], na Escola Nacional de Saúde Pública, não tinha. Então o Blois convidou a Acácia, que saiu da Seção de Malária e foi para a escola (...).

Em 1966 o Blois me chamou - eu estava na Malária, chefiando esta seção. Ele ligou para mim e disse que queria me convidar para eu participar, porque ia começar o primeiro curso e a Acácia tinha indicado o meu nome para trabalhar com ela. O Brito Bastos ia ser o professor titular do curso e nós duas íamos ser professoras assistentes dele. E o Blois queria que eu fosse para a escola para trabalhar no curso com eles, para integrar a equipe da Escola. (Entrevista com Lenita Peixoto Vasconcelos, 2004)

Dessa forma, a área de educação e saúde começou a se estruturar e a constituir uma das disciplinas oferecidas pela Escola, já nesse momento vinculada ao Departamento de Ciências Sociais. Nos outros departamentos, as atividades gradativamente iriam se consolidar através da definição dos currículos, com especificidades características de cada campo profissional, como a biologia, a engenharia, o planejamento e a epidemiologia, enfrentando cada um dificuldades diversas. O Departamento de Engenharia Sanitária, por exemplo, deparou-se com dificuldades no processo de reconhecimento de seu curso de especialização. Como menciona Szachna Eliasz Cynamon, engenheiro sanitarista cedido pela Fundação Sesp para colaborar com a estruturação desta área na escola e que terminou por ser incorporado à instituição, como muitos outros:

Um dos problemas que eu tive, desde o início, foi a questão da legalização do curso. São Paulo tinha o diploma reconhecido e nós não tínhamos.

Quem primeiro começou com especialização mesmo foi a engenharia. Você sabe de onde vem o termo 'residência'? Pensa que vem de residência médica? Não; a residência começou na engenharia, com as estradas de ferro e estradas de rodagem (...). Os nossos cursos de especialização eram 
Turma de formandos do curso de saneamento: Ensp, c.1970. Foto: Cid Fayão. Acervo Ensp. sérios, o de São Paulo e o nosso. Agora, São Paulo tinha uma escola sob a lei universitária. Nós não estávamos filiados à universidade. (Entrevista com Szachna Eliasz Cynamon, 2004)

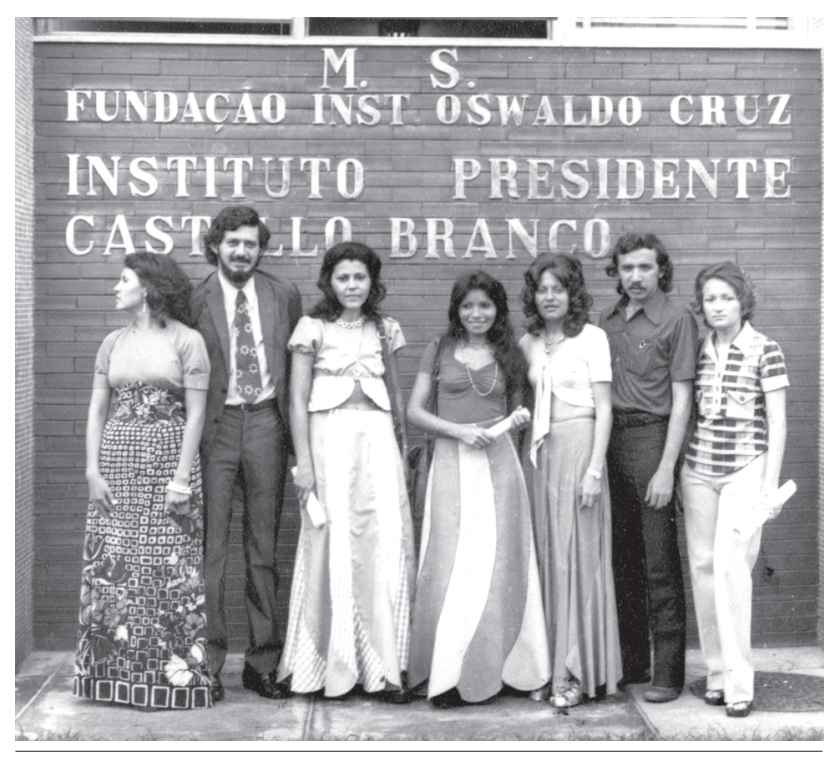

É interessante observar que a questão do vínculo universitário se mantém como um tema relevante neste processo de institucionalização das atividades da Escola. Outro aspecto que merece ser lembrado é o fato de que, entre os primeiros cursos realizados, já no ano de 1960, constava o de arquitetura de unidades médico-sanitárias, além dos cursos básicos de saúde pública para engenheiros, demonstrando já uma especificidade na aplicação dos conhecimentos técnicos neste setor.

$\mathrm{Na}$ área da biologia, que no decorrer dos anos iria também se consolidar como um setor com muitas peculiaridades, houve também apoio e liberdade para investimento em pesquisa e autonomia por parte dos profissionais ali incorporados. Luiz Fernando Ferreira, convidado por Blois para montar o departamento, em vários momentos de seu depoimento, chama a atenção para a importância desses primeiros anos de constituição da Escola, para a formação de um campo de reflexão e pesquisa.

O Blois dava tudo! Ele tinha recursos, e assim a gente aparelhou os laboratórios. Ainda tem por aí, em algum lugar, um microscópio de aluno, que servia para trabalho de campo e servia para aula. Tinha 20 microscópios. Cada um tinha um microscópio, tinha tudo! E montamos um laboratório de pesquisa, de parasitologia. 
A orientação era a mesma da universidade. Quer dizer, tinha o compromisso dos cursos e em relação à pesquisa, sempre e até hoje. Eu repito o que dizia o velho Zeferino Vaz: 'Para organizar um bom núcleo de pesquisa você escolhe um pesquisador competente e não atrapalha.' Eu escolhi quem eu quis para trazer para cá. Não tinha esse negócio de concurso, não tinha nada disso. Eu trouxe pessoal de Tóquio! Então veio Hermann Shatzmayr; Ernesto Hofer; que era da bacteriologia; o Akira, que era garoto nesse tempo, da microbiologia; o Sérgio Coutinho, que foi diretor do IOC, meu colega de turma; e uns que eram estudantes, como o Carlos Maurício, que está aí comigo até hoje, é um doutor importante. (Entrevista com Luiz Fernando Ferreira, 1999)

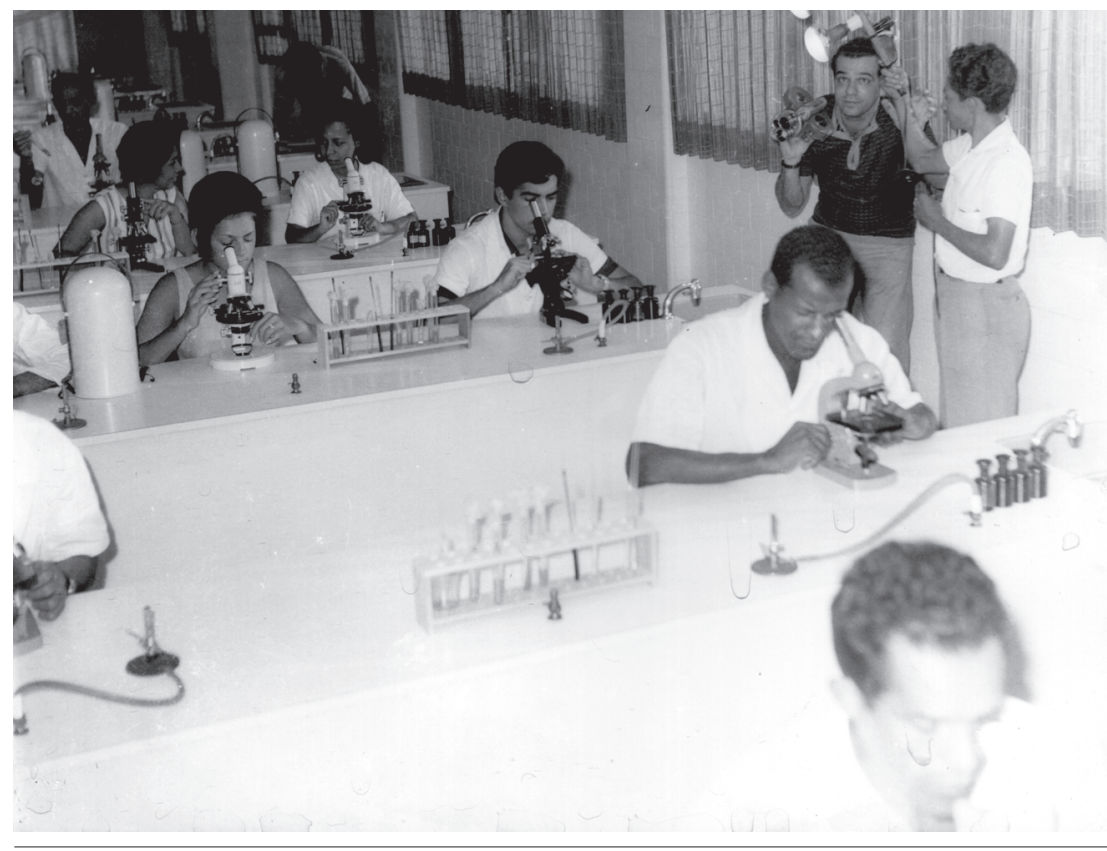

Dessa forma, o setor de ensino gradativamente ampliou o seu leque de intervenção, expandindo suas áreas de conhecimento em consonância com as mudanças que vinham sendo debatidas nos fóruns nacionais e internacionais. A criação do Departamento de Ciências Sociais e, dentro dele, a formalização de uma disciplina específica de educação e saúde são evidências dessas transformações na formação de profissionais de saúde pública.

Outra característica das atividades empreendidas na Escola, no decorrer desses primeiros anos, foi a preocupação em privilegiar alunos vinculados aos serviços de saúde das diferentes regiões do país. Nesse
Departamento de Biologia. Ensp, 1967. Foto: Cid Fayão. Acervo Ensp. 
Turma de odontologia social. Ensp, 1969. Em pé da esquerda para a direita: Lenita Vasconcelos (quarta), Acácia Mendonça (sétima), Hélio Uchôa (oitavo), Ernani Braga (nono). Foto: Cid Fayão. Acervo Ensp. aspecto, a orientação era semelhante àquelas adotadas nos cursos do DNS e do Sesp, ambos tradicionalmente preocupados com a formação e o aprimoramento de seus quadros. Esta orientação foi apresentada por Hélio Uchôa, responsável naquele momento pela área de odontologia sanitária da Escola.

Por exemplo aqui a gente abria um curso de odontologia sanitária ou social para o Brasil inteiro, e aí o pessoal se candidatava. Agora, na hora da seleção, dávamos prioridade a quem estivesse ligado a algum serviço. Se o sujeito não estivesse trabalhando, ele poderia até fazer o curso, mas se tivesse vaga sobrando. Mas a prioridade era para elementos que estivessem atuando a nível de secretaria estadual ou municipal, ou em alguma instituição federal, municipal ou estadual, quer dizer, vinculado a algum órgão. (Entrevista com Helio Uchôa, 2003)

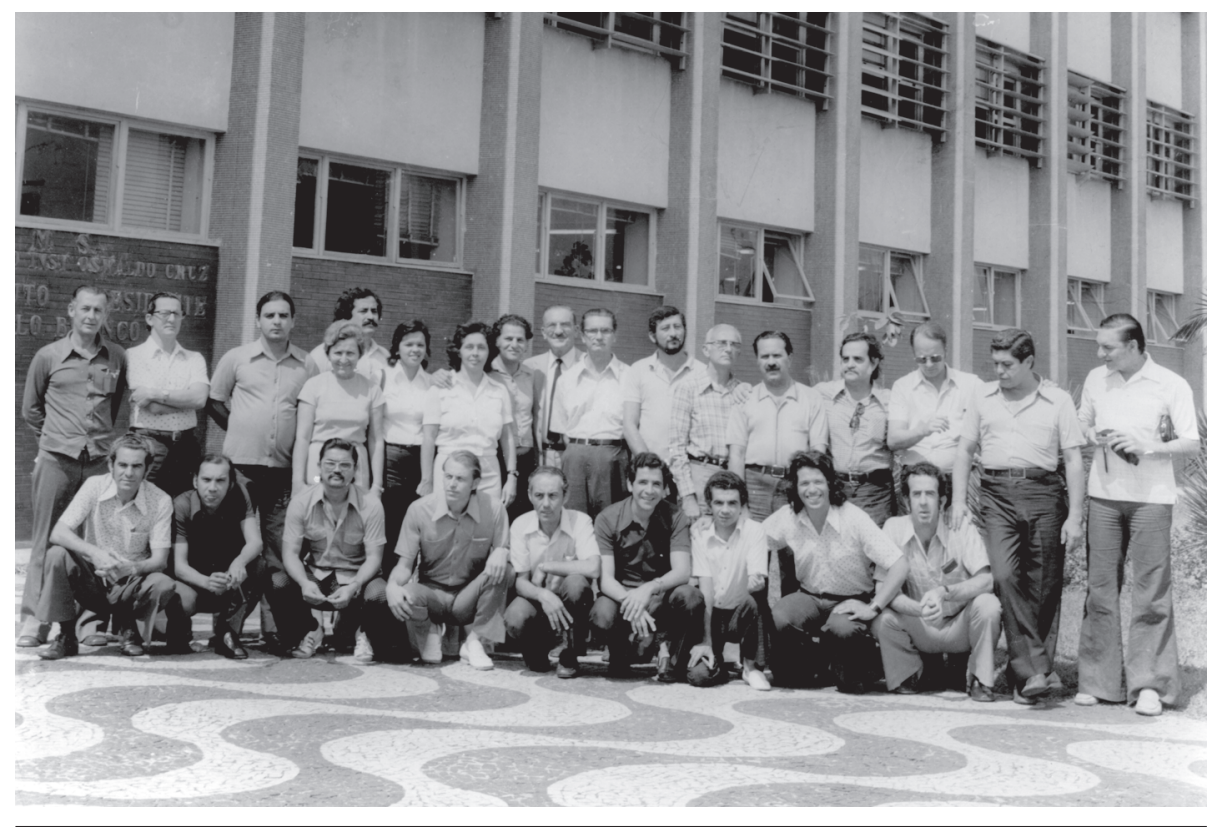

Esse olhar dedicado àqueles que se encontravam em funções dentro dos serviços de saúde era coerente com a relevância que vinha sendo atribuída à área de recursos humanos, ao mesmo tempo que se aproximava das orientações apresentadas pelo diretor e por outros professores da Escola na época, que enfatizavam a necessidade de uma aproximação com os problemas enfrentados pela população. Mesmo nos cursos com um perfil mais acadêmico, como seria o caso do mestrado, há 
uma evidente preocupação em incorporar estudantes com alguma vivência de serviços. Ilustra esta orientação a experiência relatada por Eduardo Costa:

A primeira turma do mestrado ia ser em 1967. Aí o Ernani chegou e falou: 'Bom, vocês vão conversar com o pessoal da Escola, porque é uma boa perspectiva, vocês têm de fazer o mestrado lá.'(...) E a gente veio, conversar com o Oswaldo Lopes da Costa, que era o professor de planejamento da escola. E ele nos disse: Olhem, gente jovem assim é muito pouco comum vir aqui, para [fazer] um curso assim. Todo mundo é gente de serviços da antiga (...) Mas vamos ver. Quem sabe vocês fazem uma experiência de trabalho antes? Porque (...) vocês estão vendo um pouco idilicamente; olha que não é bem assim! Eu acho que vocês deviam trabalhar um ano, no que vocês acharem bom. Trabalhem um ano em alguma área de saúde pública, de preferência, e depois venham fazer o curso.' Aí falamos com o Ernani, que nos disse : 'Se vocês quiserem, a gente pode ver se consegue alguma coisa da Fundação Sesp para vocês, com o Nélson Moraes.'(Entrevista com Eduardo de Azeredo Costa, 2004)

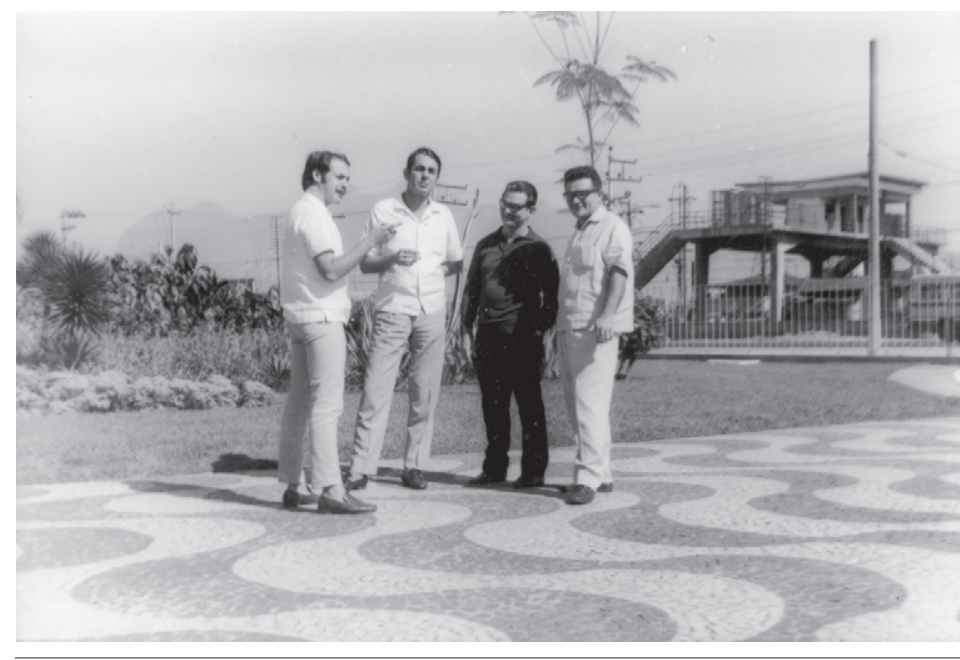

$\mathrm{Na}$ mesma linha de atuação, surgiram também as atividades voltadas para criar mecanismos de aproximação entre a Escola e a comunidade, estimulando seminários/ trabalhos de campo em regiões do interior do país, como ocorreu em 1967. Também ocorreram o convênio para possibilitar o trabalho no Posto Samuel Libânio em Vargem Grande, Jacarepaguá; a realização de grupos de teatro com os moradores residentes nas proximidades da Escola; e a criação, na própria sede da Escola, da Unidade de Atendimento Germano Sinval de Faria.
Alunos do curso de mestrado em 1968. Da esquerda para a direita: Eduardo Costa, Edson Diniz Gonçalves e dois engenheiros do Sesp - portaria da rua Leopoldo Bulhões. Acervo Eduardo Costa/Coc. 
Almoço ao término do curso de saúde pública de 1962, em casa ao lado do Posto Samuel Libânio. $\mathrm{Na}$ primeira fila, da direita para esquerda, o primeiro é o dr. Fernando Leitão. Em pé atrás, de terno e gravata, dr. Bichat de Almeida Rodrigues, tendo ao seu lado o sr. Carvalho dono da casa e do terreno que foi cedido para construção do Posto. Acervo Particular.
O seminário de campo foi realizado no Nordeste no período compreendido entre 16 e 31 de janeiro de 1967 e contou com a participação de nove alunos do curso básico de saúde pública, tendo sido supervisionado pelo médico e professor Celso Arcoverde de Freitas. Seu objetivo era o de possibilitar aos alunos uma maior compreensão dos problemas daquela região, analisando in loco as condições socioeconômicas da população, com particular atenção sobre mortalidade infantil e doenças como a peste, o tracoma e a esquistossomose. Além disso, o grupo deveria analisar o impacto sobre a região da chegada de energia de Paulo Afonso, sobre a perspectiva do desenvolvimento econômico, da irrigação na zona semiárida a propiciar múltiplas safras, a elevação do poder aquisitivo e melhoria do nível de saúde da população. (Freitas, 1998: 197)

Toda a orientação impressa ao seminário traduzia os princípios que vinham norteando os gestores da área da saúde pública e apontava em particular para a associação entre desenvolvimento e melhoria das condições de saúde. ${ }^{16}$

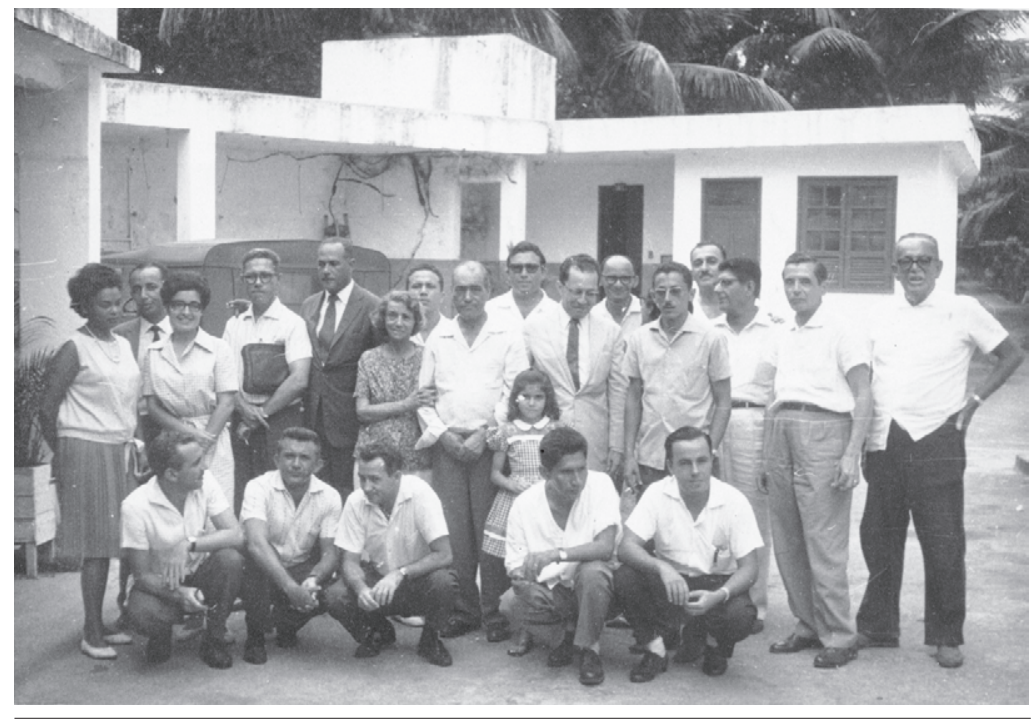

Outra experiência de trabalho importante que acompanhava esta linha de interpretação foi desenvolvida no Posto Samuel Libânio, definido como unidade de treinamento rural. O trabalho foi resultado do estágio das alunas do curso de enfermagem em saúde pública, gerando um convênio

\footnotetext{
16 O grupo que participou deste programa de ensino e pesquisa era formado, além do coordenador, por: Sergio Lemos, Lenita Peixoto Vasconcelos, Rosa Raposo, Clara Akiko, Hilda Costa, Paulo Miguel Rocha Fragoso, Cláudio Maya Monteiro e José Emílio Schiller de Souza (Freitas, 1998: 203).
} 
firmado entre a Secretaria Geral de Saúde e Assistência do Estado da Guanabara, a Fundação Sesp, o DNERu e a Ensp, em junho de 1960. Com isso, o posto passou a ter dupla finalidade: atender à população daquela área rural de Jacarepaguá e sediar o treinamento em área rurais dos alunos encaminhados pela Ensp. O convênio possibilitou o desenvolvimento de um trabalho integrado entre os profissionais destes órgãos, gerando o desenvolvimento de pesquisas, a expansão e melhoria do atendimento à população desta região e a complementação da formação dos alunos da escola. Aliando as atividades de ensino, pesquisa e atendimento à comunidade, realizou-se um levantamento das condições socioeconômicas de saúde e de saneamento da área rural de Jacarepaguá, que se encontrava sob a jurisdição do Posto Samuel Libânio. ${ }^{17}$

A gente fazia um levantamento da família. Quantas pessoas moravam na casa: pai, mãe, quantos filhos. Via as condições de habitação: se tinha água (não tinha); se tinha esgoto (não tinha). E a questão de vacinação: se as crianças eram vacinadas (ninguém era vacinado), quantos filhos a mulher tinha tido, se ela tinha perdido filhos e quantos, de que morreram (morriam de diarréia, de sarampo). Então a gente conseguiu ter um retrato muito próximo da realidade, daquela situação, daquela região em que estávamos trabalhando. E começamos a querer conhecer as curiosas da região. (Entrevista com Elsa Ramos Paim, 2004)

O trabalho desenvolvido foi beneficiado em vários aspectos pela experiência anterior em algumas atividades desenvolvidas pelo Sesp. Elsa Paim foi uma das enfermeiras que levou para Jacarepaguá sua experiência em diferentes regiões do país, quando integrava a equipe do Sesp. Implantou um trabalho de identificação e aproximação com as curiosas localidade, para orientá-las e dar suporte em casos mais complicados, e investiu no programa de formação de atendentes e visitadoras sanitárias e de preparação de laboratoristas, seguindo os mesmos padrões adotados pelo Sesp em suas atividades por diferentes regiões do país:

O trabalho era interessantíssimo, uma região como eu nunca tinha visto. E olha que eu trabalhei no interior, em muitos lugares, mas nunca tinha visto uma região tão pobre, tão desassistida, com tanto problema como aquela (...).

17 Resumo das principais atividades desenvolvidas pela Ensp durante o exercício de 1964. Ver Fundo Ensp, caixa 24, maço 3, Casa de Oswaldo Cruz/Fiocruz. 
Era uma região muito distante para ter pessoal que não fosse da própria área. E também uma filosofia do Sesp era sempre trabalhar com pessoas da própria comunidade. Então, no levantamento que a gente tinha feito lá, identificamos pessoas alfabetizadas, que podiam ser treinadas para serem atendentes e visitadoras. Atendente era a pessoa que atendia nos consultórios, dava injeção, essas coisas. E a visitadora ia fazer o trabalho de campo, que era um trabalho, tradicionalmente, da enfermeira. Nós fizemos um recrutamento e conseguimos umas meninas ótimas, formidáveis. O treinamento desse pessoal durou três ou quatro meses. (Entrevista com Elsa Ramos Paim, 2004)

Outra linha de atividades implementada pelos profissionais da Escola com a orientação de estabelecer mecanismos de aproximação e melhor atendimento às comunidades foi a experiência de teatro popular, coordenada por Luís Mendonça, cujo ponto de partida foi também um levantamento na região em torno de Manguinhos para delimitar as necessidades da comunidade local. Os trabalhos foram conduzidos pelo Departamento de Ciências Sociais, na época dirigido por Acácia Mendonça, e pelo Departamento de Epidemiologia, dirigido por Joir Fontes. O objetivo inicial era realizar um levantamento sobre as condições socioeconômicas da região de Manguinhos de modo a obter subsídios para a instalação da Unidade de Atendimento que seria inaugurada na Escola em 1967, e daria origem à Unidade Germano Sinval Faria.

Em 1966 a gente fez o curso de educação, mas nas horas vagas nos dedicamos à preparação de uma pesquisa para saber quais eram as condições da área, delimitar a que seria de atendimento dessa unidade, o tamanho da população, suas características, condições de vida e saúde etc. (...). A pesquisa surgiu da idéia de formar uma unidade e de que não se deveria organizar a unidade sem a população ser ouvida.

A pesquisa foi feita pelo grupo de ciências sociais e pelo grupo de epidemiologia; especialmente esses dois grupos trabalharam mais. O pessoal da estatística estava com o da epidemiologia; se não me engano, os departamentos eram juntos. (Entrevista com Lenita Peixoto Vasconcelos, 2004)

O trabalho de instalação da unidade foi realizado pela enfermeira Antonieta Siqueira Prado, funcionária cedida da Divisão Nacional de Tuberculose, com a ajuda, entre outros, de Hugo Tomassini. O contato com a comunidade de Manguinhos geraria outros frutos. Um deles foi uma rica experiência de teatro popular, mais uma vez sob o estímulo e apoio do diretor Edmar Terra Blois. 


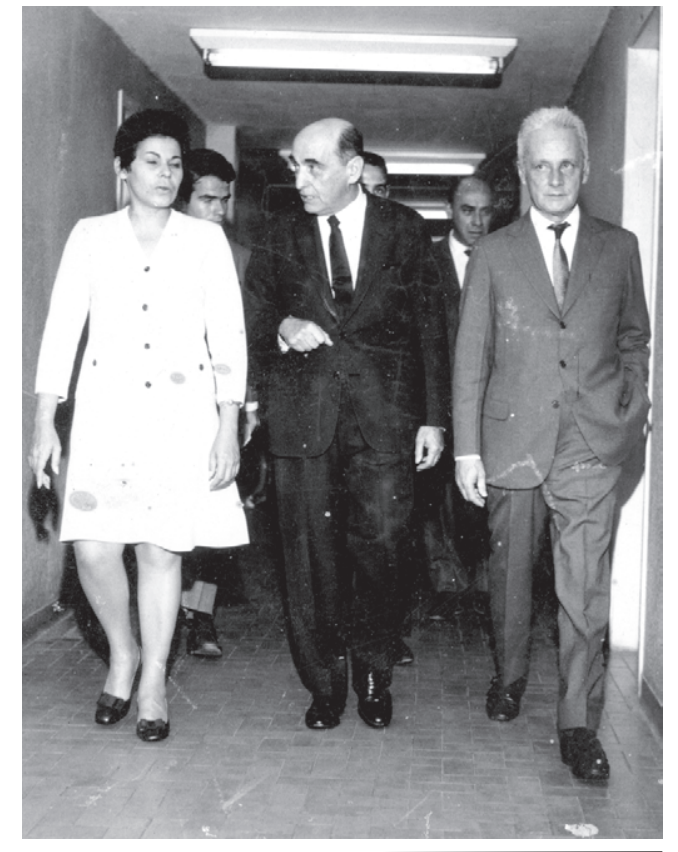

Então, nós, da educação, resolvemos fazer. Eu e Acácia, com a ajuda do Sérgio e do pessoal todo do departamento. Mas era interesse nosso fazer um trabalho de educação nesse mesmo parque João Goulart, começar alguma coisa ali. Então eu disse: 'Ah, vamos começar com uma coisa diferente.' A gente estava em plena Revolução, e tinha que ter muito cuidado.

Ali no Parque Proletário João Goulart resolvemos iniciar uma experiência, porque vínhamos de todos esses trabalhos de campo e achávamos muito importante não perder o contato com a realidade, com a clientela da saúde pública, o pessoal que deveria ser atendido na Unidade de Saúde: o pessoal da comunidade. O Luís Mendonça já tinha um trabalho numa fábrica aqui perto, em Bonsucesso, em que ele fazia uma experiência de teatro de operários dentro de fábrica. Então, o Blois na mesma hora chamou o Mendonça, que foi contratado pela escola para fazer o teatro aqui dentro. Ele era fantástico! Quando ele chegou, a gente disse: 'Vamos começar com o teatro. Educação e Saúde vão ser a partir do teatro'.

E fizeram um levantamento ali, na comunidade. Convidaram as pessoas de lá para dizer que o que queriam fazer, o Mendonça viu quem queria começar com eles. Formou-se um grupo interessado, que começou a discutir que tipo de peça eles gostariam de apresentar, se era drama, se era o quê. (...) Entre dois ou três textos, eles escolheram uma comédia. Aí já começou o trabalho de educação, com as pessoas se expressando e tomando uma decisão. Para nós, isso era muito importante. Se o 'miolo'
Inauguração da Unidade Sanitária Germano Sinval Faria. Ensp, 1967. Da esquerda para a direita: Antonieta Siqueira Prado, Leonel Miranda, Edmar Terra Blois. Foto: Cid Fayão. Acervo Ensp. 
era esquistossoma ou não sei o quê não importava, mas sim a capacidade de ver as coisas, se expressar, escolher, analisar, entende? E eles analisaram as peças, escolheram uma comédia e encenaram ela. (Entrevista com Lenita Peixoto Vasconcelos, 2004)

\section{CONCLUSÃo}

Fruto da aspiração de sanitaristas, gerada e elaborada por profissionais e gestores da saúde, integrantes dos serviços existentes, era natural que a Escola Nacional de Saúde Pública surgisse como um foco para formação e aperfeiçoamento de profissionais vinculados aos serviços de saúde, voltada para o atendimento das deficiências neste campo. Mas ela surgiu também carregada pelo idealismo, por uma certa dose de voluntarismo e pela afinidade que envolvia aqueles que se agruparam em torno do projeto.

Fortalecida pelo contexto internacional, que concentrava suas atenções sobre o processo de especialização em saúde pública, a Ensp, aos poucos definiu seu formato de ação e as áreas de conhecimento que iriam orientar a formação dos alunos. Nesse aspecto, deixou clara sua estreita ligação com as mudanças que vinham ocorrendo neste campo, incorporando novos atores, novas correntes de pensamento e reflexão, novas formas de atuar no campo pedagógico da saúde, sem desprezar a história e a experiência daqueles que a ela se incorporaram. Nasceu, assim, como um espaço de agregação, de integração na diversidade e diferença. E por diversas vezes o discurso de diferentes atores que participaram desse processo registrou a atuação e dedicação do diretor Edmar Terra Blois. De forma unânime, sua gestão foi apontada por todos que participaram desse momento da história da Escola como fundamental para a consolidação institucional. Como referem Elsa Paim e Lenita Vasconcelos, em dois significativos trechos de seus depoimentos

A gente trabalhava muito integrado. E não tinha outro jeito, porque éramos poucos. Também tínhamos uma relação muito boa. Havia um Conselho Departamental que se reunia uma vez por mês. O doutor Blois era tão empenhado em que nós trabalhássemos, que fazia reunião de noite, porque durante o dia a gente estava trabalhando, não podia fazer reunião. Então as reuniões eram à noite, lá naquelas brenhas. Já pensou? Mas depois ele mandava a caminhonete levar a gente em casa. E a reunião não tinha hora para começar, não tinha hora para acabar! Ele era (...) Como é que chama uma pessoa que é viciada no trabalho? (Entrevista com Elsa Ramos Paim, 2004) 
Ele era uma pessoa apaixonada pelas coisas que queria, era um sonhador utópico. Queria a melhoria da saúde pública para salvar milhões de pessoas, ser multiplicador e formador de pessoal da saúde pública. Era um clima de muita paixão e muito sonho, de fazer um monte de coisa legal. Em plena Revolução não foi fácil. (Entrevista com Lenita Peixoto Vasconcelos, 2004)

Esta não é, entretanto, uma história de um único grande personagem, mas uma história que incorpora, agrega muitos atores e algumas instituições. Porém, não há dúvida de que o papel empreendedor de Blois foi decisivo naquele momento para o sucesso de muitas medidas implementadas, como também o foi em parte para os desdobramentos que no futuro contribuíram para novas mudanças. Não se trata aqui de olhar a história unicamente como resultado da ação de grandes homens, mas como espaço de interação entre atores, idéias e interesses, sem descuidar do papel de cada um especificamente nesses contextos de mudanças e reformas institucionais.

\section{REFERÊNCIAS BIBLIOGRÁFICAS}

ABREU, A. et al. Dicionário Histórico-Biográfico Brasileiro. Rio de Janeiro: FGV/ CPDOC, 2001.

ATAÍDE, A. de. Conferência no XII Congresso Brasileiro de Higiene, Belém, 13 jan. 1955. In: BRASIL/MS. Conferências pronunciadas. Rio de Janeiro: Ministério da Saúde/Serviço de Documentação, 1957.

BLOIS, E. T. Responsabilidade do Ministério da Saúde na formação e organização dos profissionais de saúde e de pessoal de nível médio e auxiliar. Arquivos de Higiene, 23(1): 121-53, set., 1967.

BRAGA, E. Educação e treinamento de pessoal para as atividades de saúde. In: BRASIL/MS. Anais da IV Conferência Nacional de Saúde. Rio de Janeiro: Ministério da Saúde, 1967, p. 45-55.

BRASIL. Projeto n. 1090. Dispõe sobre proteção e defesa da saúde. Diários do Congresso Nacional, 8 set.1951a, p. 7487.

BRASIL. Projeto da Lei de Proteção e Defesa da Saúde. Diários do Congresso Nacional, 26 nov. 1951 b, p. 12.033

BRASIL. Projeto n. 1436. 28 nov. 1951. Institui a Lei Orgânica de Saúde. Diários do Congresso Nacional, 1951c. p. 12.029.

BRASIL. Lei n. 2.312, 3 set. 1954. Normas Gerais sobre a Defesa e Proteção da Saúde, 1954.

BRASIL. Decreto n. 43.926, 26 jun. 1958. Dispõe sobre a Escola Nacional de Saúde Pública e dá outras providências, 1958. 
BRASIL. Decreto n. 46.258, 23 jun. 1959. Aprova o Regulamento da Escola Nacional de Saúde Pública, do Ministério da Saúde, 1959a.

BRASIL. Decreto n. 46.259, 23 jun. 1959. Aprova o Regimento da Escola Nacional de Saúde Pública, do Ministério da Saúde, 1959b.

BRASIL. Lei n. 5.019, 7 jun. 1966. Autoriza o Poder Executivo a instituir a Fundação Ensino Especializado de Saúde Pública e dá outras providências, 1966.

BRASIL. Decreto-Lei n. 904, 1 out. 1969. Dispõe sobre entidades do Ministério da Saúde, 1969.

BRASIL/MINISTÉRIO DA SAÚDE. Anais da IV Conferência Nacional de Saúde. Rio de Janeiro: Ministério da Saúde, 1967.

BRASIL/MINISTÉRIO DA SAÚDE. Anais da Terceira Conferência Nacional de Saúde. Niterói: Fundação Municipal de Saúde, 1992.

FADUL, W. Apresentação. In: Anais da Terceira Conferência Nacional de Saúde. Niterói: Fundação Municipal de Saúde, 1992.

FREITAS, C. A. Saúde no Brasil: nomes e fatos. Recife: Bagaço, 1998.

HALL, P. \& TAYLOR, R. Political science and the three new institutionalisms. Political Studies Association, 44: 936-957, dec.,1996.

HAMILTON, W. \& FONSECA, C. M. O. Política, atores e interesses no processo de mudança institucional: a criação do Ministério da Saúde em 1953. História, Ciências Saúde - Manguinhos, 10(3): 791-825, 2003.

HORWITZ, A. Política e realizações da Organização Pan-Americana da Saúde e da Organização Mundial da Saúde nas Américas. In: Anais da IV Conferência Nacional de Saúde. Rio de Janeiro: Ministério da Saúde, 1967.

NOGUEIRA, H. Discurso do senador Hamilton Nogueira. Diários do Congresso Nacional, 8 dez., 1950.

PIERSON. Dismantling the Welfare State? Cambridge: Cambridge University Press, 1995.

SCORZELLI JÚNIOR, A. O profissional de saúde de que o Brasil necessita. Arquivos de Higiene, 23(1): 109-119, set., 1967.

VARGAS, G. O presidente Vargas e a saúde: os tópicos dedicados ao importante problema mensagem presidencial ao Congresso Nacional. Boletim do Sesp, 9: 1-5, mar., 1951. 


\section{AneXo I}

\section{Relação Nominal de Professores da Ensp SEgundo Parágrafo ÚnICO do Artigo $8^{\circ}$ do DECRETO N. 47.308 DE 02/I2/59}

- RAYMUNDO AUGUSTO DE CASTRO MUNIZ ARAGÃO Professor da Escola Nacional de Química e Diretor do Laboratório de Drogas e Medicamentos

- FUAD NASSIM MELLEM - Diretor do Laboratório de Águas do Estado da Guanabara

- GOBERT DE ARAÚJO COSTA - Chefe de Seção no Instituto Oswaldo Cruz

- THEOPHILO OTTONI NETTO - Professor da Escola Nacional de Engenharia

- DOMINGOS ARTHUR MACHADO FILHO - Professor da Escola Nacional de Veterinária

- MURILlO V. BASTOS - Diretor da Divisão de Organização Hospitalar

- FAUSTO PEREIRA GUIMARÃES - Chefe no Laboratório de Águas da Guanabara

- Alvaro MiLANEZ - Chefe de Seção da Fundação Serviço Especial de Saúde Pública (Sesp)

- HOMERO XAVIER DE ANDRADE PEDROSA - Professor da Escola Nacional de Arquitetura e da Pontifícia Universidade Católica do Rio de Janeiro (PUC/Rio) e ex-diretor do Departamento de Águas da Guanabara 
- PAUlO ACIOLY DE SÁ - Professor da Pontifícia Universidade Católica do Rio de Janeiro (PUC/Rio)

- ADILSON COUTINHO SEROA DA MOTTA - Diretor substituto do Departamento de Esgoto Sanitário da Superintendência de Urbanização e Saneamento (Sursan)

- ATAUlPHO DOS SANTOS COUTINHO - Assistente da Escola Nacional de Engenharia e ex-diretor do Departamento de Águas da Guanabara

- CARlos LEOPOLdo PHILliPOWSKI - Chefe da Seção da Fundação Serviço Especial de Saúde Pública (Sesp)

- WALDO OLIVEIRA MAGALHÃES - Técnico do Laboratório de Higiene Industrial da Fundação Serviço Especial de Saúde Pública (Sesp)

- PAULO DE GÓES - Professor da Faculdade Nacional de Medicina e da Faculdade Nacional de Farmácia

- RUY GOMES DE MORAES - Professor da Escola de Medicina e Cirurgia e da Faculdade Nacional de Farmácia

- RUBENS DE SIQUEIRA - Professor da Faculdade Fluminense de Medicina e da Escola de Medicina e Cirurgia

- NECKER PINTO - Ex-diretor Geral do Departamento Nacional da Criança (DNCr) e ex-diretor dos Departamentos de Saúde de Pública de Pernambuco e Amazonas e do Departamento de Higiene da Guanabara

- JOSÉ MESSIAS DO CARMO - Diretor do Hospital Francisco de Castro

- CLOVIS CORRÊA DA COSTA - Diretor da Maternidade do Instituto Fernandes Figueira (IFF) e professor da Faculdade de Ciências Médicas

- MÁRIO OLINTO DE OLIVEIRA - Professor da Faculdade de Ciências Médicas e diretor do Instituto Fernandes Figueira (IFF) 
- ELISA DIAS VELOSO - Chefe do Centro de Orientação Psicológica Juvenil do Departamento Nacional da Criança (DNCr)

- CeSAR BELtrão PERnetA - Professor da Faculdade Fluminense de Medicina

- MÁRIO ULISSES VIANA DIAS - Professor da Faculdade Fluminense de Medicina

- JORGE ABREU DE PAIVA - Psicólogo do Instituto de Seleção e Orientação Profissional (Isop)

- ANTONIO CARLOS BARBOSA TEIXEIRA - Professor da Pontifícia Universidade Católica do Rio de Janeiro (PUC/Rio)

- EVIO SANTOS BUSTAMANTE - Ex-diretor da Divisão de Higiene e Segurança do Trabalho do Ministério do Trabalho

- JOSÉ RODRIGUES DA SILVA - Professor da Faculdade Nacional de Medicina e chefe de clínica do Hospital Servidores

- PAULO BARRAGAT - Químico do Departamento Nacional de Endemias Rurais (DENRu)

- DAPHNIS FERREIRA SOUTO - Técnico em Higiene do Trabalho da Petrobrás

- JACQUES NOEL MANGEAU - Diretor do Serviço Federal de Bioestatística do Serviço de Educação Sanitária (SES)

- SZACHANA ELIASZ CYNAMÓN - Chefe de Seção na Fundação Serviço Especial de Saúde Pública (Sesp)

- CLARIMUNDO CHAPADEIRO - Ex-diretor da Divisão de Obras

- ERMENGARDA FARIA ALVES - Chefe de Seção da Fundação Serviço Especial de Saúde Pública (Sesp)

- ACHILLES SCORZELLI JUNIOR - Professor Interino de Higiene da Faculdade Nacional de Medicina livre docente de higiene, exdiretor da Escola Nacional de Saúde Pública (Ensp) 
- LUIZ ROMEIRO DA SILVA - Ex-diretor da Seção de Engenharia Sanitária do Departamento Nacional de Endemias Rurais (DNERu)

- MÁRIO MAGAlHÃeS DA SILVEIRA - Chefe da Seção de Epidemiologia e Bioestatística e responsável pela Seção de Estudos Econômicos Aplicados da Escola Nacional de Saúde Pública (Ensp)

- LINCOLN DE FREITAS FILHO - Ex-diretor dos Cursos do Departamento Nacional de Saúde (DNS), diretor da Divisão de Organização Sanitária (DOS) e livre-docente de higiene

- BICHAT DE ALMEIDA RODRIGUES - Diretor Geral do Departamento Nacional de Saúde (DNS)

- Eliezer JACOB ZAGURY - Diretor dos Cursos do Departamento Nacional da Criança (DNCr)

- EDMAR TERRA BLOIS - Chefe da Seção de Assistência Social do Ministério de Educação e Cultura (MEC) e diretor do Instituto de Pesquisa da Santa Casa

- HERMES AFONSO BARTOLOMEU - Diretor de Divisão no Departamento Nacional da Criança (DNCr)

- JOSÉ MARIA MURGEL TAVEIRA - Técnico do Laboratório de Higiene Industrial da Fundação Serviço Especial de Saúde Pública (Sesp)

- LuCiO DE VASCONCElos COSTA - Ex-diretor do Departamento de Saúde, ex-coordenador do Departamento Nacional de Endemias Rurais (DNERu)e chefe da Seção de Administração e Saúde Pública da Escola Nacional de Saúde Pública (Ensp)

- NILO CHAVES DE BRIO BASTOS - Chefe da Seção de Educação Sanitária da Fundação Serviço Especial de Saúde Pública (Sesp)

- NICOLAU BRAILE - Assistente de Química Tecnológica da Escola Nacional de Engenharia e Técnico do Departamento Nacional de Pesos e Medidas (DNPM) 
- JAVAN MACHADO DE GÓES - Professor do Serviço Social da Pontifícia Universidade Católica do Rio de Janeiro (PUC/Rio)

- RANDOVAL MONTENEGRO - Chefe da Seção de Estatística Hospitalar do Instituto Fernandes Figueira (IFF)

Fonte: Fundo Ensp/ Seção Secretaria Administração Geral, caixa 67, maço 2/ Casa de Oswaldo Cruz/Fiocruz. 


\section{Anexo 2}

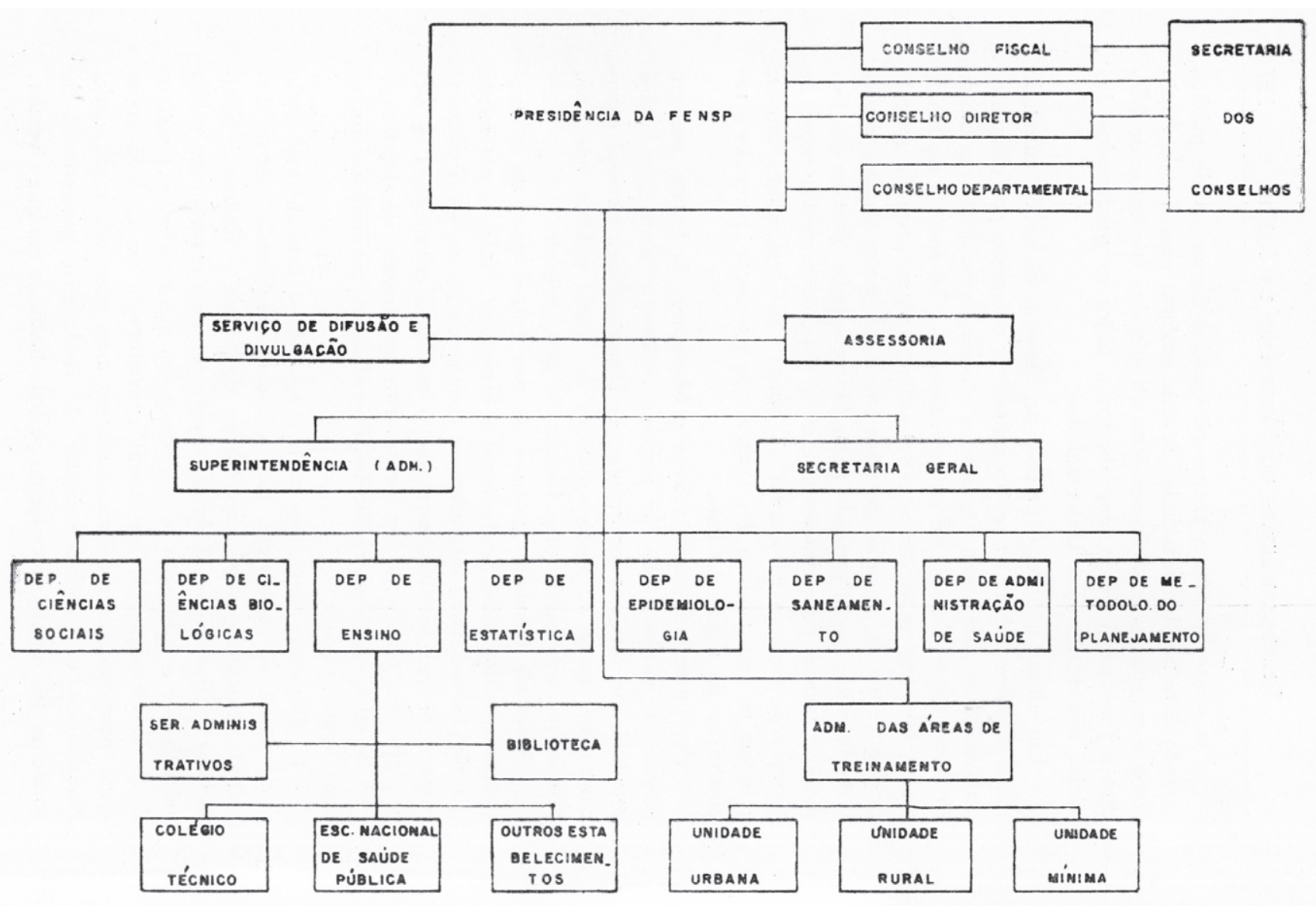




\title{
3. A Ensp e as Transformações na Sociedade e no Sistema de SAÚde No Brasil: 1970 A 1985
}

\author{
Paulo Roberto Elian dos Santos \\ Verônica Martins de Brito \\ Nísia Trindade Lima \\ Cristina M. O. Fonseca
}

\section{INTRODUÇÃO}

$\mathbf{U}_{\text {ma das mais importantes transformações ocorridas na sociedade }}$ brasileira durante a segunda metade do século XX consistiu no processo de urbanização. Ainda rural em 1960, duas décadas mais tarde tornara-se o Brasil um país de população predominantemente urbana. O percentual desses habitantes, que era de $31,2 \%$ em 1940, passou a 44,7\% em 1960 e a $67,6 \%$ em 1980, com sensível aumento na velocidade da mudança na década de 1960, quando se deu a efetiva inclusão do país na faixa das nações urbanas (Santos, 1985).

Tal fato suscitou intensos debates sobre as políticas de saúde nas décadas de 1970 e 1980, quando também se intensificaram os estudos sobre pobreza urbana e sobre impacto das migrações rurais-urbanas para a distribuição espacial de doenças, gerando, por exemplo, a redefinição de conceitos como o de endemias rurais. O processo trouxe também novos desafios para o pensamento em saúde no Brasil, que, desde a década de 1950, caracterizou-se pelo debate de idéias e apresentação de projetos de reforma que superassem a clivagem entre assistência médica previdenciária - destinada, em suas origens, aos trabalhadores urbanos incorporados ao sistema de proteção social criado a partir de 1930 - e ações de saúde pública direcionadas para o controle de epidemias e endemias, nas quais também se incluíram formas limitadas de atenção à saúde dos trabalhadores rurais.

No plano político, a experiência do regime autoritário marcou profundamente a história do Brasil contemporâneo. De 1964 a 1985, viveu o país sob a égide de governos militares, que, ao lado do cerceamento dos direitos civis e políticos, implementaram um modelo de Estado altamente centralizado, além de planos de desenvolvimento que 
(...) 0 que é interessante na minha visão é que esse momento de certa maneira refaz o IOC da origem.

(Entrevista com Luiz Fernando falando a respeito das mudanças que ocorrem na Fiocruz e na Ensp a partir dos anos de 1970) implicaram mudanças significativas para a estrutura econômica e social, com impacto nas políticas de saúde.

A história da Escola Nacional de Saúde Pública (Ensp) no período de 1970 a 1985 não pode ser interpretada sem referência a esse quadro social e político interno e também ao debate internacional sobre as concepções da saúde como direito, tendo como um dos momentos marcantes a Conferência de Alma-Ata, em 1978. Entretanto, seria equivocado reduzi-la a simples expressão de um contexto mais geral. Como observamos no artigo anterior, muitas medidas inovadoras foram adotadas, mesmo em conjunturas adversas, o que indica a complexidade dos processos em curso no país e no âmbito interno da instituição.

Durante a década de 1970, deve-se considerar a importância, para a área de saúde, de iniciativas vinculadas ao II Plano Nacional de Desenvolvimento (PND), implementado durante o governo de Ernesto Geisel (1974-1978). Sarah Escorel, em seu estudo sobre o movimento sanitarista brasileiro nas décadas de 1970 e 1980, destaca as iniciativas mais importantes, acentuando seu alcance e significado para a gênese do movimento. Segundo a autora,
Diretamente vinculados ao II PND, surgiram nessa conjuntura três espaços institucionais que podemos chamar de pilares institucionais, estímulos oficiais à estruturação/articulação do movimento sanitário: o setor saúde do Centro Nacional de Recursos Humanos do Instituto de Pesquisa Econômica e Aplicada (CNRH/Ipea), a Financiadora de Estudos e Projetos (Finep) e o Programa de Preparação Estratégica de Pessoal de Saúde da Opas (PPREPS/Opas). (Escorel, 1998: 43)

Essas alterações institucionais, que refletiam uma preocupação com a área de recursos humanos e formação de pessoal em saúde, associavam-se diretamente ao desenvolvimento da Ensp e às mudanças que iriam ter início a partir de 1974. O Programa de Preparação Estratégica de Pessoal de Saúde (Ppreps) foi criado em 1975, envolvendo os Ministérios da Saúde e da Educação e Cultura, em convênio com a Organização PanAmericana da Saúde/Organização Mundial da Saúde (Opas/OMS) e o Programa de Interiorização das Ações de Saúde e Saneamento (Piass), em 1976 (Escorel, 1998). ${ }^{1}$

A cooperação entre os dois programas, principalmente no que se refere ao desenvolvimento de recursos humanos, teve impacto expressivo

\footnotetext{
${ }^{1}$ Ver também neste livro o artigo de Tânia Celeste Matos Nunes.
} 
nas secretarias estaduais de saúde do Nordeste (Escorel, 1998). No mesmo ano de criação do Ppreps, a Ensp deu início à experiência dos cursos descentralizados que viriam se somar a esse processo de redefinição da formação de recursos humanos e de revisão dos paradigmas da saúde, para o qual também foram importantes outras experiências institucionais anteriores, como, entre outras, a da Universidade de Brasília, em que se formaram quadros importantes para a gênese do movimento sanitarista (Jouval, 2003; Rodriguez Neto, 2003).

Com a Finep, seriam estabelecidos acordos, através de Oswaldo Campos e Sergio Goes de Paula, para financiamento de dois importantes programas de pesquisa, o Programa de Estudos Socioeconômicos em Saúde (Peses) e o Programa de Estudos Populacionais e Epidemiológicos (Peppe), dos quais redundaram importantes alterações no perfil institucional da Escola, como observaremos adiante.

O Piass orientou uma série de iniciativas que inauguraram a década de 1980, tais como o Programa Nacional de Serviços Básicos de Saúde (Prev-Saúde), as Ações Integradas de Saúde, implementadas em 1983 e com um importante papel no processo de descentralização do setor, e a $7^{\text {a }}$ Conferência Nacional de Saúde, realizada em 1980. Nesta última, foram debatidos a implantação e o desenvolvimento do Prev-Saúde, a regionalização e organização dos serviços de saúde nas universidades federais e a articulação dos serviços básicos com os serviços especializados no sistema de saúde (Fiocruz, 2003).

O surgimento de duas outras instituições no decorrer dos anos de 1970 - o Centro Brasileiro de Estudos de Saúde (Cebes), em 1976, e a Associação Brasileira de Pós-Graduação em Saúde Coletiva (Abrasco), em 1979 - contribuíram também para a constituição de novas formas de associação profissional na área da saúde pública, que foram responsáveis pelas mudanças na atuação tanto no campo político como na esfera acadêmica.

Essas mudanças foram reforçadas, no que se refere ao estabelecimento de um corpo de idéias e diretrizes, pelo debate no âmbito internacional, em particular no que se refere à Conferência de Alma-Ata, promovida, em 1978, pela Opas. A Declaração de Alma-Ata englobava os seguintes valores e princípios essenciais: a saúde como um direito essencial da pessoa e das comunidades; a obrigação dos Estados em assegurar, dentro de suas possibilidades, esse direito a todos; a responsabilidade e o direito das comunidades e indivíduos em participar na proteção e recuperação de sua saúde e na gestão dos serviços para sua atenção; a
Uma coisa que a gente sempre teve uma preocupação grande foi não deixar a questão política interferir, quer dizer, o candidato ao curso, ele tinha que passar por um processo de seleção para a gente fugir da indicação política, entendeu? Eu acho que isso era uma coisa muito importante.

(Entrevista com Elsa Paim, falando sobre os cursos descentralizados ) 
precedência da promoção e da prevenção sobre o tratamento, na atenção integrada à saúde; o caráter social da saúde e a necessidade da articulação dos cuidados específicos da saúde com outras ações relativas à melhoria das condições de bem-estar; a importância particular do ambiente e da educação para a saúde; e a eqüidade e a universalidade do acesso aos serviços (Macêdo, 1997: 46).

Os primeiros números da revista do Cebes, Saúde em Debate. 1976-1977. Acervo Coc.

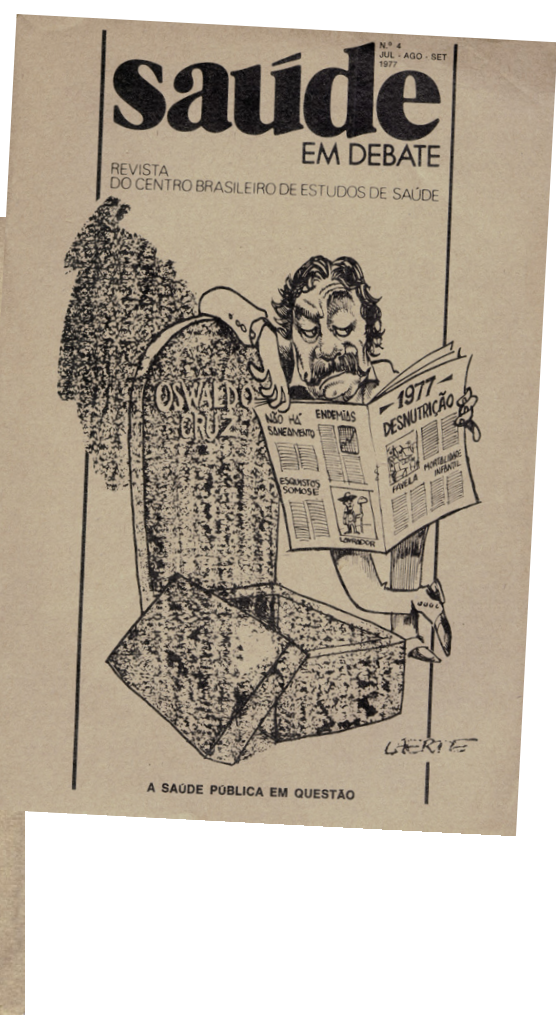

No início da década de 1980, verificou-se a institucionalização, no Brasil, da abordagem da medicina social, sob forte influência das discussões e propostas sobre educação médica incentivadas pela Opas, em particular pela pesquisa de Juan Cezar Garcia (Lima, 2002). A abordagem da medicina social comportava inúmeras clivagens e diferenciações nos planos teórico e político; encontrava-se representada pelos seguintes centros: os departamentos de medicina preventiva da Universidade Estadual de Campinas (Unicamp) e da Universidade de São Paulo (USP), o Instituto de Medicina Social da 
Universidade Estadual do Rio de Janeiro (IMS/Uerj) e a Escola Nacional de Saúde Pública da Fundação Oswaldo Cruz (Ensp/Fiocruz) (Escorel, 1998; Teixeira, 1985). Uma das implicações desse processo foi a incorporação de cientistas sociais aos quadros docentes dessas instituições, algo que, no caso da Ensp, já ocorria, como vimos, desde fins da década de 1960.

Uma série de eventos e iniciativas importantes na área da saúde marcaram a década de 1980, destacando-se os seguintes: certificação da erradicação mundial da varíola na $33^{\text {a }}$ Conferência Mundial da Saúde (1980); realização das $7^{\text {a }}$ e $8^{\text {a }}$ Conferências Nacionais de Saúde $(1980$ e 1987); criação da Secretaria Nacional de Ações Básicas de Saúde (Snabs) e da Divisão de Epidemiologia (DNE) no Ministério da Saúde, que substituiu a Fundação Serviço Especial de Saúde Pública (FSESP) na função de notificação compulsória de doenças e assumiu o Sistema Nacional de Vigilância Epidemiológica (1981); estabelecimento do Plano do Conasp - Plano de Reorientação da Assistência à Saúde no âmbito da Previdência Social pelo Conselho Consultivo de Administração Previdenciária (1982); reafirmação do conceito de 'saúde mental', propondo-se uma revolução na atenção psiquiátrica (1985); realização, em Ottawa, Canadá, da primeira conferência sobre promoção à saúde, que elabora a Carta de Ottawa; implantação das Ações Integradas de Saúde (1983); criação do Sistema Unificado e Descentralizado de Saúde (Suds, 1988); promulgação da Constituição, com o estabelecimento das bases para o Sistema Único de Saúde (1988).

No plano mais geral, o início da década de 1980 foi marcado por dois fatos significativos: grave crise econômica mundial e processo de redemocratização política do país. No contexto da crise econômica, verificou-se intenso processo de internacionalização dos mercados, dos sistemas produtivos e da tendência à unificação monetária, cujo resultado foi uma perda considerável de autonomia dos Estados nacionais. $\mathrm{Na}$ América Latina, os efeitos da crise financeira, somados à crise da dívida externa, levaram a um reforço do modelo que vinha sendo aplicado em alguns países desde meados da década anterior pelo Banco Mundial, o Fundo monetário Internacional (FMI) e o governo norte-americano, no chamado 'Consenso de Washington'. Esse modelo incluía a proposta de ajuste estrutural, segundo o qual as mudanças deveriam ocorrer através de políticas liberalizantes, privatizantes e de mercado, ou seja, centradas na desregulamentação dos mercados, na abertura comercial e financeira, na privatização de empresas públicas e na intervenção do Estado na oferta de bens e serviços de natureza social. A gênese do Sistema Único de Saúde
E outra coisa é que você multiplicou o número de sanitaristas infinitamente. Isso foi uma coisa importantíssima, até para a reestruturação das secretarias de saúde que passou a contar com pessoal especializado.

(Entrevista com Elsa Paim, falando dos cursos descentralizados ) 
Houve uma época em que se começou a falar em regionalização do serviço de saúde. Era uma coisa nova, e o secretário de saúde da Paraíba, que se chamava Propício Caldas, era um excelente técnico e começou um programa de regionalização dos serviços da Paraíba. Ele veio à Escola e fez uma belíssima palestra sobre regionalização, e eu perguntei a ele se poderíamos fazer um estágio do curso de saúde pública daquele ano na Paraíba. Ele ficou encantado e nós fomos daqui com trinta e tantos alunos, de ônibus e percorremos a Paraiba inteirinha, de carro, de caminhonete, visitando todas as unidades que estavam em processo de regionalização.

(Entrevista com Elsa Paim, falando sobre a experiência em 1972) no Brasil, por suas peculiaridades, especialmente no que se refere aos princípios da universalidade da atenção à saúde e da participação social, tem sido apontada como um movimento na contracorrente do que ocorreu nos demais países latino-americanos.

Como observam Nilson Rosário Costa e Marcos Mello (1994), a partir da década de 1980, o 'paradigma da economia da saúde', baseado nos princípios da focalização e da seletividade, passou a orientar a ação de organismos, como o Banco Mundial, contrapondo-se ao tradicional 'paradigma da saúde pública', que historicamente orientou a atuação de organismos como a Opas. Entretanto, os efeitos dessa política e sua efetivação não estão dados a priori, dependendo da capacidade de os demais atores apresentarem alternativas para os problemas contemporâneos de sustentação de políticas sociais (Lima, 2002).

No plano político nacional, o resgate dos direitos individuais, da liberdade de expressão, dos movimentos da sociedade civil e de defesa da cidadania marcaram a década de 1980 . Foi nesse contexto, que mesclava renovação política, grandes expectativas e agravamento das tensões sociais, que ocorreram profundas transformações no sistema de saúde. Uma das expressões desse movimento político mais geral, o movimento sanitarista brasileiro, considerava que, para viabilizar sua tese essencial - é obrigação do Estado criar as condições políticas, sociais, econômicas e ambientais que permitam aos indivíduos o acesso gratuito à saúde de forma universal e inalienável -, eram necessárias uma prática política e uma consciência sanitária capazes de empreender a reforma no sistema de saúde.

Como corolário do processo político de redemocratização, a nova Constituição, promulgada em 1988, consagrava princípios importantes da democracia representativa, reinstituindo a liberdade de organização partidária e a extensão do eleitorado mediante, inclusive, o direito de voto para os analfabetos e a eleição direta para presidente da República.

Os avanços conquistados pelo movimento sanitário foram também expressos no texto constitucional. Porém, apenas a partir da década de 1990 é que podemos identificar, no Brasil, a implementação de um sistema de saúde nos moldes propostos pela Constituição. Nesse aspecto, pode-se destacar a promulgação da Lei Orgânica da Saúde, ${ }^{2}$ que dispunha sobre as condições para a promoção, a proteção e a recuperação da saúde, a organização e o funcionamento dos serviços correspondentes, definindo

\footnotetext{
${ }^{2}$ A Lei Orgânica da Saúde é composta por duas leis, as de n. 8.080 e 8.142, de 1990.
} 
os parâmetros para o modelo assistencial, estabelecendo os papéis das três esferas de governo e instituindo o Sistema Único de Saúde (SUS). Foram definidos ainda, como princípios e diretrizes, a universalidade, a eqüidade e a integralidade, a descentralização com ênfase na municipalização, a regionalização e a participação popular, através do fortalecimento do exercício do controle social por meio dos conselhos municipais, estaduais e nacional de saúde.

\section{A Escola Nacional de Saúde Pública no Contexto da Reforma Sanitária}

Acompanhando esse processo abrangente de mudanças na esfera política, econômica e social, a Ensp ingressou na década de 1970 trazendo uma herança positiva de ações sistematizadas no campo do ensino e da formação e especialização em saúde pública. Os primeiros anos dessa década foram particularmente difíceis e talvez devam ser apontados como o período no qual a Escola passou por maiores dificuldades. A saída do diretor Edmar Terra Blois, em 1969, foi seguida por cortes significativos no orçamento e por uma redução substantiva do quadro de professores. O período de 1970 a 1974 caracterizou-se pela resistência e pela manutenção das atividades em condições de adversidade, que por sua vez acompanhavam o quadro político nacional, o de maior repressão durante o regime autoritário implantado em 1964.

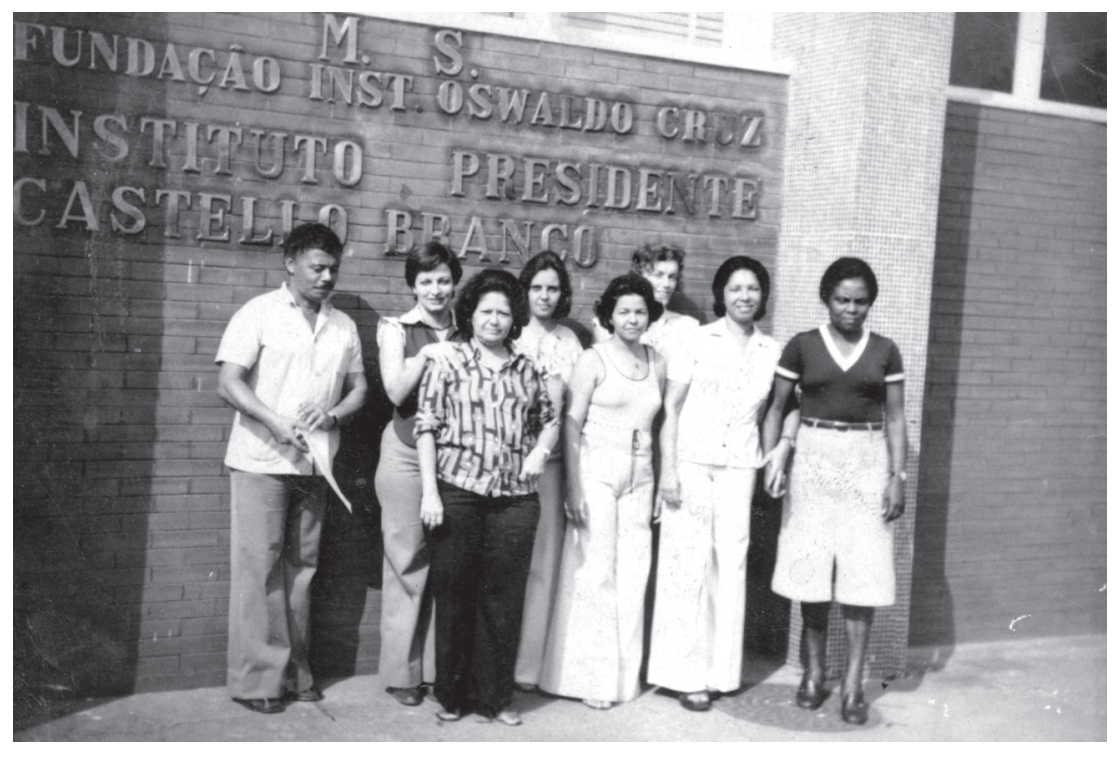

Funcionários da Biblioteca, 1976. Da esquerda para a direita: Moacir Brito, Jussara Long, Neuza de Oliveira, Regina Gandara, Jarmila Vieira do Espírtio Santo, Luiza Kraemer Conceição Costa e Mozarina de Andrade Rangel. Foto: Cid Fayão. Acervo Ensp. 
A primeira alteração que demarca esse momento se espelha na própria mudança regimental/estrutural da Escola que acompanhou a instituição da Fundação Instituto Oswaldo Cruz, definida por legislação específica em maio de 1970. Três meses depois a Escola passou a integrar a Fiocruz, com a nova denominação de Instituto Presidente Castelo Branco. ${ }^{3}$

No período de 1970 a 1974, a Ensp foi dirigida por Oswaldo Costa, médico sanitarista com atuação nessa área desde 1939, com passagens pelo Departamento Nacional de Saúde (DNS), pelo Sesp e com intensa participação em atividades internacionais conduzidas pela Opas. Era professor da Escola e concentrava sua atuação na área de administração e planejamento de saúde pública. Ao longo de sua gestão, a Ensp procurou manter suas atividades orientadas pelas três áreas que constituíram seu campo de atuação: o ensino, a pesquisa e o trabalho com a comunidade. Seu papel foi destacado por Eduardo Costa ao lembrar esse período difícil.

Eu devia uma homenagem ao Oswaldo Costa. Ele foi uma pessoa correta com todo mundo. O Oswaldo Costa fez o que ele podia fazer, se manteve íntegro. Ele não era uma pessoa de esquerda, nada disso, mas era uma pessoa íntegra, que não se misturou com as perseguições. E deu oportunidades para muita gente da escola, que, às vezes, não é reconhecida. Ele foi uma peça-chave, que não deixou a escola morrer com as cassações. (Entrevista com Eduardo de Azeredo Costa, 2004)

A partir de 1974, a dinâmica institucional da Escola começou a mudar, dando início a um processo de transformação que marcaria sua trajetória ao longo das décadas seguintes. Era o início do governo Geisel (1974-1978), e as mudanças verificadas na Ensp se associaram diretamente ao quadro de alterações institucionais que também ocorreram na Fiocruz, a partir de 1975, quando Vinícius da Fonseca assumiu a presidência da instituição, por indicação do então ministro do Planejamento Reis Veloso, com quem tinha trabalhado no Ipea, trazendo uma visão estratégica de planejamento econômico, voltado para modernização da instituição. $\mathrm{O}$ próprio presidente Geisel, em pronunciamento na $5^{\text {a }}$ Conferência Nacional de Saúde em 1975, destacou entre as prioridades do governo a recuperação da Fiocruz, reconhecendo o papel do Estado no desenvolvimento científico

3 O decreto n. 66.624, de 22 de maio de 1970, criou a Fiocruz, incorporando a ela o Instituto Fernandes Figueira (IFF), o Instituto Nacional de Endemias Rurais (Ineru), o Instituto Evandro Chagas (IEC) e o Instituto de Leprologia. Em 13 de agosto de 1970, o decreto n. 67.045 definia a inclusão da Ensp à Fiocruz, determinando também a mudança de nome. 
e tecnológico. É deste período também a implementação do I e II Plano Básico de Desenvolvimento Científico e Tecnológico (PBDCT), que repercutiu diretamente sobre a Escola. ${ }^{4}$

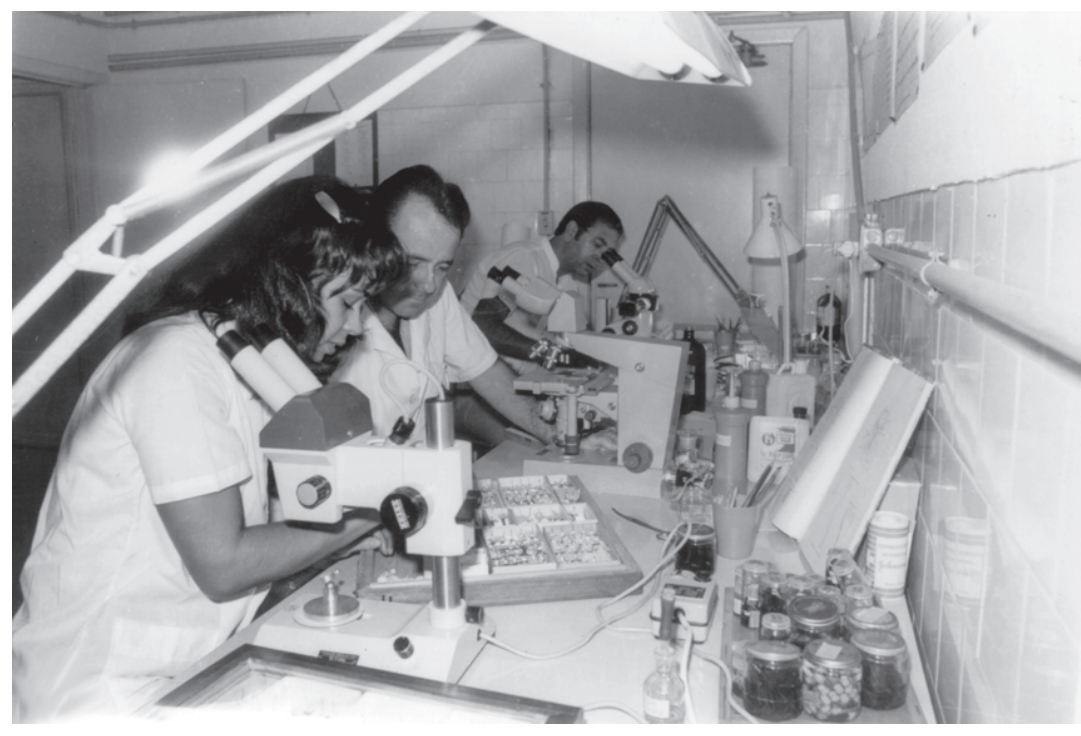

O ingresso de Vinícius trouxe implicações para a Ensp e para o Instituto Oswaldo Cruz (IOC), com uma política deliberada de investimento em pesquisa. Como conseqüência, o Departamento de Biologia da Escola perdeu a maior parte de seus professores, que, aos poucos, transferiram-se para o instituto, como descreve Luiz Fernando Ferreira:

a idéia do Vinícius era acabar com o Departamento de Ciências Biológicas da Escola de Saúde Pública, porque juntou com o IOC. Biologia é no IOC. Começou a ir todo mundo para lá. Foi o Herman, o Sérgio Coutinho, o Jarbas (...). (Entrevista com Luiz Fernando Ferreira, 1999)

Este foi um movimento específico do Departamento de Biologia devido às características do trabalho ali desenvolvido, pois a partir desse momento ocorreu um processo de incorporação gradativa de novos profissionais à Escola, em um movimento de recomposição do quadro de
Laboratório da Ensp, s.d. Foto: Cid Fayão. Acervo Ensp.

\footnotetext{
4 Administração Vinícius da Fonseca. Síntese das Atividades desenvolvidas no triênio agosto de 1975-agosto de 1978. Seção Secretaria de Administração Geral, caixa 4, maço 4, Casa de Oswaldo Cruz/Fiocruz. O I PBDCT é de 1973-74 e o II PBDCT foi publicado pela presidência da República em 1976. Ver Pena (1977).
} 
Por que a gente conseguiu sair para os cursos descentralizados? Porque a gente tinha um pensamento, a gente tinha uma experiência, a gente tinha um curso de saúde pública aqui na escola.

(Entrevista com Arlindo Fábio Gómez de Sousa, 2003) professores tão esvaziado nos anos anteriores. Vários acontecimentos contribuíram para isso, o primeiro deles na esfera da gestão administrativa, quando o então diretor da Ensp Oswaldo Costa assumiu ainda em 1974, antes da vinda de Vinícius da Fonseca, a presidência da Fiocruz, sendo substituído na direção da Ensp por Ernani Braga. Essa alteração motivou também o retorno de Eduardo Costa, que, nos meses seguintes, seria articulador de mudanças significativas para a Escola.

O Oswaldo Costa me telefonou dizendo assim: 'Eduardo, volta. O Ernani vai ser diretor da Escola. Cara, nós precisamos de você aqui, você vai ter um cargo, os planos são completamente diferentes (...)' Eu voltei. (Entrevista com Eduardo de Azeredo Costa, 2004)

Nesta época, a Finep havia ficado com a incumbência de elaborar o programa do II PBDCT. Procurado por Sergio Goes, que, juntamente com Oswaldo Campos, coordenava o Setor de Estudos e Pesquisas da Finep, Eduardo Costa seria contratado como assessor para incluir no PBDCT um programa que possibilitasse investimentos para a Escola, recuperando sua capacidade de ação. Com essa orientação, foram elaborados, em colaboração com outros profissionais da Ensp como Arlindo Fábio Gómez de Sousa, o Peppe e o Peses.

Esse seria mais um importante momento de reformulação para a Escola. A partir daí, com a disponibilidade de um volume de recursos significativos, a Ensp deu início ao desenvolvimento de novas pesquisas ao mesmo tempo que abriu suas portas à incorporação de novos profissionais, reafirmando, em um novo momento de sua história, seu perfil como uma instituição de congraçamento, sua "marca de receptividade, de capacidade de acolhimento e de agregação" (Entrevista com Arlindo Fábio Gómez de Sousa, 2003).

Dessa forma, em 1975, Antônio Sergio Arouca e um grupo de professores do Departamento de Medicina Preventiva da Unicamp, em divergência com o então reitor Zeferino Vaz, transferiram-se para o Rio de Janeiro e incorporaram-se à Escola. Arouca passou a ser o coordenador do Peses e Eduardo Costa do Peppe, iniciando-se um processo de importantes mudanças no campo da pesquisa científica no interior da Escola.

$\mathrm{O}$ Peses representou também forte estímulo à utilização das ciências sociais em saúde, promovendo uma crítica ao movimento preventivista de origem norte-americana e à abordagem da história natural das doenças e enfatizando perspectivas histórico-estruturais que realçavam o papel central a ser desempenhado pelo Estado (Arouca, 2003). 
Paralelamente a esses acontecimentos, outra importante alteração passou a ser elaborada na área de ensino da Ensp em 1975 - convém lembrar, mesmo ano de criação do Ppreps -, quando começou o investimento em uma política de descentralização dos cursos de saúde pública para outras regiões do país.

Com os cursos descentralizados, teve início uma importante experiência que trouxe impactos para a área da saúde em todo o país, contribuindo de forma significativa, tanto para a expansão da especialização em saúde pública como para a consolidação da carreira de sanitarista. Os cursos tinham como objetivo acelerar a capacitação profissional e formar uma massa crítica na área de recursos humanos que possibilitasse a expansão da rede permanente de serviços. Este projeto foi viabilizado a partir de reuniões com o corpo docente da Escola e através de contatos com representantes de secretarias de saúde estaduais. O acordo inicial para dar início ao projeto resultou em uma parceria efetiva no decorrer dos anos seguintes (Uchôa \& Paim,1982). ${ }^{5}$

O trabalho passou a ser desenvolvido a partir de uma parceria entre a Ensp, as secretarias estaduais de saúde e as universidades locais. Este triângulo institucional permitiu, por um lado, a incorporação de muitos profissionais qualificados, após a realização dos cursos, pelos próprios serviços estaduais, muitas vezes em nível central; por outro lado, levou ao fortalecimento da área de saúde pública dentro das universidades, contribuindo para a consolidação da pós-graduação no decorrer dos anos seguintes. Arlindo Gómez de Sousa chama claramente a atenção para este aspecto:

Os cursos eram [dados pela] Escola Nacional de Saúde Pública [junto] com a Secretaria de Saúde e a universidade. Normalmente era este o triângulo, eram os três que participavam. Mas o certificado era nosso; quem podia dar a titulação era a Escola de Saúde Pública. Com isso e é o que eu quero deixar muito claro - Departamentos de Medicina Preventiva, Social, Higiene foram crescendo. O grande crescimento dos Departamentos de Medicina Preventiva e Social se dá nessa época, com a contribuição decisiva da Escola Nacional de Saúde Pública, aliada a outras circunstâncias. (Entrevista com Arlindo Fábio Gómez de Sousa, 2003)

É importante não esquecer, como fazem observam os próprios participantes deste processo, Elsa Paim e Hélio Uchôa (1982: 26), que a experiência dos cursos descentralizados para formação e especialização em saúde pública já havia sido realizada durante os anos de 1940, sob a orientação do então diretor do DNS, João de Barros Barreto. Ver também o artigo anterior deste livro.
0 que eu quero acentuar é 0 caráter pessoal disso. Quer dizer, é 0 ator, é o personagem, é a força desse ator. Enquanto a gente está aqui conversando, o Luiz está sempre acentuando isso, a presença desse ator. $E$ em determinados momentos esse ator é fundamental, e a gente está falando do Blois, a gente está falando do Ernani, está falando do Oswaldo, do Arouca, são atores importantes. Haveria outros? Claro que havia outros atores também que poderiam substituir! Não importa, o que acontece é que eles foram, atores de personagens importantes!

(Entrevista com Arlindo Fábio Gómez de Sousa, 2003) 
Turma do curso básico de saúde pública - 1978. Acervo Particular Tânia Fernandes.

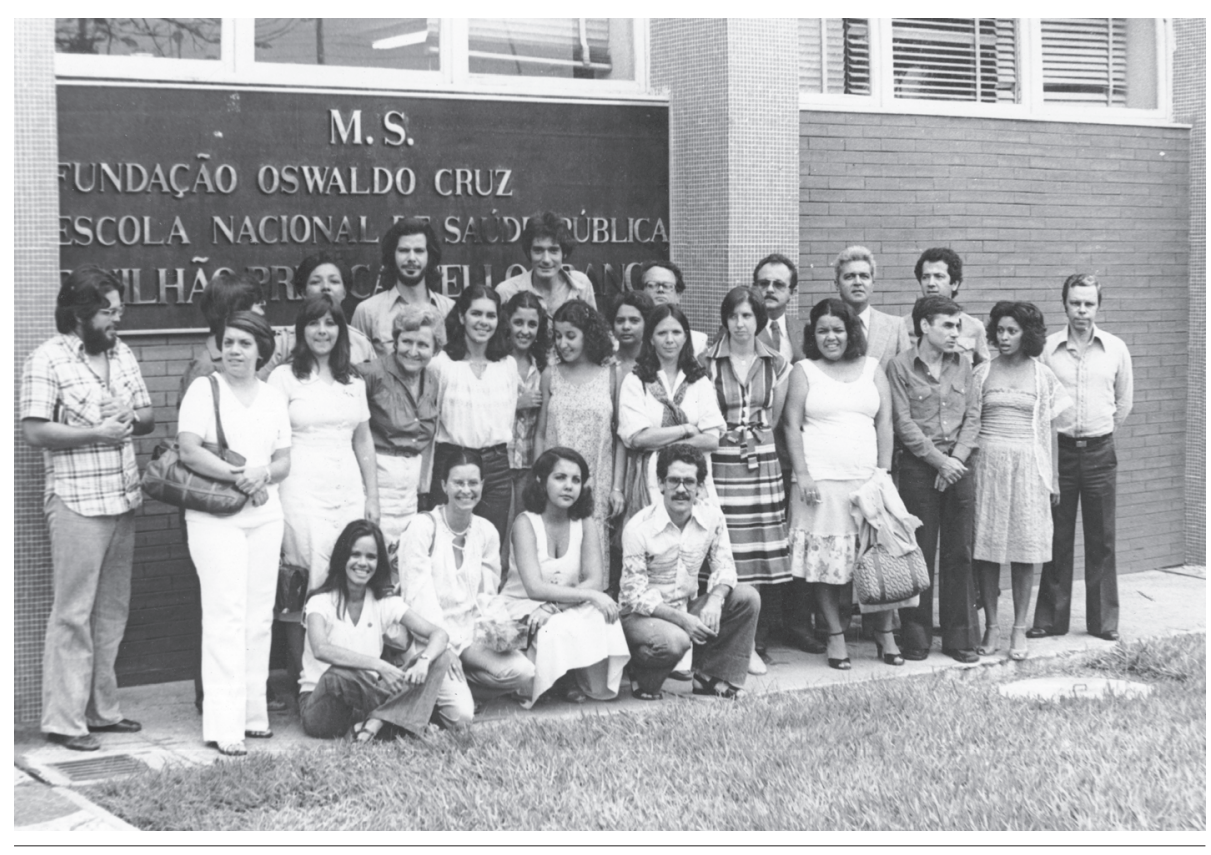

A política de descentralização dos cursos de saúde pública implicou efetivamente uma reformulação no processo de ensino e de especialização, pois a partir daí os antigos cursos básicos de saúde, ministrados até então pela Escola, ganharam um outro perfil, inserindo-se em uma lógica que era definida como um 'processo de educação continuada' (Uchôa \& Paim, 1982). Nesse sentido, instituiu-se uma hierarquia para a formação do sanitarista, que seguiria em várias etapas até chegar ao doutorado. Em carta redigida por Ernani Braga ao dr. Humberto M. Novaes em $1980,{ }^{6}$ esta trajetória é explicitada:

Em 1980 com o curso de doutorado os cursos da Ensp alcançaram seu último estágio hierárquico. A Escola Nacional de Saúde Pública adotou em 1975 a hierarquização dos cursos de preparação de profissionais de saúde pública em níveis de aperfeiçoamento - curso básico -, especialização - curso de especialização - e pós-graduação stricto sensu - curso de mestrado e curso de doutorado -, obedecendo-se a um esquema modular, a um sistema de créditos e uma progressiva seletividade. Em 1977 foi alcançado o segundo estágio na hierarquização com a instalação,

6 Carta de Ernani Braga, vice-presidente da Fiocruz e diretor da Ensp, ao dr. Humberto M. Novaes, assessor regional em Educação de Administração em Saúde, Organização Pan-Americana da Saúde, de 1980, com anexo intitulado "Resumo sobre as atividades da Escola Nacional de Saúde Pública”. Ver Fundo Ensp/Seção Direção, caixa 64, maço 1, Casa de Oswaldo Cruz/Fiocruz. 
na sede da Ensp, do primeiro curso de especialização em saúde pública, renovado nos anos subseqüentes. Chegou-se em 1979 ao terceiro estágio de hierarquização: a abertura, também na sede da escola, do primeiro mestrado em saúde pública, stricto sensu vale repetir, uma vez que em 1967 e 1968 foi ministrado um mestrado sem tal qualificação. Por fim em 1980, foi atingido o último estágio hierárquico: o curso de doutorado em saúde pública.

O ponto de partida para essa reformulação encontrava-se, portanto, nos cursos descentralizados que passaram à coordenação de Hélio Uchôa. No primeiro ano, 1975, foram realizados dois cursos além do que se realizava normalmente no Rio de Janeiro, um em Porto Alegre e outro em Belém. A partir de então os cursos foram se ampliando, chegando, em 1980, a 16 estados. No total, entre 1975 e 1980, foram realizados 50 cursos nos diversos estados do país. É interessante observar que esse processo de expansão orientou-se por uma divisão territorial que delimitava as áreas geográficas a partir de uma sede local. Dessa forma, o curso com sede em Belém atendia aos candidatos da região Norte; o curso com sede em Recife, os candidatos dos estados do Rio Grande do Norte, Paraíba, Pernambuco e Alagoas; o curso com sede em Salvador, os candidatos dos estados de Sergipe, Bahia e Espírito Santo; e o curso com sede em Porto Alegre, os candidatos dos estados do Paraná, Santa Catarina e Rio Grande do Sul (Uchôa \& Paim, 1982: 27). Houve, dessa forma, uma regionalização na execução do processo de ensino conduzido pela Escola, que, por um lado, contribuiu para a identificação de problemas regionais específicos e, por outro, permitiu maior afinidade nas discussões e proposições apresentadas. Assim, a Ensp expandiu sua atuação para todo o país de forma sistematizada, a partir de uma coordenação central, ao mesmo tempo que contribuía para consolidar um campo de reflexão na área da saúde pública.

Paulatinamente, os professores da Escola contribuíram para a formação de corpo docente nas diversas localidades, capacitando-o a dar prosseguimento aos cursos, mantendo sua atuação como supervisores ou professores nas disciplinas que não contavam com especialistas locais. A parceria com a universidade desempenhou papel relevante para assegurar uma base acadêmica e a formação de profissionais qualificados. Essa experiência teve repercussões sobre a Ensp e foi descrita por Elsa Paim, que participou diretamente desse processo:

No início a participação da gente era muito grande na parte docente (...). Naquelas áreas onde não havia professores específicos para determinada disciplina, nós é que íamos. Então, os docentes da Escola participavam
A ousadia, ela tem que extrapolar o nível da responsabilidade e dos cânones, senão não vai, você não rompe, não é ? E eu acho que é isso que, digamos assim, é o que a gente conseguiu viver nessa experiência da Escola de Saúde Pública!

(Entrevista com Arlindo Fábio Gómez de Sousa, 2003) 
praticamente em todo o processo: na discussão inicial do curso, na seleção dos alunos, na seleção do corpo docente. Isto é importante: a gente fazia entrevista com o corpo docente (...) e, depois, essa participação começa a ser maior na parte de supervisão, avaliação e discussão e menos na sala de aula. Eu acho que isso foi muito bom para os estados e foi muito bom para nós da Escola, que passamos a conhecer a realidade das secretarias de Saúde do Brasil inteiro. No lugar de se ter depoimento de alunos que vinham dos estados, a gente passou a ver e conhecer o processo de Saúde de cada estado. Para mim foi um crescimento enorme! Já pensou? Você está aqui dentro, no Rio, dando curso para gente que vem de fora e, de repente, é você que vai ao encontro deles. Você cresce muito!

(...) Eu volto a dizer que foi uma experiência muito interessante, não só para os estados, mas, sobretudo, para a escola. Deu para os professores uma visão que a maioria não tinha. Eu, por exemplo, tinha sido de serviço, então eu conhecia muito serviço. No Sesp eu viajava muito para os estados. Mas tinha professor na escola que não conhecia e só aí foi tomar contato com a realidade brasileira, até para trazer contribuições para os próprios cursos da escola. Eu acho que o curso de saúde pública, os básicos, foram muito enriquecedores para a escola, foram importantes para os estados e também foram importantes para nós. (Entrevista com Elsa Ramos Paim, 2004)

Pelas palavras de Elsa Paim é possível perceber que uma das características dos primeiros anos de constituição da Escola mantinha-se presente, acompanhando as inovações e modificações adotadas: a preocupação em conhecer a realidade brasileira, em manter sempre contato com a população para uma atuação condizente com as condições sociais e as especificidades da política de saúde de cada região. Arlindo Fábio Gómez de Sousa, em seu depoimento, também ressalta a importância dos cursos descentralizados e de como viveu essa experiência:

Minha contribuição foi mais forte em relação aos cursos descentralizados, eu acho, (...) e a parte que mais empolgou. Eu dava 400 e tantas horas de aula por ano em seis ou sete estados brasileiros diferentes. Tinha um curso no Rio Grande do Sul de odontologia social que eu dava aula durante a Semana Santa. Então era segunda, terça, quarta até quinta-feira de manhã. Eu tinha que cumprir os créditos, não sei se eram trinta horas naquele tempo, então cumpria durante a Semana Santa. (Entrevista com Arlindo Fábio Gómez de Sousa, 2003)

Acompanhando este leque de mudanças que se iniciaram a partir do ano de 1975, foram elaboradas novas regulamentações para os cursos, reformulado o estatuto da Escola, novos quadros salariais estabelecidos, 
tudo conduzido principalmente por Arlindo Souza e Eduardo Costa. No bojo deste processo, foram também instituídas as bolsas de Treinamento Avançado em Serviço (TAS), como forma de preparação intensiva de recursos humanos em atividades que se realizavam na Ensp: avaliação de necessidades de recursos humanos para a saúde; tecnologia de preparação de diferentes categorias de recursos humanos para a saúde; estudos e pesquisas de interesse para o aperfeiçoamento tecnocientífico dos profissionais de saúde.

Esse modelo daria origem, em 1979, à implantação, na Ensp, do Programa de Residência Médica em Saúde Pública e Medicina Social, a partir de um acordo estabelecido com o Instituto Nacional de Previdência Médica e Assistência Social (Inamps), na qualidade de co-participantes do projeto que visava à formação de médicos como sólido preparo em medicina geral, além da indispensável formação em administração e planejamento em saúde, epidemiologia e ciências sociais aplicadas à saúde. Ela seria coordenada por Paulo Buss, que descreve esse processo:

Então fui ajudar a montar, a trabalhar as residências do Inamps. Porque eu comecei a trabalhar o TAS, o Treinamento Avançado em Serviço, que era uma espécie de residência, porém não tinha este nome. Mas o movimento da residência médica no Brasil se estruturou, e fui trabalhar na organização das residências do Inamps junto com o Nildo [Aguiar], que morreu, e a doutora Rosa Castelar. Eu propus ao Nildo que abríssemos uma residência em saúde pública, e então criamos um laço maior com a Escola. Criou-se a residência em saúde pública na Ensp, que foi um sucedâneo, digamos, do TAS. O grupo original era Tizuko, Eduardo Maranhão, Sherrine e eu (...).

Só pra vocês terem uma idéia, foram alunos dos dois primeiros programas pessoas do seguinte porte: Pedro Barbosa; o Dadá, Eduardo; Zulmira; Ivani, que agora está aqui no município; Sheila, que trabalha na escola; Chico Braga; a Dora, o Evandro Coutinho (...). Quer dizer, toda a geração que hoje é sênior na escola começou nessa residência. Vocês imaginam o que era: um grupo altamente politizado, vindo da Universidade Federal ou Uerj, altamente combativo e, claro, combatendo a própria residência. Não poderia ser de outra maneira. (Entrevista com Paulo Marchiori Buss, 2004)

No final dos anos de 1970, as atividades na área de pesquisa também se expandiram, demonstrando que a escola entrara definitivamente em uma nova fase. Foi realizada uma pesquisa sobre distribuição geográfica dos recursos humanos em saúde no território nacional, com o objetivo de
Tinha dois laboratórios de referência nacionais em variola para toda a campanha do Brasil: São Paulo, no Adolpho Lutz e o da Ensp, que era do Hermann, lá da escola. 0 laboratório de referência não foi do $10 \mathrm{C}$, na variola, foi da Ensp. Aqui no IOC, o que tinha era produção da vacina antivariólica, mas 0 diagnóstico era lá.

(Entrevista com Eduardo Costa, 2004) 
Projeto de hipertensão realizado no Rio Grande do Sul, 1978 -

Esfigmomanômetro de coluna de mercúrio adaptado para a pesquisa epidemiológica. Acervo Eduardo Costa/Coc. subsidiar a elaboração de modelos de currículos por objetivos e de material instrumental/convênio Instituto Presidente Castelo Branco - Serviço Federal de Processamento de Dados (IPCB/ Serpro). A atividade compreendeu levantamento e análise de dados relativos a 3.956 municípios brasileiros.

Em 1978 teve início outra importante atividade de pesquisa, por iniciativa do Departamento de Epidemiologia: o Inquérito de Hipertensão, realizado no Rio Grande do Sul. Maria do Carmo Leal, que havia ingressado no curso básico de saúde pública da Ensp em 1976, participaria deste projeto, coordenado por Eduardo Costa e que contou com a participação de outros profissionais da Escola, como Carlos Henrique Klein, Paulo Sabroza e José Wellington Araújo: o projeto acabou envolvendo todo o Departamento de Epidemiologia:

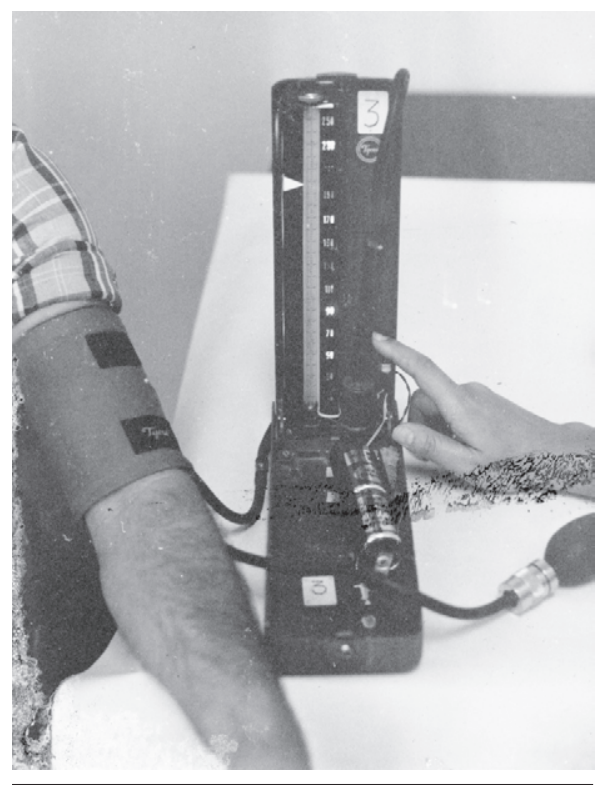

Foi o primeiro inquérito populacional de hipertensão arterial feito no Brasil. Um trabalho muito bem feito. O Eduardo estava fazendo doutorado na London School e desenhou esse estudo com uma orientação muito boa, além de já ser muito bom epidemiologista nessa época. Era um estudo transversal, um inquérito, mas bem feito porque a suposição inicial, que até hoje está em pauta na discussão científica e era a tese do Eduardo, era saber da importância do consumo 
de sal na determinação dos níveis pressóricos. É uma discussão interessantíssima que ainda está em pauta, e o que se sabe hoje em relação ao tema não se sabia naquela época.

(...)

Então foi um estudo muito bem feito. Eu aprendi muito a fazer pesquisa ali. Foi uma escola, entende? E foi importante porque o departamento todo se envolveu; os estatísticos aprenderam a manipular grandes bancos de dados (...). (Entrevista com Maria do Carmo Leal, 2004)

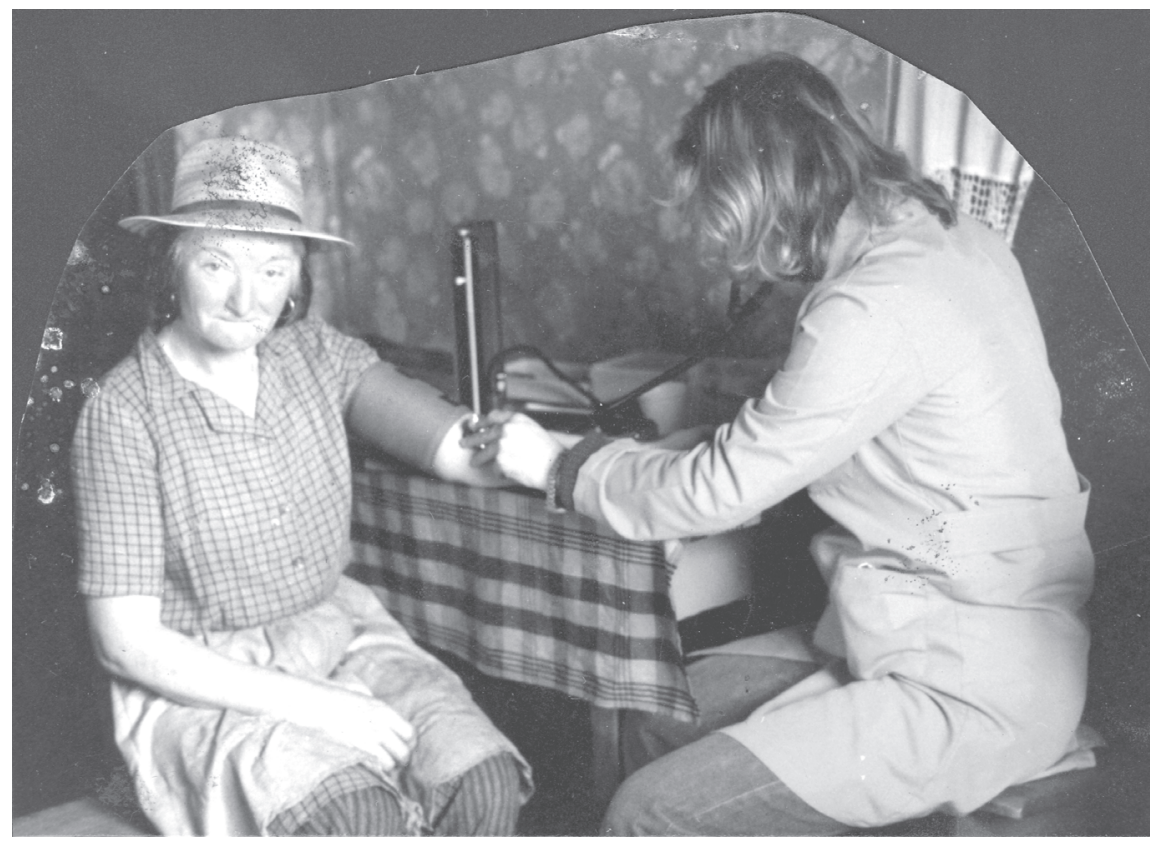

Com esta linha de atuação a Escola chegou à década de 1980 tendo como diretor Ernani Braga (1980-1983), que iniciou um processo de transformação orientada pelas recomendações da OMS aos países membros no que se refere a instituições de saúde pública. Foi substituído por Arlindo Fábio Gómez de Sousa, que dirigiu a Ensp até o ano de 1985, quando foi sucedido por Frederico Simões Barbosa.

Foram implementadas políticas que visavam a estreitar laços de cooperação com instituições nacionais de ensino e pesquisa em saúde, instituições de fomento à pesquisa como Conselho Nacional de Desenvolvimento Científico e Tecnológico (CNPq); Coordenação do Aperfeiçoamento de Pessoal de Nível Superior (Capes); Finep e também agências internacionais como a OMS/Opas e a Fundação Kellogg. Tais
Trabalho de campo - Projeto de hipertensão realizado no Rio Grande do Sul, 1978 - Acervo Eduardo Costa/Coc. 
Defesa de Mestrado de Maria do Carmo Leal, 1981. Na primeira fila da esquerda para a direita: Eduardo Costa, Ana Tambelini, Ernani Braga, Arlindo de Sousa, não identificado. $\mathrm{Na}$ segunda fila Luiz Fernando Ferreira, Miriam Struchiner, Paulo Sabroza. Acervo Particular Maria do Carmo Leal. articulações resultaram em financiamentos para projetos de pesquisa, auxílio da OMS para que os departamentos de Epidemiologia e de Ciências Sociais se tornassem referência nacional e internacional no apoio a preparação e aperfeiçoamento de profissionais de saúde de países africanos de língua portuguesa e na implementação de política de aperfeiçoamento dos membros docentes-pesquisadores em cursos no exterior. Foi também implementado em 1982 o Projeto Reunião, Análise e Difusão de Informações sobre Saúde (Radis) -, com o apoio da Secretaria de Ciência e Tecnologia, da Secretaria Geral do Ministério da Saúde, que visava a disseminar informações sobre aspectos socioeconômico-sanitários de forma a subsidiar o trabalho de planejamento de técnicos, sanitaristas, professores e estudantes da área de saúde pública.

Nesse momento, a Escola mantinha os seguintes cursos: curso de saúde pública, curso para engenheiros de saúde pública, cursos de pósgraduação (mestrado e doutorado), 14 cursos descentralizados e o programa de residência em saúde pública e medicina social. ${ }^{7}$

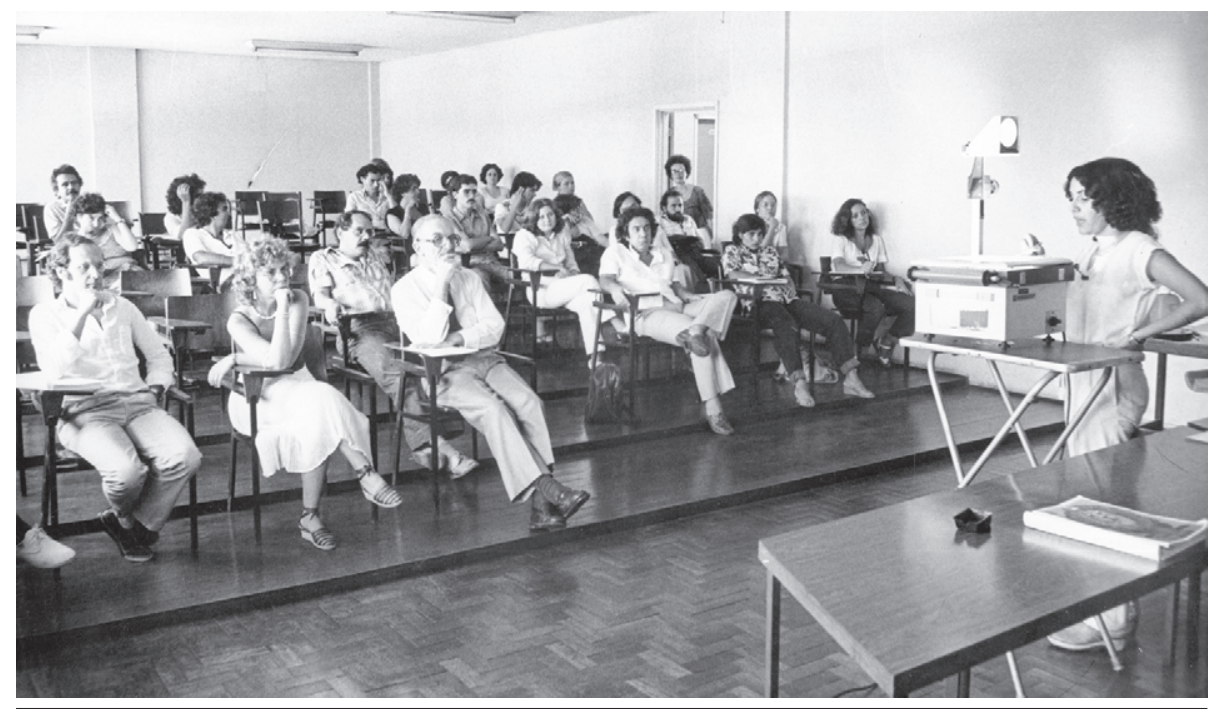

As áreas de concentração oferecidas pelo curso de especialização em saúde pública em 1980 epidemiologia, planejamento em saúde, odontologia social e laboratório de saúde pública foram oferecidas em 1982 como cursos de especialização. Neste ano, além da residência em saúde pública e medicina social, dos cursos de saúde pública, mestrado/doutorado e cursos descentralizados, a Ensp oferecia também: curso para engenheiros de saúde pública; curso de especialização em planejamento de saúde; curso de especialização em epidemiologia; curso de aperfeiçoamento para epidemiologistas da Sucam; curso nacional de pneumologia sanitária; curso de especialização em psiquiatria social; curso de especialização em laboratório de saúde pública; e curso para laboratoristas de análise de água. Ver relatórios da Ensp de 1980 e 1982, Fundo Ensp/Seção Direção, Casa de Oswaldo Cruz/Fiocruz. 
A Unidade de Treinamento Germano Sinval Faria, no início da década de 1980, acompanhou o movimento de integração interna, através da introdução de uma série de novas atividades com os departamentos da Ensp, e externa, ampliando o diálogo com as comunidades residentes próximas à Fiocruz. Assim, foram discutidas e avaliadas ações no campo da saúde mental, nutrição, recreação infantil, assistência odontológica, serviço social, vigilância epidemiológica e desenvolvimento da participação comunitária. Na época, a unidade concentrava as ações relativas aos serviços de saúde realizados pela Ensp, pois a antiga unidade de treinamento rural, o Posto Samuel Libânio, voltara a ser administrada pelo estado, desde 1975, quando a direção da Escola suspendeu o convênio que lhe permitia participar das atividades ali realizadas, sob o argumento de que a região de Vargem Grande, na qual se localizava o posto, perdera as características de área rural devido ao desenvolvimento local. As atenções da Escola se voltaram para Montes Claros (Minas Gerais), como uma área para treinamento rural.

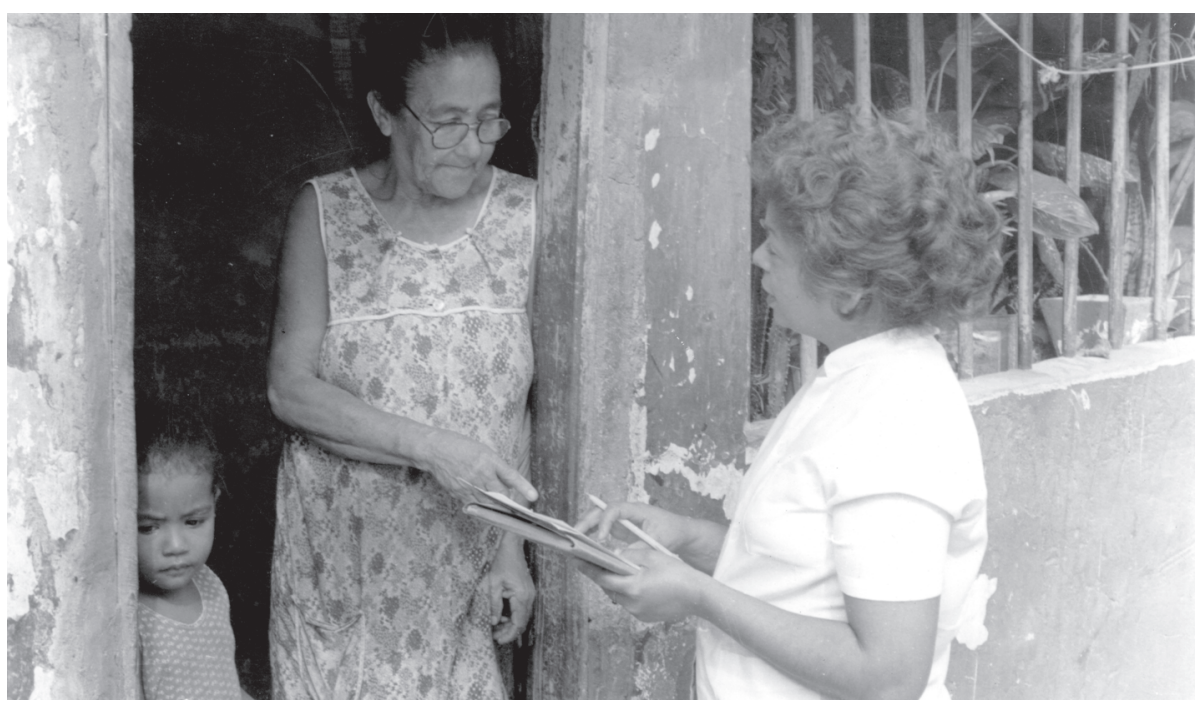

A Ensp participou também ativamente no apoio à estruturação e ao desenvolvimento do Programa Nacional de Imunização, ao Sistema Nacional de Vigilância Epidemiológica e na iniciativa de erradicação da poliomielite no Brasil, nas Américas, na África e Ásia. O Programa Ampliado de Imunização (PAI) foi desenvolvido a partir de um plano de ação PAI/Opas/Ensp, compreendendo a cooperação técnica com as secretarias municipais e estaduais de saúde; capacitação de pessoal;
Visitadora sanitária, Manguinhos, 1972. Foto: Cid Fayão. Acervo Ensp. 
preparação de material instrucional; manuais; normas técnicas etc. Essa cooperação foi um desdobramento da participação da Ensp/Fiocruz no Taller del Programa Ampliado de Inmunización (PAI) para Escuelas de Saúde Pública em Wasghington (1980) e patrocinado pelo PAI/Opas, em que se discutiu metodologia e conteúdo do programa, aprovando-se a inclusão do material nos cursos de saúde pública com os ajustes requeridos por cada país.

No âmbito dessas iniciativas, podemos incluir a participação da Ensp e de seus membros docentes na Abrasco,$^{8}$ que, como observamos, havia sido criada em 1979. Entre seus objetivos destacavam-se os de apoiar, articular e promover a comunicação entre as instituições de pesquisa e ensino da saúde coletiva e outros segmentos da sociedade civil, organizações governamentais e não-governamentais, incentivando e participando ativamente do debate nacional em torno das propostas da Reforma Sanitária.

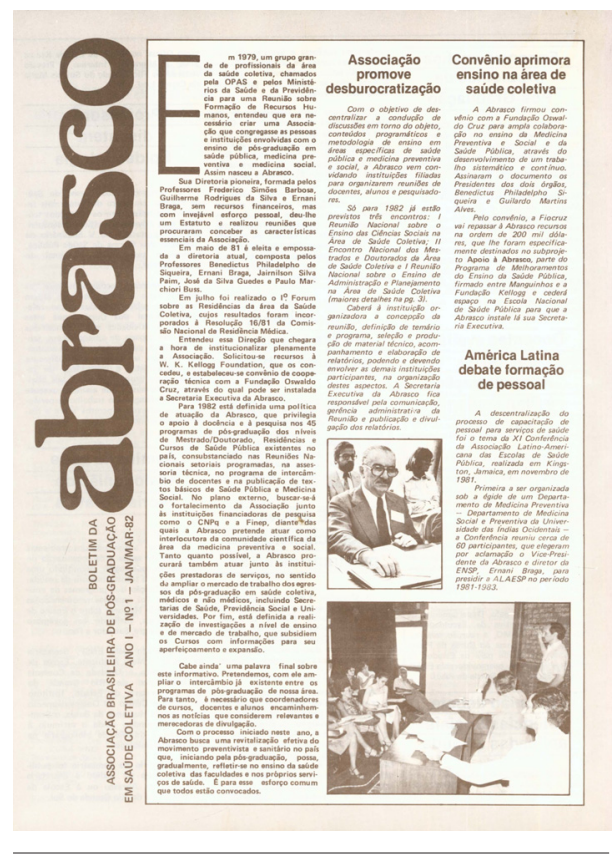

No cenário político que antecedeu a $8^{\text {a }}$ Conferência Nacional de Saúde, destacaram-se a campanha das Diretas Já e a vitória de Tancredo

\footnotetext{
8 Embora autônoma, a Abrasco foi instalada em 1982 mediante convênio com a Fiocruz, em espaço cedido pela Ensp e aí colocou em operação, sob a responsabilidade de um membro do corpo docente da instituição, sua secretaria executiva.
} 
Neves no Colégio Eleitoral, tendo como vice José Sarney. Iniciou-se, assim, em março de 1985, um período de transição democrática no qual novos canais de participação e negociação foram abertos, ainda que sob hegemonia de setores conservadores. No mesmo ano, assumiu a presidência da Fundação Oswaldo Cruz o sanitarista Sergio Arouca, indicado pelo presidente José Sarney e apoiado por movimento interno à Fiocruz e externo, com base em lideranças político-partidárias e do movimento sanitarista. Em sua gestão, foram instituídos mecanismos de gestão participativa $^{9}$ - com destaque para o Conselho Deliberativo e o Congresso Interno com delegados das unidades tecnocientíficas - e criadas novas unidades, departamentos ${ }^{10}$ e cursos de pós-graduação. Foram também reintegrados à instituição os pesquisadores cassados em 1970.

O período que se inaugura na história da Escola Nacional de Saúde Pública em 1985 esteve diretamente associado às mudanças que ocorreram na própria Fiocruz, com a posse de Sergio Arouca na presidência da instituição. Completava a Escola, naquele momento, 31 anos de existência jurídica, se considerarmos o estatuto legal de 1954, e 26 anos de efetivas atividades no campo do ensino e da formação em saúde pública, se contarmos os primeiros cursos realizados ainda em novembro de 1959. Havia passado por diversas alterações de cunho político e legislativo e contado com a colaboração de muitos profissionais, das mais diversas especializações e de diferentes instituições da área da saúde pública, que lhe permitiram consolidar-se como uma escola de referência e com papel reconhecido na história das políticas públicas de saúde no Brasil.

\footnotetext{
9 Destacam-se entre os principais mecanismos de gestão participativa o I Congresso Interno da Fiocruz, ocorrido em 1988, e a instituição de eleição para diretores de unidades.

10 Em 1985 foi criado, na Ensp, o Centro de Estudos da Saúde do Trabalhador e Ecologia Humana (Cesteh).
}

Na prova de seleção pra Pernambuco - aí já não sei se foi 82, 83, a bibliografia recomendada para a prova de seleção tinha alguma coisa que eles consideraram que era subversiva. E o Ernani assumiu. Veio o processo pra cá, e ele disse que a responsabilidade era do diretor da Escola Nacional de Saúde Pública. E os demais cursos de Saúde Pública se manifestaram. Então não só o Ernani foi extremamente positivo em trazer 'pra ele' a questão, como também os demais cursos descentralizados começaram a enviar correspondência ao ministro da Saúde dizendo pra ele: Atenção, porque os cursos descentralizados são importantes e a gente quer manter. Então a gente viu o que é que a gente aprendeu, que quanto mais nós tivéssemos vinculações com secretarias estaduais da Saúde e com universidades, maior garantia de permanência o nosso projeto tinha.

(Entrevista com Arlindo Fábio Gómez de Sousa, 2003) 


\section{ReFERÊNCIAS BIBLIOGRÁFICAS}

\section{FONTES ARQUIVISTICAS}

Casa de Oswaldo Cruz/Departamento de Arquivo e Documentação:

Fundo Escola Nacional de Saúde Pública/Seção Secretaria de Administração Geral.

Fundo Escola Nacional de Pública/Seção Direção.

Coleção História Administrativa da Fiocruz.

\section{LIVROS E PERIÓDICOS}

AROUCA, S. O Dilema Preventivista: contribuição para a compreensão e crítica da medicina preventiva. Rio de Janeiro: Fiocruz, 2003.

COSTA, N. R. \& MELO, M. A. Desenvolvimento sustentável, ajuste estrutural e política social: as estratégias da OMS/OPAS e do Banco Mundial para a atenção à saúde. Planejamento e Políticas Públicas, 11: 49-108, 1994.

ESCOREL, S. Reviravolta na Saúde: origem e articulação do movimento sanitário. Rio de Janeiro: Fiocruz, 1998.

FIOCRUZ. Tema. Programa Radis (Reunião, Análise e Difusão de Informações sobre Saúde), Escola Nacional de Saúde Pública, n. 20, fevereiro de 2003.

JOUVAL JR., H. E. Encontros de vida. Divulgação em Saúde para Debate, 28: 40-52, jul., 2003.

LIMA, N. T. O Brasil e a Organização Pan-Americana da Saúde: uma história de três dimensões. In: FINKELMAN, J. (Org.) Caminhos da Saúde Pública no Brasil. Rio de Janeiro: Fiocruz, 2002.

MACÊDO, C. G. Notas para uma História Recente da Saúde Pública na América Latina. Brasília: Opas, 1997.

PENA, M. V. J. Saúde nos planos nacionais de desenvolvimento. Dados, 16: 69-96, 1977.

RODRIGUEZ NETO, E. Memórias, memorial. Divulgação em Saúde para Debate, 28: 100, jul., 2003.

SANTOS, W. G. dos. A pós-revolução brasileira. In: JAGUARIBE, H. et al. (Orgs.) Brasil: sociedade democrática. Rio de Janeiro: José Olympio, 1985.

TEIXEIRA, S. M. F. As ciências sociais em saúde no Brasil. In: NUNES, E. D. (Org.). As Ciências Sociais em Saúde na América Latina: tendências e perspectivas. Brasília, Opas/OMS, 1985.

UCHÔA, H. W. \& PAIM, E. R. A experiência da Ensp na descentralização dos cursos de saúde pública. In: ABRASCO. Ensino da Saúde Pública, Medicina Preventiva e Social no Brasil. Rio de Janeiro: Nutes/Clates/Ensp/Abrasco, 1982. v.1. 


\section{BibLIOGRAFIA}

ALMEIDA, C. Saúde e eqüidade nas reformas contemporâneas. Saúde em Debate, 24(54): 6-21, jan./abr., 2000.

BARBOSA, F. S. A Escola Nacional de Saúde Pública ao fim deste século. Cadernos de Saúde Pública, 4(4): 446-450, out./dez., 1988.

BUSS, P. M. Promoção e educação em saúde no âmbito da Escola de Governo em Saúde da Escola Nacional de Saúde Pública. Cadernos de Saúde Pública, 15 (supl. 2), 1999.

BUSS, P. M. A experiência comunitária da Fiocruz: desenvolvimento local integrado e sustentável em Manguinhos, Rio de Janeiro. Saúde em Debate, 24: 31-43, maio/ ago., 2000.

FIOCRUZ. Gestão de saúde: curso de aperfeiçoamento para dirigentes municipais de saúde: programa de educação à distância. Rio de Janeiro/Brasília: Fiocruz/ UNB, 1998.

FONSECA, C. As campanhas sanitárias e o Ministério da Saúde, 1953-1990. In: BENCHIMOL, J. L. (Coord.). Febre Amarela: a doença e a vacina, uma história inacabada. Rio de Janeiro: Fiocruz, 2001.

OLIVEIRA, J. A. A saúde pública hoje: notas para um debate sobre conjuntura em saúde e a situação da Ensp ao seu interior. Cadernos de Saúde Pública, 4(3): 326333, jul./set., 1988.

ORGANIZAÇÃO PAN-AMERICANA DA SAÚDE (OPAS). Notas para uma história Recente da Saúde Pública na América Latina. Brasília:Opas/OMS, 1997.

ORGANIZAÇÃO PAN-AMERICANA DA SAÚDE (OPAS). A Saúde no Brasil. Brasília: Opas/OMS, 1998.

SABROZA, P. C. Saúde Pública: procurando os limites da crise. Rio de Janeiro: Departamento de Grandes Endemias/ Ensp/Fiocruz, ago.1994, 17p. (Mimeo.) 


\section{A Escola Nacional de Saúde Pública Sergio Arouca: UM LABORATÓRIO DE IDÉIAS PARA A SAÚDE}

Paulo Roberto Elian dos Santos Verônica Martins de Brito Nísia Trindade Lima Cristina M. O. Fonseca

\section{INTRODUÇÃO}

$\mathrm{Na}$ conjuntura do final da década de 1980, a Ensp desempenhou papel importante no processo de ampla reforma que visava à implementação do Sistema Único de Saúde (SUS), estabelecido pela Constituição Federal de 1988. Nesse período, buscou, em sua atuação, sintonia e capacidade de interlocução com os programas do Ministério da Saúde (MS) e secretarias, ao mesmo tempo que redirecionava seu objeto de atenção e seus quadros eram chamados a participar diretamente da gestão pública, ocupando funções de coordenação em programas nacionais, passando a influenciar decisões em áreas como atenção básica, saúde do trabalhador, controle de endemias, políticas de medicamentos, vigilância epidemiológica, rede de laboratórios de saúde pública, políticas de saneamento, entre outras.

Após essa fase, nos anos de 1990, a Escola pareceu 'voltar-se mais para dentro', com o objetivo de "aprofundar certas questões, testar a validade de antigas convicções e principalmente aumentar sua capacidade de contribuir para a produção acadêmica" (Sabroza, 1994: 12). Nos anos mais recentes, a presença de seus quadros em funções de gestão pública e seu papel na formação de recursos humanos qualificados para a atividade acadêmica e para a gestão do sistema de saúde têm se intensificado.

A década de $1990^{1}$ iniciou-se com um grande desafio para a área de saúde no Brasil: implementar as conquistas formalizadas no texto

Nos primeiros anos da década de 1990 destacam-se algumas importantes iniciativas. Em agosto de 1994 foi realizada a 1ª Conferência Pan-Americana de Educação em Saúde Pública com o tema Democracia e Equidade: repensando a saúde pública. Promoção conjunta das duas associações continentais, a Associação Latino-Americana e do Caribe de Educação em Saúde Pública (Alaesp) e a Association of Schools of Public Health (ASPH), o evento destinava-se a debater o papel das 
constitucional. À Escola coube reavaliar o seu papel e adequá-lo ao novo contexto. Apesar das importantes conquistas incorporadas à nova Constituição, o período, inaugurado pelo governo Collor de Mello (19901992), trouxe sérias dificuldades para a implementação das diretrizes do SUS. Em agosto de 1992, em um cenário marcado por crise ética e política, foi realizada a $9^{\text {a }}$ Conferência Nacional de Saúde, que tinha como desafio apontar caminhos para a superação da grande distância entre princípios, diretrizes e normas expressos na Constituição de 1988 e nas leis complementares de 1990 e a forma como estava sendo implementado o SUS.

Indo além dos problemas relativos à conjuntura política inicial da década de 1990, é possível indicar um quadro internacional bastante desfavorável à consolidação de políticas sociais abrangentes e redistributivas. Em linhas gerais, desde os anos de 1980, foi se elaborando uma agenda para o setor saúde, formulada principalmente pelo Banco Mundial e pelo Fundo Monetário Internacional (FMI), na qual à esfera pública caberia uma ação direcionada apenas para grupos sociais impossibilitados de responder às ofertas de mercado para o provimento desses serviços. Daí se afirmar que a reforma sanitária brasileira tem sido "construída na contra-corrente das tendências hegemônicas da reforma dos Estados" (Levcovitz, Lima \& Machado, 2001: 270). Tal afirmação não deve implicar, entretanto, atribuir-se menor importância às tensões e contradições existentes no país e referidas aos distintos projetos e interesses envolvidos na definição e implementação das políticas de saúde.

No Brasil da década de 1990, a despeito de o SUS estar orientado por princípios como universalidade, integralidade, hierarquização, descentralização e participação da sociedade, sua implementação ocorreu em um quadro adverso à adoção de políticas sociais universais. Entre outros obstáculos, podem ser destacadas medidas voltadas para a redução do tamanho do Estado e do quadro do funcionalismo público e mudanças

escolas de saúde pública do continente diante das condições de saúde e das recentes transformações dos sistemas de saúde que se verificavam em inúmeros países americanos, além de estabelecer um processo de cooperação entre estas instituições. Em outubro ocorreu a $1^{\text {a }}$ Conferência Nacional de Ciência e Tecnologia em Saúde. No mesmo ano, realizou-se a Conferência Interamericana sobre Violência, Sociedade e Saúde, promovida pela Opas. O Ministério da Saúde inicia, também em 1994, a implementação do Programa Saúde da Família, voltado para as ações de prevenção, promoção e recuperação da saúde das pessoas, de forma integral e contínua, por meio do atendimento prestado na unidade básica de saúde ou no domicílio, pelos profissionais (médicos, enfermeiros, auxiliares de enfermagem e agentes comunitários de saúde) que compõem as equipes de saúde da família. Outro programa do ministério que merece destaque é o de Agentes Comunitários de Saúde, além de div rrsas ações programáticas de âmbito nacional voltadas para a atenção integral à saúde da mulher, da criança e do adolescente (Opas/OMS, 1998). 
significativas nas relações de trabalho - com aumento do segmento informal, do desemprego estrutural e formas precárias de vínculos no próprio setor público, com implicações para a qualidade da atenção à saúde.

Há que se considerar também dificuldades estruturais que vêm sendo apontadas pelos estudiosos desse processo e que nos remetem à história política e social do país, em particular no que se refere ao quadro de desigualdades sociais, aos contrastes regionais e às características da dinâmica política de um regime federalista com forte ênfase na esfera central de decisão. No âmbito específico da área de saúde, destaca-se a força do modelo médico-assistencial com base no setor privado (Cordeiro, 2001; Bahia, 2001).

Das diretrizes do SUS, a descentralização tem sido indicada como a que mais se efetivou. Comparativamente a outras áreas de política social como educação, assistência social e habitação, a saúde foi o setor em que melhor se delineou um modelo descentralizador. Entretanto, alguns autores observam que o processo de descentralização na área de saúde, nos anos 1990, deve ser visto como processo parcial, indicando-se inúmeras contradições na normalização das responsabilidades e das fontes de financiamento do sistema de saúde entre as esferas municipal, estadual e federal (Elias, 2001). Ressalte-se a necessidade de uma avaliação política do processo de descentralização em sua relação com o modelo federativo definido pela Constituição de 1988 (Cohn, 2001; Vianna, 2001; Elias, 2001).

Deve-se considerar, ainda, que, na proposta política de reforma da saúde no Brasil, a descentralização sempre esteve atrelada às estratégias de democratização e incorporação de novos atores sociais (Teixeira, 1990; Gershman, 1995). Uma das mudanças mais significativas decorrentes da criação do SUS consistiu no estabelecimento de mecanismos decisórios que fortaleceram instâncias colegiadas - com destaque para os conselhos municipais - e a representação dos diferentes atores envolvidos no sistema de saúde.

Durante a década de 1990 e os primeiros anos do novo século, a Ensp participou, ao lado de outras instituições e atores sociais, do esforço de reflexão acadêmica e construção política relativos à recente experiência do SUS. Não caberia nos limites deste texto detalhar a participação de seus quadros profissionais e ex-alunos na formulação e implementação de políticas, aspecto bastante expressivo dessa história. Outro aspecto importante refere-se à consolidação da pós-graduação da Ensp, reafirmando sua condição de maior instituição de ensino das Américas voltada para a saúde pública. A avaliação de políticas públicas e a construção de novos
0 Hélio Uchôa também dava aula de odontologia que, aliás, foi uma coisa que a Escola perdeu, que a Escola já teve importantíssima e que nós perdemos no tempo. Acho que a gente tem que recuperar aquilo.

(Entrevista com Maria do Carmo Leal, falando sobre o curso básico de saúde pública em 1976) 
modelos de formação, como a Escola de Governo em Saúde, inserem-se igualmente entre as ações priorizadas pela Escola nos últimos anos. O balanço desse conjunto diversificado de iniciativas e experiências consiste em importante tarefa, tanto para seu quadro de profissionais como para todos os interessados em avaliar as relações entre pesquisa, ensino, serviços e implementação de políticas públicas.

Mas não apenas no que se refere à implementação do SUS colocam-se questões e novos desafios para a Ensp. O período que se iniciou em 1985, marcado pela redemocratização política do país, foi também caracterizado pela progressiva ampliação do conceito de saúde, com a valorização de perspectivas interdisciplinares, novos temas e novas abordagens. Tal ampliação, como se sabe, não se verifica sem que ocorram tensões e conflitos em torno de idéias, programas e diretrizes institucionais. Uma perspectiva menos interna à abordagem de diferenças e tensões pode contribuir para visão mais ampla sobre esses novos desafios. Temas como desenvolvimento humano, ${ }^{2}$ relações entre saúde e ambiente, ${ }^{3}$ promoção da saúde, saúde de grupos específicos, novos desafios no campo da bioética, redefinições no conceito de saúde mental - apenas para citar alguns exemplos - e sua explicitação em uma agenda mais ampla, inclusive no âmbito internacional, indicam a complexidade com a qual os programas de pesquisa e formação de recursos humanos em saúde necessariamente têm de lidar e os cuidados ante qualquer tentativa de reducionismo. A pluralidade de perspectivas, formações profissionais e projetos para a saúde é parte essencial da história da Ensp.

2 No plano externo, em 1990, o Programa das Nações Unidas para o Desenvolvimento (PNUD) lançava o primeiro relatório sobre o desenvolvimento humano (Macêdo, 1997). A noção de desenvolvimento humano como síntese do desenvolvimento, ainda que com importantes antecedentes históricos, está baseada no trabalho do economista indiano Amartia Zen.

3 Cabe registrar também a realização da Conferência das Nações Unidas sobre o Ambiente e o Desenvolvimento (Unced), realizada no Rio de Janeiro em junho de 1992, que reafirmava a importância do ambiente e de sua proteção e uso adequado para o desenvolvimento, retomando o alerta de Estocolmo em 1972. Dentre o conjunto de acordos e compromissos coletivos firmados entre os chefes de governo ali presentes, destaca-se a Declaração do Rio sobre Meio Ambiente e Desenvolvimento, que continha 27 princípios sobre os direitos e obrigações dos Estados, e a Agenda 21, que constituía um programa de ação voltado para a implementação dos princípios estabelecidos na Declaração do Rio. É possível identificar uma ampla interface entre a Agenda 21 e a saúde, uma vez que se buscava estabelecer uma relação significativa entre a deterioração ou melhoria das condições ambientais e seus impactos nas condições de vida e saúde dos seres humanos. 


\section{Novos Tempos: a EnSP NO PERÍOdo de 1985-2004}

A partir de 1985, com a nomeação de Sergio Arouca para a presidência da Fiocruz, muitas das idéias defendidas no âmbito interno à Escola puderam se expressar e viabilizar no contexto institucional mais amplo. Propostas de gestão participativa, ampliação da agenda de pesquisa a partir de abordagens interdisciplinares, ênfase em programas de difusão da informação científica e de formação de recursos humanos em diferentes níveis de ensino, entre outras ações inovadoras, passaram a integrar as novas diretrizes institucionais.

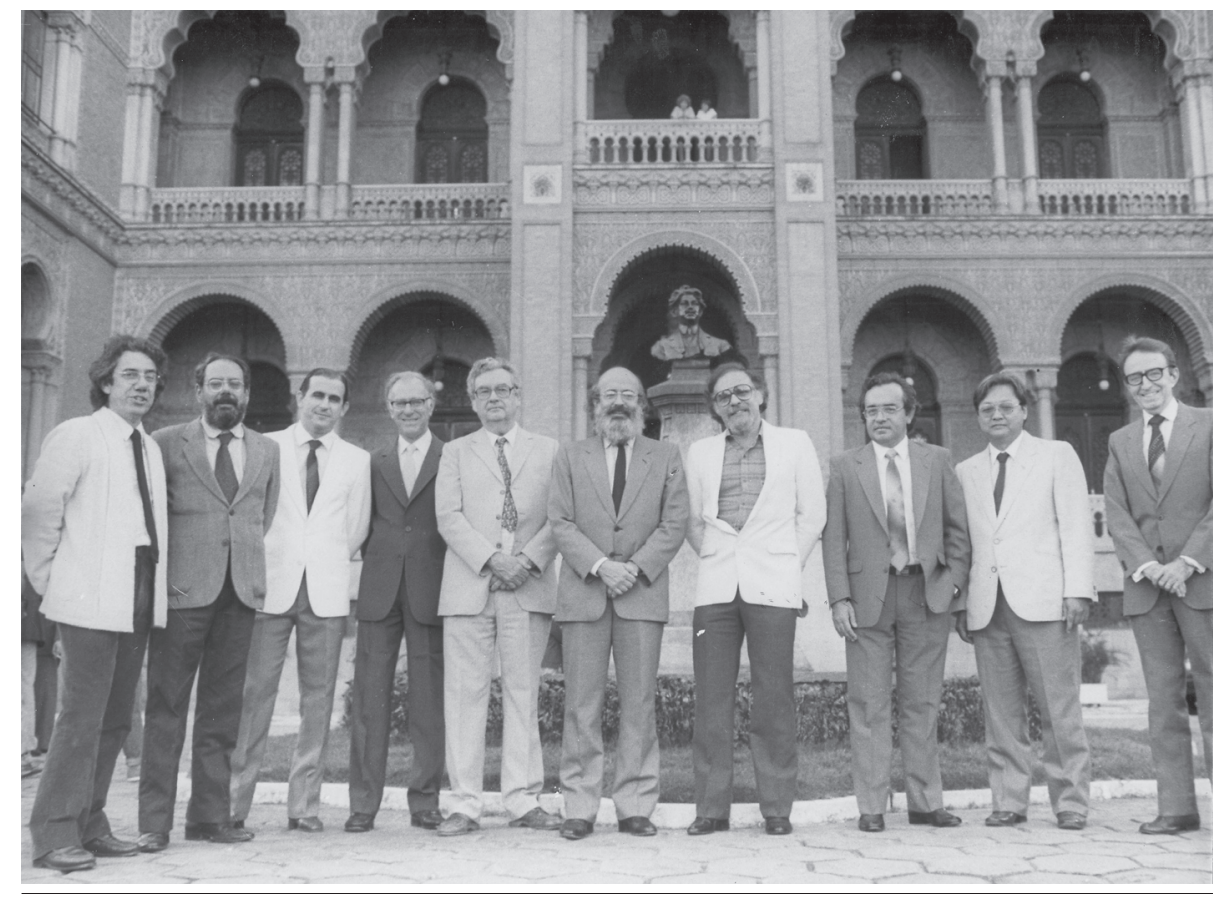

A combinação de um processo democrático interno com ampliação de recursos permitiu à Escola uma série de iniciativas que garantiram avanços nos programas de pesquisa e de ensino. Para Paulo Buss, vice-diretor na gestão de Frederico Simões Barbosa (1985-1989), o Programa de Apoio à Reforma Sanitária (Pares), a eleição da diretoria, o convênio com o Instituto Nacional de Assistência Médica e Previdência Social (Inamps) e o programa de Pesquisador Visitante foram ações importantes que contribuíram também para a reestruturação do programa de pós-graduação.

A gestão de Frederico Simões Barbosa foi a primeira na Ensp a resultar de um processo eletivo. De acordo com Paulo Buss, a eleição
Posse dos vice-presidentes e diretores da gestão Arouca em 24 de maio de 1985. Da esquerda para a direita: Arlindo Fábio Gómez de Sousa (vice-presidente de Desenvolvimento); Luiz Fernando da Rocha Ferreira da Silva (vice-presidente de Recursos Humanos); Paulo Alberto Mafra Boechat (diretor do Instituto Fernandes Figueira); Luiz Rey (superintendente do Instituto Nacional de Controle de Qualidade em Saúde); Frederico Simões Barbosa (diretor da Escola Nacional de Saúde Pública); Antonio Sergio da Silva Arouca (presidente da Fundação Oswaldo Cruz); Naftale Katz (diretor do Centro de Pesquisas René Rachou); Carlos Médicis Morel (vice-presidente de Pesquisa); Akira Homma (superintendente de Bio-Manguinhos); Paulo Barragat (assessor da presidência). Acervo Comunicação Social Fiocruz. 
correspondeu ao momento político vivido pela Fiocruz após a nomeação de Sergio Arouca para a presidência, que, por sua vez, derivou de ampla mobilização política:

A gente ficava até nove horas da noite ligando pra deputado (...) ligava e pedia: 'Manda carta, manda (...)'. Na época acho que era só fax; não tinha e-mail nem celular (...) Aí conseguimos emplacar na Nova República. Quando aconteceu isso, o Arouca imediatamente sugeriu que a gente fizesse eleição na escola. Aquela história de criar independência, de uma instituição mais participativa. E me lembro como se fosse hoje: eu ficava na minha sala na Abrasco, no segundo andar. (Entrevista com Paulo Marchiori Buss, 2004)

As iniciativas implementadas durante essa gestão contribuíram para fortalecer a posição da Ensp no cenário acadêmico e também na oferta de informação especializada de qualidade, através da difusão e disseminação de textos acadêmicos e técnicos e da promoção de eventos nos quais os profissionais da saúde pública pudessem se atualizar e debater as questões relacionadas à área. Entre essas iniciativas destacamse o Pares, que contou com suporte da Fundação Kellogg graças à intermediação de Mário Chaves colaborador da Escola no período compreendido entre 1986-1989. Convidado por Sergio Arouca para elaborar o programa, Mário Chaves destacou que a concepção do projeto enfatizava o trabalho com a comunidade do bairro de Manguinhos, dele participando também os diversos departamentos da Escola. Com um volume de recursos significativos repassados pela Kellogg, a Ensp pôde desenvolver tecnologias apropriadas à gestão e às práticas de saúde no âmbito dos Sistemas Locais de Saúde.

O Pares iniciou suas atividades com a análise dos modelos municipais/distritais de atenção à saúde, a cargo dos departamentos estaduais de saúde, sendo também responsável pela criação de um laboratório de tecnologias educacionais (hoje Secretaria de Desenvolvimento EduacionalSDE), do parque gráfico e da modernização da biblioteca Lincoln de Freitas Filho (Fiocruz, 2003). Financiou também a implementação do Programa de Educação Continuada (PEC/Ensp), voltado para a produção de material impresso destinado a apoiar o desenvolvimento dos profissionais da área da saúde pública em suas atividade de ensino, pesquisa e extensão, e a expansão do Centro de Documentação (Cedoc). Sua linha editorial incluía o Boletim da Escola Nacional de Saúde Pública, textos de apoio, Cadernos de Saúde Pública, material instrucional - manuais, normas técnicas do Programa Ampliado de Imunização (PAI) -, entre outros. 


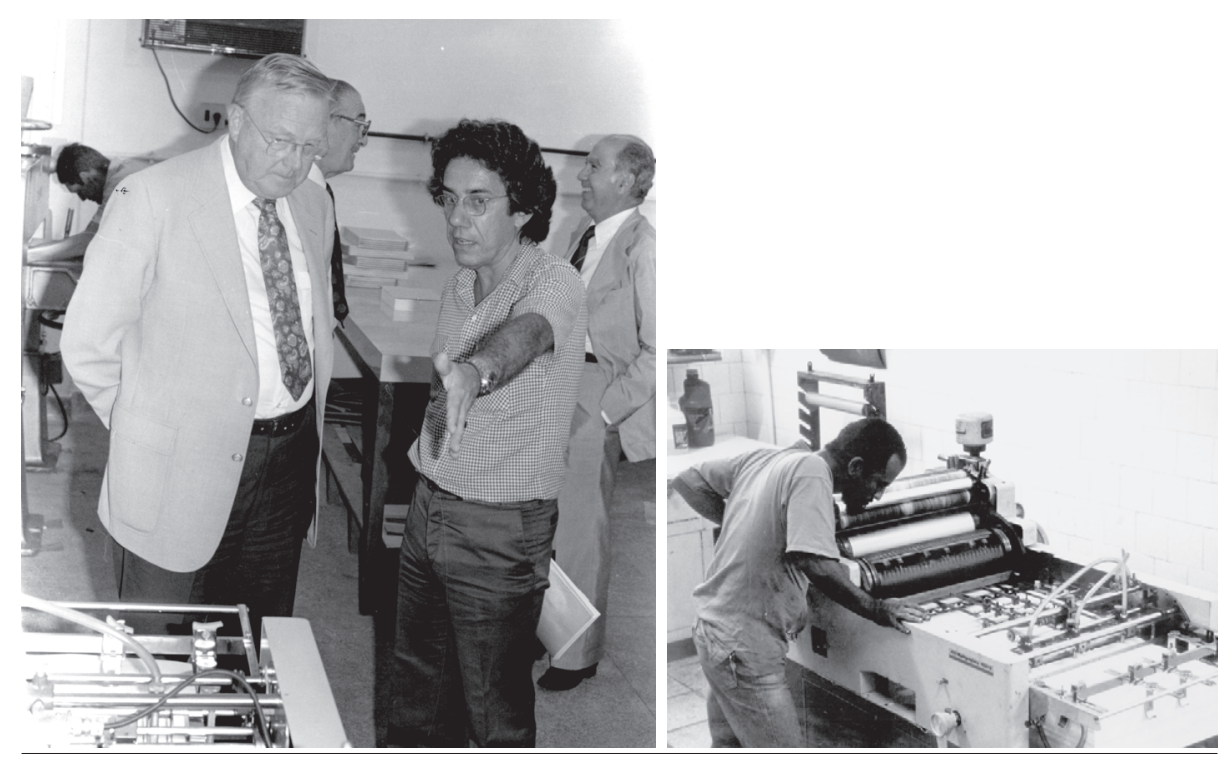

Além de Sergio Arouca, a partir de 1985 outros participantes do movimento sanitarista - que, como se sabe, compreendia divisões políticoideológicas significativas - passaram a ter a oportunidade de exercer cargos de suma importância no sistema de saúde. Muitos já haviam ocupado posições de destaque ainda no contexto do regime autoritário, e a transição para o regime democrático não implicou superação de obstáculos, muitos dos quais relacionados a uma tradição administrativa que impunha inúmeras dificuldades às reformulações propostas (Oliveira, 1989).

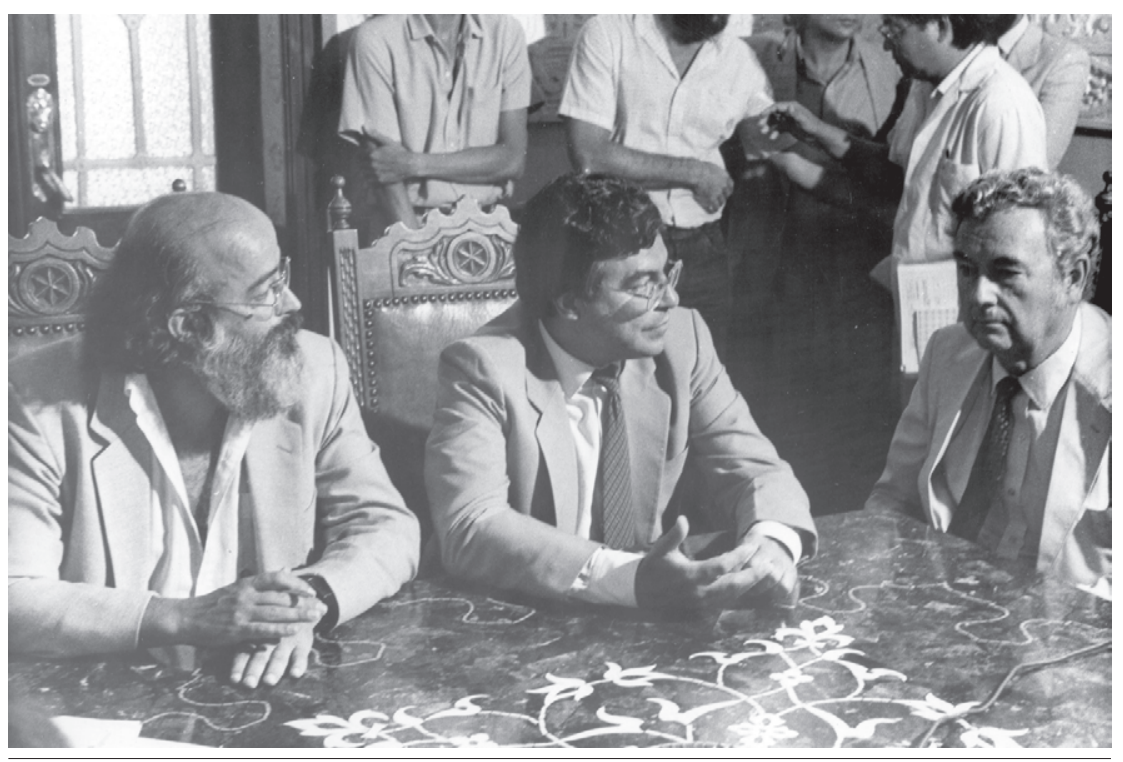

Iํ plano - da esquerda para direita: diretor da Fundação Kellogg e Arlindo Fábio Gómez, diretor da Ensp; 2ำ plano - da esquerda para direita: Ernani Braga e Mário Chaves nas instalações do PEC, s.d.

Gráfica do Programa de Educação Continuada, s.d.

Fotos: Cid Fayão. Acervo Ensp.
Da esquerda para a direita: Antonio Sergio Arouca (presidente Fundação Oswaldo Cruz), Hésio Cordeiro (presidente do Instituto Nacional de Previdência e Assistência Social) e Frederico Simões Barbosa (diretor da Escola Nacional de Saúde Pública) em reunião na Fiocruz, 1985-1989. Acervo Comunicação Social Fiocruz. 
Debate popular sobre saúde. Encontro Preparatório para a $8^{\mathrm{a}}$ Conferência Nacional de Saúde. Maceió, 15 a 17 dez. 1985. Foto: Adailsom Calheiros. Acervo: Casa de Oswaldo Cruz. Departamento de Arquivo e Documentação. Coleção 8aㅡ Conferência Nacional de Saúde.
Com a indicação do sanitarista Hésio Cordeiro, também figura de destaque do movimento sanitarista, para assumir a presidência do Inamps, a Fiocruz, ainda sob a gestão de Sergio Arouca, estabeleceu um importante convênio de cooperação técnica com esse órgão, com o objetivo de promover cursos e pesquisas que contribuíssem para o desenvolvimento de processos institucionais de recursos humanos nos serviços de saúde. A iniciativa teve em vista compatibilizar a atuação dos profissionais de saúde com os objetivos consignados pelo movimento da Reforma Sanitária, por meio, por exemplo, de sua capacitação para funções de planejamento, gerenciamento, direção e chefia de sistemas e instituições de saúde, bem como de aperfeiçoamento de docentes e pesquisadores no planejamento e na administração em saúde.

Foi esse o cenário de participação efetiva da Ensp na construção e implementação do projeto da Reforma Sanitária. No fórum da $8^{\mathrm{a}}$ Conferência Nacional de Saúde, em março de 1986, discutiram-se teses que sublinhavam a importância da participação popular e do controle social nesse processo. A Comissão Nacional da Reforma Sanitária, criada após a conferência, atuou de forma a ampliar o debate estabelecendo interlocuções com sindicatos, associações de moradores, igrejas, partidos políticos e setor privado, este responsável por $85 \%$ dos leitos hospitalares do país, na época. Tais interlocuções geraram emendas populares que legitimaram as teses defendidas na conferência e contribuíram na elaboração do capítulo sobre saúde da Constituição de 1988.

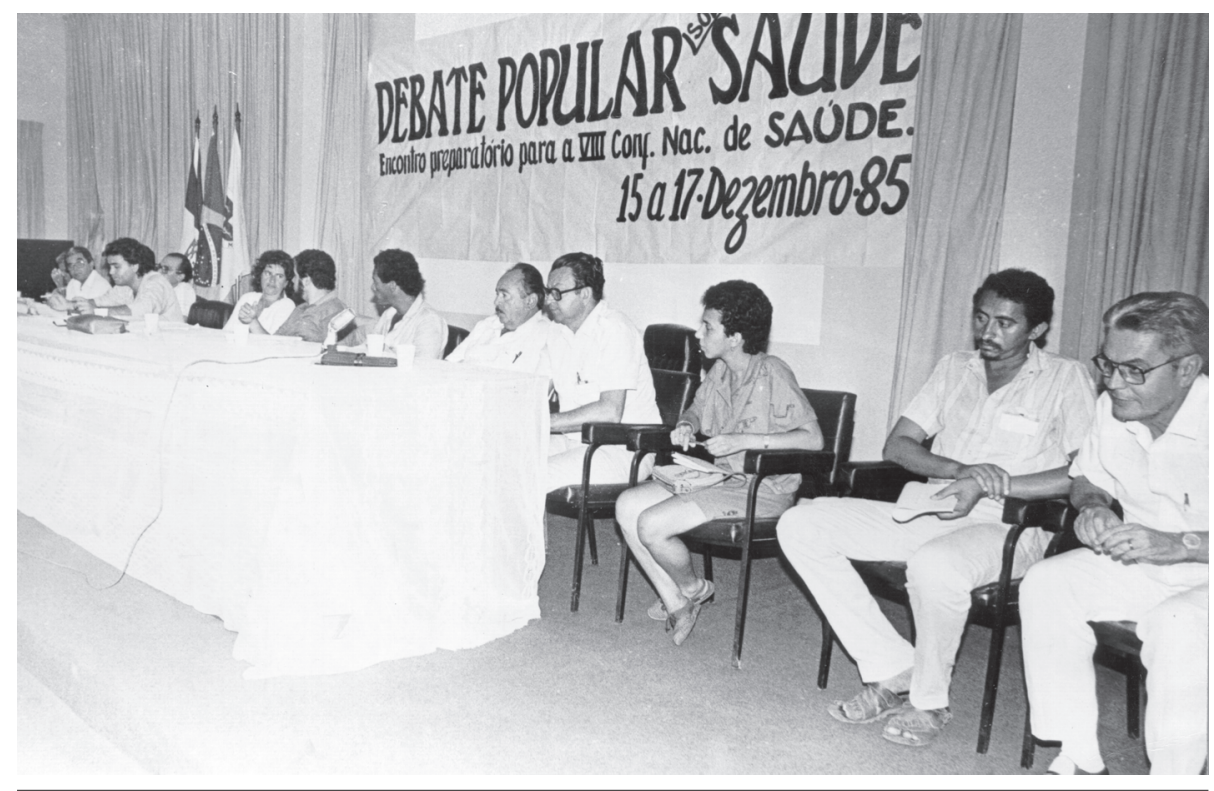




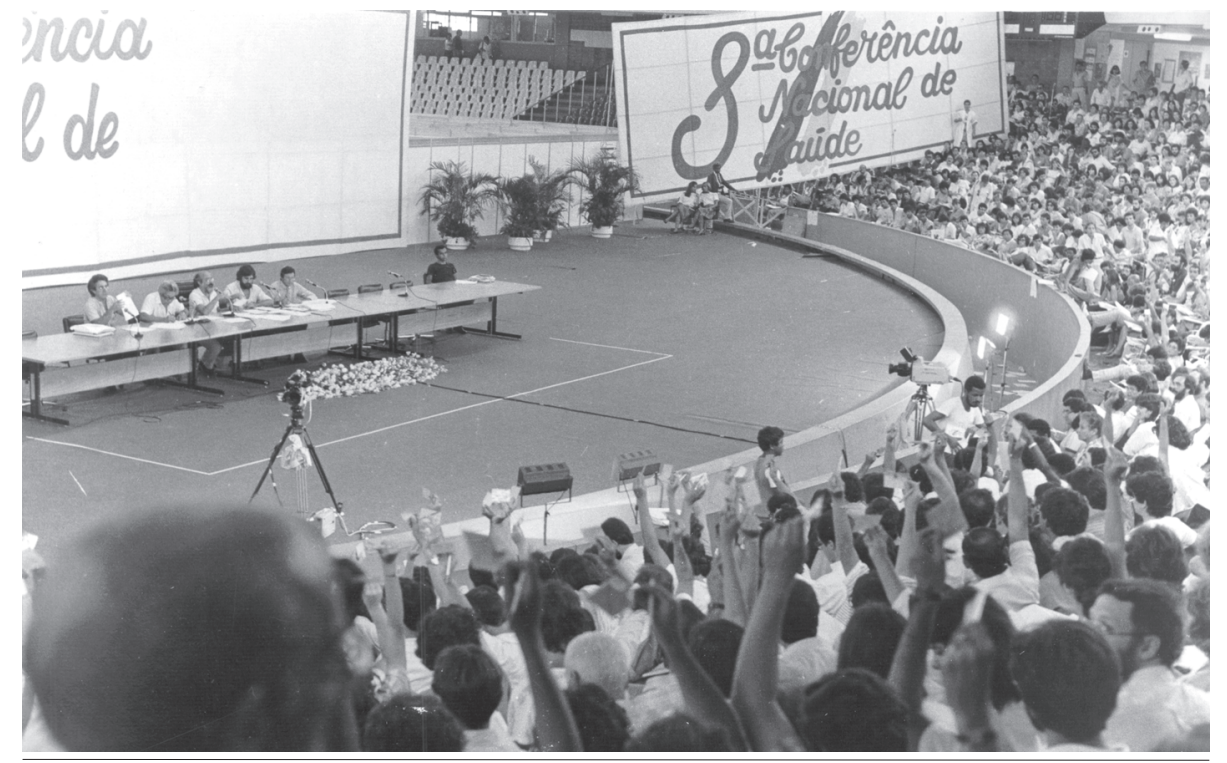

Em 1990, durante a primeira gestão de Paulo Buss como diretor da Ensp (1989-1993), foi reaberto o doutorado, a partir do trabalho desenvolvido por Maria Cecília Minayo, que coordenou a pós-graduação e criou uma comissão encarregada de reestruturar tanto o doutorado como o mestrado. Segundo Adauto Araújo, diretor da escola entre 1994 e 1998, a configuração atual do Programa de Pós-Graduação em Saúde Pública da Ensp $^{4}$ teve como ponto de partida esta reformulação, realizada no início da década de 1990. Como parte dessa estratégia, definiu-se como um dos eixos prioritários a formação de doutores no país e, sobretudo, no exterior. Priorizaram-se investimentos na estruturação e qualificação dos quadros acadêmicos da Ensp com o propósito de obter, a médio e longo prazos, melhoria da qualidade de ensino e padrões de formação dos alunos, cuja maioria era formada por profissionais e gestores de saúde.

$\mathrm{Na}$ gestão de Adauto Araújo, intensificaram-se os investimentos na pós-graduação, e diversas outras iniciativas destinadas à formação de recursos humanos começaram a ser esboçadas, como os cursos de mestrado profissional. Novas frentes de atuação desse período foram a criação da
Plenária da $8^{\text {a }}$ Conferência Nacional de Saúde. Brasília, mar., 1986. Foto: Álvaro Pedreira. Acervo: Casa de Oswaldo Cruz. Departamento de Arquivo e Documentação. Coleção $8^{a}$ Conferência Nacional de Saúde.

4 Atualmente a Ensp conta em seus quadros com 141 doutores, dos quais 82 atuam como docentes da pós-graduação stricto sensu estruturado em oito subáreas de concentração: planejamento e gestão de sistemas e serviços de saúde; epidemiologia geral; endemias, ambiente e sociedade; saúde e sociedade; saneamento ambiental; saúde, trabalho e ambiente; toxicologia ocupacional/ ambiental; e políticas públicas e saúde. Os demais atuam nos cursos lato sensu. Ver (Entrevista com Adauto Araújo, 2004) 
Fundação de Ensino, Pesquisa, Desenvolvimento Tecnológico e Cooperação à Escola Nacional de Saúde Pública (Fensptec) e as primeiras formulações para um Programa de Ensino a Distância. De acordo com o depoimento de Paulo Buss relativo à sua segunda gestão como diretor da Ensp:

O Adauto já tinha lançado no final da gestão dele duas iniciativas importantes: a Ensptec, depois Fenpstec - que nos permitia, por força de lei, uma cobertura para receber recursos externos e contratar e remunerar pessoas - e a educação a distância (...). Eu tive o privilégio de herdar essas duas propostas, aprofundá-las e implementá-las de fato. E somamos a elas outras duas: a gestão da diversidade, pluralidade e qualidade de conhecimento e intervenções que a Escola podia realizar; e a estratégia da Escola de Governo, que era uma idéia de comprometer-se com a geração de inovações para o Sistema Único de Saúde na sua face de saúde pública. (Entrevista com Paulo Marchiori Buss, 2004)

Não obstante as dúvidas e críticas que pairavam com relação à iniciativa, a Fensptec surgiu para a captação de recursos destinados à realização de projetos, além de organizar e normalizar as atividades de consultoria e prestação de serviços de profissionais da unidade, até então sem qualquer acompanhamento e avaliação por parte das chefias dos departamentos e das direções. Ao mesmo tempo, previa-se a obtenção de remuneração partilhada entre os membros das equipes envolvidas nos projetos. Posteriormente, o $3^{\circ}$ Congresso Interno, realizado em 1998, deliberou a transformação da Fensptec em Fundação para o Desenvolvimento Científico e Tecnológico em Saúde (Fiotec), voltada para estimular, fomentar e apoiar o desempenho das inúmeras funções realizadas pelo conjunto das unidades da Fiocruz.

A discussão em torno de políticas de incentivo, não limitadas à captação de recursos mediante projetos, permanece na instituição e provavelmente seria colocada em termos mais adequados se fossem avaliadas ações que guardem alguma semelhança com os propósitos iniciais da Fensptec, podendo-se mencionar, entre outras, as discussões que vêm orientando o debate sobre a lei de inovação.

O papel da saúde pública nos anos 1990, na visão de seus profissionais e quadros dirigentes, deveria ser redefinido de modo a combinar as perspectivas mais tradicionais, centradas em intervenções qualificadas tecnicamente, com um marco explicativo mais amplo que permitisse, inclusive, a mudança de certas práticas tradicionais e a incorporação de outras. Ao lado das ações realizadas no âmbito dos departamentos - construídos, em linhas gerais, para contemplar as diferentes áreas de conhecimento (ciências 
sociais, planejamento, epidemiologia, saneamento), especialmente em fins da década de 1980 - intensificaram-se outros formatos organizacionais, relacionados a novas temáticas, abordagens e problemas que demandam ações interdisciplinares. Nesse período, pode-se destacar a criação, em 1989, do Centro Latino-Americano de Estudos sobre Violência e Saúde (Claves); do Núcleo de Doenças Endêmicas Samuel Pessoa, em 1990; do Núcleo de Estudos Locais de Saúde (Elos), em 1995; e do Projeto Desenvolvimento Local Integrado e Sustentável (Dlis/Manguinhos), em fins de 1999.

Com o objetivo de realizar pesquisas de cunho epidemiológico e socioantropológico, privilegiando abordagens estratégicas em saúde, o Claves atua de forma articulada com órgãos do poder público, movimentos sociais organizados, outros núcleos de estudos e centros de atenção a vítimas de maus-tratos e violência, ao mesmo tempo que estimula a formação de recursos humanos nesta área.

Mais do que romper a estrutura administrativa e o 'modelo departamental', o objetivo que levou, no início da década de 1990, um grupo de pesquisadores dos departamentos de Ciências Biológicas e Epidemiologia e Métodos Quantitativos em Saúde a criar o Núcleo de Doenças Endêmicas Samuel Pessoa foi o de realizar estudos que integrassem os enfoques biomédicos, epidemiológicos e socioeconômicos. Em 1993, o núcleo se transformaria em departamento, consolidando a integração de pesquisas de campo em diferentes comunidades. Segundo Adauto Araújo, o núcleo surgiu da iniciativa de um grupo de pesquisadores, entre os quais incluía-se o diretor da escola à época, Frederico Simões Barbosa, que, sob a liderança de Paulo Sabroza, reuniam-se em uma sala no Departamento de Ciências Biológicas:

A gente se reunia com os alunos - era um núcleo de professores e alunos - para estudar as doenças endêmicas, mas com um outro enfoque que não unicamente o epidemiológico, incluindo a visão das ciências sociais, da antropologia. Logo depois o Carlos Coimbra veio fazer parte deste núcleo. (Entrevista com Adauto Araújo, 2004)

De forma semelhante, buscando aliar pesquisa, ensino e cooperação, a criação do Elos, em 1995, propiciou o surgimento de um espaço capaz de congregar pesquisadores e professores em torno dos temas relacionados à saúde das populações em nível local. A partir da definição do bairro da Maré, na cidade do Rio de Janeiro, como locus de desenvolvimento do programa de trabalho, este núcleo tem por objetivo desenvolver metodologias de educação popular e saúde orientadas a facilitar a participação da população local na gestão de sua realidade de saúde.
Quando se reabriu o doutorado em 90-9I tinha muita gente da própria instituição fazendo 0 doutorado, eram pessoas já mais do que experientes, que não tinham sido tituladas ainda. Isso acontece aqui e acontece no Instituto Oswaldo Cruz também numa determinada época. Coincide com a exigência da titulação, com as normas da Capes determinando que pra você dar aula de especialização ou em uma pós-graduação stricto sensu, tem que ter o título de 'doutor'. Agora, tinha também muita gente de serviço. Se mesclava na turma o pessoal da chamada 'área acadêmica' e o pessoal da saúde pública que tem uma origem no serviço. Quer dizer, as pessoas que estavam na universidade dando aula, fazendo pesquisa e aqueles que vinham dos serviços em busca também de um aperfeiçoamento, de uma melhoria no seu trabalho, no seu conhecimento.

(Entrevista com Adauto Araújo, 2004) 
Alunos de mestrado. Ensp, 1989. Núcleo de Doenças Endêmicas Samuel Pessoa, com os professores Valmir Laurentino e José Wellington de Araújo a procura de barbeiros no Sítio do Mocó, São Raimundo Nonato, Piauí. O trabalho fazia parte do treinamento de agentes de saúde e da tese de mestrado de dois alunos. Foto: Adauto Araújo. Acervo Particular.

Adauto Araújo - pesquisador da Ensp necropsiando animal cercado de crianças no povoado de Zabele, São Raimundo Nonato, Piauí, 1985, durante trabalho de campo. Foto: Márcia Chame. Acervo Laboratório de Paleoparasitologia.
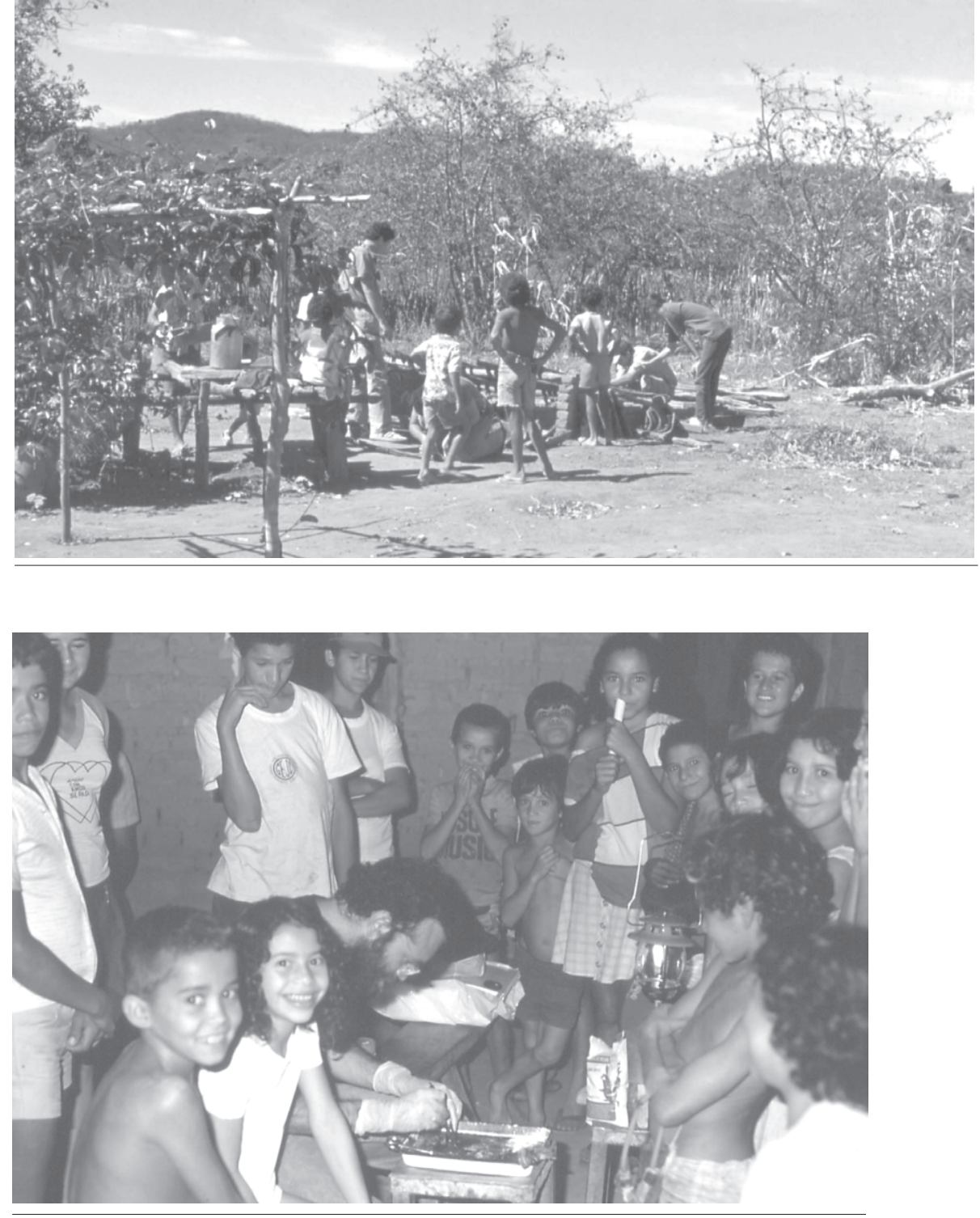

Uma outra dimensão do trabalho da Escola refere-se à mobilização e à interação com a sociedade civil. Nessa perspectiva, a partir de meados da década de 1990, vem se realizando a experiência do Dlis, desenvolvido no bairro carioca de Manguinhos por um conjunto de parceiros que incluem a Fiocruz, a prefeitura da cidade do Rio de Janeiro, entidades da sociedade civil local, entidades privadas e outros órgãos públicos. Com base na participação comunitária e abrangendo os campos da geração de trabalho e renda, habitação e urbanização, saúde e alimentação e desenvolvimento 
social e educação, o projeto permitiu à Ensp realizar pesquisas e desenvolvimento de tecnologias e metodologias nos referidos campos, visando a incorporá-las aos seus cursos e a incrementar sua capacidade de cooperação técnica em promoção da saúde. Partindo de uma perspectiva de promoção da saúde que valoriza o papel dos determinantes gerais sobre as condições de saúde, o Dlis inscreve-se entre aquelas experiências que buscam intervir no amplo conjunto de aspectos que influem na saúde, incluindo aqueles considerados, segundo uma ótica mais restrita, como externos à esfera do indivíduo e do setor saúde.

Outro setor da escola que desenvolve atividades nesse campo é o Centro de Saúde Escola Germano Sinval Faria, constituído atualmente por um conselho gestor, uma chefia e quatro coordenações: ação comunitária; assistência; ensino e pesquisa; e desenvolvimento tecnológico. Uma das vertentes atuais de atuação do Dlis ocorre em interação com o trabalho desenvolvido pela coordenação de ação comunitária, destinada ao desenvolvimento de atividades na área de promoção da saúde. ${ }^{5} \mathrm{~A}$ escola mantém, portanto, sua estratégia de investir em uma constante interação com a comunidade, característica que preserva desde a sua fundação.

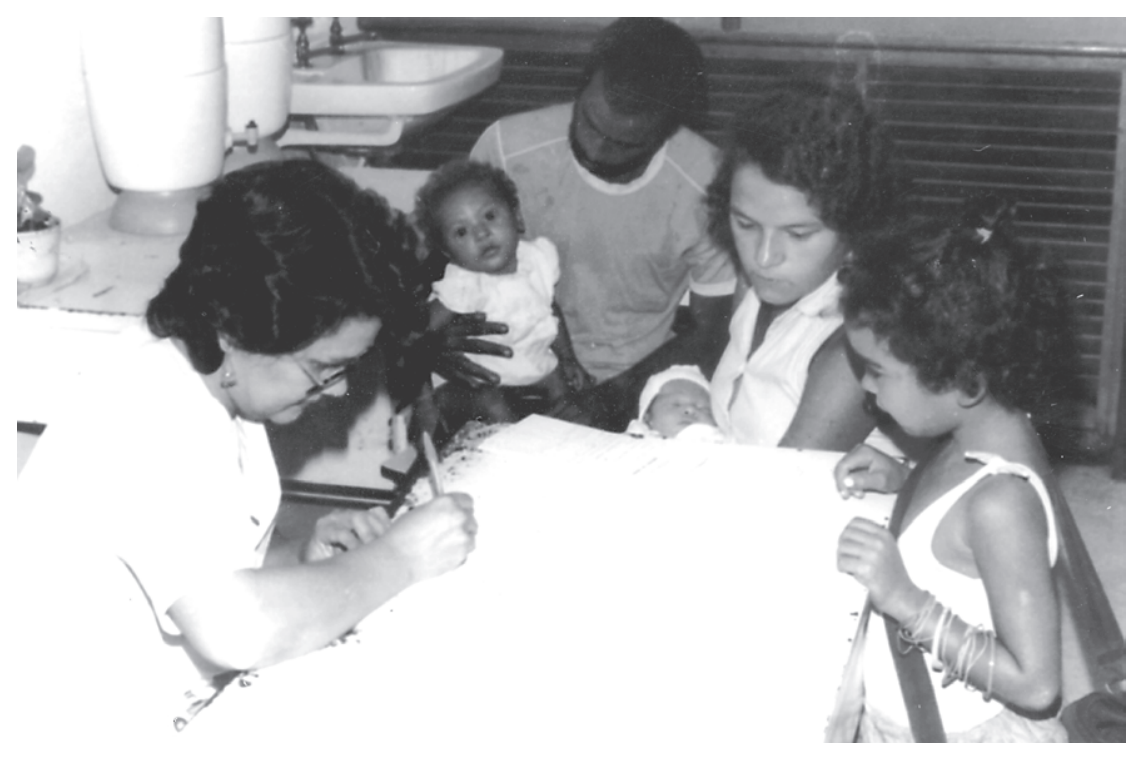

Atendimento no Centro de Saúde Escola Germano Sinval Faria, s.d. Foto: Cid Fayão. Acervo Ensp.

5 Neste sentido vêm sendo desenvolvidos dois programas: o Grupo de Saúde e Desenvolvimento Social do Fórum Regional Acorda Manguinhos e Estratégia de Saúde da Família/ESF, para moradores do Parque João Goulart e Mandela de Pedra, no bairro carioca de Manguinhos. 
Antonio Sergio Arouca (presidente da Fiocruz) inaugurando o Centro de Estudos da Saúde do Trabalhador e Ecologia Humana (Cesteh) criado em 1987, s.d. Foto: Cid Fayão. Acervo Ensp.

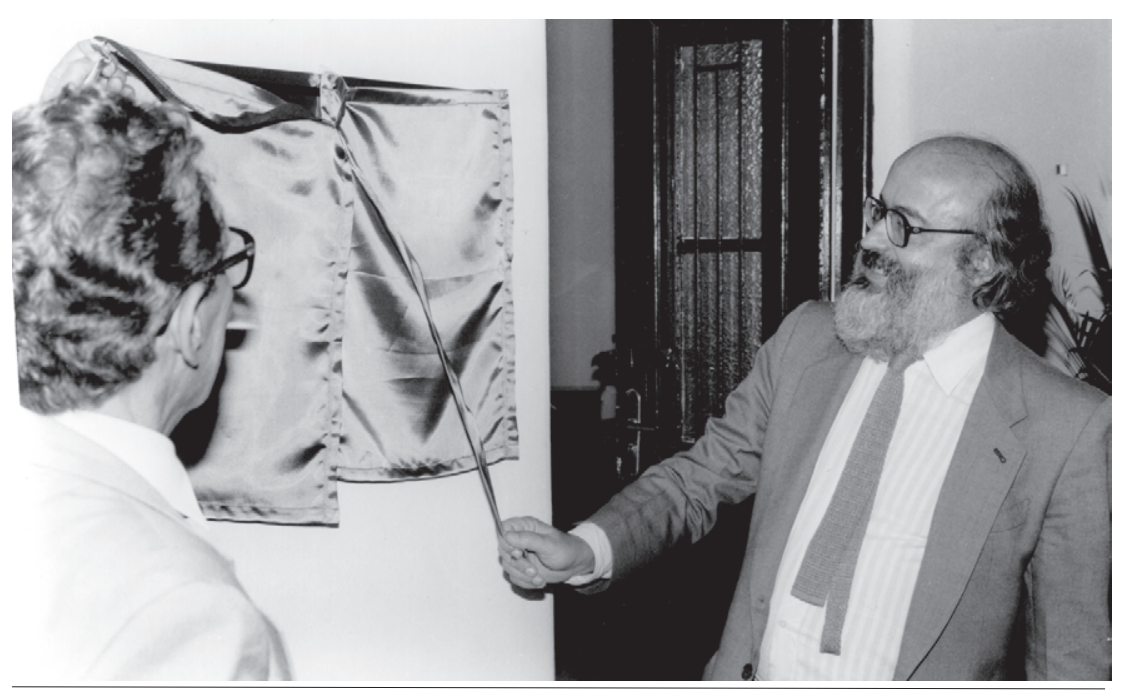

Deve-se observar que, pelo menos desde 1985, outras iniciativas de natureza interdisciplinar, muitas vezes de difícil realização no âmbito das estruturas departamentais, foram implementadas. Uma delas foi o Centro de Estudos da Saúde do Trabalhador e Ecologia Humana (Cesteh), atualmente um departamento da Ensp, que tem por objetivos básicos realizar pesquisas, atividades de cooperação técnica e formar recursos humanos para a área, dentre os quais técnicos para atuação nos programas de saúde do trabalhador, no âmbito do SUS e outras instituições, e novos pesquisadores provenientes de cursos de especialização, mestrado e doutorado.

A perspectiva inter e multidisciplinar - marca da trajetória da escola - pode ser identificada nessas iniciativas. Verifica-se também a multiplicação das áreas temáticas de interesse, que nas últimas duas décadas expandiram o entendimento do que seria objeto de investigação em saúde. Os programas de pesquisa da escola, desde o início dos anos 1990, incluem as variadas áreas do conhecimento no campo da saúde pública e indicam a diversidade de linhas e projetos de pesquisa, definidos de acordo com grandes eixos temáticos como doenças prevalentes no país; políticas de saúde e reorganização dos serviços; práticas de saúde; e relações da saúde com o Estado e a sociedade. ${ }^{6}$ Constata-se, pois, que não apenas os desafios da

6 O Relatório de Atividades da Fiocruz de 1990, no item dedicado à pesquisa em saúde coletiva na Ensp, relaciona um conjunto de projetos que abordam diversos temas, entre os quais: política de saúde e reforma sanitária; movimentos sociais e saúde; saneamento e saúde ambiental; saúde do trabalhador e ecologia humana; economia da saúde; estudos demográficos e sobre reprodução humana; epidemiologia das doenças endêmicas (incluindo Aids); epidemiologia do câncer; saúde mental; educação em saúde; violência e saúde; saúde das populações indígenas; saúde do idoso; vigilância sanitária etc. (Fiocruz, 1990). 
implantação do SUS, mas também a diversidade e a complexidade inerentes à abordagem da saúde pública nas duas últimas décadas do século XX constituíram-se em temas de reflexão e contribuição incorporados ao projeto institucional da Ensp.

A expansão de temas de interesse pode revelar, na visão de determinados grupos, uma 'dispersão' ou 'ausência de foco' nas questões centrais, que nos remetem às definições de investimentos em pesquisa, ensino e serviços. No final da década de 1990, durante as discussões do processo eleitoral que conduziria Paulo Buss ao seu segundo mandato (1998-2000), dentre as linhas de ação apresentadas uma apontava para a 'gestão da diversidade', reconhecendo todas as iniciativas de ensino, pesquisa e cooperação como algo a ser respeitado e incentivado e, ao mesmo tempo, imprimindo o fomento e o estímulo a algumas prioridades, que se traduziriam em um Programa de Pesquisa Estratégica. Este programa, lançado no início da segunda gestão de Buss, investigou métodos e técnicas a serem apropriados estrategicamente pelo sistema de saúde. ${ }^{7}$ Ao mesmo tempo, foi concebida a idéia de Escola de Governo em Saúde, que visava a um compromisso com a geração de inovações para o SUS, formando quadros de gestores que atuam nos estados e municípios. Isto significou, na visão dos dirigentes da Ensp, uma 'reorientação estratégica' do programa de ensino, pesquisa e cooperação técnica no sentido de ampliar a capacidade de governança de sistemas, serviços, organizações e programas de saúde, assim como de gerar novos conhecimentos e tecnologias com o mesmo fim, consolidando o papel estratégico da instituição como agência pública governamental.

Na gestão de Jorge Bermudez, que teve início em 2001, definiramse como ações prioritárias: estruturação e consolidação das três coordenações da Escola (Escola de Governo em Saúde, pós-graduação e Desenvolvimento Institucional e Gestão); uma ampliação da participação da Escola na capacitação profissional dos quadros do MS e de suas agências reguladoras, como a Agência Nacional de Saúde e a Agência Nacional de Vigilância Sanitária; e consolidação da Escola de Governo em Saúde, por meio de inúmeras estratégias, dentre as quais destacam-se as tecnologias de educação a distância, ferramentas essenciais neste processo.

Para cumprir sua missão e desenvolver seus programas institucionais de ensino, pesquisas, serviços de referência, informação e
0 ministério articulava isso.

Através das coordenações estaduais e as coordenações estaduais com as locais. E a Ensp foi se envolvendo cada vez mais, se voltando pra dentro do serviço de saúde 'mesmo', formando pessoal. Por isso que eu não sei, não tem como quantificar, mas a importância dessa instituição na constituição do Sistema Único de Saúde do Brasil é enorme. Porque esteve formando as pessoas nos mais recônditos lugares, nas mais diferentes frentes.

(Entrevista com Maria do Carmo Leal, sobre os cursos descentralizados, 2004)

O programa, lançado em 1998, teve em seu segundo edital 68 projetos apresentados, dos quais 20 foram selecionados, com a participação de 180 professores e alunos. 
A Ensp tem esses dois braços bem demarcados. A área acadêmica e a área de envolvimento mesmo com 0 serviço de saúde, que, aliás, é a função social da Ensp e da Fiocruz por ser do ministério. Então isso, na década de 1980, a Ensp vive esses dois movimentos. Um movimento de 'grande' crescimento da área acadêmica científica da pesquisa e um movimento de grande envolvimento também com os serviços de saúde nos cursos regionalizados, depois nos cursos de especialização por área específica: epidemiologia, planejamento, de ciências sociais nos estados.

(Entrevista com Maria do Carmo Leal, 2004) comunicação e desenvolvimento institucional, a Ensp está estruturada da seguinte forma: como instância deliberativa o Conselho Deliberativo e a Direção, aos quais estão vinculadas as coordenações de pós-graduação, Escola de Governo e Desenvolvimento Institucional e Gestão'. Possui oito departamentos: Ciências Sociais; Epidemiologia e Métodos Quantitativos em Saúde; Administração e Planejamento em Saúde; Ciências Biológicas; Saneamento e Saúde Ambiental; Endemias Samuel Pessoa; Centro de Estudos da Saúde do Trabalhador e Ecologia Humana (Cesteh); e Centro de Saúde Escola Germano Sinval Faria (CSEGSF). A Escola abriga ainda os seguintes centros de referência, núcleos interdepartamentais e multidisciplinares e de apoio às atividades de ensino, pesquisa e serviços: Centro de Documentação e Informação (Cedoc), Claves, Elos, Núcleo de Assistência Farmacêutica (NAF), Núcleo de Estudos Político-Sociais em Saúde (Nupes), Secretaria de Desenvolvimento Educacional (SDE); e Laboratório de Informática (Labi).

$\mathrm{Na}$ face mais acadêmica da Ensp, deve-se ressaltar a experiência do periódico Cadernos de Saúde Pública e do curso de pós-graduação. Os Cadernos de Saúde Pública, criados em 1985, sob coordenação de Frederico Simões Barbosa e Luiz Fernando Ferreira, vêm desempenhando importante papel na consolidação e divulgação da pesquisa em saúde coletiva, compreendendo as várias subáreas do conhecimento que a integram. Publicação bimestral, atende à comunidade científica da área de saúde coletiva de maneira ampla, veiculando artigos originais nas áreas de epidemiologia, parasitologia, microbiologia, nutrição saúde ambiental, ciências sociais aplicadas à saúde, dentre outras (Ensp, 2004). O trecho a seguir de editorial do número comemorativo dos 20 anos da publicação, destaca dados expressivos:

\footnotetext{
Durante a primeira década de publicação, cerca de $48 \%$ dos autores eram externos, nos últimos volumes chegou a $81 \%$. Outro dado significativo é que $13 \%$ dos autores que publicaram em CSP nos últimos anos são do exterior, sobretudo da América Latina, Europa, EUA e Canadá (...). Quanto à circulação e disseminação, pode-se afirmar com segurança que CSP figura atualmente dentre as revistas científicas mais lidas no país. (Coimbra Jr., 2004: 4)
}

Outra importante publicação periódica da Ensp é a Revista Radis do Programa Reunião Análise e Difusão de Informação sobre Saúde (Radis). Criado em 1982, o programa distribui cerca de 40 mil exemplares da revista, que tem por finalidade promover a disseminação de informações sobre saúde pública entre produtores de conhecimento e gestores do SUS (Ensp, 2004: 10). 
A colaboração entre docentes da Ensp e grupos de pesquisa no exterior tem se intensificado nos anos recentes. Dados para o período de 2001-2003 indicam expressiva colaboração nas áreas de paleoparasitologia e paleoepidemiologia; saúde dos povos indígenas e antropologia médica; sistemas e serviços de saúde na América Latina e Caribe; métodos epidemiológicos; geografia da saúde; desigualdades sociais e raciais em saúde; violência e saúde; estudos sobre Aids; saúde do idoso; toxicologia reprodutiva; políticas de acesso e distribuição de medicamentos; saúde e ambiente; gênero, trabalho e saúde; abordagens ecossociais sobre riscos ocupacionais; avaliação econômica de tecnologias em saúde; saúde mental; avaliação de programas de promoção da saúde; epidemiologia do câncer; teoria e prática da pesquisa-ação; reformas da saúde em perspectiva comparada; e elaboração de instrumentos de acreditação de cursos de saúde pública (Ensp, 2004).

Em 2002, procedeu-se à redefinição das linhas de pesquisa da Ensp. Atualmente, 27 linhas integram o programa de pesquisa e configuram-se como referências para o desenvolvimento de projetos pelos estudantes de pós-graduação: avaliação de políticas; sistemas e programas de saúde; avaliação de serviços e tecnologias de saúde; bioética; biotecnologia e saúde; cultura, saúde e enfermidade; desigualdades sociais e saúde; determinação e controle de endemias; economia em saúde; educação, saúde e cidadania; epidemiologia de doenças crônicas; epidemiologia de doenças transmissíveis; formulação e implementação de políticas públicas em saúde; gênero e saúde; informação e saúde; modelagem em saúde e ambiente; nutrição e saúde pública; paleopatologia e paleoparasitologia; planejamento e gestão em saúde; políticas e sistemas de saúde em perspectiva comparada; profissão, trabalho e formação em saúde; promoção da saúde; saúde ambiental; saúde e trabalho; saúde indígena; saúde mental; toxicologia e saúde; vigilância e saúde e violência e saúde (Ensp, 2004).

O crescimento da oferta de cursos pela Ensp vem se expressando em números bastante significativos nas áreas de stricto e lato sensu, esta última responsável por $93 \%$ dos alunos formados no período $1990-2000 .{ }^{8}$ No final desse período, a escola adotaria um novo sistema de formação de pessoal em nível de mestrado. Ainda em 1999, foi implantada a modalidade

\footnotetext{
Neste período, em que a oferta quadruplica, foram oferecidos 320 cursos com 7.739 vagas, as quais resultaram em 6.129 matrículas e 5.672 formados. Estes números fazem parte dos resultados de uma pesquisa sobre os cursos lato sensu da Ensp entre 1990-2000, realizada pela coordenação da pós-graduação, e encontram-se no Relatório Final de Pesquisa (Oliveira \& Barbosa, 2001).
} 
'profissionalizante' no programa de pós-graduação strictu sensu da Ensp, cuja origem pode ser apontada em meados da década, quando se iniciou a discussão da implementação da proposta denominada 'Programa de Especialização em Saúde Pública com Progressão seletiva para o Mestrado', cuja finalidade era possibilitar ao aluno do curso de especialização optar por continuar sua formação, no segundo ano do programa, já em nível de mestrado. ${ }^{9} \mathrm{O}$ atendimento às demandas de diversos setores do MS, secretarias estaduais e municipais e outros organismos da saúde e a compatibilização de qualidade acadêmica com flexibilidade de carga horária foram os fatores que nortearam a criação dos cursos de mestrado profissional a partir do ano de 2002. ${ }^{10}$

O Programa de Pós-Graduação stricto sensu da Ensp conta hoje com 82 docentes-orientadores. Desde a criação do mestrado, em 1977, foram defendidas 645 dissertações; no doutorado, criado em 1980, 187 teses foram defendidas até 2003. Anualmente o programa recebe de 70 a 80 mestrandos e de 30 a 35 doutorandos. Cabe ressaltar o ingresso de estudantes do exterior, principalmente de países sul-americanos, centro-americanos e africanos.

A criação de programas interinstitucionais, nos moldes definidos pela Coordenação de Aperfeiçoamento de Pessoal de Nível Superior (Capes), consistiu em importante iniciativa. Realizou-se, nessa modalidade, curso de doutorado com a participação do Centro de Pesquisas Aggeu Magalhães da Fiocruz, do Instituto Materno Infantil de Pernambuco, da Universidade Federal de Pernambuco, tendo se transformado em curso independente em 2003. Experiências semelhantes foram desenvolvidas em nível de mestrado com a Universidade Estadual de Ponta Grossa (Paraná) e Universidade Federal do Pará (UFPA). Dentro desse modelo, permanece o curso realizado em Manaus, em cooperação com a Universidade Federal do Amazonas (Ufam) e o Centro de Pesquisa Leonidas e Maria Deane (Fiocruz).

Teve início, em 2003, processo de discussões com o objetivo de se criar de mestrado e doutorado em saúde pública na região Norte, onde não há atualmente curso de pós-graduação em saúde coletiva. Contando com a participação de diversas instituições de pesquisa e ensino da região amazônica, esta iniciativa tem por objetivo criar condições para um programa permanente de alto nível na região (Ensp, 2004).

9 Ver documento Mestrado Profissionalizante na Ensp - antecedentes e situação atual, elaborado pela coordenação da pós-graduação para discussão na escola. 30/09/2002. Disponível em: $<$ www.ensp.fiocruz.br>.

10 O primeiro curso de mestrado profissional foi o de gestão em sistemas e serviços de saúde, dirigido para profissionais da Secretaria de Atenção à Saúde do Ministério da Saúde. A partir de então surgiram: gestão em ciência \& tecnologia em saúde (2002); regulação em saúde complementar; e gestão da informação e da comunicação em saúde (2003). 
A criação, em 2002, do mestrado em saúde pública, modalidade profissionalizante com duas áreas de concentração - gestão em saúde e vigilância em saúde - teve por objetivo a formação de profissionais do sistema de saúde

comprometidos com processos dinâmicos de transformação institucional e de inovação gerencial, para atuarem como formadores e indutores de processos de mudança em suas instituições de trabalho mediante a adoção de novos conceitos e práticas, desenvolvendo produtos de aplicabilidade ao desenvolvimento do SUS e do sistema de ciência e tecnologia. (Ensp, 2004: 22)

$\mathrm{Na}$ área de gestão em saúde incluem-se atualmente os cursos de gestão em sistemas e serviço de saúde, oferecido para técnicos da Secretaria de Atenção à Saúde do MS; gestão em ciência e tecnologia em saúde, oferecido para técnicos da área de gestão da Fiocruz; regulação em saúde suplementar, oferecido para técnicos da Agência Nacional de Saúde Suplementar; Gestão de Informação e Comunicação em Saúde, oferecido para técnicos da área de informação e comunicação da Fiocruz. $\mathrm{Na}$ área de concentração em vigilância em saúde, é realizado o curso de Vigilância em Saúde, para técnicos da Secretaria de Vigilância em Saúde da Fundação Nacional de Saúde (Ensp, 2004: 22).

É possível estabelecer relação entre essa experiência recente e os cursos descentralizados de meados da década de 1970. Como observa Maria do Carmo Leal:

(...) a parte que eu acompanho de perto tem relação com os serviços de saúde. Nós temos, digamos assim, uma nova versão (...) da formação de recursos humanos, moderna, atual, que são os mestrados profissionalizantes. Esses cursos nada mais são do que uma reatualização daquele antigo momento em que a Ensp fez os cursos de saúde pública, que naquela época eram os cursos descentralizados de saúde pública. É uma versão totalmente diferente esta de agora, porque é uma pósgraduação stricto sensu, mas retoma a mesma idéia de quadros qualificados para o sistema de saúde. Naquela época era formar o especialista (...); hoje é formar o mestre. A Ensp está sempre fazendo isso, porque ela tem duas feições: uma feição que é ligada com (...) o serviço de saúde, a do olhar para a sociedade, e uma outra que também é ligada à sociedade mas com um olhar diferente, que é a perspectiva acadêmica. (Entrevista com Maria do Carmo Leal, 2004)

Esse comentário é interessante para a reflexão sobre a tendência a se contrapor às novas orientações impressas na Ensp e no perfil acadêmico, acentuado por uma série de iniciativas adotadas desde a década de 1980:
Precisava de gente pra treinar 0 pessoal do Brasil a montar um programa de imunização nos estados e municípios, como aprender minimamente a avaliar 0 impacto da vacina, alguns rudimentos de epidemiologia e de planejamento, abordando a questão da imunização. E eu caí de cabeça pra ajudar porque eu sempre fui favorável a qualquer coisa que viesse pra melhorar a saúde da população. Naquela época, na Ensp, as campanhas de vacina eram consideradas uma coisa 'out' porque não ia resolver o problema de saúde. Havia uma discussão centrada nas condições de vida, era uma questão da esquerda da época. Entretanto, eu sempre fui do tipo que qualquer coisa que pudesse ajudar eu estou dentro e comecei a me envolver às custas de ter recebido muitas críticas por ajudar o Ministério da Saúde da época a montar as campanhas de imunização. Mesmo assim fui.

(Entrevista com Maria do Carmo Leal falando sobre o início do Programa Nacional de Imunizações (PNI) 2004) 
A Ensp tem a maior pósgraduação das Américas. De 2003 para o mestrado e doutorado em 2004 se inscreveram 440 candidatos. A gente realizou a prova de seleção no sábado porque senão não tinha sala, não tinha espaço pra fazer.

(Entrevista com Adauto Araújo, 2004) olhares diferentes, porém ambos vinculados à sociedade. Como observamos no primeiro artigo deste livro, a tensão entre as vertentes acadêmicas e as direcionadas para ações e serviços no sistema de saúde é constitutiva do campo da saúde pública, e estaria fadada ao fracasso qualquer tentativa de harmonizá-las artificialmente. Por outro lado, a relação entre idéias e práticas é bastante complexa, como vêm demonstrando, entre outros campos de conhecimento, os estudos sociais da ciência. Trata-se efetivamente de uma via de mão dupla na qual seria igualmente estéril determinar a que termo deve ser atribuída antecedência - idéias ou práticas -, pois ambos são atos sociais.

$\mathrm{Na}$ construção histórica do campo da saúde coletiva, a revisão de conceitos como o de medicina preventiva (Arouca, 2003); as redefinições das idéias e práticas em relação à saúde mental (Amarante, 2000); as redefinições conceituais referidas às relações entre saúde, ambiente e espaço (Sabroza, 1994); o debate sobre promoção da saúde (Zancan \& Bodstein, 2002), para ficar apenas em alguns exemplos, são constitutivos da área de saúde coletiva e encontram-se presentes na formulação de políticas e na orientação impressa aos serviços.

Além dessa tensão que está na origem da história da saúde pública nos mais diversos contextos nacionais, um tema recorrente consiste nos obstáculos existentes para a maior troca entre os profissionais da Ensp. Não apenas o crescimento - o tamanho da instituição - foi apontado, mas principalmente os padrões atuais de avaliação do trabalho acadêmico, que privilegiam de modo quase exclusivo a produção científica em sentido estrito. Aqueles que viveram os períodos de formação e de esforços pioneiros - sobretudo as décadas de 1970 e 1980, em que a fraca institucionalização de algumas atividades era compensada por um ambiente descrito como de grande efervescência de idéias e debates acadêmicos e políticos preocupam-se com o estabelecimento de fóruns de debate mais freqüentes e integradores. O depoimento de Maria do Carmo Leal, diretora da Ensp de 1993 a 1994, destaca este ponto:

(...) o que eu acho que está acontecendo é que as pessoas estão assoberbadas, nos últimos tempos, com uma produtividade enorme que elas têm de mostrar (...). Por exemplo, a gente tem que produzir muitos artigos para manter a bolsa de produtividade do CNPq. É muito competitivo. E não é só para ganhar mil reais de complementação salarial, mas porque isso dá prestígio para a pós-graduação. A gente quer que a nossa pós-graduação tenha uma nota ótima, e os professores se esforçam muito para que a Fiocruz tenha um bom desempenho (...) [Há] um nível 
de competição acadêmica enorme, como nunca tivemos, então as pessoas passam o tempo todo trancadas na sala trabalhando no computador, fazendo artigo para publicar, conversando com aluno, preparando aula, fazendo o trabalho delas, e têm tido pouco tempo para trocar. Mas o que sinto, pelo menos aqui no meu departamento, é que elas sentem muita necessidade disso. O que está faltando é oportunidade. Acho que se a oportunidade existir, elas irão, porque sentem necessidade. Pelo menos as do meu departamento, com quem eu converso mais; sei que elas sentem que crescem quando fazem esses contatos com outras áreas. (Entrevista com Maria do Carmo Leal, 2004)

A necessidade de estimular as trocas acadêmicas e de construir um ambiente em que o aprofundamento em áreas especializadas do conhecimento não crie obstáculos para uma visão mais ampla dos problemas e da agenda de pesquisa em saúde tem sido apontada em diversas análises no campo da saúde coletiva e da ciência e tecnologia no país, não se caracterizando como uma peculiaridade da Ensp.

No caso da saúde, identifica-se, hoje, um movimento intenso de valorização das condições de trabalho no setor e de atualização das diretrizes no campo da formação de recursos humanos. Uma das expressões desse movimento pode ser identificada na criação da Secretaria de Gestão do Trabalho e da Educação na Saúde no MS. Outra manifestação, no campo internacional, pode ser identificada na criação de programa internacional dedicado à definição de ampla agenda para a formação de recursos humanos na área de saúde, envolvendo enfoques interdisciplinares e valorizando a história da saúde como dimensão crucial na construção da identidade dos atores individuais e institucionais. ${ }^{11}$ Tais iniciativas recentes permitem, de certo modo, que se estabeleçam comparações com o momento de criação da Ensp, caracterizado no país e no contexto internacional como de intenso debate sobre os caminhos da profissionalização na área da saúde.

A Ensp chega ao século XXI com uma importante base institucional, construída ao longo de 50 anos. Esse processo pode ser visto em suas diferenças conjunturais e descontinuidades, mas também revela a criação de tradições de pesquisa e a continuidade de esforços individuais e de grupos que, em determinadas circunstâncias, alcançaram êxito na definição de políticas. Torna-se importante observar, à luz de uma perspectiva histórica, a trajetória institucional na qual se destaca a socialização profissional e política dos diferentes atores que vieram

11 Ver $<$ www.rockfound.org/documents/631/jli_brochure $>\mathrm{e}<$ www.globalhealththtrust.org $>$. 
O Paulo Sabrosa é uma pessoa que é capaz de estar dentro de um laboratório trabalhando com um computador, fazendo imagens de satélite, pensando (...), dando aula brilhantemente (...). Vai para o campo, vê um cachorro com suspeita de leishmaniose, raspa o bichinho, prepara a lâmina, olha a lâmina, olha no microscópio com um espelho (...): 'Ah, é leishmaniose mesmo!'. Volta pra ver se tem caso humano, traz as pessoas pra fazer 0 exame no hospital lá, caindo aos pedaços. É uma pessoa capaz de fazer todas essas coisas. Isso é muito dificil! A pessoa tem que ter uma formação mesmo nessa área, e eu acho que ai a formação de médico auxilia bastante. A formação na área biomédica, talvez. Porque uma enfermeira é capaz de ter esse treinamento também, pode fazer exatamente a mesma coisa (...).

(Entrevista com Adauto Araújo, 2004) participar da construção desse projeto, forjando, a um só tempo, sua identidade e contribuindo para conformar a identidade da instituição. Naturalmente, a Ensp não foi uma experiência única, isolada e autônoma em relação a outras instituições no campo da saúde, mas revelou singularidades e capacidade de encontrar soluções criativas em diferentes cenários.

O tema do protagonismo, muitas vezes lembrado em retrospectivas históricas sobre a Fiocruz e acentuado em visões mais pessimistas sobre o papel atual da Ensp, deve ser revisto, considerando-se a crescente complexidade do país e das áreas de ciência e tecnologia em saúde e de saúde coletiva. Ganha destaque a defesa da pluralidade de instituições, contemplando-se as diversidades regionais e de perspectivas que compõem o campo múltiplo, diverso e complexo da saúde no Brasil.

Cabe destacar, a propósito, a importância das escolas de saúde pública na formação de gerações de profissionais e na construção de bases comuns e valores compartilhados para o que poderíamos denominar o artesanato intelectual da saúde coletiva. Por esta razão, ao discutirmos o papel da Ensp e a valorizarmos como 'Escola', acentuamos também a disseminação dessas idéias e práticas por meio de diversas estratégias cursos descentralizados; periódicos como os Cadernos de Saúde Pública e a Revista Radis; Escola de Governo; programas de pós-graduação interinstitucionais, entre tantas outras que vêm se sucedendo no tempo.

Ao darmos início à pesquisa da qual resultou este texto, chamounos a atenção o pequeno número de trabalhos acadêmicos sobre a história da formação em saúde pública no Brasil. À medida que fomos desenvolvendo o estudo, realizando entrevistas e identificando fontes primárias sobre a história da Ensp, percebemos a confluência de várias histórias e de várias escolas de saúde pública que, por razões as mais diversas, se encontraram nesse espaço físico e social. Ao identificar, portanto, os caminhos trilhados e as alternativas para o esforço permanente deste projeto de construção institucional, apresentamos aqui uma pequena contribuição a esta reconstituição histórica.

Valendo-nos mais uma vez das palavras de Hobsbawn (1998: 71), convém lembrar que

todo estudo histórico (...) implica uma seleção, uma seleção minúscula, de algumas coisas da infinidade de atividades humanas no passado, e daquilo que afetou essas atividades. Mas não há nenhum critério geral aceito para se fazer tal seleção e, na medida em que haja algum em qualquer momento dado, é provável que mude. 
Lançamos, assim, nossa proposta para novas reflexões e futuros debates que estimulem trabalhos originais neste campo relacionado à formação e especialização em saúde pública.

\section{REFERÊNCIAS BIBLIOGRÁFICAS}

\section{FONTES ARQUIVISTICAS}

Casa de Oswaldo Cruz/Departamento de Arquivo e Documentação: Fundo Escola Nacional de Saúde Pública/Seção Direção.

\section{LIVROS E PERIÓDICOS}

AMARANTE, P. Ensaios: subjetividade, saúde mental sociedade. Rio de Janeiro: Fiocruz, 2000.

AROUCA, S. O Dilema Preventivista: contribuição para a compreensão e crítica da medicina preventiva. Rio de Janeiro: Fiocruz, 2003.

BAHIA, L. Planos privados de saúde: luzes e sombras no debate setorial dos anos 90. Ciência \& Saúde Coletiva, 6(2): 329-339, 2001.

COHN, A. Questionando o consenso sanitário. Ciência \& Saúde Coletiva, 6(2): 300302, 2001.

COIMBRA JR., C. E. A. Cadernos de Saúde Pública: 20 anos. Cadernos de Saúde Pública, 20(1): 4-5, jan.-fev., 2004.

CORDEIRO, H. Descentralização, universalidade e eqüidade nas reformas da saúde. Ciência \& Saúde Coletiva, 6(2): 319-328, 2001.

ELIAS, P. E. Afinal, de qual descentralização falamos? Ciência \& Saúde Coletiva, 6(2): 310-312, 2001.

ESCOLANACIONAL DE SAÚDE PÚBLICASERGIOAROUCA(Ensp). Relatório Capes - 2001/2003. Rio de Janeiro, março de 2004.

FUNDAÇÃO OSWALDO CRUZ (Fiocruz). Pioneirismo e inovação: o ensino na Fundação Oswaldo Cruz. I Mostra de Ensino da Fiocruz - ll a l4 de novembro de 2002. Rio de Janeiro, Fiocruz, 2003.

FUNDAÇÃO OSWALDO CRUZ (Fiocruz). Relatório de Atividades - 1990. Rio de Janeiro: Fiocruz, 1990.

GERSCHMAN, S. A Democracia Inconclusa: um estudo da reforma sanitária brasileira. Rio de Janeiro: Fiocruz, 1995.

HOBSBAWN, E. Sobre História. São Paulo: Companhia das Letras, 1998.

LEVCOVITZ, E.; LIMA, L. D. de \& MACHADO, C. V. Política de Saúde nos anos 90: relações intergovernamentais e o papel das Normas Operacionais Básicas. Ciência \& Saúde Coletiva, 6(2): 269-291, 2001. 
MACÊDO, C. G. Notas para uma História Recente da Saúde Pública na América Latina. Brasília: Opas/OMS, 1997.

OLIVEIRA, J. A. A saúde pública hoje: notas para um debate sobre conjuntura em saúde e a situação da Ensp ao seu interior. Cadernos de Saúde Pública, 4(3): 326333, jul./set., 1989.

OLIVEIRA, E. S. \& BARBOSA, C. M. (Coord.). Os Cursos Lato Sensu da Ensp: 19902000 - um diagnóstico. Rio de Janeiro: Fundação Oswaldo Cruz/Escola Nacional de Saúde Pública/Daps, 2001. (Relatório final de pesquisa) Disponível em: $<$ www.ensp.fiocruz.br/documentos/egressos.htm>.

ORGANIZAÇÃO PAN-AMERICANA DA SAÚDE(OPAS). A Saúde no Brasil. Brasília: Opas/OMS, 1998.

SABROZA, P. C. Saúde Pública: procurando os limites da crise. Rio de Janeiro, ago., 1994. (Mimeo.)

TEIXEIRA, S. M. F. Descentralização dos serviços de saúde: dimensões analíticas. $R A P, 24(2): 78-99,1990$.

VIANA, A. L. D. Descentralizando: uma política (ainda) em debate. Ciência \& Saúde Coletiva, 6(2): 302-305, 2001.

ZANCAN, L. \& BODSTEIN, R. C. de A. Dlis-Manguinhos como estratégia de promoção da saúde. Saúde em Foco, 23: 49-63, 2002.

ZANCAN, L.; MARCONDES, W. B. \& BODSTEIN, R. C. de A. Promoção da Saúde como Caminho para o Desenvolvimento Local: a experiência em Manguinhos $R J$. Rio de Janeiro: Abrasco, 2002. 
UMA HISTÓRIA DE VIDA NA SAÚDE PÚBLICA 


\section{Ao Mestre com Carinho}

(Texto de Arlindo Fábio Gómez de Sousa, 1984)

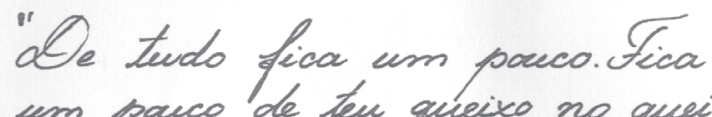
um pauco de teu queivo no quei to de tua qulla", disse o poeta. pai me perguntem parque, mas quero falar de suas maís. Ollatos geandes e gates, sempre prontas Ia un gesto donativo (..." "épreciso arajar, conhecer autros lugaces, ticar - mofo "), da caliguafia bequena e precisa (..." cada dia fico mais exigente. Pas resisto deixar de cabis oa, um texto. ofs ecases. All' as exases.

of inesistivel. Pas posso deicar de covigílas "); mais que fechadas expeimiram toda a indignaciós de suas palavras (..." se querem atengir a COscola, isso é conigo"); maios de desportista (... "nas quadeas que exis tiam onde e' loje a Ch. Grincesa "Fabel "), do nadada e re. mador (... "na Elagoa Podizo de Freitas tolas as tardinhas"), maios do valiscador (... "esses oneus desenhos em aitias má̃s"); más que ajudaram a escrever grande parte da históia da Gaide Ariblica do Brasil no viltimo meio século, mas que

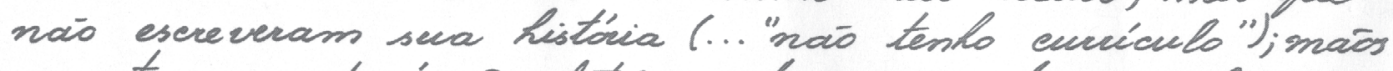
que tivavam do ógás eletiónico tangos y atreas milongas más, quando seu rosto, virado para nós, mosteava o eneanto. mento do coracaio-menins que via-faria a mágica do som, refletindo no soviso dos lálics entreabertos toda sua liçá de saber eviver. Naís que teaballavam ate' seu illtimo momento e que contenuam a nos apentar o caminho. Mais do cacinho da despedida ("fleus")

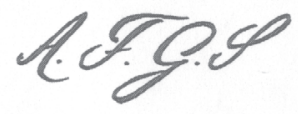




\section{Entrevista com Ernani Braga'}

LF - Como você se interessou por saúde pública, de onde veio sua motivação e seu interesse pela área?

EB - Acho que devo começar explicando meu ingresso no curso de medicina. Não pertenço a uma família composta tradicionalmente por médicos. Meu tetravô, Joaquim Inácio de Santos Paiva, foi o primeiro cirurgião-mor da Santa Casa de Porto Alegre, inaugurada em 1826 pelo barão de São Leopoldo, então governador da província. Depois dele quase ninguém da família se interessou por medicina. Meu pai, por exemplo, era advogado. Eu também não tinha, quando jovem, nenhuma intenção de ser médico. Mas no Rio Grande do Sul daquela época vivia-se um clima positivista, de liberdade de profissões, e qualquer um podia fazer o que quisesse. Eu, quando estudante, vivi nesse mundo. Fui colega de ginásio do Golberi, a quem substituí como chefe dos escoteiros. Meus contatos eram mais com o rio de La Plata, mais com o tango do que com o samba.

LF - Em que cidade você morava?

EB - Na cidade de Rio Grande, porto de mar. Morei primeiro na fronteira, em Itaqui, depois na cidade de Rio Grande. Vim para o Rio de Janeiro por influência da família, que tinha muitos almirantes, generais e marechais. Um de meus avôs foi almirante e comandante de esquadra. E em Rio Grande aportavam muitos navios de guerra. Eu os visitava e me

A entrevista com Ernani Braga (EB) foi realizada por Luiz Fernando Ferreira (LF), Lisabel Klein (LK), Sergio Arouca (SA) e Mabel Imbassay (MI) no dia 16 de junho de 1978. A edição é de Regina Celie Simões Marques. 
encantava com as bandas de música, os uniformes, todo aquele ambiente. Então resolvi entrar para a Marinha, ainda que me dissessem: "Não se meta nisso, é miséria dourada e só para quem tem recursos".

O Exército era mais democrático. Havia a Escola Militar, no subúrbio de Realengo, recebia-se um pequeno soldo, vivia-se modestamente. Mas na Marinha não. Os rapazes vinham de famílias com uma certa tradição nesta arma e tinham de levar um enxoval para a Escola Naval, que compreendia roupas de linho e até um espadim. Meu pai, um juiz remediado, teria dificuldades em me oferecer esses privilégios, mas estava disposto a fazer alguns sacrifícios para me atender.

Cheguei ao Rio de Janeiro em 1929. Tive de falsificar a minha certidão de nascimento, porque ainda não completara 16 anos, a idade de ingresso na Escola Naval. Nessa ocasião, a cidade passava por seu último surto de febre amarela urbana, o que preocupou minha família, impressionada com histórias de gaúchos que vinham para o Rio e morriam da doença. Eu também estava assustado e já não gostava tanto da Marinha. Primeiro porque eu enjoava; minha viagem por mar foi horrível. Segundo, porque não gostei de certas normas disciplinares que sofri na viagem, mas os parentes me disseram que era normal, e eu ainda estava tentando contemporizar.

Então chegou a época do exame de admissão. Eu estava bem preparado, me saí relativamente bem e meu ingresso estava garantido. Mas houve um imprevisto: a banca examinadora agiu com extrema severidade e resolveu reprovar entre 70 e $80 \%$ dos candidatos, o que provocou uma grande reação; resolveram, então, realizar um novo exame. A essa altura eu já não queria mesmo entrar para a Marinha. Morava com a minha avó, um tio médico, cuja especialidade denominava-se otorrino-oftalmolaringologista, e dois filhos dele que cursavam medicina. Esses primos me diziam: "Não vá para a Marinha, isso é uma loucura! Venha fazer medicina. O que falta a você?". Na verdade, só me faltava fazer o exame de latim, que não estudara porque não era exigido na Marinha. "Então você vai ao Rio Grande, faz a prova, volta para cá e entra para a medicina”. E foi o que fiz. Voltei ao Rio Grande, estudei latim durante um ano e fiz o chamado exame final preparatório, enquanto trabalhava como bancário.

Voltei para o Rio de Janeiro, já então com 16 anos, e fiz o exame para a Faculdade de Medicina. O fato é que entrei para medicina mais por influência da família do que propriamente por vocação. Se meu tio fosse engenheiro, eu teria sido engenheiro. Eu era versátil em diversas áreas: jogava bem futebol e basquetebol, nadava bem, tocava alguns instrumentos musicais. 
LK - Por que você escolheu o Rio de Janeiro, se já existia a Faculdade de Medicina de Porto Alegre?

EB - Sim, existia. Essa escola, inaugurada no final do século XIX, foi a terceira em atividade no Brasil. Mas estudar no Rio de Janeiro era mais barato para mim. Em Porto Alegre eu teria de morar em uma pensão; no Rio de Janeiro, poderia viver com parentes e só teria a despesa da viagem. Tomei um navio e me instalei em casa de minha avó e meus tios, no Jardim Botânico, sem qualquer ônus de moradia e alimentação para meu pai, que era juiz e ganhava mal.

Então entrei para a medicina, um curso bastante desordenado, tal como ainda é hoje, com as disciplinas isoladas uma das outras. Mas tive professores fascinantes, homens extraordinários, como Carlos Chagas, Miguel Couto, Pacheco Leão, Benjamim Batista e Pinheiro Guimarães. Era interessante porque, apesar de estrelas, eles nunca formaram uma constelação, vivia cada qual no seu canto.

Em casa, meu tio era, como falei, otorrino. Meus primos já se encaminhavam para as suas especialidades ainda no início do curso, um na dermatologia e outro na oftalmologia. E eu ficava meio perdido, em casa e na escola, me relacionando ora com uns e ora com outros. Quase optei por ser otorrino, incentivado por meu tio. Também estive perto de escolher a psiquiatria, simplesmente porque um parente distante, era professor dessa matéria. Na verdade, eu não tinha um interesse particular em saúde pública, que na escola era abordada por Barros Barreto muito indiretamente e mais pelo viés da epidemiologia, no sexto período do curso.

\section{LF - O professor não era mais o Afrânio Peixoto?}

EB - O João de Barros Barreto encarregava-se das aulas práticas. Afrânio Peixoto era o professor, dava belas conferências sobre a filosofia da saúde pública, mas não me motivavam muito. Naquela época minha intenção era voltar para o Rio Grande do Sul e clinicar. Lá havia bons clínicos, cirurgiões e especialistas, mas a área de doenças parasitárias e infecciosas não era muito conhecida, era um campo fraco para o médico. Só comecei a me interessar por esses assuntos quando passei a freqüentar serviços de dermatologia, como o do Eduardo Rabelo, e de doenças venéreas e a me relacionar com o grupo do Chagas, Eurico Villela e Genserico de Souza Pinto, que tratava dos problemas de malária, doença de Chagas e tripanossomíases em geral. 
Depois de formado, permaneci mais um ano no Rio de Janeiro, preparando-me para voltar para o Rio Grande, quando soube de um curso no Centro Internacional de Leprologia, presidido por Rabelo e com sede na cidade, e resolvi fazê-lo. Foram meus colegas de turma Joir Fontes, Gercino de Pontes e João Baptista Rizzi. O Joir, primeiro assistente e um grande clínico, impressionava-nos com a sua competência para diagnosticar e medicar os casos mais complicados.

Concluído o curso, retornei para Rio Grande e empreguei-me no Serviço Antivenéreo das Fronteiras, recém-criado na ocasião para combater o terrível treponema brasileiro, que preocupava os países limítrofes. O serviço atuava em postos localizados nas cidades do estado - Uruguaiana, Itaqui, São Borja, Santana do Livramento e outras. E eu tinha também uma pequena clínica, com a clientela muito reduzida, típica de uma cidade pequena como era o Rio Grande.

Um dia, recebi um telegrama de Souza Araújo, chefe do Serviço de Lepra de Manguinhos, no Rio de Janeiro, convidando-me para fazer o censo de lepra em Pernambuco. Solteiro, independente e curioso por conhecer o restante do Brasil, resolvi aceitar. A família só faltou me amarrar para impedir que eu fosse. Para eles, o Nordeste brasileiro era exatamente como o Saara. E também havia o perigo dos cangaceiros. Lampião e Corisco ainda estavam por lá, e os parentes achavam que eu estava para entrar em uma aventura da qual não sobreviveria. Mas persisti e, em 22 de novembro de 1937, embarquei no navio que me levaria ao Rio de Janeiro. Aqui firmei o contrato que me nomeava médico interino classe K, da Delegacia Federal de Saúde. Tomei um avião e fui para Recife, com escalas em Vitória, Belmonte, Caravelas, Canavieiras, Ilhéus, Salvador, Aracaju e Maceió. Que beleza de cidade é Recife, toda verde, cheia de rios! Foi amor à primeira vista. Gostei da cidade, gostei do ambiente, gostei do lugar. Fui recebido por Alfredo Norberto Bica, um primo de São Gabriel que havia sido companheiro de faculdade, tendo se formado dois anos antes de mim. Ele era o delegado federal de Saúde e foi meu primeiro chefe.

Já na primeira noite, bebendo um drinque no bar antes do jantar, sentou-se a meu lado um cidadão. "O senhor é daqui?", perguntou-me. "Não, estou chegando". "E o que o senhor faz?" "Eu sou médico." "Eu também. O que o senhor faz?" "Vim fazer o censo da lepra para o governo." "Pois eu trabalho nesse campo. Sou o chefe do Serviço da Lepra daqui". Dali a pouco já estávamos cantando em duas vozes (risos); fomos para Olinda ouvir seresta. Era Gil Campos, homem formidável, que morreu há 
pouco tempo. A história dele é das mais alegres e simpáticas da boemia inteligente pernambucana.

Trabalhei primeiro em Recife, onde o número de casos de lepra era relativamente grande, não sei se por ser uma região quente, úmida, com certa densidade populacional. Escrevi um pequeno trabalho a esse respeito. Mas me tentava muito viajar pelo interior e comecei a trabalhar por lá. Eu tinha o cuidado de não dizer nunca para onde ia e quando sairia, por causa dos cangaceiros, mas nunca houve problemas com eles. Durante essas viagens entrei em contato com as reais necessidades de saúde do povo. Vi áreas afetadas por peste, malária, todas as síndromes de subdesenvolvimento e com muito pouca assistência, apesar dos esforços do governo estadual, que oferecia uma certa cobertura de saúde com o Sistema de Unidades Sanitárias. Mas essas unidades dedicavam-se mais a ações específicas de combate a doenças transmissíveis e ao atendimento das necessidades primárias e correntes da população.

Em certa ocasião, passou por Pernambuco o doutor João de Barros Barreto, diretor geral do Departamento Nacional de Saúde, um homem que entrou para a história da saúde pública no Brasil. Ele recrutava jovens promissores para o curso de Saúde Pública que naquela ocasião era realizado aqui em Manguinhos. Era um curso um pouco mais longo, com uma duração de cerca de 18 meses. Não se fazia medicina tropical e doenças parasitárias; aprendia-se entomologia.

LF - Microbiologia, parasitologia...

EB - Sim, com Lacorte, Oliveira Castro, aquela gente toda. Então eu fiz este curso e terminei em 1941. Àquela altura eu já me interessava mais por áreas como saúde ocupacional e higiene do trabalho, muito por influência de Barros Barreto, que era professor do curso. Logo depois, ele me levou para trabalhar como assistente em seu gabinete e, ao mesmo tempo, assistente da cadeira que ele lecionava. Eu dava aulas práticas, saía para visitar fábricas, tudo relacionado à saúde ocupacional.

LF - Não havia em Manguinhos, nessa época, um laboratório de higiene industrial chefiado pelo Barreto?

EB - Sim; na verdade, era uma divisão chamada Higiene Industrial. Se eu tivesse permanecido no Rio de Janeiro, talvez fosse para lá também. Mas o governo de Getúlio Vargas queria expandir sua atuação, em matéria 
de saúde, e criou a figura dos sanitaristas federais, que eram alocados em cada estado, com exceção de São Paulo, como diretores ou secretários de saúde. Muitos ocuparam essa função: Aquiles Scorzelli Jr. na Paraíba; Bichat de Almeida Rodrigues no Paraná; eu no Pará; Bonifácio Costa no Rio Grande do Sul; Amilcar Barca Pellon, Manoel Uzeda, Eugênio Porto e vários outros. Todos foram cedidos a governos estaduais, para se responsabilizarem por órgãos ou secretarias de saúde. De certo modo, era também uma estratégia para canalizar a ajuda federal para os estados, que era mais centralizada, sem a multiplicidade de organismos que há hoje. Essa colaboração se fazia através do Departamento Nacional de Saúde, órgão do Ministério da Educação e Saúde que gozava de muita independência e autonomia.

Antes de ir para o Pará, atuei também como delegado federal de saúde. Já havia, como hoje, as delegacias federais de saúde, mas elas eram executivas também. Antes da criação dos serviços nacionais de febre amarela, malária, peste e outros, as campanhas contra essas doenças, com exceção da febre amarela, eram realizadas pelas delegacias, pequenas representações do Departamento Nacional de Saúde nos estados. Então, com o staff das delegacias e mais o sanitarista federal como diretor ou secretário de Saúde, a ação federal era muito intensa. Essas doenças de caráter nacional, sobretudo as transmitidas por vetores, requerem a organização de um sistema de saúde pública de cobertura, de comunidades de saúde, voltadas predominantemente para ações preventivas, programas de treinamento de pessoal etc.

Um evento que ocorreu naquela época modificou muito a minha vida. Foi o surto de malária (Anopheles gambiae) no Nordeste, em 1937. Souza Pinto já tinha encontrado o mosquito lá, em 1934 ou 1935, mas o fato foi ignorado e a epidemia se agravou tremendamente entre 1937 e 1938. Chegou então o primeiro grupo de colaboradores, chefiado por Maneco Ferreira e composto por Bustamante e outros. Eles constataram que os mecanismos regulares da administração nacional de saúde não permitiriam que ali se estabelecesse uma campanha com flexibilidade suficiente para controlar a situação, que significava, em última análise, erradicar o mosquito transmissor que tinha vindo da África. O grupo propôs que isso fosse feito em colaboração com a Fundação Rockefeller, que atuava, então, predominantemente, na área da saúde. De fato, essa fundação mobilizou gente muito boa, todas já nos anais da história moderna da malária, como Strow, Racket, Watson e o próprio Fred Soper.

Este mesmo grupo daria origem ao Sesp (Serviço Especial de Saúde Pública). Durante a Segunda Guerra, o governo norte-americano 
fechou acordos com diversos países, que tinham por propósito a produção de matérias-primas estratégicas, como a borracha, e a extração de minerais, como a mica. Os acordos eram um excelente negócio para os Estados Unidos, porque impediam que os preços fossem alterados. No caso da borracha, por exemplo, fixavam seus preços e, em contrapartida, ofereciam uma certa assistência aos países, sob o pretexto de proteger os trabalhadores envolvidos na produção.

$\mathrm{Na}$ realidade isso nunca funcionou muito bem. O Serviço Especial de Mobilização de Trabalhadores para a Amazônia (Semta) ${ }^{2}$ - era chamado de 'Senta-te e Espera, Miserável Trabalhador para a Amazônia' (risos). O Maneco foi o chefe médico desse serviço, que selecionava e embarcava os trabalhadores para a Amazônia. Os homens eram jogados no meio da floresta, sem dominar a técnica da extração da borracha, e não houve praticamente nenhum aumento da produção. O Brasil como um todo não se beneficiou com o acordo. No que concerne à saúde, se o preço da borracha tivesse flutuado livremente conforme as leis de mercado, certamente o país teria mais recursos para investir nessa área, até mesmo na Amazônia. Mas isso é história política, é assim que as coisas ocorrem (risos).

Eu estava em Belém, como diretor de Saúde do Pará, quando o Sesp passou à administração nacional. No início houve uma certa resistência ao Sesp, por parte de nosso pessoal, porque seus dirigentes eram quase todos ligados ao Instituto de Assuntos Interamericanos e tinham muito menos preparo, experiência e qualificação em saúde pública do que nós. Eram pessoas arrebanhadas nos Estados Unidos, sem competência e experiência suficientes. E chegou o momento em que não houve alternativa senão entregar a administração do Sesp a brasileiros. Houve, então, uma grande mudança. Marcolino Candau assumiu, junto com Sérvulo Lima, no Rio de Janeiro; Paulo Antunes, de São Paulo, foi para a Amazônia; e eu, que estava no Pará, fui convidado a ir para a região do Vale do Rio Doce. E então aí começou a fase nacionalizante do Sesp.

No Sesp defendíamos a tese de que saúde é indivisível, deve ser alcançada por ações que vão do saneamento até as formas de assistência à saúde. Foi uma boa escola, pelo menos para que um grupo de médicos e outros brasileiros tomassem posição. E passou a ser um elemento importante na preparação de pessoal. Naquela fase dava-se grande importância a toda a equipe de saúde, e o Sesp chegou a ter de 80 a 100 engenheiros sanitaristas.

O Semta foi criado em 1942 após a assinatura dos Acordos de Washington pelo presidente do Brasil, Getúlio Vargas, e o presidente dos Estados Unidos, Franklin Delano Roosevelt. 
O ensino de enfermagem, no Brasil, modificou-se muito também na ocasião. A enfermagem era dominada por duas senhoras: uma no Rio de Janeiro, chamada Nair Neto dos Reis, diretora da Escola Ana Néri; e outra em São Paulo, Edith Frankel, originária do Rio. As duas, a despeito de serem inimigas irreconciliáveis, preponderavam sobre todo o panorama da área. Quando teve oportunidade, o Sesp convocou um grande número de moças, todas com nível superior, para fazer cursos de enfermagem e saúde pública no exterior, e elas renovaram o campo. O Sesp também participou da criação de novas escolas de enfermagem no Brasil; eu mesmo estive envolvido diretamente com as de Manaus e Recife.

(...)

Quando trabalhava no Vale do Rio Doce, me ofereceram a oportunidade de fazer um curso de saúde pública na Universidade de Columbia, nos Estados Unidos. E foi bom, porque tive contato com bons epidemiologistas, estatísticos e administradores da área de saúde, além de me aperfeiçoar na língua inglesa.

LF - Você já tinha feito um curso aqui, não é?

EB - Não só tinha feito o curso como já ingressara na carreira de sanitarista, que havia sido criada naquela ocasião.

LF - Eu gostaria que você falasse sobre as diferenças entre esses cursos.

EB - Eram a mesma coisa. Os cursos de saúde pública eram praticamente iguais, a não ser pela ênfase, no curso brasileiro, em doenças tropicais, parasitárias e infecciosas. E o daqui era também um curso mais longo, de um ano e meio, enquanto o norte-americano não era acadêmico. Mas abordavam-se as mesmas matérias: epidemiologia, estatística...

LF - E a parte laboratorial, muito forte aqui, também tinha lá?

EB - Muito pouco, quase nada.

LF - E a microbiologia?

EB - Também quase nada. Eu fiz o curso de saúde pública para ingressar como médico sanitarista na carreira que haviam implantado havia pouco tempo. Fiz parte do primeiro grupo concursado, com Silvia 
Hasselman e outros. Por fim, quando eu já estava em final da carreira, o coronel Darci Siqueira, do famoso Dasp (Departamento de Administração do Serviço Público), resolveu jogar todos os aposentados para o início de carreira; de modo que, após todas essas minhas andanças, o senhor coronel Darci me devolve para onde comecei (risos). É ridículo e triste ao mesmo tempo.

Os anos que passei no Vale do Rio Doce me fizeram aprender muito. Era a época da reconstrução da estrada de ferro e havia muito trabalho de campo: problemas de malária, de engenharia sanitária e de saúde em geral da região. Enfim, tínhamos oportunidade não só de promover certas idéias, mas também de executá-las. Algumas eram até sofisticadas. Pela primeira vez, na América do Sul e no Brasil, fez-se fluoração de água. Em Baixo Guandu, com o Mário Chaves, realizou-se higiene dentária. O serviço tinha sociólogos, como Charles Wagley. Quer dizer, já se pensava a saúde no contexto social como algo que não pode ser isolado.

LF - É possível identificar a época em que o trabalho com a saúde pública deixa de se orientar apenas pelos princípios da bacteriologia e parasitologia e passa a recorrer também às contribuições das ciências sociais? Como se caracterizou esse processo?

EB - Aconteceu, a meu ver, na fase do Sesp, com o desenvolvimento de suas atividades. Houve até um certo conflito entre o Sesp e o Ministério da Saúde, por esta razão. Barros Barreto, que procurava promover as atividades de saúde sob essa ótica, nunca esteve satisfeito com o fato de o Sesp ter sido criado fora do Departamento Nacional de Saúde. Apesar de subordinado ao Ministério, não pertencia ao Departamento. Mas a mudança aconteceu nesse momento, muito por influência do trabalho realizado em campo, da sociologia, da moderna epidemiologia e das outras profissões de saúde envolvidas.

LF - Foram os americanos que trouxeram essa concepção?

EB - Eu diria que em grande parte sim. Por exemplo, o saneamento básico como condição fundamental para melhora da qualidade de vida foi um preceito encampado pelo Baiting e os engenheiros brasileiros que compunham seu grupo. Eles criaram a moderna engenharia sanitária no Brasil. A não ser a firma de Saturnino de Brito e outras poucas, não havia nada; a engenharia sanitária era muito primitiva. 
Parece-me que foi nesse momento que a posição tradicional começou mudar, o que a certa altura resultou até em um conflito institucional e administrativo. O presidente Getúlio Vargas, influenciado pelo professor Olinto de Oliveira, um eminente pediatra, extinguiu arbitrária e autoritariamente o Setor da Criança do Departamento Nacional de Saúde e criou o Departamento Nacional da Criança. A ação federal junto aos estados, então, passou a ser feita através de duas linhas de ação, e só recebia ajuda para as crianças o estado que criasse também seus departamentos e secretarias de saúde infantil. Então, fez-se uma separação total, com a família dividida em dois setores: as crianças e os demais. A medida repercutiu até no plano acadêmico, em que se criaram as cátedras de Puericultura e Pediatria, como se fossem disciplinas diferentes. Esta é uma invenção totalmente brasileira, que não existe em nenhum outro lugar.

Retornando à visão abrangente da saúde, ela de fato ocorreu muito por influência dos que vinham de fora, dos bons elementos que participaram conosco daquelas ações, mas foi fruto também de uma consciência nossa, dos brasileiros envolvidos, porque entendemos que era o momento de lançar nossas posições sobre a maneira correta de proceder em matéria de trabalho em saúde, especialmente nas zonas rurais e mais remotas.

Enfim, foi esta a oportunidade que o Sesp me deu, a de ingressar mais profundamente no campo da saúde pública. Depois disso, em fins de 1953 ou início de 1954, quando eu era superintendente do Sesp, foi criado e instalado o Ministério da Saúde e surgiu um novo Departamento Nacional de Saúde, para o qual fui nomeado diretor geral. O Instituto Oswaldo Cruz, o Sesp como órgão especial, o Departamento Nacional da Criança e o Departamento Nacional de Saúde passaram a constituir o setor da saúde do governo federal. Em agosto de 1954, quando o presidente Getúlio Vargas se suicidou, esse cenário começou a mudar novamente. Deixei a direção do Departamento e tomei outros rumos também.

Há um fato interessante que convém deixar registrado. $\mathrm{Na}$ madrugada de 24 de agosto de 1954, quando Getúlio se suicidou, todos os ministros fugiram, o governo literalmente desapareceu, inclusive o meu ministro, Mário Pinotti (risos). Na ausência da autoridade maior, resolvi assumir o Ministério, por minha própria conta. Chamei os colegas e disse: "Meu departamento é o maior de todos, então vamos assumir a responsabilidade de tomar conta disso. Fiquem em contato comigo". Recordome de que, na manhã do segundo dia, telefonei para o diretor do Departamento de Administração. "Ministro?", ele disse. "Ei, não faça isso!" (risos). Essa situação durou cerca de 72 horas. Depois, o Ministério da Saúde, 
que desfrutava de uma certa integridade e algum respeito, passou a ser parte do butim político. Assumiu o ministério um cidadão do Paraná, Ataíde...

LF - Aramis de Ataíde.

EB - Sim. E vieram outros mais, inclusive o famoso Salsano, que era o médico espírita do Ademar de Barros. Então, o Ministério da Saúde passou por uma fase de tremenda desordem; pode-se dizer até, francamente, de grande corrupção. Foram momentos terríveis, dos quais vocês devem ter ouvido falar. Costumo dizer que quem não se corrompeu naquela ocasião é incorruptível. O que não era oferecido?! As 'caixinhas do Ademar' funcionavam que era uma beleza. O Ministério da Saúde passou a ser propriedade dele e de seu partido durante um certo período. Nessa ocasião, já havia me afastado do ministério, portanto, não fui testado e não sei se sou corruptível (risos).

Eu havia me transferido para a Capes (Coordenação do Aperfeiçoamento de Pessoal de Nível Superior), com o Anísio Teixeira à frente dela. Estavam lá Almir Castro e Celso Barroso Leite. A Capes era um órgão extremamente interessante no plano de formação e aperfeiçoamento de pessoal para as necessidades do país. Mas não se dedicava muito à formação no campo de saúde, até a Fundação Rockefeller reaparecer no Brasil. A Fundação havia se afastado um pouco do país, ainda que continuasse a fazer alguma pesquisa de febre amarela, mas ela retornou interessada em colaborar para a formação de pessoal em saúde e medicina e estimular a pesquisa biomédica. Em princípios de 1955, chegou ao Brasil Robert Watson, um norte-americano que esteve muito tempo na China, antes de Mao, e depois viveu na Índia por muitos anos. Ele vinculouse à Capes, através de um convênio entre esta e a Fundação Rockefeller, para promover um programa de aperfeiçoamento e preparação de médicos e enfermeiras. E logo iniciou-se um crescimento espantoso de escolas médicas no Brasil. Entre 1960 e 1970 criaram-se no Brasil 52 escolas de medicina, um número maior do que o observado na União Soviética, desde a revolução até os dias de hoje.

Havia necessidade de preparar gente, e a idéia era simples: verificavam-se os centros de excelência do país que podiam realizar treinamento de pessoal; a Fundação Rockefeller fornecia recursos à Capes para que esta concedesse bolsas de estudos. Com isso, mobilizou-se gente de todo o Brasil para ser treinada em patologia, fisiologia. Nessa mesma época, o peronismo expulsou todo o grupo de fisiologia da Argentina, que 
veio, então, ensinar no Rio Grande do Sul. Havia o Nelson Chaves em Pernambuco, com a nutrição, o grupo de Ribeirão Preto; o Chagas no Rio de Janeiro, em biofísica. Mas por que não as outras disciplinas? Porque a ajuda só era dada àquelas instituições cujo corpo docente se dedicasse predominantemente à pesquisa, e apenas para elas os bolsistas em regime integral podiam ser encaminhados.

Trabalhei vários anos nesse programa, não só no Brasil, mas também fora dele. A Fundação Rockefeller atuava na Argentina, no Uruguai, Chile, Peru e na Bolívia e, embora cedido para o programa no Brasil, eu dava umas 'fugidas' a esses países como seu colaborador. Aliás, o programa ainda realizava intercâmbios de caráter internacional, levando elementos nossos para outros países e trazendo os estrangeiros. Essa experiência me levou a uma outra área, a de recursos humanos, e passei a me dedicar mais aos programas de formação de pessoal na área da medicina, me afastando da área de administração de saúde pública, ainda que mantivesse muito contato com o curso de Saúde Pública do Ministério da Saúde, de cuja criação participei.

Esse curso surgiu um pouco por acaso. Em 1954, quando eu estava na direção do Departamento Nacional de Saúde, o grupo de lá soube de uma lei engavetada no Senado, de autoria do então deputado Rui Santos, chamada Lei Básica de Saúde. Era um misto de lei e código sanitário e contemplava três providências importantes: a implantação do Laboratório de Drogas e Medicamentos; a criação da Escola Nacional de Saúde Pública, subordinada ao Ministério da Saúde; e o princípio de tempo integral para a carreira de Saúde Pública. Graças a contatos que fiz pessoalmente com o presidente da Comissão de Saúde do Senado, conseguimos que a lei, sem qualquer emenda, fosse aprovada naquela instância sem ser preciso retornar à Câmara; ela voltaria ao ministério para eventual correção de alguns trechos confusos. Assim foi criada a Escola Nacional de Saúde Pública. Dos Estados Unidos vieram, imediatamente, elementos para assessorar a sua implantação - o Mário Wegman, o Bichat Rodrigues, o Hudson de Barros Silva - e começamos a dar os primeiros passos. Na ocasião, convidei Raimundo Muniz Aragão para implantar o Laboratório de Drogas e Medicamentos; ele aceitou e passou dez anos lá. O Muniz era membro do Conselho Universitário e estabelecemos entendimentos para que a Escola tivesse, desde o início, mandato universitário, preservando ao mesmo tempo sua vinculação ao Ministério da Saúde. Com o fim do governo de Getúlio Vargas, houve aquela confusão toda e o assunto seguiu por outros caminhos, até que Edmar Terra Blois conseguiu levar adiante a idéia da criação da Fundação 
de Ensino Especializado de Saúde Pública, que depois se transformou no que é hoje a Escola Nacional de Saúde Pública.

Como disse, meu trajeto profissional dirigiu-me à área de formação de pessoal e desliguei-me completamente de administração de saúde. Em 1962, por decisão de uma reunião em Viña del Mar, foi criada a Federação Pan-Americana de Associações de Faculdades de Medicina e convidaram-me para ser o seu primeiro diretor executivo, cargo que exerci durante quatro anos. Depois, candidatei-me à direção da Divisão de Educação e Treinamento da OMS (Organização Mundial da Saúde). O diretor anterior se aposentara, depois de exercer a função desde que a organização fora criada. Fui selecionado e mudei-me para Genebra, onde fiquei sete anos. Ao voltar ao Brasil, vim para cá.

\section{LF - Veio ser nosso diretor.}

EB - É. Já no fim da gestão de Mário Machado de Lemos no Ministério da Saúde, Oswaldo Costa foi nomeado presidente da Fundação Oswaldo Cruz e convidou-me para dirigir a Escola Nacional de Saúde Pública. Oswaldo havia sido meu colega de turma no curso de Saúde Pública e fomos bons amigos. Assumi a direção da Escola durante oito ou nove meses.

O fato é que o regresso ao Brasil me fez recuperar o interesse por saúde pública, administração de serviços de saúde e planejamento de saúde, e passei a retomar antigos contatos, participar de eventos... Hoje meu único vínculo formal é com a universidade, como professor adjunto, e desfruto de muita independência. Atualmente, estou envolvido no processo de união do Instituto de Puericultura com o Hospital Universitário, de modo a que o instituto se integre, num processo de cobertura de saúde materno-infantil, nessa área docente-assistencial, cuja implantação agora vai mesmo começar. Também estou atuando no programa de mestrado em Administração Pública, com ênfase em saúde, da Fundação Getulio Vargas, e colaborando com a Abem (Associação Brasileira de Ensino Médico) nas discussões sobre a formação do clínico médico, o antigo clínico geral, que começa a desaparecer e ceder lugar ao especialista. É preciso que se estabeleça um certo equilíbrio nesse processo, que não se elimine o especialista porque ele é cada vez mais necessário; mas, por outro lado, esse processo leva ao desaparecimento do generalista se partirmos para uma outra forma de cobertura de saúde. 
LF - Você teve uma participação importante na estruturação do Hospital Universitário da Universidade Federal do Rio de Janeiro. Como se comporta este hospital diante da concepção de medicina que você defende? A reação dos superespecialistas é muito forte?

EB - É difícil a implementação de alguns conceitos e algumas idéias, e consciência educacional se faz muito lentamente. Edgard Ford, no livro Learning to Be, estima um prazo de pelo menos dez anos entre a idéia e a sua implantação no campo educacional, e a experiência internacional confirma este cálculo. Na OMS tivemos oportunidade de observar esse processo nos lugares em que não havia formação de médicos, como os países africanos que se tornaram independentes na década de 1960. A formação é feita sobre um sistema de saúde, seja ele qual for, desde que coerente com a realidade local. O componente educacional deve ser lógico e transmitir uma soma de conhecimentos suficiente para que se executem as funções inerentes à tarefa médica. Mas o indivíduo em formação tem de ser conectado a sua realidade específica, que se traduz nos recursos disponíveis e nos contextos nosológico e socioeconômico. Assim, é possível construir algo eficiente em matéria de cobertura de saúde.

No Brasil, é diferente, nós temos uma tradição acadêmica. Eu sempre digo que a minha escola, a sua escola eram compostas por estrelas que nunca formaram uma constelação. Um hospital universitário é um hospital geral que serve de campo de aprendizado para algumas profissões ligadas à saúde. Nele dois elementos têm de ser o centro das atenções: o paciente, que deve ter garantidos o seu atendimento e a sua internação, esta sempre que necessária; e o estudante. Mas não era esta a concepção prevalecente; o hospital era mais ou menos para o nosso deleite, para a nossa satisfação intelectual e profissional: "O meu serviço, a minha clínica...".

É muito difícil reverter esse quadro, mas continuamos tentando, com seminários, encontros de motivação e sensibilização do corpo docente. Em 1977, participei de um esforço desta natureza. Conseguimos reunir, durante esse ano, cerca de 280 profissionais e professores da área de enfermagem, das mais refinadas vedetes aos jovens professores, para debater essa realidade. Felizmente era um hospital recente, com menos de cinco anos de funcionamento, do contrário não sei se teríamos conseguido. A intenção era conscientizar a equipe de que o hospital tem um compromisso social, não é mais uma armadilha para capturar doentes raros e tampouco é propriedade do corpo docente. Este atua com responsabilidade e capacidade, mas sob os preceitos mencionados. 
Como foi feito esse trabalho? A cada mês, durante três manhãs sucessivas, realizava-se o encontro, com grupos que não excediam de 30 pessoas No primeiro dia, em cerca de meia hora, cabia a mim introduzir o tema: a relação do processo de formação com os sistemas de saúde, a integração docente assistencial, a evolução desse processo. Depois ressaltava que, em termos de formação de pessoal, continuávamos pensando como no passado, em 1935, época em que eu estava na escola, e que era preciso modificar aquela ordem de coisas. Evidentemente não somos, nem podemos ser, contra os centros de excelência e a formação do especialista, contingência do desenvolvimento de qualquer sociedade. Eles ocorrem em todas áreas - medicina, artes, ciência, literatura etc. -, mas não se pode alienar o conhecimento, como se existisse independentemente do resto.

Ainda no primeiro dia, após a minha introdução, falava alguém da Previdência Social. Ali estiveram Gentille de Melo, Murilo Vilela Bastos e outros, que abordavam não as virtudes da Previdência, mas as angústias causadas pelo seu crescimento, as preocupações com o seu desenvolvimento futuro, as intenções de seu entrosamento nesse processo e o entendimento necessário entre as várias instituições de saúde. Por fim, o J. Rodrigues Coura discorria sobre o que seu grupo entendia por 'trabalho de saúde na comunidade'. Depois abriam-se os debates, os mais amplos possíveis, sem roteiro. No primeiro dia, as perguntas ainda não eram muito precisas, havia uma certa indefinição.

No segundo dia, o tema era o hospital: as redefinições por que havia passado, as modificações ocorridas, desde as arquitetônicas até as operacionais, as novas normas de funcionamento e como isso representava um passo adiante, uma tomada de posição por parte da Universidade, que aliás foi expressa em um documento e entregue ao governo. Em seguida vinha alguém da área de computação, a ressaltar a extrema simplicidade do computador, do qual não se pode prescindir quando se lida com muitos números, muita gente e muitos recursos, além de ser muito útil nas operações técnicas do hospital e na pesquisa. O Henri Jouval, então, encerrava falando sobre a abertura do hospital para a comunidade e as interfaces propostas. Ele representava um grupo de trabalho, presidido pelo José Rodrigues Coura, que tentava redefinir o ambulatório do novo hospital com base em um estudo que revelou que nenhum dos ambulatórios da universidade, cerca de 80 ou 90, funcionava a contento.

No terceiro dia, o foco era o processo educacional. Alice Reis Rosa falava pela graduação, Neri Guimarães, pela pós-graduação e Luís Carlos Lobo encerrava com metodologia e tecnologia educacional. Era 
interessante observar a atitude das pessoas nesse dia. Suas perguntas revelavam que estavam conhecendo algo diferente, fruto de uma evolução que até então não tinham percebido. Porém alguns reclamavam: "Eu pensei que fosse médico, vejo que não sou médico; pensei que fosse professor, vejo que não sou professor. No fundo, sou instrumento de um processo de mudança”. É verdade! (risos). Isto foi dito pelo Sílvio Fraga, 'muito' especialista, 'muito' dermatologista. O paciente que chegasse a esse novo hospital seria examinado pelo médico geral, que deveria ser capaz de identificar o motivo que levou o indivíduo até lá. Somente em última instância o encaminharia ao especialista, e apenas aos casos desesperadores seria recomendada a internação. Há médicos que nunca concordaram com essa concepção e até hoje são contrários a ela. Para eles, o que estávamos fazendo ali, na realidade, não era um encontro, seminário ou conferências, mas verdadeiros 'cursilhos' acerca de uma determinada política e filosofia (risos).

Não sei se o movimento terá sucesso, mas há esperanças, porque à frente dele há pessoas de muito prestígio na classe médica e no corpo docente da faculdade. Há outros elementos jovens, que lutam com dificuldades. Esse processo de doutrinação não é fácil.

Agora mesmo faremos outra reunião sobre o que discutimos em Campinas: a formação do médico generalista. O que impede, afinal de contas, que as escolas de Medicina preparem seus estudantes de modo a terem uma formação geral e abrangente que lhes permitam ir para casa sem perder a face, deixar de se esconder na cidade grande e não prescindir, para o seu desempenho, de uma equipe invisível? Se forem inteligentes, podem até ser muito bem-sucedidos na sua vida profissional, mas nada indica que serão suficientemente capazes como médicos, no sentido abrangente do termo, nem mesmo bons especialistas. Então o que se discute é isto: até que ponto precisamos ir para alcançar um equilíbrio, para que as escolas de medicina se sintam comprometidas com uma formação abrangente. Trata-se, como já mencionei, de um processo de remotivação do corpo docente.

LF - Dr. Ernani, o curso de saúde pública, a própria Escola de Saúde Pública, tem início num período em que a Escola de Medicina tem essa estrutura que você mencionou, que a gente conheceu, em que alguma coisa mais próxima da saúde pública é apenas o velho curso de higiene. Na realidade, ela supre alguma coisa nessa época. Eu pergunto: como você vê a Escola de Saúde Pública diante de toda essa mudança do ensino médico e a criação 
do Departamento de Medicina Preventiva? Quais são as suas sugestões para o cenário atual?

EB - Este tema foi objeto de um encontro de peritos em Genebra, no último ano em que estive na OMS. Das três reuniões, uma tratou da educação e outra sobre o ensino de saúde pública. Esta última tomou por base o levantamento, por amostragem, de um bom número de escolas de saúde pública no mundo e constatou apenas modificações inexpressivas no processo tradicional de ensino. Recomendou-se, então, que nos países em desenvolvimento se procurasse fazer com que o médico, ao terminar o curso, já tivesse uma preparação satisfatória no campo da saúde em geral, e que sua formação, se ele quisesse enveredar por este setor, pudesse ser feita na própria faculdade, em programas de especialização voltados especificamente para organização ou serviços de saúde. Naquelas reuniões de Viña del Mar, as indicações para que as escolas de medicina enfatizassem o ensino de saúde pública através de departamentos de medicina preventiva já eram resultado das recomendações de Colorado Springs, nos Estados Unidos.

Mas depois a tendência se inverteu. Mesmo na Faculdade de Medicina de Brasília - eu participei de seus primeiros passos - optou-se por não criar um departamento de medicina preventiva. Seria uma escola com uma visão geral de saúde pública, de saúde comunitária. Os corpos docente e discente assumiriam responsabilidades em relação aos problemas de saúde da comunidade, e não apenas dentro do hospital. Foi esta a filosofia que predominou e que, de certo modo, transferiu-se para as escolas que hoje são montadas na África. Nenhuma tem departamento de medicina preventiva. A primeira dessas escolas foi em Camarões, criada com a ajuda de José Roberto Ferreira e um canadense. Nós três fomos lá para convencer o governo a configurar uma escola de medicina diferente do modelo francês. $\mathrm{Na}$ verdade, propúnhamos uma adaptação, a uma outra comunidade, dos conceitos adotados na Faculdade de Medicina de Brasília. Notem que elas não são denominadas escolas de medicina e sim centros universitários de ciências da saúde, e recomenda-se expressamente que não se criem escolas de saúde pública. As já existentes, centros de excelência com grande knowhow, são locais de formação de um estado-maior, academicamente mais sofisticadas, e é evidente devem permanecer; sua extinção seria um absurdo, em virtude dos conhecimentos e da capacidade que acumularam. Mas não se justifica criar, hoje, uma escola de saúde pública em Mali, Gabão, Uganda. A especialização existe; há mestrados - até mesmo em Saúde 
Pública -, porém, no processo regular de formação acadêmica. E o mesmo vem ocorrendo em outros países onde não há essa tradição universitária, que dificulta a realização de algumas coisas.

É esta a minha opinião, coerente com o relatório que apresentei na época e a proposta que elaborei e realizei. Não há nada de revolucionário nas recomendações; elas apenas revelam essas tendências. É hora de pensar diferente, sem recusar o que foi feito ou rejeitar o que há de bom, mas também sem insistir em modelos que não têm mais razão de ser. Eu não criaria uma nova escola de saúde pública no Brasil, mas não acabaria com esta (risos). Mas sei que o Brasil está condenado a desenvolver novas escolas, em outros estados, para prestígio de alguém e por outras decisões estranhas.

SA - Desde o Estado Novo, o senhor passou por diferentes formas de governo e diversas tendências, como o desenvolvimentismo. Como o senhor vê as mudanças de ênfase da natureza da saúde pública, durante todo esse tempo?

EB - É uma boa pergunta, mas não é fácil respondê-la. Não sei se a importância da qualidade de saúde do povo brasileiro era bem entendida, do ponto de vista da sociologia moderna ou da abordagem de vocês. Apenas tinha de haver um órgão para tratar dos assuntos de saúde, das doenças transmissíveis que pairavam por aí. Sabíamos que deveria haver um 'trabalho de saúde pública', mas não sei se era compreendido como um programa inerente ao desenvolvimento da sociedade; nunca senti que isso se fizesse conscientemente. Se havia resultados, estes provinham mais de ações de combate, ações paliativas para a solução de problemas que estavam ali, na nossa frente, e que devíamos enfrentar de uma maneira ou outra. Eu diria que foram os sociólogos, quando vieram trabalhar com o Sesp, que nos chamaram a atenção para esses outros aspectos.

No tempo do Getúlio Vargas, aqueles que estavam empenhados no trabalho de saúde tinham muita liberdade de ação e autoridade. Não me recordo de ter havido qualquer interferência política nas ações de saúde. Pelo contrário. Pelo contrário; o presidente foi muito decisivo quando se precisou agir rapidamente, como foi o caso do surto de malária no Nordeste. Assim como no próprio desenvolvimento do Sesp, também naquela ocasião, pois a mudança exigia a passagem de um estado de coisas inteiramente político para um contexto que permitisse realizar algo diferente.

No período de Juscelino Kubitschek, o Sesp teve bastante apoio, talvez tivesse havido uma influência pessoal da ligação do Penido e dos 
Penido com Juscelino. O Osvaldo Penido era chefe da Casa Civil. Mas Juscelino era um homem muito simpático, receptivo e acompanhou de perto a criação do Sesp no Vale do Rio Doce, ocasião em que estabeleci com ele relações pessoais.

Já o período atual é diferente, e eu o vejo com muita preocupação, até mesmo com uma certa decepção. Logo após a revolução de 1964, criaram-se dois grandes conselhos, o de Desenvolvimento e o de Segurança, mas o setor social não foi objeto de atenção por parte das forças políticas, do governo e do regime que então teve início. Não é preciso se aprofundar em nenhuma análise para constatar que a atual situação é preocupante. A qualidade de saúde não melhorou, tampouco a realidade socioeconômica. É uma situação que preocupa todos, os problemas se agravam cada vez mais e o desacerto das instituições é enorme. Como vivo no meio, me relaciono com pessoas, mas não tenho vínculo com as instituições da área, costumam desabafar comigo. Vem o pessoal da Previdência e me diz: "Não é possível nenhum entendimento com o pessoal da Saúde!" O pessoal da Saúde reclama: "Não é possível nenhum entendimento com o pessoal da Previdência!" Mas há os que buscam um acordo, e tenho visto alguns documentos com este fim.

Às vezes convidam-me para reuniões. Outro dia, por exemplo, o novo presidente do Inamps (Instituto Nacional de Assistência Médica da Previdência Social) me chamou para conversar com ele, Woodrow Pimentel Pantoja e Felipe Cardoso. A mim, que não tenho nada a ver com assuntos de saúde do estado ou do município. O presidente do Inamps, um almirante, parece ser um homem sério e tive dele uma boa impressão. Mas não se definiu ainda uma política de saúde, ou pelo menos não se sabe qual é ela. Não lemos nos jornais ou ouvimos alguma autoridade se pronunciando sobre isso, o que nos permitiria tirar conclusões, como também não há uma política explicitamente formulada. Este parece ser o caminho que seguiremos nas próximas décadas, não obstante a existência de grupos pensando muito seriamente nisso. Na Previdência, por exemplo, há um pessoal empenhado nessa definição. Sei também de pessoas dos Ministérios da Saúde e da Previdência que estão trabalhando juntas nessa questão, e a recomendação delas, que tenho lido, me parece lógica. Mas quando ouço o Ministério se pronunciar sobre política de saúde, o tipo de cobertura que se espera, os mecanismos operacionais que anunciam para alcançá-la, tudo me confunde e preocupa. De certo modo retira-se do Estado, por um lado, e da comunidade, por outro, o direito de fazer o que seria, normalmente, sua responsabilidade. Há pouco tempo assisti a uma apresentação, na 
Fundação Getulio Vargas, sobre a criação de órgãos colegiados, a idéia é boa, mas tenho dúvidas sobre a sua execução. É como se a ajuda e orientação federais, para serem executadas no plano nacional com uma abordagem sistêmica, dependessem de sistemas colegiados de âmbito estadual.

$\mathrm{Na}$ semana passada estive em uma reunião na Escola Superior de Guerra, um debate muito interessante sobre planejamento familiar. Compareceram o padre Leme Lopes, o secretário de Assistência Social de São Paulo, Valter Rodrigues, da Benfam (Sociedade Civil de Bem-Estar Familiar no Brasil) e o advogado José Nabuco. Também lá o que se viu foi um grande desacerto. A meu ver, as opiniões e os debates mostraram que a formulação da política e a definição de estratégias são muito casuísticas e conjunturais. Surgiram questões das mais estapafúrdias, por parte de pessoas, aparentemente, de bom nível cultural. Houve um que disse: "Não me preocupa o problema populacional no Brasil, porque já fiz o cálculo e posso botar toda a população do mundo na Baía de Guanabara" (risos). Outro afirmou: "O Brasil pode ter dois bilhões e quinhentos milhões de habitantes”. Ora, o que nos preocupa não é a quantidade de pessoas, mas o ritmo com que elas nascem. É preciso saber se o Estado está em condições de acompanhar esse ritmo com oferta suficiente de educação, saúde, proteção, emprego etc. para todos. Não é o controle de natalidade que nos preocupa, pois ele pode ser incluído nas ações de orientação sobre contracepção, mas todo o resto. Afirmar que o Brasil pode ter um determinado número de habitantes é de uma simplicidade assustadora! E são estes os termos dos debates entre políticos, agentes sanitários e outros. Não sei o que há; parece-me que falta uma certa acuidade geral (risos).

SA - Quando lemos sobre a história da saúde pública, alguns programas são abordados um pouco vagamente, como por exemplo o atendimento urbano. Segundo essa história, parece que a saúde pública sempre esteve voltada para o combate das grandes endemias ou os problemas rurais. Como era feito o trabalho de saúde pública nos centros urbanos, sobretudo quando estes tomaram vulto com a industrialização, na década de 1950 ?

EB - Essa foi uma fase em que o governo federal teve uma ação mais intensiva no plano da saúde. A saúde urbana era sempre realizada pelos estados e municípios, com o governo federal procurando reforçar as ações. O sistema era aquele tradicional: unidades regionais de saúde, distritos de saúde, cobertura, vigilância epidemiológica. Mas não havia, como não há hoje, grande preocupação com o fenômeno da urbanização e 
seus efeitos sobre a saúde pública. Nunca se controlou o fluxo das populações, que gerou o problema de uma concentração urbana cada vez maior. E não vejo nenhuma modificação substancial entre o que se fazia antes e o que se faz agora. Tenho a impressão de que o sistema de saúde do município do Rio de Janeiro é exatamente igual ao de 1941, quando elaborei o trabalho 'Custo do serviço de saúde pública no Distrito Federal', depois publicado. O Rio era então Distrito Federal. Fiz um levantamento, por cada Distrito de Saúde, de pessoal, custos, consumo etc. e relacionei os resultados à evolução dos índices de saúde e das taxas de mortalidade, entre outros.

SA - E chegou à conclusão de que quanto mais se gastava, pior era (risos).

EB - Tirei uma boa nota nesse trabalho, feito no curso para a cadeira de J. P. Fontenelle, Administração e Organização de Saúde. Mas ele ficou preocupado: "Você está mostrando que quanto mais se aplica em saúde mais as coisas pioram?" Porque os problemas não são apenas no campo da saúde, e nós, pobres homens da saúde pública, não vamos resolvê-los sozinhos.

Anos depois, uma conversa que tive com o Carlos Lacerda veio confirmar isso. Ele fora eleito governador do novo estado da Guanabara, mas já nos conhecíamos antes. Mandei até ele o Santos Paiva, um colega de turma meio aparentado, gente de São Gabriel. Lacerda pediu-lhe para me sondar sobre uma colaboração no governo e eu recusei porque tinha outros compromissos. Um dia, ele já eleito, dois colegas médicos, Marcelo Garcia e Leme Rocha, vieram me buscar: "Ele quer falar com você". Fui até a casa onde ele estava com a esposa e mais uma pessoa, e conversamos sobre vários assuntos. Depois falou: "Agora vamos ao próximo item da agenda: quero convidá-lo para secretário de Saúde do novo estado da Guanabara. E vou the dar as razões por que você tem de aceitar". Sentado em uma cadeira alta e eu, em uma poltrona baixa, ele falava por cima de mim (risos): "Pensei em fulano, que não pôde; pensei em sicrano, que também não pôde. Por fim, acho que você é a pessoa que resolve a situação. Nem sei sobre sua posição política e em quem você votou". Respondi: "Bem, já que você perguntou, votei em você, porque minha mulher é uma das suas 'mal-amadas' (risos) e, em matéria de voto, sou dominado por ela. A questão é que a situação da saúde não se modifica porque não se altera o resto. De que adianta ser seu secretário de saúde para lidar com um sistema hospitalar obsoleto, com as unidades sanitárias fazendo o que 
fazem? Quanto às condições fundamentais, eu poderia fazer uma campanha de vacinação, diminuir um pouco os casos de varíola - que ainda havia naquela ocasião - e sarampo, mas isso qualquer rapaz decente, em início de carreira, faz. Não vou me empenhar, a essa altura da vida, com projetos desse tipo. E eles não são fundamentais para o seu governo; importantes são outras coisas: saneamento básico, habitação, saúde, melhora dos baixos níveis socioeconômicos da população. Portanto, não posso aceitar seu convite. Mas lhe asseguro que aceitarei, com muito prazer, o convite para ser secretário do seu sucessor, se você fizer o governo que eu espero e atender a todos esses problemas". Ele não acatou meus argumentos, e nossa conversa foi longa, interminável. Na verdade - hoje posso admitir - recusei porque não confiava em sua estabilidade emocional. Mesmo sendo meu conhecido e tendo votado nele, receava que pudesse fazer 'algo intempestivo'. Pedi-lhe então um prazo de 24 horas para responder, findo o qual enviei-lhe uma carta por intermédio de Marcelo Garcia, que depois me telefonou dizendo: "Entreguei a carta. Sou eu o secretário".

SA - O Ministério da Saúde tinha uma participação maior no Executivo do que tem atualmente?

EB - O Ministério teve grande participação no Executivo até a queda de Getúlio Vargas. Depois perdeu sua própria capacidade de manter tal posição.

LK-Até 1954 ?

EB - Sim. Até então o ministério tinha, realmente, uma presença muito grande no Executivo. Mas depois, também, houve outros fenômenos muito estranhos. Foi a época das campanhas, o Brasil passou a funcionar por meio de campanhas e o Ministério da Saúde, também. Não havia cidadão a dirigir qualquer órgão do ministério que não quisesse ter a sua. $\mathrm{O}$ nosso querido e amigo, bom, competente, colega Barca Pellon, da Divisão de Organização Sanitária, por exemplo, arranjava um dinheirinho e fazia a campanha do tracoma, da bouba, disso e daquilo, interferindo nas ações dos próprios estados e desprestigiando-as. Hoje, as ações são conjuntas, mas na ocasião era assim que funcionavam. O Ministério da Saúde deixou de desempenhar, por muito tempo, o papel de principal moderador e orientador do planejamento da Saúde, causando uma certa inconsistência 
nos planos locais e, com isso, perdendo muito prestígio junto aos estados. Em 1954, quando eu estava na direção do Departamento Nacional de Saúde, conversei com alguns secretários estaduais de Saúde, tentando compor uma frente única junto ao governo federal, no sentido de garantir que os estados passassem a formular os problemas, com base nos quais as ações federais seriam ajustadas. É assim que funcionam os organismos internacionais: eles elaboram a sua programação de acordo com aquilo que os países exprimem.

Não percebo, realmente, muita diferença com o que ocorre hoje. Agora me preocupa a Previdência Social, porque anda mal e pode entrar em veredas muito perigosas. Outro dia tive uma conversa com o almirante Gérson Coutinho. Ele quer dar racionalidade às suas ações e compor com as secretarias de saúde dos grandes estados e municípios, no que está certo. Por outro lado, pretende fazer uma pequena reforma, sob o argumento de que não haveria, no plano federal e no Ministério da Previdência, uma política claramente formulada, ignorando ou desconhecendo estudos que vêm sendo feitos, inclusive, no âmbito do próprio ministério.

Parafraseando aquele prefeito de São Paulo - que afirmou "São Paulo precisa parar" e o mandaram embora -, eu diria: há que conter as ações verticais da Previdência no campo da Saúde. Porém, não há que sustar seu entendimento e entrosamento com as demais instituições responsáveis pelas ações de saúde. Cabe ao Estado planejar e coordenar tudo o que se faz em matéria de saúde na área sob sua jurisdição, mas se a composição com as esferas locais não se realizar, se as ações verticais da Previdência continuarem, parece-me que ela pode até cair em uma situação ilegal. A lei do Sistema de Saúde é muito clara. Agora, como operacionalizála são 'outros dez mil réis'. Se for feito através de mecanismos muito formais, em que o secretário se tem por senhor absoluto, nunca funcionará. É preciso, sim, que sua equipe de planejamento e execução trabalhe em conjunto com as mesmas equipes de cada estado, compatibilizem ações e se entendam no nível operacional, sem nenhuma formalidade, para a solução dos eventuais problemas.

SA - Como é realizada a escolha dos ministros da saúde? Porque nos outros ministérios parece haver uma lógica.

EB - O critério é não entender de saúde (ri). E não é só atualmente; tem sido assim desde que o ministério foi criado, com exceção do ministro Mário Machado de Lemos, que tinha formação em saúde pública, trabalhou 
na comunidade internacional, foi pediatra do Departamento Nacional da Criança e Secretário de Saúde de um novo estado. Eu diria que ele foi a única exceção, ainda que não se possa desconsiderar seus interesses políticos.

LF - A regra é esta?

EB - Sim; e se aplica inclusive ao atual ministro. Não lhe faltam inteligência e conhecimento no plano das ciências biomédicas, porém ele não possui aquele tipo de experiência que esperamos ver em um homem que atua na área de saúde. Mas é difícil saber se isso é mesmo essencial; eu, pessoalmente, acredito que sim.

SA - O estranho é que os ministros não são políticos nem técnicos. No Ministério da Educação, por exemplo, observamos a nomeação de pessoas por motivos nitidamente políticos, apesar de não serem técnicos em educação. Na área da Saúde, os ministros nomeados nem sequer são políticos, não é?

EB - Não conheço a lógica dessas nomeações, mas o que se destaca é o desapreço que teve o setor da Saúde por parte de todos os governos, em qualquer época. Não se considera essa área um pré-requisito para o desenvolvimento e o recurso humano, meta e instrumento deste. $\mathrm{O}$ primeiro ministro da saúde, Miguelzinho [Miguel Couto Filho] era um anjo de pessoa, mas de saúde não entendia nada! Depois veio o Mário Pinotti, promotor, líder, mas o que sabia sobre saúde? Em uma ocasião, quando ia representar o Brasil na Conferência Pan-Americana da Saúde, em que se apresentariam os resultados da campanha contra o Anopheles gambiae, ele visitou o Instituto Evandro Chagas em Belém. O Damasceno Costa mostrou-lhe, então, uma caixa com o mosquito transmissor da malária naquela região: "Aqui está a fêmea do aquasalis". Ao que Pinotti respondeu: "Não, não é fêmea; é macho" (risos). O macho se distingue a olho nu porque tem bigodes pontudos, nem é preciso uma lupa (risos).

E depois houve aquela sucessão de ministros. Eu não sabia o número total deles a partir de 1954, até ler o levantamento feito pela Fundação Getulio Vargas: foram 20. Até o Armando Falcão foi ministro da Saúde ${ }^{3}$ (risos).

Armando Falcão assumiu interinamente a pasta da Saúde em 1º de janeiro de 1961, em substituição ao ministro também interino Pedro Paulo Penido. Em 31 de janeiro do mesmo ano, com a posse do presidente da República Jânio Quadros, Armando Falcão afastou-se do cargo. (Ver Dicionário Histórico-Biográfico Brasileiro, 2001. v. 2). 
SA - Em que governo?

EB - Durante uma transição política qualquer, quando o Jânio caiu ou outra situação semelhante. Sei que ele era ministro da Justiça e ocupou interinamente a pasta da Saúde, enquanto se buscava um nome para ela. São essas as histórias que correm por aí sobre a escolha de ministros da saúde. "Vamos pôr alguém com um prestígio pessoal maior, que esteja em posição de poder...". Tem sido assim até hoje.

SA - Um outro critério para a nomeação de ministros é a representação dos estados no governo federal, o que também não se observa na pasta da Saúde. No fim, o único critério restante é o de ser médico do presidente, não é? (risos).

EB - No governo atual ou no do Médici, houve um momento em que correu o boato de que o médico do presidente, meu amigo Eduardo Farah, então reitor da Universidade do Rio Grande do Sul, seria ministro da Saúde ou da Educação.

EB - Não entendo como se tomam essas decisões. O que sei é que, sistematicamente, as pessoas nomeadas não são da área da saúde. Houve aquele eminente psiquiatra e neurocirurgião, grande caçador de perdizes (risos), Maurício de Medeiros, que não era capaz de ir a nenhum lugar porque tinha pavor de avião. Houve o Raimundo de Brito, cirurgião que fizera uma boa administração no Hospital dos Servidores. Houve brigadeiros, alguns aviadores como o Wilson Fadul, no governo Goulart...

SA - Ele era brigadeiro?

EB - Não sei ao certo, mas era da Aeronáutica e - segundo alguns amigos que o conheceram - até uma pessoa interessante. Às vezes corre o perigo de alguém da saúde ser ministro, como o episódio que vou contar agora, ocorrido durante o parlamentarismo, quando Brochado da Rocha, um desses gaúchos que se metem em tudo, foi primeiro ministro. O doutor Marcolino Gomes Candau era diretor geral da Organização Mundial da Saúde - um cargo eletivo do qual, para se afastar, é preciso notificar a assembléia com seis meses de antecedência -, quando o presidente João Goulart simplesmente assina um decreto nomeando-o ministro da Saúde. Veio então o Candau ao Brasil para explicar ao Jango: "Presidente, não 
posso largar o cargo de diretor geral assim, de repente. Se o senhor quiser que eu venha, me dê tempo para que eu possa me desvincular". O Goulart compreendeu que não tinha agido corretamente e respondeu: "Muito bem, então o senhor me sugere um nome". E Candau me indicou. Na época, eu estava em Moçambique ou Angola, em missão pela OMS, alheio ao que se passava. Mas era grave o perigo de ser colhido naquela armadilha, porque o Jango me conhecia, por intermédio de meu irmão, desde os tempos de juventude em Porto Alegre, e eu era funcionário público federal. Ele teria todo o direito de me convocar e intimidade para fazê-lo, e eu não poderia negar. Mas, graças a Deus, o governo parlamentarista caiu, ou pelo menos o Brochado da Rocha afastou-se do cargo de primeiro-ministro, e minha indicação não foi adiante. Hoje eu poderia estar cassado, sem ter nada a ver com a história! (risos).

SA - Como o senhor, que resistiu a tantos convites, foi trabalhar na Secretaria de Saúde?

EB - Ah, isso eu posso explicar. Eu já tinha me afastado da Escola de Saúde Pública e estava na Universidade Federal do Rio de Janeiro. Na ocasião, começava a implantação do novo governo do estado do Rio de Janeiro, e o Clementino Fraga Filho me disse que o governador estava organizando grupos de trabalho para coordenar os diversos setores da administração e queria saber se eu podia coordenar o grupo de Saúde. Aceitei, desde que não se cogitasse meu nome para qualquer posição na administração pública, o que eu não queria de jeito nenhum. O governador não só assumiu comigo esse compromisso, como disse: "Vou fazer o mesmo com as outras pessoas que estou convidando, para que não pensem que serão, necessariamente, secretários".

Comecei então o trabalho, com uma certa correria e recursos limitados, e tive muita ajuda daqui, do Pantoja. Não havia recursos para fazer o Plano de Saúde do estado, contei apenas com a boa vontade e colaboração voluntária dos amigos. Eu só tinha uma sala no Itamarati, uma datilógrafa e um cafezinho horrível, que consegui depois de muitas brigas (risos). Em todo caso o plano foi feito, graças ao apoio da Escola de Saúde Pública daqui, do Ministério e da Previdência. O plano saiu bom; fundia os dois sistemas de saúde, então completamente desordenados, dos antigos estados do Rio de Janeiro e da Guanabara. Mas ainda não haviam escolhido o secretário de Saúde, que deveria vir trabalhar conosco. Eu recebia recados e respondia que meu passe não estava à venda: "Minhas 
chuteiras já estão penduradas". Estava angustiado, receoso de ter de assumir um cargo que não desejava pelas mesmas razões que havia exposto ao Carlos Lacerda. Por fim, a 20 dias da posse do governador, tivemos uma divergência em uma conversa e eu lhe disse: "Cabe ao senhor resolver o que deve ficar com o estado e o município; a decisão é sua". "Não, eu não quero que seja minha, eu quero que seja nossa e convido-o agora, formalmente, para ser o meu secretário de Saúde", respondeu-me. Lembreilhe do nosso acordo original, falei-lhe da intenção de me dedicar a atividades acadêmicas e do meu desejo de não trabalhar mais em administração, mas ele insistiu. E foi então que, talvez por cansaço e angústia, cometi a grande tolice de dizer: "A essa altura, não tenho como recusar o convite".

Uma semana depois da posse constatei que ia me desgastar, me consumir, além de estar abrindo mão de um projeto de vida em que não se incluía qualquer pretensão a uma carreira pública. Chamei o Pantoja, que eu indicara para subsecretário, e mandei por ele uma carta ao governador, afirmando que motivos particulares, imperiosos e imprevistos, me obrigavam a lhe pedir que me desobrigasse do compromisso. Ele concordou, solicitando apenas que meu afastamento não se fizesse de modo a parecer que houvera um conflito entre nós, o que não era mesmo verdade. As interpretações sobre a minha saída foram várias: publicaram uma caricatura insinuando que a cúpula do governo estourara, disseram que eu estava cardíaco e com câncer(...). Eu fui para a fazenda do meu irmão, no Rio Grande, tomar chimarrão e comer churrasco (risos). O Pantoja foi nomeado secretário, por decisão do próprio governador. Muita gente pensa que minha saída deveu-se a reivindicações não atendidas. O fato é que o almirante Faria Lima foi muito correto comigo e nunca houve nenhum atrito entre nós; eu apenas não soube ser categórico na minha recusa, no momento do convite. A culpa foi inteiramente minha.

LF - Realmente, ocorreram várias versões e boatos, na época.

EB - Sim, e alguns foram originários dos próprios auxiliares do governador. Mas ele era muito cordial comigo. Outro dia encontrei-o em um hospital e ele me deu um grande abraço. Aliás, em parte alguma, nem nos registros do estado, consta que eu tenha sido secretário da Saúde, a não ser em documentos e atos oficiais que assinei nos dias em que ocupei o cargo. Foram 20 dias no cargo, de 15 de março a 4 de abril de 1975, até a exoneração sair. Mas não fui pago, e a lei não permite reivindicar direitos 
se não houve remuneração. De maneira que o posto não consta no meu currículo.

SA - Acho que seria interessante, em um segundo encontro, conversarmos mais sobre a Fundação Sesp.

EB - Sobre ela tenho elementos e dados interessantes, que focalizam as mudanças ocorridas. Sobre o Sesp, posso falar inclusive de alguns aspectos políticos de sua evolução. No tempo em que atuei lá, cheguei a me relacionar diretamente com alguns ministros, como Antônio Balbino, Simões Filho, Pedro Calmon e Clemente Mariani. (...) 
PARTE II UMA CASA DE PENSAMENTO E AÇÃo 


\title{
5. Os Primeiros Tempos: edmar TERRA BLOIS E SÁVIO ANTUNES
}

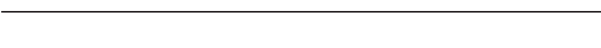 \\ Se não houver o heróico e o romântico \\ no pano de fundo do sagrado, a vida é \\ entediante, morna, sem graça. \\ (Dos cadernos de Teologia do Abade Schultz)
}

Luiz Fernando Rocha

Ferreira da Silva

Os primeiros tempos eram sem dúvida de Cavalgadas em terras de mouro. Tempos de audácia, acima da burocracia. Inovavase, criava-se.

Duas figuras pontificavam. Edmar Terra Blois era o presidente da então Fundação Ensino Especializado de Saúde Pública (Fensp). Segundo relato próprio, freqüentou a Universidade da Lapa e recebeu seu diploma da nossa querida e saudosa Faculdade Nacional de Medicina da Universidade do Brasil, na Praia Vermelha. Ainda estudante de quinto ano, freqüentou o curso de Aplicação do Instituto Oswaldo Cruz, exigência da época para em seguida graduar-se sanitarista. Foi aluno do curso de sorologia do professor Khan, diretor do Instituto de Análise e Pesquisa da Santa Casa e ainda professor titular de medicina preventiva da Escola de Ciências Médicas de Volta Redonda.

Sávio de Albuquerque Antunes era a eminência parda. Cultura ampla e invejável, sensível, sempre capaz de opinar com segurança nos assuntos mais diversos. Era especialista em cultura geral. Espírito inquieto, nunca chegou a terminar um curso superior. Escola Politécnica até o terceiro ano. Curso de Física, até o segundo. Profundo conhecedor de matemática e estatística, recebeu o título de Estatístico, quando da fundação da Escola Superior de Estatística, pelo reconhecimento de seus méritos. Além disso, grande entendido em ciências sociais. 
Foi proprietário de um sebo, que, como era de se esperar, foi a falência: Livraria Rodolfo Coutinho, em homenagem a seu mestre. Vendeu máquinas agrícolas. E costumava comentar a sua viajem-aventura a convite de João Alberto, então ministro, durante a segunda guerra, levando gente para a Amazônia, para o trabalho de extração da borracha.

Era a ele que recorríamos muitas vezes, antes de chegarmos ao Blois com alguma reivindicação ou idéia nova. Foi muito o que com ele aprendemos ao longo dos anos de convivência diária. Há muito de Sávio Antunes nessa casa.

Encontro o passado da nossa história quando, em 1813, os Estudos de Medicina e Cirurgia do Rio de Janeiro incluem as lições de higiene, etiologia, patologia e terapêutica, sendo professor o dr. Vicente Navarro de Andrade, o Barão de Inhomirim, que, segundo Sigaud, exerceu as suas funções como os mestres mais distinguidos do seu tempo de Edimburgo, Paris e Montpellier.

Era o início do ensino da higiene entre nós.

Em 1917 e 1918 o curso de Medicina Pública preparava profissionais para as atividades de Medicina Legal e Saúde Pública. É, entretanto, em 1925 que a chamada Reforma Rocha Vaz, por inspiração de Carlos Chagas, então diretor geral do Departamento de Saúde Pública, cria a especialização em saúde pública com o curso de Higiene e Saúde Pública, anexo à Cadeira de Higiene da Faculdade de Medicina do Rio de Janeiro. Em 1940, esse curso é transferido para o Instituto Oswaldo Cruz.

Em 3 de setembro de 1954 cria-se a Escola Nacional de Saúde Pública.

Finalmente, a 7 de junho de 1966, a lei n. 5017 autoriza o poder executivo a instituir a Fundação Ensino Especializado de Saúde Pública, a obra de Edmar Terra Blois e Sávio Antunes.

$$
* * * *
$$

O primeiro Conselho Departamental que se reunia sob a presidência de Blois, empossados a 26 de janeiro de 1967, tinha a seguinte composição: 
- Departamento de Ensino: Professor Sávio de Albuquerque Antunes;

- Departamento de Ciências Biológicas: Professor

Luiz Fernando Rocha Ferreira da Silva;

- Departamento de Ciências Sociais: Professor Sérgio

Luiz Silveira de Lemos;

- Departamento de Epidemiologia: Professor Nelson

Luiz de Araújo Moraes;

- Departamento de Metodologia do Planejamento:

Professor Oswaldo Lopes da Costa;

- Departamento de Saneamento: Professora Szachna

Eliasz Cynamon;

- Departamento de Administração de Saúde:

Professor Bichat de Almeida Rodrigues;

- Departamento de Estatística: Professor Maurício de Pinho Gama.

Em 1966, recém-transferido da Universidade para a Fensp, Blois me chamou no escritório e disse: 'Luiz Fernando, você vai me representar na reunião de Salvador. Prepara uma apresentação da nossa Escola, capricha'. Habituado com reuniões científicas, não me preocupei e parti para a Bahia.

No primeiro dia da reunião, é que entendi que se tratava de algo bem diferente do que eu imaginava. Era uma reunião do Ministro da Saúde, então Raimundo de Brito, com os secretários de Saúde do Nordeste, e o tema, distribuição de verba. Eu deveria, substituindo Blois, assessorar o ministro durante os debates.

Era realmente uma situação bastante desconfortável. Fui salvo pelo Professor Achiles Scorzelli Junior que também fazia parte da equipe do ministro. Tinha sido meu professor e, conhecendo-me bem, disse em voz baixa: 'Luiz Fernando, senta aqui do meu lado, que eu te dou as dicas'. E graças a ele, tudo correu bem.

Foi a minha primeira participação em debate político. 
Tento recompor, com algumas anotações esparsas que Natalina, minha eterna secretária, guardou até hoje e com o que sobrou na memória, o que era a Fensp em 1966.

Os dois últimos andares, oitavo e nono eram alojamento para alunos e professores visitantes. De acordo com os padrões da época, um andar para as moças e outro para os rapazes. E com fiscalização intensa. Cada alojamento era constituído de um dormitório e de uma sala para estudo. Constam das minhas anotações que se dispunha então de 108 vagas.

No sexto andar, estava o Departamento de Ciências Biológicas com os laboratórios para ensino e pesquisa de Microbiologia e Parasitologia. A aparelhagem mais moderna foi comprada, para que se pudesse funcionar em alto nível. No quinto andar, o Laboratório de Engenharia Sanitária. O quarto andar, como até hoje, aliás, foi todo ocupado por salas para aulas teóricas. A administração geral e a administração de ensino até hoje estão localizadas no terceiro andar. No primeiro andar, o anfiteatro Achiles Scorzelli Junior com capacidade para 300 pessoas, e decorado com mural projetado por equipe vencedora de concurso ao qual compareceram 42 artistas entre nacionais e estrangeiros. Ainda no primeiro andar, a Biblioteca Lincoln de Freitas Filho.

Os alunos vinham do Brasil inteiro, além de São Paulo, naturalmente. Era o único curso de Especialização em Saúde Pública. No segundo andar, o refeitório, servido por garçom de paletó branco impecável e gravata borboleta preta. Louça de excelente qualidade. E tudo por conta da casa, inclusive bolsa para os alunos e passagem de ida e volta de avião. Automóvel com chaffeur para os chefes de departamento.

Encontro ainda as seguintes anotações de época:

"A construção do biotério, das estações experimentais para o ensino de tratamento de água e esgoto, bem como as áreas de recreação deverão estar concluídas até março de 1967.

A Unidade Sanitária Germano Sinval de Farias foi construída anexo ao edifício da Escola. De tipo urbano ela deverá atender a uma população de 30.000 pessoas em área constituída pelos seguintes universos: Favela, Área industrializada e Área residencial e comercial.

No momento realizam-se levantamentos das condições socioeconômicas, de saúde e saneamento das áreas.

A escola possui ainda já em funcionamento, uma Unidade Sanitária tipo rural, localizada em Jacarepaguá, atendendo a uma população de 11.000 pessoas, operando em convênio com o Sesp e com o governo do Estado da Guanabara. 
No primeiro ano, os cursos ainda eram separados pela profissão de origem. Os cursos básicos constavam de matérias essenciais para a compreensão dos diversos problemas de saúde pública. Assim, os cursos Básico de Saúde Pública para médicos, Básico de Saúde Pública para enfermeiros, para veterinários, para farmacêuticos e para dentistas. E os cursos de especialização que compreendiam o ensino da diversificação do campo da saúde pública, como leprologia, saúde mental, arquitetura de unidades médico sociais, técnicas de laboratório, organização e administração hospitalar, tisiologia clínica e sanitária, educação sanitária e odontologia sanitária.

De anotações de época: "O curso de Especialização em Educação Sanitária, de nível superior, constitui uma experiência nova em nosso país e foi aberto a profissionais egressos das ciências biológicas, sociais, de psicologia e educação. Esse curso já se encontra em realização e conta com a presença de 15 alunos".

Os cursos de nível médio visavam à preparação de pessoal auxiliar, como inspetor de saneamento, visitadora sanitária, práticas de laboratório etc. Já começavam também os cursos descentralizados. Em Belém, Recife, Belo Horizonte e Porto Alegre, o curso de Atualização em Técnicas de Saúde Pública para médicos de duração de dois meses em tempo integral.

$* * * *$

Uma Escola, na sua concepção maior, é constituída por um grupo de pessoas, que cria conhecimento e transmite esse conhecimento a outros. Estabelece uma linha de pensamento, uma proposta de soluções para determinados problemas. Os discípulos, recebidas as informações, desenvolvida a capacidade crítica e diante de novas vivências, complementam, desenvolvem ou contestam as idéias vigentes.

Frei Pedro, preocupado com a educação do jovem Imperador, escreveu: "Que meu Augusto Pupilo seja versado nas ciências e nas artes e também nos ofícios mecânicos".

A nossa Escola tem sido uma casa de pensamento e ação, com fundamentação teórica ampla, do nível molecular ao social, com um objetivo prático claro, melhores condições de saúde para a população. 
E quis o destino que fosse aqui, na modesta estação de Manguinhos, onde no início do século XX, Oswaldo Cruz fundava o Instituto, cujo nome correria mundo, elevando tão alto a nossa ciência, que se implantasse a Fundação Ensino Especializado de Saúde Pública.

Surgiram ambas de necessidades concretas da nossa realidade. $\mathrm{O}$ primeiro, para a produção de soro e vacina contra a peste; o segundo, para o preparo de mão-de-obra para a saúde pública. Surgiram ambas da capacidade de realização de homens que não se curvaram às fórmulas convencionais.

Abriu-se, em ambos os casos, um leque de possibilidades bastante amplo. No Instituto, se fizeram estudos básicos de zoologia, hidrobiologia, química, botânica etc. Na escola, estudos de ciências sociais, política, história e até paleoparasitologia.

Oswaldo construiu o seu castelo com verba desviada da saúde pública. E com fausto, com tijolos de Marseilhe, louça inglesa, azulejos portugueses. Tudo importado. "O templo da ciência deve ser faustoso".

Blois fez a abertura dos cursos da Escola, tendo a seu lado na mesa, não as autoridades costumeiras, mas uma bela jovem de minissaia bem curta e generoso decote. E quando alguém vacilava diante de um desafio, gostava de dizer: "Lembrem-se sempre das palavras de Danton no tribunal: audácia, mais audácia, sempre audácia”.

Contava Pedro Calmon que, na guerra da independência, na Bahia, com os brasileiros já quase derrotados, o comandante manda ordem ao corneteiro. 'Tocar a retirada'. Mas por qualquer razão em vez de retirada, ela toca: 'Avançar a degola'. Foi por isso que venceram.

\section{$* * * *$}

É preciso conhecer o Brasil, disse Sávio certa vez. E vamos começar pelo rio São Francisco. Prepara-se a caravana que sai do Rio e vai terminar em Recife com um seminário no Instituto Joaquim Nabuco. Sávio é o comandante da expedição. Durante a viagem, pontifica com seus conhecimentos de geografia, história, agricultura e economia etc. Sem dúvida, aprendeu-se muito, tanto alunos, como os professores mais jovens. Decidida no sábado à tarde, partiu-se no domingo. E tudo deu certo. O tempo de planejamento era mais que suficiente.

Assim era, naqueles tempos. 
Mais de uma vez levei lista de compras ao Blois.

"Santoro", gritava ele para o administrador. "Isso é para o Dr. Luiz Fernando, e eu quero tudo aqui amanhã”. E acreditem ou não as direções atuais, no dia seguinte estava tudo no laboratório.

$$
* * * *
$$

Nas velhas anotações, encontro: " $O$ ato constitutivo da Fundação e seu estatuto elaborado pelos professores, Achilles Scorzelli, Manuel José Ferreira, Rinaldo de Lamare, José Roberto Ferreira sob a presidência de Edmar Terra Blois e com assistência jurídica do dr. Cid Heráclito de Queiroz já estão prontos".

O Estatuto da Fundação reflete as modernas tendências do ensino, da pesquisa e da administração, atendendo, por um lado, as exigências universais dos critérios científicos e técnicas, e, por outro, através de seus termos, pode-se verificar que se está atento à realidade nacional.

Não faltaram cristãos atrevimentos

Nessa pequena casa lusitana

De África tem marítimos assentos

É na Ásia mais que todos soberana

Na quarta parte nova os campos ara

$E$, se mais mundo houvera, lá chegara.

(Os Lusíadas) 


\section{A Valorização do 'Instituinte' na Construção do Modelo de Escola Nacional: A ENSP DE 1970 A 1989}

\section{INTRODUÇÃO}

$\mathbf{R}_{\text {efletir e escrever por ocasião dos } 50 \text { anos da Escola Nacional }}$ de Saúde Pública (Ensp) é uma rica oportunidade de revisitar uma história construída com técnica, luta, criatividade e dedicação pelas equipes que por ali têm passado e de ressaltar as diferentes iniciativas que, ao longo desse meio século de existência, conformaram o atual modelo. O mergulho nessa história convida a falar de uma instituição que cresceu na adversidade, atravessou o período dos governos militares com muita altivez e habilidade, construindo um espírito de corpo que se tornou atributo essencial para o equilíbrio e para a geração de sucessivos projetos de inovação.

Os primeiros 20 anos foram decisivos para a criação de uma base técnica e política fundamental ao diálogo de uma jovem Escola de Saúde Pública vinculada a uma estrutura governamental como o Ministério da Saúde. A ênfase inicial se estabeleceu em torno dos quatro grandes eixos que informavam a política de saúde da época, e deles derivaram os processos de renovação estabelecidos a partir da década de 1970. São eles: a educação em saúde, a epidemiologia de serviços, a administração de saúde e o saneamento. Estas eram as referências que estruturavam as práticas de saúde pública dos serviços da época, com forte influência da Fundação Serviços de Saúde Pública (FSESP), também vinculada ao Ministério da Saúde, e com uma outra expressão de prática dos serviços estaduais e municipais de saúde, que também influenciavam os conteúdos de cursos, notadamente aqueles relacionados aos programas materno-infantil e de controle da tuberculose.

Na década de 1960, o país esteve submetido a expressivos fenômenos no âmbito da política geral, todos eles com influência na dinâmica da saúde pública brasileira. Os três primeiros anos da década, 
que correspondem ao governo João Goulart, de grande efervescência política de caráter progressista, deram lugar aos primeiros anos do regime militar. Após sucessivas intervenções nas instituições, o governo militar editou o ato institucional n. 5, trazendo o cerceamento das liberdades democráticas e o desmonte de inúmeras instituições de ensino.

Nesse contexto, a reforma universitária foi implantada e, dentre outras medidas, determinou o reordenamento radical da lógica de organização universitária, induzindo à criação de novas estruturas que alteravam a orientação até então existente de formatação das faculdades por categorias de cursos correspondentes à organização profissional. Às escolas ou faculdades assim organizadas juntaram-se os institutos, espaços que os estudantes passaram a freqüentar de forma socialmente desarticulada nos primeiros anos de sua formação acadêmica. Nessas unidades, foram organizadas as ciências básicas, com conteúdos relacionados a um conjunto de profissões, mas a sua implantação em institutos, além de se apresentar como uma medida racionalizadora, representou um concreto retardamento da convivência dos novos estudantes com suas respectivas corporações (escolas de medicina, engenharia, nutrição, dentre outras). Nas escolas vinculadas às universidades, os alunos passaram a freqüentar apenas a etapa profissionalizante dos cursos.

Pela sua localização na Fiocruz, a Ensp vivenciou outras conseqüências de medidas repressivas, como a cassação de cientistas renomados, e teve alguns de seus professores demitidos. Mas não foi atingida pelas orientações de caráter organizativo impostas pela reforma às universidades, mantendo-se, dessa forma, como uma escola de formação de sanitaristas, uma corporação que se formou em torno da relação ensino ensino-serviço, constituindo, na década de 1960, o embrião do que se tornaria uma base sólida para o desenvolvimento do projeto de 'escola nacional', configurada com mais nitidez a partir dos anos de 1970.

Nesse contexto, foi editado pelo governo federal o decreto-lei n. 200, que estabeleceu as bases estruturantes da nova administração pública, "visando à execução de planos e projetos de forma racional". ${ }^{1}$ Essas concepções reorientadoras da administração pública provocaram na Ensp um debate em torno da atualização dos cursos e de sua adequação à

As atividades da administração federal e especialmente a execução dos planos e programas de governo serão objeto de permanente coordenação, mediante a atuação das chefias subordinadas e a instituição e funcionamento de comissões de coordenação em cada nível administrativo. Ver decreto-lei 200 , art. $1^{\circ}$, cap. II. 
realidade. $\mathrm{O}$ curso de formação de sanitaristas até então existente, segundo Eduardo Costa, um de seus docentes, formava 'diplomatas da saúde', concepção que não se coadunava com as novas propostas de preparação de quadros de governo, podendo ser considerada a primeira indicação de que a Ensp deveria se encaminhar para um projeto de Escola de Governo, que foi 'adotado e tecido' ao longo dos anos subseqüentes.

Nós estávamos querendo formar o sanitarista generalista. A gente queria o livro de Marhon, mas a concepção do curso tinha como expectativa formar um diplomata da saúde; um cara que participaria bem de reuniões internacionais, mas não teria capacidade de intervenção. Queríamos que o sanitarista fosse um dirigente. Para isso, os instrumentos deveriam ser políticos, mas também técnicos, para intervir diante dos problemas da população, através de conteúdos da epidemiologia. (Entrevista com Eduardo de Azeredo Costa, 1998)

A história da Ensp dos últimos 30 anos revela que as iniciativas de projetos que conformaram o seu atual modelo se relacionaram com as matérias relativas à qualificação para o trabalho ao mercado de trabalho e à relação ensino-serviço. Mas foi na dimensão política que essas expressões adquiriram significado e passaram a integrar as bases que vêm formando as sucessivas gerações de professores e de sanitaristas e que projetaram a Ensp como uma escola que adquiriu relevância na formação de recursos humanos para a saúde coletiva de todo o país.

Em todas as décadas é possível identificar uma grande vitalidade no processo de renovação do modelo de Escola, da oferta de cursos e das linhas de pesquisa. Sua organização departamental reflete o grau de relevância que as áreas de epidemiologia, ciências sociais, engenharia sanitária e saúde do trabalhador e ecologia humana adquiriram ao longo do processo de construção do campo da saúde coletiva. Vale destacar que o processo mais contemporâneo de construção da Ensp, nos anos recentes, está perfeitamente integrado à reconfiguração do campo, sendo ela própria uma instituição emblemática dessa história.

Ao serem apresentados à moderna Ensp em seus catálogos de cursos, eventos, folderes, páginas de comunicação eletrônica e outros processos de divulgação utilizados pela Escola, jovens alunos e visitantes costumam demonstrar perplexidade com a sua vitalidade, como um centro de formação que esteve sempre no setor público e que 'forma quadros' para esse mesmo setor, em cursos de lato ou stricto sensu para alunos de todo o país e de outros países. 
É possível que alguns perguntem a si próprios: de onde vem essa vitalidade? Talvez em suas interrogações ainda acrescentem a constatação de que a década de 1990 se inicia com o governo Collor, instalando-se em todo o país uma certa descrença nas estruturas públicas, produzindo uma avaliação do senso comum de que os jovens não desejariam mais integrar carreiras que fossem tão dependentes da estrutura pública como a de saúde pública. Na mistura de interrogação com a busca de compreensão, o aluno ou visitante vai encontrar uma escola que nessa mesma década implantou novos projetos estruturantes como os mestrados profissionais, a educação a distância e a Escola de Governo, sem prejuízo da reestruturação de seu programa de mestrado e doutorado, que também ocorreu nesse período integrando-se perfeitamente ao sistema Capes, dando uma demonstração inequívoca de sua capacidade de renovação, inclusive em épocas de crise como aquela. E seguindo um pouco adiante, na direção das origens dessa Escola, os interlocutores vão se deparar com uma densa história vivenciada nas suas três primeiras décadas de existência, por seus trabalhadores e dirigentes, e nela vão encontrar muitos fatos que revelam uma permanente 'atitude de renovação', que foi apreendida pelos atores institucionais em sucessivas experiências e diferentes ciclos de governo com os quais a Ensp interagiu de forma ativa.

$\mathrm{Na}$ análise sistemática de sua história, realizada pelo resgate de documentos, da evolução dos cursos de 1970 a 1989 e por depoimentos de atores-chave que estiveram na Escola nesse período, é possível identificar que essa criatividade e capacidade empreendedora se atualizam com um adensamento da visão política, incorporação de prestígio e solidez tecnocientífica, o que pode ser observado pela análise das programações, mesmo em conjunturas muito adversas para o setor público como no governo Collor.

A revisão dessa história permite o resgate de fatos que relacionam permanentemente a Escola com a discussão e conformação do sistema de saúde brasileiro. A partir de 1970, principalmente, esta história está permeada pela compreensão de que saúde pública e política se fazem numa relação muito íntima. Os movimentos, projetos, programas e a participação ativa em processos de renovação das políticas de saúde parecem indicar que as escolas de saúde pública devem perseguir seus objetivos guiadas por essa noção. A postura crítica que foi construída pela Ensp em sucessivos ciclos revela que a interação com a realidade de forma inquieta e produtiva favorece à renovação e à abertura de diálogo com os novos ambientes, deles retirando matéria fundamental aos novos 
ciclos de criação. A evolução e a problemática envolvida nessa história representam a tradução de uma metodologia de relação da Escola com a sociedade e de aprimoramento cotidiano de um projeto que cresceu produzindo um ensino impregnado de uma atitude crítica e de compromisso com a realidade social brasileira.

Este texto tomará como referência, prioritariamente, os cursos lato sensu e a relação da Escola com o sistema de saúde brasileiro, com ênfase no período de 1970 a 1989.

\section{Do Diplomata da Saúde ao Sanitarista: O MODELO FICA MAIS SÓLIDO E SE TORNA NACIONAL}

A racionalidade apontada na lógica de reorganização do Estado brasileiro na década de 1960 estava articulada a um contexto político internacional, no qual o governo se inseriu associando-se a outros países da América Latina e firmando pactos de governabilidade que tinham como referência o cenário político turbulento da época, em toda a região. As ações decorrentes dos acordos firmados deveriam ter impacto na área social dos países, que, nesse tempo, eram governados por regimes ditatoriais em quase sua totalidade.

São exemplos dessa participação brasileira a $1^{\text {a }}$ Reunião dos Ministros do Interior em Punta del Este (1961) e a 1 $1^{\text {a }}$ Reunião dos Ministros de Saúde das Américas (1963), ambas apontando caminhos de reorganização do Estado e das práticas estatais.

A planificação do social proposta pela Carta de Punta del Este cria as condições propícias ao desenvolvimento desse discurso planejador, à elaboração de técnicas, à formação de intelectuais que darão coerência a esse discurso e procurarão legitimá-lo pela sua abordagem 'científica' para a intervenção na realidade social. A partir daí, estabelecem-se as estratégias para a difusão desse movimento, com apoio de organizações internacionais, visando a sua assimilação pelo Estado. (Paim, 1986b: 69-70)

Analisando essa conjuntura sob o prisma dos recursos humanos, Teixeira (1982: 42) também ressalta a importância da emergência da noção de recursos humanos em saúde, produzindo, no interior do governo, um processo que implicou a "modernização progressiva da ideologia estatal".

Coerente com as orientações que se seguiram aos compromissos assumidos internacionalmente pelo governo, realizou-se, em 1967 no Rio de Janeiro, a $4^{\text {a }}$ Conferência Nacional de Saúde, tendo como tema principal 
os recursos humanos, ${ }^{2}$ com uma participação expressiva de docentes da Ensp. Em seu programa, foram abordadas as questões que permeavam a visão de planejamento do setor, antecipando uma problemática ligada ao planejamento de recursos humanos que seria materializada pelo governo, na década de 1970, no Plano de Preparação Estratégica de Pessoal de Saúde (Ppreps), componente indutor da expansão da rede de serviços públicos de saúde na dimensão dos recursos humanos.

O conjunto de medidas governamentais que se instituíram nesse período favoreceu a constituição de uma base sólida de conteúdo técnico e de uma linha de pensamento na Ensp voltada para a formação de 'quadros' engajados nas esferas federal e estadual de governo. Os processos seletivos dos cursos de saúde pública faziam uma busca ativa de profissionais inseridos nas secretarias estaduais de saúde e nas diretorias regionais da Fundação Sesp e da Superintendência de Campanhas (Sucam), órgãos federais com muita relevância na prestação de serviços de saúde pública em todo o país à época, que se deslocavam até o Rio de Janeiro para freqüentar os cursos. Essa clientela era vinculada a fortes corporações da prestação de serviços de saúde pública e, nesse período, organizava-se em carreiras de funcionários públicos que valorizavam o grau de especialização, refletindo em um aumento significativo da procura pelos cursos da Ensp.

O número de concluintes dos cursos de saúde pública passou de 23, em 1970, para 65 em 1975, sendo que em 1970 se inscreveram 48 alunos para a seleção, número que chegou a 144 em 1975. Este fenômeno pode ser atribuído ao fato de os cursos serem multiprofissionais, como também à articulação que a Escola passou a estabelecer com os outros órgãos de governo, que reconheciam o título de sanitarista com uma correspondente ascensão funcional e um aumento da remuneração (Nunes, 1998).

Vários setores faziam demandas à Escola. Existia no Sesp um plus em salário, que os funcionários recebiam, por especialização. (Entrevista com Arlindo Fábio Gómez de Sousa, 1998).

Tirando os militares, que eu não sei explicar, com os outros órgãos tinha muito o espírito de atender às necessidades de promoções das pessoas em suas carreiras respectivas. Como na área militar, as promoções eram baseadas

2 A 4a Conferência Nacional de Saúde foi realizada de 30/08 a 04/09 de 1967 no Rio de Janeiro e contou com a participação de três professores da Ensp entre os palestrantes, discorrendo sobre os temas "O Profissional de Saúde que o País Necessita", "Pessoal de Nível Médio e Auxiliar" e "Responsabilidade do Ministério da Saúde na Formação e Organização dos Profissionais de Saúde e do Pessoal de Nível Médio e Auxiliar" (Brasil/MS, 1993a). 
nos títulos, e os cursos eram instrumentos para isso. Estava se desenhando a carreira de sanitaristas. (Entrevista com Eduardo de Azeredo Costa, 1998)

Por ocasião do anúncio do II Plano Nacional de Desenvolvimento $(\mathrm{PND})^{3}$ em 1974, o ministro da Previdência proferiu discurso na Escola Superior de Guerra recomendando como medidas necessárias a redução das desigualdades sociais e a ampliação da área de atendimento das necessidades sociais da população em termos de escolas, habitação, níveis sanitários básicos, proteção médica e previdenciária, colocando-as como pressupostos para o processo de distensão política, recomendação que guarda coerência com os compromissos assumidos pelo governo brasileiro, na Reunião de Ministros da Saúde em 1972, no Chile (Opas, 1972).

A explicitação das áreas de importância para os investimentos sociais no II PND favoreceu a articulação de algumas representações de trabalhadores no interior do governo, abrindo espaços para a formulação de programas de extensão de cobertura como o Programa Nacional de Interiorização das Ações de Saúde e Saneamento (Piass - Brasil, 1976), que, em seus desdobramentos, buscou uma aproximação entre o Ministério da Saúde, as secretarias estaduais de Saúde e a Organização Pan-Americana da Saúde (Opas). Vale ressaltar que a extensão de cobertura foi uma política que se implantou em toda a América Latina nesse período, com a participação da Opas, com modelos peculiares em cada país.

Fruto de definições estratégicas nacionais, estabeleceu-se o acordo interministerial que envolveu os Ministérios da Educação, da Saúde e a Opas. ${ }^{4}$ No âmbito do acordo, estruturaram-se as ações de cooperação técnica

O II Plano Nacional de Desenvolvimento (PND) foi anunciado pelo então Presidente Geisel, em 10 de setembro de 1974, consubstanciando 'metas tentativas' a serem alcançadas entre 1975 e 1979. Em sua $1^{a}$ parte, o PND refere o Brasil como potência emergente e, dentre outros temas, aborda uma estratégia de desenvolvimento social, onde estão tratados os temas de distribuição de renda, emprego e salários e valorização dos recursos humanos. O Cap. XIV aborda a Política Científica e Tecnológica (Brasil, 1974: 131-140).

4 A organização do grupo de trabalho da Opas que passou a integrar o Acordo Interministerial teve características muito peculiares no Brasil em relação aos outros países. Para coordenar o grupo técnico responsável pelas ações de recursos humanos do acordo, foi incorporado um técnico que atuava anteriormente na Superintendência de Desenvolvimento do Nordeste (Sudene) com formação sólida em programas de desenvolvimento regional, o dr. Carlyle Guerra de Macedo. Ele estabeleceu fortes laços de trabalho com grupos técnicos do Ministério da Saúde, exercendo com extrema habilidade essa função no desenvolvimento das atividades que decorreram da formalização do acordo. Esse coordenador foi figura destacada na $7^{\text {a }}$ Conferência Nacional de Saúde, realizada em 1980, e, mais tarde, Carlyle Guerra não seria escolhido diretor-geral da Organização PanAmericana da Saúde. (Depoimentos concedidos para a dissertação de mestrado da autora, "A supervisão em Saúde: um estudo exploratório em instituições públicas no âmbito federal e estadual”, defendida na UFBa em 1986). 
aos estados, tendo a extensão de cobertura de serviços como denominador de uma ação que articulava o Piass (extensão de cobertura de serviços) e o Ppreps (formação de recursos humanos). Os dois programas se constituíram, dessa forma, em estruturantes da estratégia de expansão delineada como diretriz de governo (Brasil, 1975, 1976).

Os estímulos que emergiram do ambiente político e do processo de implantação desses programas favoreceram a formulação de propostas por grupos de docentes que, no interior da Ensp, vinham problematizando os modelos de cursos adotados. Nesse debate, os professores da Escola buscaram construir projetos que se articulassem ao ambiente mais amplo e à nova conjuntura, favorecendo sua aproximação com grupos progressistas de outras instituições governamentais de ensino ou de serviço.

No mesmo período, a Opas também disseminava em todo o continente, com atenção especial para o Brasil, uma estratégia de reformulação da educação médica, visando ao fortalecimento dos departamentos de medicina preventiva e elegeu a Ensp como uma parceira privilegiada através do Programa de Estudos Socioeconômicos e Sociais em Saúde (Peses - Brasil, 1978). Os estudos e a forma organizativa de parceria desta Escola com as universidades localizadas em diferentes estados brasileiros fizeram do Peses estratégia fundamental ao modelo da Ensp, permitindo a produção de importante material de reflexão para o movimento que deu origem aos conceitos de medicina social e saúde coletiva e a outras reformulações que vieram a se configurar nesse campo.

Como parte das propostas elaboradas pelos docentes, no movimento que paralisou os cursos em 1974, foram formuladas propostas pedagógicas que previam uma reinterpretação do curso básico e a criação de outros ciclos de especialização. Mas, no campo da formação de recursos humanos para os serviços de saúde, foram outros dois projetos que produziram maior impacto na mudança da forma de relação da Ensp com a formação de quadros para o sistema de saúde brasileiro: o Programa de Cursos Descentralizados e a criação da residência de medicina social articulada ao Programa de Apoio às Residências (PAR), instituído pelo Instituto Nacional de Assistência Médica e Previdência Social (Inamps). O primeiro estabeleceu novas bases de relação da Ensp com o Sistema de Saúde; o segundo trouxe para a Escola a possibilidade de problematizar as práticas de serviços prestados pelo Inamps, alterando radicalmente o referencial de serviços até então tomados como campo de atenção e prática de seus docentes, permitindo ainda a abertura de vagas para jovens recémformados: "A introdução desse curso na Escola renovou a prática de 
técnicas e políticas do ensino da saúde pública, aproximando-a da medicina social e, posteriormente, da saúde coletiva" (Entrevista com Paulo Marchiori Buss, 1998).

O contexto de reformas que atingia o setor público da saúde e que avançava através das atividades do Piass e do Ppreps junto às secretarias estaduais gerou demandas de reorganização do Sistema de Saúde, requerendo a ampliação e qualificação das equipes; o curso de saúde pública era o caminho que dava acesso a essa formação. ${ }^{5}$

A crescente procura de profissionais dos serviços de saúde pelos cursos da Ensp evidenciava um apoio das secretarias estaduais de saúde, e o Programa de Cursos Descentralizados foi o projeto que permitiu dar uma resposta política formal a essa demanda. A organização da proposta contava com recursos específicos alocados pela Fundação Oswaldo Cruz em articulação com o Ppreps, com uma retaguarda docente mobilizada para a missão e com um conjunto de instrumentos que deu corpo à cooperação da Ensp com os estados, assim organizados:

- Instrumento convenial entre a Fiocruz e a secretaria estadual, e em alguns casos, com a participação da universidade local;

- Reconhecimento da coordenação local, firmado pela Ensp, mediante indicação do conveniado;

- Estratégia de incentivo à participação de corpo docente local, com crescente envolvimento das universidades;

- Apoio da Ensp ao processo de seleção e instalação do curso, e responsabilização pelas disciplinas que não fossem preenchidas pelos docentes locais;

- Desenvolvimento da capacidade local de adaptação de conteúdo e metodologias, respeitando o currículo mínimo estabelecido pela Ensp;

- Trabalho sistemático de divulgação, para facilitar a inscrição de candidatos e de algumas atividades docentes realizadas nos estados satélites (Uchôa \& Paim, 1982: 40).

Entre os resultados creditados ao processo de descentralização dos cursos, Uchôa e Paim destacam: permanente interesse das secretarias de saúde; maior integração das universidades com os serviços de saúde; progressiva capacitação das coordenações locais de cursos; criação de carreira de sanitaristas em algumas secretarias estaduais de saúde; mudanças na estrutura dos cursos ministrados pela Ensp e intercâmbio de experiências docentes. 
Essas exigências de caráter formal se constituiriam nas principais orientações que nortearam os movimentos da Escola junto aos estados, no Programa de Cursos Descentralizados, e refletem uma linha política de compartilhamento e inclusão, traduzida em mecanismos que podem ser considerados como as primeiras referências mais significativas de uma 'escola nacional', assim mencionadas por professores que participaram dessas definições:

Lembro que a essa altura já tinha Peses-Peppe andando e desenvolvendo suas pesquisas. O grupo que não estava nesses dois projetos iria se envolver com os cursos descentralizados. Ficava um grupo que participava do experimento aqui e outros que eram caixeiros-viajantes. Ia um professor da Escola e escolhia um ex-aluno, daí o relacionamento com as Preventivas.

\section{(...)}

Na relação com as universidades optamos pelas Preventivas na realização dos cursos, para absorver disciplinas. Isso foi uma estratégia definida por nós, como Escola donativa. Pensamos em como criar uma rede e fortalecer os departamentos. Achávamos que os cursos de saúde pública influenciariam a graduação. Os convênios eram tripartites. Essa também era uma opção para buscar viabilidade enquanto Escola, e não como um Centro de Formação. (Entrevista com Arlindo Fábio Gómez de Sousa, 1998)

Sem prejuízo da análise da contribuição fundamental dos cursos regulares já existentes na década de 1970, notadamente do curso de saúde pública, pode-se considerar que a incorporação dos três projetos mencionados mudou a Ensp, trazendo para o seu interior as novas bases de interlocução evidenciadas por cada um desses programas, influenciando os projetos já existentes e consolidando parcerias entre os aliados que integravam o ambiente político mais amplo e que estavam em posições estratégicas nas instituições-alvo de suas articulações.

A decisão pela criação do Programa de Cursos Descentralizados não foi um ato burocrático vinculado a diretrizes do Ministério da Saúde. A construção do projeto vinha sendo debatida por docentes com a direção da Escola, em negociações que buscavam um reconhecimento maior do seu trabalho; nesse contexto, foi possível negociar mudanças substantivas na lógica organizativa dos cursos e na remuneração dos professores.

O Ernani Braga veio para a Escola, e a gente resolveu repensar as coisas. Mas ele não durou; foi para a Secretaria de Saúde. A gente ganhava mal e não dava para declarar greve naquele contexto, mas conseguimos armar 
uma confusão e parar os cursos no primeiro semestre de 1974. O Oswaldo Costa [diretor da Escola] tinha seus contatos lá, e desse movimento saiu um princípio de carreira com Almeida Machado e a aprovação de várias propostas de reformulação do ensino: eu tinha planejado retomar um mestrado progressivo, implantar a residência em saúde pública, que começaria no início do ano; o curso de saúde pública começaria no meio do ano. Haveria um segundo período de cinco meses para quem fosse fazer o mestrado. Eram múltiplas entradas e múltiplas saídas. Em dois anos fariam os dois cursos. Daí saiu a divisão dos cursos em básico e especialização. (Entrevista com Eduardo de Azeredo Costa, 1998)

O clima reformista persistiu durante todo o período de implantação dessas propostas, que avançaram em um contexto sociopolítico favorável à modernização das instituições públicas, quando a formação de recursos humanos ganhou relevância vinculada à modernização das estruturas. Assim também começaram a ser discutidas as possibilidades de expandir os limites da Escola para outros espaços do país.

Estava recém-criada a Escola de Saúde Pública do Rio Grande do Sul. O Ossanay então foi dirigi-la, e um dia ele veio à Ensp para discutir sobre os seus cursos. Queria dar validade a um curso de curta duração que seria realizado lá no Rio Grande do Sul. Discutimos como seria um curso básico de saúde pública que atendesse à Secretaria de Saúde daquele Estado. E fizemos uma discussão sobre o assunto, porque a epidemiologia local não podia ser igual à outra. (Eduardo de Azeredo Costa, 1998)

Havíamos feito uma consultoria no norte do Brasil, com vistas à organização de um livro sobre febre amarela. Era o Rubens Brito. Fizemos contato com a Sudam, também com a Elisa, no Pará. Ela tomou a descentralização dos cursos como algo seu também. (Entrevista com Arlindo Fábio Gómez de Sousa, 1998)

As razões para adotar uma proposta de descentralização dos cursos foram sendo identificadas, e já começavam a surgir manifestações dos serviços por uma maior necessidade de sanitaristas formados. Havia, entre os docentes, a constatação de que esse modelo deveria levar em conta uma referência geral da formação dos sanitaristas, mas também contemplar a diversidade nacional e as características locais.

Sabíamos que muitos alunos não voltavam ao seu estado de origem, o que provocava uma reação dos dirigentes de suas instituições. A grande maioria tinha dificuldade de converter os modelos nacionais quando retornava. Finalmente, havia uma percepção de alguns professores de 
que esse era um projeto político, que poderia servir de canal de modificação das estruturas de serviço, com o qual alguns professores tinham identidade. (Entrevista com Arlindo Fábio Gómez de Sousa, 1998)

Tomada a decisão de iniciar o programa, a Ensp elegeu o Pará e o Rio Grande do Sul como os estados em que implantaria a experiênciapiloto com a descentralização do curso básico de saúde pública, expandindose no ano seguinte para os estados da Bahia e de Pernambuco e, posteriormente, para todas as regiões do país.

A Escola que queria formar o diplomata na década de 1960 passou a ser interpretada, nesse contexto, como aquela que queria "formar o operário quanto à classe subalterna, o cidadão dócil e o operário competente" (Cury, 1995: 62), modelo que se tornou alvo de um esforço de superação, em um cenário de efervescência política. Os projetos assumidos pela Ensp na década de 1970 foram capazes de materializar a superação dessa visão, de "transmissora de conhecimentos apolíticos" (Cury, 1995: 62), abrindo espaços para a incorporação de novos docentes que se transferiram de Campinas devido a problemas políticos; entre estes, estava o professor Sergio Arouca, que se aliou aos professores mais antigos na luta por um novo caminho político para a Escola.

A chegada à Ensp do grupo de Campinas permitiu a incorporação de competências relacionadas à pesquisa inexistentes até então, que se processou no período em que o governo brasileiro decidiu apoiar a ciência e a tecnologia, favorecendo a aproximação da Fundação Oswaldo Cruz com a Financiadora de Estudos e Projetos (Finep), tendo como resultado o financiamento do Programa de Estudos Econômicos e Sociais (Peses) e do Programa de Estudos e Pesquisa Populacional e Epidemiológica (Peppe). Esse recursos possibilitaram a incorporação de novos docentes e permitiram a sistematização e rediscussão de conteúdos da saúde pública tradicional, com a formulação de novos conceitos que passaram a fazer parte do cotidiano da pesquisa e do ensino da saúde pública brasileira.

A sistemática do Peses-Peppe e o ambiente de debate que se estabeleceu nesse período produziram desdobramentos nas grades curriculares e na estruturação de novas disciplinas, que absorviam as descobertas efetuadas pelos técnicos envolvidos com os projetos. Dentre eles vale destacar a incorporação, em 1980, da disciplina saúde pública como prática social no curso de saúde pública, a constituição da área de vigilância epidemiológica como integrante do núcleo de ensino da epidemiologia e a conseqüente incorporação do Programa Ampliado de Imunizações, em parceria com o Ministério da Saúde e a Opas. O curso de 
Especialização em Planejamento expressou essa mudança no mesmo período, absorvendo no módulo de planejamento, a disciplina organização sociopolítica e poder público e, posteriormente, os estudos de políticas globais, intervenções que alteraram a lógica disciplinar anterior calcada na administração combinada com conteúdos das ciências sociais e da educação em saúde: "O Peses e o Peppe eram coisas paralelas. Surgiram de uma inquietação interna e foram buscar gente de fora. Ajudaram a avançar uma crise que existia dentro da Escola, que tinha quadros minguados" (Entrevista com Arlindo Fábio Gómez de Sousa, 1998).

As entrevistas dos docentes revelaram que, desde o início de 1970, existia o desejo de superar uma lógica de formulação que parecia superada, o que só foi possível a partir da aprovação do Projeto Finep, que viabilizou a incorporação de novos quadros.

Em 1975 eu estava em Campinas, no Departamento de Medicina Preventiva, com um grupo em que o grande desafio era a reforma do currículo médico, com a introdução das ciências sociais e a participação no movimento latino-americano para repensar a teoria da saúde, com Garcia e Zé Roberto Ferreira. Nesse ano levamos trombadas na Unicamp e viemos para a Ensp. Tínhamos teses e formação de cientistas. Tinha grupo de resistência na Escola. O encontro desses dois grupos é o novo. (Entrevista com Antônio Sergio Arouca, 1998)

A incorporação de um grupo com formação sólida, que funcionou como um esforço importante para a busca de um novo projeto para a Ensp, não poderia se dar de uma forma simples. A tensão que se estabeleceu entre o 'novo' e o 'velho' nesse momento foi relatada por representantes dos dois grupos, que têm leituras próprias desse processo. Suas análises refletem o modo como cada um deles vivenciou essa transição até a consolidação de um novo modelo (Entrevista com Arlindo Fábio Gómez de Sousa e Antônio Sergio Arouca).

O conflito é parte inerente a qualquer processo. Havia a necessidade de fazer adaptações. Essas pessoas donativas e abertas deviam ceder espaços para os novos, e incentivá-los. Os conflitos não foram suficientes para barrar o processo. Jair e Elza Paim seguraram as barras todas. O Jair, por exemplo, como diretor era muito doce, e segurava as barras com o Presidente [da Fiocruz]. Eles tinham prestígio e absorveram os que tinham outros atributos. O que vem de novo entra em conflito, mas costura e se transforma numa luta de sobrevivência, à luz das relações pessoais, mas também carinhosas e muito estreitas. Era um projeto de vida que se confundia com um projeto de instituição. (Entrevista com Arlindo Fábio Gómez de Sousa, 1998) 
O ambiente escolar da Ensp modificou-se substancialmente na década de 1970, e a associação entre a experiência acumulada dos primeiros tempos na relação com os serviços e a incorporação de novas teorias no campo da saúde pública constituíram um 'capital' significativo, preparandoa para absorver mais uma inovação. Os cursos de saúde pública centralizados e descentralizados e os outros cursos de especialização davam conta de formar o pessoal de carreira das instituições públicas, mas era residual a aprovação de recém-formados nos processos seletivos. Para suprir esta lacuna e com um olhar especial no futuro, e no sistema de saúde como um todo, a Ensp absorveu uma terceira vertente inovadora, com o Programa de Residência em Medicina Preventiva e Social no final da década. Com essa decisão, consolida de forma mais institucionalizada a experiência anterior de um Treinamento Avançado em Serviço, modelo que integrava o conjunto de cursos que se estruturaram ao longo da década como parte da negociação dos docentes com a direção. A residência complementava também a experiência da Escola com os serviços, uma vez que esse curso dava acesso aos serviços do Inamps, trazendo para a Ensp a vertente da assistência médica curativa e, com ela, as discussões que envolviam a análise crítica ao modelo incorporado pelo instituto e às políticas de saúde hegemônicas à época.

$\mathrm{Na}$ fase anterior a essas decisões, o curso de saúde pública foi redesenhado. Passou a ser compreendido como 'básico' de uma carreira de formação e se complementava com a especialização em planejamento ou epidemiologia e o treinamento avançado em serviço (TAS), que privilegiava a experiência e a problematização das questões de saúde pública e era realizado com o apoio do Centro de Saúde Germano Sinval Faria, também da Ensp. Até então, a Escola não tinha uma relação formal com o Inamps, e a integração da residência ao PAR instituiu essa possibilidade.

A residência em medicina preventiva e social foi criada em 1979; propiciou a integração da Ensp aos programas de residência similares e adquiriu relevância na identificação de jovens quadros, tornando-se referência para a formação e absorção dos novos docentes, que passariam a integrar as equipes envolvidas nos processos de reformulação da Escola a partir de então.

Na década de 1970 o Inamps contou com uma diretoria que resolveu inovar, criando dez programas de residência entre os melhores departamentos de Medicina Preventiva. Eram o Nildo Aguiar na Diretoria de Administração e Milton Machado na Coordenação das Residências do Inamps. O programa era dirigido a médicos e tinha bolsa de estudos. 
Era uma opção importante para os médicos. (Entrevista com Paulo Marchiori Buss, 1998).

Todas essas experiências revelam que os educadores da Ensp optaram pela dinamização da Escola, o que gerou a construção dos novos modelos, todos articulados às experiências externas que apresentavam um potencial de problematização e renovação das políticas de saúde. O processo de associação com esses grupos permitiu que a Escola ocupasse espaços como ator político desses movimentos, reformulando o ensino com a prática política. O Peses produziu uma aproximação importante da Ensp com os departamentos de Medicina Preventiva, que, nesse período, também passavam por uma completa reformulação, como parte de uma estratégia de mudança dos cursos médicos, que tinha como objetivo o fortalecimento desses departamentos no âmbito das faculdades de medicina.

Com esse programa, a Ensp passou a participar de um conjunto de iniciativas voltado para a renovação do conhecimento sobre os temas de planejamento, das políticas de saúde e da reorganização ou rearticulação dos serviços, relacionadas por Donnangelo (1983: 32), como uma linha de pesquisa que vai "progressivamente buscando evidenciar, com maior ou menor refinamento metodológico, as articulações econômicas, políticas e ideológicas da prática sanitária na sociedade brasileira", onde também se destacam, além do Peses (1976). Para a autora, exemplificam essa produção: Medicina e Sociedade, de Maria Cristina Donnangelo (1973); A Questão da Saúde no Brasil, de José Carlos Brasal (1978); As Instituições Médicas no Brasil: instituição e estratégia de hegemonia, de Madel Luz (1979); Saúde, Medicina e Trabalho no Brasil, de Cristina Possas (1980); e Previdência Social e Processo Político no Brasil, de Amélia Cohn (1981).

No interior da Ensp, o Peses e o Peppe cumpriram um papel estratégico de renovação do pensamento em saúde pública, favorecendo a formação e incorporação de docentes titulados, possibilitando a instalação de sua pós-graduação stricto sensu em 1977. Os cursos descentralizados promoveram uma completa reformulação da oferta de cursos de formação de sanitaristas no país, crescendo como estratégia de cooperação e de efetivo reforço aos serviços de saúde com uma visão crítica da saúde pública. A residência em medicina preventiva e social trouxe para a Escola a problemática da assistência médica e inovou em relação à clientela, apostando em jovens recém-formados dos cursos da área de saúde. Seus egressos eram portadores de uma visão crítica e renovada do processo saúde-doença, da política de saúde e da epidemiologia. Todos esses projetos 
viabilizaram a formação e a absorção de docentes, em contextos e lógicas que se transformavam a cada momento, e o crescimento desses profissionais era integrado às agendas dos projetos.

Na segunda metade da década de 1970, como parte do processo de fertilização política também relacionado às atividades de ensino, nasceram o Centro Brasileiro de Estudos em Saúde (Cebes) e a Associação Brasileira de Pós-Graduação em Saúde Coletiva (Abrasco). Ambos iniciaram, nesse período, uma importante trajetória de articulação política, de produção editorial, de formação de docentes e de apoio à construção do campo da saúde coletiva, da qual foram atores e partícipes fundamentais durante a década de 1980, adquirindo relevância na 'engenharia política' que resultou na criação do Sistema Único de Saúde brasileiro (SUS).

\section{O Aprofundamento da Relação Ensino-Serviço com Democracia e Participação: a ensp e o nascimento de um NOVO SISTEMA DE SAÚDE}

A década de 1980, para a Ensp e a saúde pública brasileira, pode ser compreendida como um período de preparação da base técnica, gerencial e política do sistema de saúde que viria a ser instituído pela lei n. 8.080, de 1990, estratégia que se processou em uma seqüência de mobilizações de caráter técnico-político, envolvendo grupos engajados em instituições de ensino e de serviços. Esses atores tomaram a redemocratização do país como questão mais ampla e a construção de um novo sistema de saúde, como um lugar privilegiado de tradução da Reforma Sanitária brasileira.

'Saúde e Democracia' foi tema recorrente de seminários, oficinas e documentos, nesse período, e se tornou expressão cunhada pelo Cebes, entidade fundamental para a construção das bases de um sistema de saúde plural, descentralizado e com ampla participação da sociedade em suas decisões.

Desde a década de 1970, o Cebes aglutinou docentes dos departamentos de medicina preventiva e social, alunos dos cursos de saúde pública e de pós-graduações na área e técnicos dos serviços de saúde engajados no movimento de redemocratização do país e de reformas no setor saúde. Mas foi durante os anos de 1980 que algumas estratégias definidas nesse percurso produziram ações mais concretas e que valem a pena ser recuperadas, pela forte relação que tiveram com o crescimento de grupos progressistas vinculados às instituições de ensino e serviços. Os 
docentes da Ensp estiveram envolvidos com esses processos, muitos dos quais desenhando estratégias e tantos outros, no exercício da coordenação técnica e política, destacando-se, entre eles, a $8^{\text {a }}$ Conferência Nacional de Saúde realizada em 1986. A participação de professores da Escola neste evento expressou-se em diferentes contribuições, desde a produção de textos até a realização de palestras em vários estados do país. A coordenação geral foi exercida pelo professor Sergio Arouca, em perfeita articulação com os docentes, incorporando contribuições fundamentais à configuração que a conferência adquiriu.

Todo esse movimento possibilitou a construção de arcos de aliança da Ensp com outros parceiros da academia e dos serviços, estabelecendo parcerias institucionais relacionadas aos projetos de caráter progressista no interior do sistema de saúde.

Após a realização da $7^{\text {a }}$ Conferência em 1980, iniciou-se uma fase de aproximação entre os ministérios da Saúde e da Previdência, com vistas ao aperfeiçoamento do sistema nacional de saúde e à formulação de políticas mais atualizadas em relação ao quadro de referência existente naquele momento. O Prev-saúde foi o primeiro produto desses entendimentos, mas se construiu numa relação conflituosa entre os dois ministérios, tornando inviável a sua implantação. A pressão exercida pelos atores que participaram dessas negociações resultou na divulgação do documento do Conselho Consultivo da Administração de Saúde da Previdência (Conasp), em agosto de $1982,{ }^{6}$ que reorientava a assistência à saúde previdenciária.

O plano apontou para a definição de alguns parâmetros de cobertura, para uma reordenação burocrático-gerencial e para a adoção de procedimentos normativos vinculados às internações hospitalares (Cordeiro, 1991) e foi considerado racionalizador diante da crise da Previdência Social que já vinha se evidenciando em múltiplas facetas desde a década de 1960. A frustração dos técnicos engajados que integravam as equipes do Ministério da Previdência e Assistência Social (MPAS) com o plano não produziu perplexidade. Ao contrário, o grupo de trabalho envolvido com o tema, coordenado por Eleutério Rodrigues Neto, formulou a estratégia das Ações Integradas de Saúde (AIS), que, para Cordeiro (1991: 36),

\footnotetext{
O documento apresentado ao conselho consultivo da administração de saúde da previdência propôs medidas quanto ao modelo vigente de prestação de serviços de saúde no âmbito da Previdência Social, reorientando a assistência à saúde previdenciária e definindo também as estratégias para sua implementação.
} 
"representavam o início da incorporação dos setores público e privado nas atividades de planejamento, que romperiam com a concepção dominante da dicotomia entre serviços/ações preventivas e curativas, ainda que o enfoque do planejamento se vinculasse estritamente à capacidade instalada de assistência individual".

A proposta das AIS incorporou uma visão de gestão colegiada que se expressava em Comissões estaduais (CIS) regionais (CRIS) e locais (CIMS) e em uma comissão federal, a Comissão Interministerial de Planejamento (Ciplan), que reunia representantes dos Ministérios da Saúde, Previdência e Assistência Social e Educação e Cultura, acrescendo, posteriormente, o Ministério do Trabalho. Ainda que as decisões dependessem da aprovação das instâncias centrais, estava instalado, por esse mecanismo, um processo de gestão colegiada que lançaria as bases de outras mudanças embasadoras da prática colegiada de planejamento e gestão entre as instituições integrantes do sistema de saúde, articulada à idéia-força de 'Saúde e Democracia', disseminada no interior do movimento sanitário, marca registrada do Cebes, desde a sua criação em 1976.

O avanço do processo de implantação das AIS permitiu a participação de pessoas com pensamentos políticos variados e ideologicamente divergentes em relação às concepções existentes de sistema de saúde, o que favoreceu a manutenção de um debate permanente, envolvendo grupos representativos vinculados às instituições universitárias, ao Cebes, à Abrasco, às comissões de saúde dos partidos políticos, às entidades de profissionais de saúde, aos trabalhadores rurais e ao movimento da reforma sanitária (Cordeiro, 1991).

Essas primeiras formulações passaram a integrar a agenda dos atores políticos das instituições, com uma adesão progressiva. Em palestra proferida na Bahia em 1995 sobre a 'Reorganização dos Serviços de Saúde e as Ações Integradas de Saúde', o professor Jairnilson Paim (1986a) ampliou o debate e problematizou as idéias do projeto, apresentando dez motivos para apostar nessa estratégia:

- Princípios e objetivos consistentes com os do movimento de democratização da saúde;

- Planejamento e administração descentralizados;

- Instâncias deliberativas permeáveis à negociação política;

- Possibilidade concreta de participação popular organizada;

- Percurso para o estabelecimento do Sistema Unificado de Saúde;

- Respeito ao princípio federativo; 
- Respaldo de forças atuantes no setor;

- Perspectivas mais concretas de viabilidade;

- Incorporação do planejamento à prática institucional;

- Responsabilidade das universidades na formulação e implementação de políticas de saúde.

O debate em torno das AIS beneficiou-se também de uma vigorosa ação política da Abrasco e do Cebes, que atuavam de forma articulada, criando, através de sucessivos eventos, condições mais favoráveis para a construção de consensos entre os grupos que queriam as reformas na saúde. Nessa perspectiva, vale mencionar as reuniões promovidas pelas duas entidades, realizadas em 1984 em Brasília e Curitiba, que trataram das perspectivas das políticas de saúde. A primeira foi realizada na câmara de deputados e contou com a participação de parlamentares representantes do Movimento Sanitário ${ }^{7}$ e de entidades privadas prestadoras de serviço. Nessa oportunidade, só houve consenso quanto ao diagnóstico de que "era necessário ampliar as dotações para a Saúde" (Cordeiro, 1991: 39). No Seminário de Curitiba, os presentes concluíram por "reforçar a posição do Movimento Sanitário no sentido de promover a unificação do sistema de saúde, a descentralização, a participação da população nas decisões e fiscalização", reconhecendo as AIS "como uma etapa ou momento estratégico para preparar a base técnica e gerencial do setor público para as reformas" (Cordeiro, 1991: 39).

Esses e outros esforços contribuíram para a organização de documentos importantes entregues ao presidente Tancredo Neves, por ocasião da sua campanha à Presidência da República, destacando-se, entre eles, o documento da comissão de elaboração do plano de ação do seu governo, que contou com a colaboração de membros do movimento da reforma sanitária e um outro, construído por parlamentares do Partido do Movimento Democrático Brasileiro - PMDB (Rodrigues Neto, 1997).

Essa fase foi superada pela eleição do presidente Tancredo Neves, posteriormente substituído pelo presidente José Sarney. Constituída a nova equipe de governo, delinearam-se as estratégias de ação de cada ministério no que se referia à saúde, e algumas dificuldades começaram a aparecer

Movimento Sanitário: expressão que passou a ser utilizada na década de 1980, no âmbito do setor saúde, para reconhecer o processo de construção de atores sociais que se envolveram na construção e implementação da Reforma Sanitária brasileira e que teve na regulamentação do SUS uma expressão fundamental. 
na transformação dos documentos em práticas institucionais efetivas, assim expressas por um dos negociadores da saída do impasse que se estabeleceu no interior do governo, entre grupos progressistas dos dois ministérios:

Com o advento da Nova República, dois baianos ocuparam a Saúde e a Previdência: Carlos Santana e Waldir Pires. Hésio vai para a Previdência e eu para a Saúde. Começa a discussão da 'unificação'. Era um embate político complicado e nós nos dividimos. Desse embate saiu a seguinte questão: queremos discutir o nosso projeto, já discutido em várias oportunidades, inclusive no Simpósio da Câmara dos Deputados. Enquanto isso, nessas sessões meio confusas, a câmara aprovou o projeto de passagem do Inamps para o Ministério da Saúde e Sarney não fez a passagem. Santana pediu demissão e Waldir argumentou que a Previdência era um patrimônio dos trabalhadores. Falei: 'Então vamos consultar e vamos convocar Deus e o mundo organizado desse país para

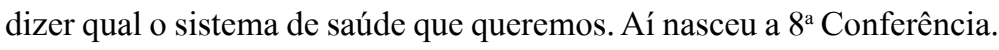
(Entrevista com Antônio Sergio Arouca, 1998).

Os processos de preparação e realização da $8^{\mathrm{a}}$ Conferência Nacional de Saúde cumpriram um papel fundamental na mobilização de apoio para as próximas etapas de construção do sistema de saúde, espaços abertos à participação, onde os centros de formação de recursos humanos em saúde pública, como a Ensp, tiveram oportunidade de exercitar a prática do ensino vinculada aos processos que deram continuidade à luta pela construção do Sistema Único de Saúde do Brasil (Nunes, 1998).

A $8^{\text {a }}$ Conferência foi antecedida de pré-conferências, com expressiva participação de professores da Ensp, que também produziram documentos técnicos e políticos, participaram de relatórios e de mesas redondas da conferência e da coordenação geral.

A $8^{\text {a }}$ Conferência estabelece-se como diferencial, na perspectiva de organização de uma nova ordem institucional para o Sistema de Saúde brasileiro. A Comissão Coordenadora tomou como definição que sua dinâmica deveria permitir uma ampla consulta sobre o modelo de sistema de saúde, e que as representações dos participantes deveriam refletir o pensamento de técnicos e de dirigentes, mas também de docentes, de usuários organizados em diferentes representações, de representantes da classe política, de trabalhadores do setor, entre outros. (Brasil/MS, 1986)

$\mathrm{O}$ ambiente de fertilização que antecedeu a $8^{\text {a }}$ Conferência não arrefeceu no período subseqüente. A organização da Comissão de Nacional da Reforma Sanitária possibilitou a construção de pautas que iam sendo apropriadas pelo movimento de trabalhadores e pelos parlamentares 
considerados progressistas. Também para essa atividade foram mobilizados professores da Ensp. Vale destacar que esses mesmos atores participaram, em sua área de competência, das conferências específicas por temas, que se seguiram à conferência.

A seqüência de eventos, comissões integradas e processos interinstitucionais, mediada pelas agendas políticas das entidades envolvidas com os desdobramentos da $8^{\text {a }}$ Conferência, favoreceu a construção de um consenso em torno do modelo de sistema, após sucessivas reuniões da Plenária da Saúde, fórum no qual as escolas desempenharam um papel fundamental, em uma agenda que reuniu representantes de centros formadores, de serviços de saúde e do movimento profissional e sindical. Nesse espaço, passaram a ser discutidos os pontos que subsidiaram a ação dos parlamentares com propostas que, depois de aprovadas, delinearam o Sistema Único de Saúde brasileiro. Esse trabalho teve uma expressiva participação dos docentes da Universidade de Brasília (UnB), coordenados por Eleutério Rodrigues Neto, e culminou com o reconhecimento, na Constituição de 1988, da saúde como direito de todos e dever do Estado.

O resgate da discussão efetuado neste texto foi focalizado no setor saúde; nele foram abordados apenas alguns aspectos que contribuíram para o avanço das idéias de Reforma Sanitária no país e, em torno desse movimento, alguns elementos que, naquela conjuntura, favoreceram o crescimento das escolas, particularmente da Ensp, como atores fundamentais dos novos rumos da política de saúde no país. Não se tratou, no entanto, dos ciclos de renovação da história política do país, que nessa etapa saía do regime ditatorial instaurado desde 1964, cujo plano político era o 'pano de fundo' de toda essa trajetória, em um processo definido pelos governantes da época como 'lento e gradual'. Também ainda não foram abordados mencionados os processos pedagógicos-políticos peculiares que se contornaram no interior da Escola e que, nesse período, formaram uma 'via de mão dupla' com todo esse movimento. Sua reconstituição parece importante, o que não será feito de forma exaustiva, mas suficiente para entender a Escola Nacional de Saúde Pública como um lugar privilegiado, no qual os movimentos contraditórios de retomada da normalização do país permitiram uma atuação inteligente do ponto de vista político, inserindo-se na pauta de reorganização do setor e fortalecendo-se como um espaço de crítica e de construção de possibilidades para os ciclos que se sucederam à redemocratização do país. 


\section{A Valorização do 'Instituinte' na Reconstrução dos Modelos de Cursos e de Escola}

Tomando como referência os contextos compreendidos entre 1970 e 1989 e analisando os processos que conformaram as experiências da Ensp nesse período, é possível situá-la como uma 'instituição dinamizadora', como propõe Testa. Em sua abordagem sobre o tema, ele considera que "a contradição se estabelece a partir da tensão entre o dinamismo da organização e a elasticidade da instituição". Sob esta ótica, o autor ressalta que "a legitimidade constrói o instituinte e a legalidade é o que estabiliza o instituído", complementando com a ponderação de que "a legalidade se adquire através de um ato pontual em que os atores formais existentes sancionam o status de legal, enquanto o legítimo corresponde a uma liderança política, intelectual e moral, elemento central de construção de viabilidade dos projetos" (Testa, 1997b: 56-60).

Com base em tal concepção, é possível questionar o entendimento de instituições como pólos necessariamente conservadores, atribuindo-lhes a capacidade de abrigar atores que por sua vez se constroem como sujeitos no exercício de sua liderança, relacionando-se com seus trabalhadores e com os destinatários de suas idéias (Testa, 1997). Nessa dimensão estão os projetos do Peses, na sua estratégia de relação com a Escola, e da residência em medicina social, no seu vínculo com o PAR, coordenado pelo Inamps. Suas relações, concepções e processos de implantação sugerem a superação do instituído, absorvido pela legalidade até então existente, e a ampliação de espaços institucionais para a construção de viabilidade dos projetos, nas negociações entre as instituições que se envolveram (Nunes, 1998).

$\mathrm{Na}$ análise dos projetos de ensino que se relacionaram com os serviços, em que são exemplares os cursos descentralizados, é importante considerar a existência de um espaço contraditório nas instituições, atravessado por forças que vão além dos limites estabelecidos pela física do estabelecimento (Kononovich \& Saidón, 1991), entendendo essas instituições, assim, como lugares onde se constroem as possibilidades de negociação entre representantes de esferas diferentes, em torno de objetivos comuns (Nunes, 1998: 160).

Dadas as características do regime ditatorial que atravessou grande parte dessa história, como entender o poder dialógico revelado pelas experiências configuradas nos diferentes períodos, que coincidiam com a exacerbação das idéias autoritárias do regime militar, em que os valores relacionados ao controle, à hierarquia e à disciplina eram referências que 
embasavam inclusive os planos de governo que regulamentavam a organização do trabalho?

Em Madel Luz (1981: 32), podemos entender o poder como "uma estrutura normalizante das relações sociais de subordinação" cujas normas se propõem a "unificar interesses diversos, relações conflituosas", permitindo a existência de "discursos de várias razões". Ainda que nesse período as estruturas governamentais tenham produzido documentos como guias orientadores de uma visão supostamente unificadora, como é o exemplo do decreto-lei n. 200, concentrando o poder de decisão nos escalões mais altos da administração, sua distribuição no interior das organizações parece caracterizar-se pela existência de 'brechas', que poderiam ser ocupadas, numa atuação tática, por atores em conexão. Sua movimentação torna-se possível no contexto das práticas institucionais, que são relações sociais de poder, expresso em ordem e dominação, estabelecendo, portanto, relações conflituosas - por serem relações sociais - e contraditórias - do ângulo da estrutura (Luz, 1981).

Entre as experiências abordadas, é possível identificar conteúdos que representavam o confronto com as políticas hegemônicas existentes, como os Programas de Extensão de Cobertura - com o fortalecimento da atenção básica - e o Programa de Cursos Descentralizados - com a multiplicação das oportunidades de cursos de formação de sanitaristas em todo o país, cuja execução estava vinculada a convênios da Ensp com instituições estaduais não padronizadas a priori. Suas escolhas, de estado para estado, eram também fruto de uma análise política vinculada à sua capacidade de resposta ao projeto, calcada, principalmente, na visão de parceria apresentada nesse trabalho.

Esses eram espaços de debate do 'novo' que, entre outros resultados, articulavam o geral com o específico, favorecendo o exercício da crítica do real (política de saúde) em bases referenciadas pela ciência e pela técnica, relacionadas a uma noção mais ampla dos fenômenos políticos da época. Ainda na dimensão das políticas não-hegemônicas, pode-se destacar o projeto das 'Ações Integradas de Saúde', cuja implantação possibilitou a integração entre as instituições, tendo o planejamento como instrumento político que propiciava o debate entre atores diferentes e o novo sistema de saúde como perspectiva. Esta experiência estabeleceu as primeiras referências para a estrutura de gestão do Sistema Único de Saúde, constituído formalmente no ano de 1990.

Os projetos e as experiências revelaram que a existência de um 'tempo histórico' se sobrepôs ao 'tempo cronológico' que rege as 
instituições e está ligado à sua reprodução cotidiana. Alternativamente, o tempo histórico tem uma pressa qualificada, podendo, com isso, operar idas e voltas, altos e baixos, inerentes aos processos desenvolvidos pela ação humana (Testa, 1997a). Para o autor, "o tempo histórico é incompreensível sem os aceleramentos que se imprimem à ação humana e que o transformam assim, em equivalente à transformação da contradição em conflito", construindo-se, dessa forma, "no espaço onde a história se constrói” (Testa, 1997a: 45).

Parece evidente que as instituições que captaram as possibilidades do 'novo', como é o caso da Ensp,

optaram pela organização de projetos que se estabeleceram como caminhos de renovação, mas sua viabilidade só se tornou possível, quando os atores de sua condução reconheceram nessas estruturas, um campo de possibilidades para viabilizar projetos renovadores, e a partir dessa concepção, desafiaram a legalidade do instituído, oferecendo-se como meio de construção da legitimidade instituinte, tomando como campo de atuação as políticas, os serviços de saúde e as práticas de ensino da Saúde Pública. (Nunes, 1998: 163)

O 'novo' na relação ensino-serviço que se estabeleceu naquele contexto reflete a visão de Anthony Giddens, retratada por Lukes (1980: 25-29), que "reconhece a existência de metas coletivas" e adverte que "os valores por trás delas podem ser o resultado de uma 'ordem negociada', construída sobre conflitos entre partidos que têm poder diferencial".

Observa-se durante todo o período uma tendência à associação de grupos e à adoção de uma estratégia de ocupação de espaços. Tal associação resultou em uma estreita vinculação entre as políticas, os serviços de saúde e o ensino da saúde pública. Compreendê-las nessa dimensão não pressupõe minimizá-las como fontes possíveis de outras análises, mas "valorizá-las enquanto instrumentos que deram concretude ao ensino da Saúde Pública na relação com os serviços e as políticas de saúde" (Nunes, 1998: 164).

Essas possibilidades foram construídas por atores dedicados a um trabalho político-estratégico que tomaram as "instituições como referências de espaços de poder e experimentação de práticas, submetidas permanentemente a tensões de natureza técnica, política e ideológica, e por isso mesmo, como espaços abertos à criação de possibilidades" (Nunes, 1998: 165).

A densidade dos fatos que integram a história da Ensp nos 20 anos abordados por este resgate reflete uma multiplicidade de dimensões que foge ao enquadramento das teorias da educação, mesmo aquelas 
consideradas teorias críticas. A partir da realidade estudada, consideramos que era necessário superar "tanto o poder ilusório (que caracteriza as teorias não críticas), como a impotência (decorrente das teorias críticoreprodutivas)" (Saviani, 1994: 41), permitindo, dessa forma, compreender essa experiência na dimensão de um processo educativo que possibilitou a construção de uma base técnica e política e que teve a contradição como parte integrante do processo de sua constituição (Nunes, 1998). Nesse caso, entendida não apenas "como categoria interpretativa do real, mas também como sendo, ela própria existente no movimento do real, como motor interno do movimento, já que se refere ao curso do desenvolvimento da realidade" (Cury, 1995: 30). A concepção de Cury parte do reconhecimento de que "a contradição é destruidora, mas também é criadora já que se obriga à superação, pois a contradição é intolerável" (Cury, 1995: 35).

Nesse sentido, parece exemplar o depoimento que revelou a necessidade de transformar o perfil de formação de sanitaristas, de um diplomata para um técnico voltado para as questões de saúde de sua comunidade, expressa pela turma de 1968. Esta mesma inquietação retorna à agenda da Ensp com a discussão do sanitarista-administrador de serviços, seguindo-se às outras alternativas pedagógicas de ensino e de pesquisa incorporadas no período, até a absorção, em 1980, da disciplina saúde pública como prática social no curso de saúde pública, discussão que passou a ocorrer também nos outros centros formadores filiados à Abrasco, produzindo um novo diferencial interpretativo para a intervenção na realidade social e de saúde.

O processo de descentralização dos cursos permitiu o alargamento do espaço da contradição, mediatizado pela educação, levando o ensino para um limite mais próximo do sistema de saúde. Também a partir desse momento, a incorporação da residência em medicina preventiva e social como projeto possibilitou a articulação da Escola com uma área menos permeável ao discurso de renovação pelo público, na época representada pelo MPAS, incorporando novos objetos e um novo repertório às intervenções educativas.

A forma de organização adotada com o Programa de Cursos Descentralizados produziu uma ampliação do espaço escolar e criou condições favoráveis para o surgimento de agentes pedagógicos (Cury, 1995), que se tornaram porta-vozes inseridos nas negociações das escolas entre si, com o sistema de saúde e com a própria sociedade (Nunes, 1998).

$\mathrm{Na}$ década de 1980, a adoção da estratégia das AIS pelas instituições e a realização da $8^{\text {a }}$ Conferência Nacional de Saúde em bases 
renovadas possibilitaram a organização dos docentes, favorecendo o surgimento de um movimento de construção de 'novas idéias' para um 'novo sistema de saúde'. Participar de relatórios, mesas-redondas, palestras, conferências, pré-conferências, conferências específicas integrava o cotidiano dos docentes. As relações entre eles e os projetos formulados passaram a ser estabelecidas com lógicas que privilegiavam a proximidade entre o ensino e os serviços, ambos em transformação. Diversificaram-se os modelos de centros formadores no país, com a criação dos Núcleos de Estudos em Saúde Coletiva (NESCs) no interior das universidades, recompondo também o espaço da pós-graduação em saúde coletiva, recriado a partir de então.

"A produção intensiva de fatos políticos, técnicos e científicos no âmbito da saúde, favoreceu a circulação de atores no interior do campo, o que poderia ter permitido sua conexão, em posições favoráveis a um processo de enredamento" (Nunes, 1998 : 172). No interior do campo, os atores se constroem pelo poder de revelar, "quando fazem com que sejam vistas ou previstas coisas que só existiam no estado implícito, confuso, quando não recalcado. Representar, trazer à luz, produzir, isso não é pouca coisa. E então é possível, nesse sentido, falar de criação" (Bourdieu, 1990: 179-180).

A mobilização de atores no interior do campo da saúde coletiva revelou-se intensa nesse período, possibilitando a articulação de pessoas e instituições que tinham na Ensp um espaço privilegiado de produção de saberes e práticas, o que lhe atribuiu um papel central na aproximação com os sistemas estaduais de saúde, conferindo-lhe o sentido de um laboratório "capaz de deslocar fenômenos, assim como exportar e deslocar produtos científicos" (Vinck, 1992: 97).

Nessa dimensão, podemos interpretar como elementos nãohumanos as referências bibliográficas constantes dos relatórios de cursos, as competências colocadas à disposição das atividades, os docentes, os coordenadores e o corpo administrativo dos cursos, os seminários de avaliação dos cursos descentralizados, assim como as teses e os artigos que circularam. Podem ser considerados porta-vozes que atuaram como recursos alimentadores dos projetos que iam sendo construídos no interior da Escola. A classificação da autora parece adequada para localizar a idéia de portavozes da rede de cursos descentralizados. Sua construção se referencia em Callon (1989: 22): "todos os bens sobre os quais um laboratório age, mobiliza, transforma e fabrica, constituem, qualquer que seja a categoria à qual ele pertença, porta-vozes ou representantes que, logo que são mobilizados mobilizam com eles todos os atores humanos ou não humanos". 
De acordo com Nunes (1998: 176), "Parece claro que o espaço da rede incorpora movimentos, iniciativas, polêmicas e exercícios de liderança, onde os atores se constroem, interagem e se diferenciam. $\mathrm{Na}$ relação entre laboratório restrito e laboratório ampliado, alguns atores se movem, emprestando densidade e mobilidade à dinâmica das relações".

Entendemos, assim, a Ensp como um ator-rede que, através da formação de sanitaristas, decide emprestar densidade às iniciativas que conformam os cursos descentralizados. Como ator-rede, chancela um modelo de formação, que se traduz no 'laboratório ampliado' e se expressa através dos eventos locais, 'enredando' parceiros e porta-vozes, 'estabelecendo conexões' e 'disponibilizando produtos e processos' que alimentariam as revisões que se processavam no ensino da saúde pública. Nessa dinâmica, o ator-rede funciona como um elemento propulsor, transferindo sua importância para o processo de enredamento, atraindo aliados e desarticulando oponentes, podendo ser, ele mesmo, "uma rede pela qual circulam uma ampla diversidade de elementos, visões de mundo e modos de conduta" (Teixeira, 1997: 10).

\section{CONCLUSÃo}

A combinação de resultados dos projetos implantados pela Ensp com as mudanças ocorridas nas políticas de saúde no período estudado de 1970 a 1989, revela, no final do período, um panorama radicalmente modificado no que se refere à perspectiva das políticas de saúde do Brasil. A promulgação da lei n. 8.080 em 1990 abriu o caminho para a institucionalização de uma nova realidade na gestão pública de saúde brasileira, e o processo político que construiu a sua viabilidade permaneceu intimamente ligado aos centros de formação em saúde coletiva.

A Ensp atuou como instituição protagonista dessa história; foi ator e partícipe do enfrentamento entre a 'determinação atual' e a 'determinação histórica', segundo a classificação de Testa. Para o autor, "quanto maior for o peso da determinação histórica, maior será o conservadorismo (interno) de uma instituição; quando predominar a determinação atual, será maior a adaptabilidade institucional a situações novas ou mutáveis" (Testa, 1992: 113).

Levando em conta essa referência para compreender o período estudado, é possível constatar que predominou na Ensp a 'determinação atual' em um ciclo também pródigo de movimentações reestruturantes da sociedade brasileira. Nesse período, instituições condutoras de políticas 
públicas, escolas, entidades, profissionais, sindicatos, atores, estudantes e cidadãos defrontaram-se com um cenário onde o exercício da crítica ao sistema de saúde correspondia ao engajamento em projetos que também dialogavam com a luta pela democracia desejada para o país.

Nessas circunstâncias, as instituições também se reconfiguraram, abrindo espaço para o exercício das lideranças que ali empreendiam suas atividades profissionais. Dessa forma, as instituições abandonaram o perfil de pólos conservadores e adquiriram a capacidade de abrigar atores que, por sua vez, se construíram como sujeitos no exercício de sua liderança, relacionando-se com seus trabalhadores e com os destinatários de suas idéias (Testa, 1997).

As 'cenas' aqui abordadas se construíram quando as dificuldades passaram a se estabelecer nos espaços de convivência da sociedade, favorecendo o surgimento de um movimento em que a ação coletiva e organizada dos trabalhadores do meio sindical permitiu o deslocamento da 'cena' para o pólo da prática política, estabelecendo um novo cotidiano, no qual "a autonomia dos movimentos rompe com a tradição política da tutela e da cooptação, e, por isso mesmo, fazendo a política criar novos lugares para exercitar-se" (Sader, 1988: 11).

No âmbito mais geral, nascia naquele momento um novo sujeito social na figura dos próprios movimentos sociais representados por indivíduos "até então dispersos e privatizados", que passaram a "se definir e a se reconhecerem mutuamente, a decidir e agir em conjunto e a redefinir-se a cada efeito resultante das decisões e atividades realizadas" (Sader, 1988: 10).

Aquele era um momento de "desconfiança dos sujeitos com relação às instituições políticas e com os sistemas políticos de mediações", mas, em lugar da apatia, ocorreu a valorização das diferenças entre os movimentos e a busca de sua autonomia (Sader, 1988); os espaços políticos foram recriados com a revalorização do espaço público, no interior do Clube de Mães, das Comissões de Saúde, das oposições sindicais; os sujeitos dos movimentos passaram a falar em 'conscientização', 'reflexão crítica' e 'socialização do saber' nos correspondentes espaços da Igreja, da esquerda e no sindicato; e os movimentos sociais passaram a operar como "fontes populares de informação, aprendizado e conhecimentos políticos, que tendem a ser ampliados e redefinidos pela sua própria prática e dinâmica" (Sader, 1988: 12-13).

A referência ao pensamento de Sader não tem a intenção de aprofundar análises sociológicas sobre os movimentos sociais da época, mas trazê-las à luz, para considerá-las relacionadas com as questões aqui 
abordadas destacadas. Quando Novos Personagens Entraram em Cena é uma obra que discute as experiências e lutas dos trabalhadores da Grande São Paulo na década de 1970 e que consideramos importante resgatar para, nessa dimensão, compreender como as instituições, equipes e os projetos analisados se relacionaram com um novo sujeito coletivo, exercitando uma nova forma de criação do ensino da saúde pública e das políticas de saúde do Brasil.

Nesse contexto, a Ensp foi ao mesmo tempo um ambiente e um personagem privilegiado de na construção das idéias e dos projetos que emergiram das sucessivas conjunturas, enredando-se com parceiros dos serviços e das academias, participando ativamente do processo técnicopolítico que resultou no novo sistema de saúde brasileiro e instituindo-se, nesse processo, como uma verdadeira 'escola de governo' da saúde, de caráter nacional.

\section{REFERÊNCIAS BIBLIOGRÁFICAS}

\section{LIVROS E PERIÓDICOS}

BOURDIEU, P. O campo intelectual: um mundo à parte. In: BOURDIEU, P. (Org.) Coisas Ditas. São Paulo: Brasiliense, 1990.

BRASIL. Decreto Lei 200. Lei 5540. Diário Oficial da União. 25/02/1967, 1967.

BRASIL. II Plano Nacional de Desenvolvimento (PND) - 1975/1979. Rio de Janeiro: Gráfica da Fundação IBGE, 1974.

BRASIL. Programa de Interiorização das Ações de Saúde e de Saneamento no Nordeste. Instituto de Brasília: Planejamento Econômico e Social/Centro Nacional de Recursos Humanos, 1976.

BRASIL. MS/MEC/OPAS. Programa de Preparação Estratégica de Pessoal de Saúde. Brasília: 1975. (Mimeo.)

BRASIL/MS. Relatório Final da 8a Conferência Nacional de Saúde. Brasília-DF, 1986.

BRASIL/MS. Política de Formação de Recursos Humanos para o Setor Saúde. Conferência proferida por ocasião da $4{ }^{\mathrm{a}}$ Conferência Nacional de Saúde realizada em Brasília. Cadernos RH Saúde, 1993a.

BRASIL/MS. Princípios norteadores do sistema único de saúde. descentralização das ações e serviços de saúde - a ousadia de cumprir e fazer cumprir a lei. Brasília: Ministério da Saúde, 1993b.

CALLON, M. Introducion. In CALLON, M. (Org.) La Science et ses Reseaux. Paris: La Découverte, 1989.

CORDEIRO, H. Sistema Único de Saúde. Rio de Janeiro: Ayuri Editorial Ltda, 1991. 
CURY, C. J. Educação e categorias. In: CURY, C. J. (Org.) Educação e Contradição. São Paulo: Cortez, 1995.

DONNÂNGELO, C. A pesquisa na área de saúde coletiva no Brasil - a década de 70. Ensino da Saúde Pública, Medicina Preventiva e Social no Brasil, 2: 19-35, 1983.

KONONOVICH, B. \& SAÍDÓN, O. Conceptualizaciones acerca del dispositivo. In: KONONOVICH, B. \& SAÍDÓN, O. (Orgs.) La Escena Institucional. Buenos Aires: Lugar Editorial, 1991.

LUKES, S. O poder, uma visão radical. Cadernos da UNB. Brasília: Editora Universidade de Brasília, 1980. p. 7-57.

LUZ, M. T. Estratégia de hegemonia e instituições médicas. In: LUZ, M. T. (Org.) As Instituições Médicas no Brasil: instituição e estratégia de hegemonia. Rio de Janeiro: Graal Ltda, 1981.

NUNES, T. C. M. A Especialização em Saúde Pública e os Serviços de Saúde no Brasil de 1970 a 1989, 1998. Tese apresentada para obtenção do grau de doutor na Escola Nacional de Saúde Pública da Fundação Oswaldo Cruz.

ORGANIZAÇÃO PAN-AMERICANA DA SAÚDE (OPAS). Plan decenal de salud para las americas. Informe Final de la Reunión Especial de Ministros de Salud de las Américas. Santiago do Chile: Opas, 1972.

PAIM, J. S. Ações integradas de saúde (AIS): porque não dois passos atrás. In: PAIM, J. S. (Org.) Saúde, Crise e Reforma. Salvador: Centro Editorial e Didático da Universidade Federal da Bahia, 1986a. (Coleção Monográfica Série Reitor Miguel Calmon, 2)

PAIM, J. S. O Movimento pelo planejamento de saúde da América Latina. In: PAIM, J. S. (Org.) Saúde, Crise e Reforma. Salvador: Centro Editorial e Didático da Universidade Federal da Bahia. 1986b. (Coleção Monográfica Série Reitor Miguel Calmon, 2)

PROGRAMA DE ESTUDOS SOCIOECONÔMICOS EM SAÚDE(PESES): Investigação Nacional sobre o Ensino da Medicina Preventiva. Relatório de Pesquisa. Rio de Janeiro: Ensp/Fiocruz, 1978. (Mimeo.)

RODRIGUES NETO, E. A via do parlamento. In: FLEURY, S. (Org.) Saúde e Democracia. A Luta do Cebes. São Paulo: Lemos Editorial, 1997.

SADER, E. Quando Novos Personagens Entraram em Cena. São Paulo: Paz e Terra, 1988.

SAVIANI, D. As teorias da educação e o problema da marginalidade. In: SAVIANI, D. (Org.) Escola e Democracia. Campinas: Mercado das Letras, 1994.

TEIXEIRA, C. F. Educação em Saúde: contribuição ao estudo da formação dos agentes da prática de saúde no Brasil, 1982. Dissertação de Mestrado, Salvador: Faculdade de Medicina, Universidade Federal da Bahia.

TEIXEIRA, M. O. Uma Análise Sociotécnica nas Relações de Parceria entre Centros de Pesquisa e a Construção de Tecnologias no Setor Energético, 1997. Dissertação de Mestrado, Rio de Janeiro: Universidade Federal do Rio de Janeiro.

TESTA, M. Pensar em Saúde. Porto Alegre: Artes Médicas/Abrasco, 1992. 
TESTA, M. Analisis de instituciones hipercomplejas. In: Merhy E. \& ONOCKO, R. (Orgs.) Agir em Saúde: um desafio para o público. São Paulo/Buenos Aires: Hucitec/Lugar Editorial, 1997a.

TESTA, M. Pensamiento estratégico. In: TESTA, M. (Org.) Saber en Salud: la construcción del conocimiento. Buenos Aires: Lugar Editorial, 1997b.

VINCK, D. Itineraires praxeologiques en science. In: Politique de la Science et de la Technologie. Du Laboratoire Aux Reseaux. Le Travail Scientifique en Mutation. Bruxelas: Commission das Communantés Europeéneres, 1992.

\section{ENTREVISTAS REALIZADAS}

Entrevista 01 dr. Paulo Marchiori Buss Entrevista 02 dr. Arlindo Fábio Gómez de Sousa Entrevista 06 dr. Eduardo de Azeredo Costa Entrevista $07 \mathrm{dr}$. Antonio Sergio Arouca
Em 28.03.1998

Em 05.04.1998

Em 09.04.1998

Em 11.04.1998

\section{ENTREVISTAS DE ORIENTAÇÃO PARA O TRABALHO DE CAMPO}

Entrevista dr. Paulo Sabroza

Entrevista dr. Jaime Oliveira agosto de 1997

agosto de 1997

\section{BibLIOGRAFIA}

ALMEIDA FILHO, N. Novos Paradigmas em Saúde: tentativas de aplicação. Salvador: Universidade Federal da Bahia,1997. (Mimeo.)

ALMEIDA FILHO, N. \& PAIM, J. S. A Saúde Coletiva e a "Nova Saúde Pública”: novo paradígma ou velha retórica. Salvador: Universidade Federal da Bahia, 1995. (Mimeo.)

AROUCA, A. S. O Dilema Preventivista: contribuição para compreensão e crítica da medicina preventiva, 1975. Tese de Doutorado. Campinas: Faculdade de Ciências Médicas da Universidade de Campinas.

ASSOCIAÇÃO BRASILEIRA DE PÓS-GRADUAÇÃO EM SAÚDE COLETIVA (ABRASCO). Relatórios Finais dos Grupos de Trabalho do Curso 'Ensino da Saúde Pública', jul., 1981-1982.

ASSOCIAÇÃO BRASILEIRA DE PÓS-GRADUAÇÃO EM SAÚDE COLETIVA (ABRASCO). Relatório Final do I Fórum Nacional sobre Residência em Medicina Preventiva, Medicina Social e Saúde Pública, 1982.

ASSOCIAÇÃO BRASILEIRA DE PÓS-GRADUAÇÃO EM SAÚDE COLETIVA (ABRASCO). V seminário de avaliação dos cursos de saúde pública da Ensp, 1980-1981. Ensino da Saúde Pública, Medicina Preventiva e Social no Brasil, 1983. v.2. 
ASSOCIAÇÃO BRASILEIRA DE PÓS-GRADUAÇÃO EM SAÚDE COLETIVA (ABRASCO). Encontro Nacional de Residentes em Saúde Coletiva: Relatório. Ensino da Saúde Pública, Medicina Preventiva e Social no Brasil, 1984.

ASSOCIAÇÃO BRASILEIRA DE PÓS-GRADUAÇÃO EM SAÚDE COLETIVA (ABRASCO). VI Seminário de Avaliação dos Cursos de Saúde Pública Descentralizados. Relatório. Ensino da Saúde Pública, Medicina Preventiva e Social no Brasil, 1984. v.2.

ASSOCIAÇÃO BRASILEIRA DE PÓS-GRADUAÇÃO EM SAÚDE COLETIVA (ABRASCO). II Fórum Nacional de Residências em Medicina Preventiva e Social: relatório, 1984.

ASSOCIAÇÃO BRASILEIRA DE PÓS-GRADUAÇÃO EM SAÚDE COLETIVA (ABRASCO). Curso de Atualização para Docentes e Pesquisadores em Planejamento de Saúde: relatório, 1984.

ASSOCIAÇÃO BRASILEIRA DE PÓS-GRADUAÇÃO EM SAÚDE COLETIVA (ABRASCO). Grupo de Trabalho sobre Avaliação e Proposta para os Cursos de Saúde Pública - 1984: relatório, 1984.

ASSOCIAÇÃO BRASILEIRA DE PÓS-GRADUAÇÃO EM SAÚDE COLETIVA (ABRASCO). Multiprofissionalidade nas residências em medicina preventiva e social: informe final. Ensino da Saúde Pública, Medicina Preventiva e Social no Brasil, 1984. v.2.

ASSOCIAÇÃO BRASILEIRA DE PÓS-GRADUAÇÃO EM SAÚDE COLETIVA (ABRASCO). I Reunião Nacional sobre Ensino e Pesquisa em Epidemiologia, Estudos de Saúde Coletiva, 4: 93-105, 1986.

ASSOCIAÇÃO BRASILEIRA DE PÓS-GRADUAÇÃO EM SAÚDE COLETIVA (ABRASCO). Seminário sobre perspectivas da epidemiologia frente a reorganização dos serviços de saúde. Estudos de Saúde Coletiva, 4: 111-124, 1986.

ASSOCIAÇÃO BRASILEIRA DE PÓS-GRADUAÇÃO EM SAÚDE COLETIVA (ABRASCO). Pesquisa em saúde coletiva. Estudos de Saúde Coletiva, 4: 41-50, 1986.

ASSOCIAÇÃO BRASILEIRA DE PÓS-GRADUAÇÃO EM SAÚDE COLETIVA (ABRASCO). A Produção Científica na Área da Saúde Coletiva no Brasil. 19841988. Caxambu, 1988. (Mimeo.)

ASSOCIAÇÃO BRASILEIRA DE PÓS-GRADUAÇÃO EM SAÚDE COLETIVA (ABRASCO). Relatório final do encontro nacional de pós-graduação em saúde coletiva e reforma sanitária. Estudos de Saúde Coletiva, 125-155, 1988.

ASSOCIAÇÃO BRASILEIRA DE PÓS-GRADUAÇÃO EM SAÚDE COLETIVA (ABRASCO). Relatório final do VII Seminário de Avaliação dos Cursos de Saúde Pública. Estudos de Saúde Coletiva, 5: 143-155, 1988.

BOURDIEU, P. Algumas propriedades do campo. In: BOURDIEU, P. (Org.) Questões de Sociologia. Rio de Janeiro: Marco Zero, 1983.

BRAGA, E. A figura do educador. In: BRAGA, E. (Org.) O Pensamento de Ernani Braga. Rio de Janeiro: PEC/Ensp, 1984. v.1.

BRASIL. I Plano Nacional de Desenvolvimento-PND 1972/1974, Rio de Janeiro: Gráfica da Fundação IBGE, 1971. 
BRASIL. Da seguridade social. In: Constituição da República Federativa do Brasil. art. 196-200. Salvador: Empresa Gráfica da Bahia, 1988.

BRASIL/MEC. Programa de Integração Docente-Assistencial - IDA. Série Cadernos de Ciências da Saúde, 3, 1981.

BRASIL/MS. Seminário Nacional de Avaliação e Perspectivas de Coordenação Nacional de Cursos Descentralizados: a perspectiva institucional de formação em saúde coletiva no Brasil. Rio de Janeiro: Ensp/Fiocruz, 1980.

BRASIL/MS. Programa do Curso Prático: Nível Nacional - Programa Ampliado de Imunizações-PAI. Rio de Janeiro: Ensp/MS, 1981.

BRASIL/MS. Portaria Ministerial 33062, de 23 de agosto de 1982. Cria o Plano de Reorientação da Assistência à Saúde, 1982.

BRASIL/MS. $8^{\text {a }}$ CONFERÊNCIA NACIONAL DE SAÚDE. Centro de Documentação do Ministério da Saúde. Anais... Brasília, 1986.

BRASIL/MS. Comissão Nacional da Reforma Sanitária. Documento II. Brasília, 1987.

BRASIL/MS. VII Conferência Nacional de Saúde. Anais... Brasília: Ministério da Saúde, 1991.

BRASIL/MS. Relatório Final da I Conferência Nacional de Recursos Humanos para a Saúde. Brasília, 1996.

BUSS, P. M. A experiência do programa de apoio às residências em medicina social, medicina preventiva e saúde pública. In: ABRASCO. Ensino da Saúde Pública, Medicina Preventiva e Social no Brasil. Rio de Janeiro: Nutes Clates, 1982. v.1.

CAMPOS, F. E. \& GIRARDI, S. N. Caracterização dos Programas de Residência de Medicina Preventiva e Social no Brasil: ensino da saúde pública, medicina preventiva e social no Brasil. Rio de Janeiro: Abrasco, 1984.

CEBES. Revista Saúde em Debate, 36: 2, 1992.

COSTA, M. G. S. A Prática e a Formação do Sanitarista: o caso de Alagoas 1979 1986, 1988. Dissertação de Mestrado, Salvador: Faculdade de Medicina, Universidade Federal da Bahia.

COUTINHO, U. A Pós-Graduação na Escola Nacional de Saúde Pública. Rio de Janeiro: Ensp, 1980. (Mimeo.)

DE BRUYNE, P; HERMAN, J \& De SCHOUTHEETE, M. Dinâmica da Pesquisa em Ciências Sociais: os pólos da prática metodológica. Rio de Janeiro: Livraria Francisco Alves Editora S. A., 1977.

ELIAS, P. E; MARSÍGLIA, R \& GONÇALVES, R. B. Contribuições para o debate sobre residência em medicina preventiva e social no Brasil. Estudos de Saúde Coletiva, 5: 27-46, 1988.

ESCOREL, S. Projetos Montes Claros - palco e bandeira de luta, experiência acumulada do movimento sanitário. In: FLEURY, S. T. (Org.) Projeto Montes Claros: a utopia revisitada. Rio de Janeiro: Abrasco, 1995.

FLEURY, S. Introdução. In: FLEURY, S. T. (Org.) A Utopia Revisitada. Rio de Janeiro: Abrasco, 1995. 
FLEURY, S. Introdução. In: FLEURY, S. (Org.) Saúde e Democracia: a luta do Cebes. São Paulo: Lemos Editorial, 1997.

FREITAG, B. Quadro teórico. In: FLEURY, S. (Org.) Escola, Estado e Sociedade. São Paulo: Moraes, 1980.

GARCIA, J. C. Análisis de la educación médica en la América Latina. In: GARCIA, J. C. (Org.) La Educación Médica en América Latina. Washington: Opas, 1972.

GARCIA, J. C. El proceso de enseñanza. In: GARCIA, J. C. (Org.) La Educación Médica en América Latina. Washington: Opas, 1972.

GIOVANELLA, L. As origens e as correntes atuais do enfoque estratégico em planejamento de saúde na América Latina. Cadernos de Saúde Pública, VII: 1, jan.-mar., 1991.

GOULART, F. O movimento municipalista de saúde, a conjuntura política e as políticas de saúde. In: GOULART, F. (Org.) Municipalização. Rio de Janeiro: Abrasco/ Conasems, 1996.

HOCHMAN, G. A Ciência entre a comunidade e o mercado: leituras de Kuhn, Bourdieu, Knoor Cetina e Latour. In: PORTOCARRERO, V. (Org.) Filosofia, História e Sociologia das Ciências. Rio de Janeiro: Fiocruz, 1994.

IRIART, C. et al. Tecnoburocracia Sanitária: Ciência, Ideologia y Profesionalización en la Salud Pública. Buenos Aires: Lugar Editorial, 1994.

LABRA, M. E. O Movimento Sanitarista nos Anos 20: da conexão sanitária internacional à especialização em saúde pública no Brasil, 1985. Dissertação de Mestrado. Rio de Janeiro: Escola Brasileira de Administração Pública da Fundação Getúlio Vargas.

LABRA, M. E; VANSTRALEN, C \& SCOCHI, M. J. A especialização em saúde pública no Brasil no período 1982 - 1986. Estudos de Saúde Coletiva, 5: 47-96, 1988.

LATOUR, B. Joliot: l'histoire et la physique Mêlées. In: SERRES, M. (Org.) Elements L'Histoire des Sciences. Paris: Bordas, 1989.

MARSÍGLIA, R. G. Relação Ensino/Serviços: dez anos de integração docente assistencial (IDA) no Brasil. São Paulo: Hucitec, 1995.

MAYER, A. C. A importância dos "quase-grupos" no estudo das sociedades complexas. In: BIANCO, B. F. (Org.) Antropologia das Sociedades Contemporâneas. São Paulo: Global Universitária, 1987.

MELLO, C. G. O sistema de saúde em crise. Coleção Saúde em Debate. São Paulo: Cebes/Hucitec, 1981.

MINAYO, M. C. S. A pós-graduação em saúde coletiva: um projeto em construção. Rio de Janeiro, 1997. (Mimeo.)

MULLER, J. S. Políticas de Saúde no Brasil: a descentralização e seus atores. Cadernos da Nona, 1: 43-59, 1992.

NUNES, E. D. Juan Cesar Garcia entrevista Juan César Garcia. In: NUNES, E, D. (Org.) As Ciências Sociais em Saúde na América Latina: tendências e perspectivas. Brasília: Opas, 1985. 
NUNES, E. D. Saúde Coletiva: uma trajetória em questão: refletindo sobre a produção científica no campo das políticas de saúde. Rio de Janeiro, 1993. (Mimeo.)

NUNES, E. D. Saúde coletiva: história de uma idéia e de um conceito. Conferência apresentada na reunião sobre Residência em Medicina Preventiva e Social. São Paulo: Abrasco, 1995. (Mimeo.)

NUNES, T. C. M. A formação de recursos humanos: algumas anotações referenciadas pela constituição do campo da Saúde Coletiva no Brasil. Divulgação em Saúde para Debate, 14: 53-58, ago., 1996.

NUNES, T. C. M; CAMPOS, F; \& TELLES, J. L. Modalidades de formação em saúde coletiva. Relatório da oficina de trabalho realizada no IV Congresso Brasileiro de Saúde Coletiva: Saúde, o Feito por Fazer. Recife: Abrasco, 1994. (Mimeo.)

NUNES, T. C. M. \& TEIXEIRA, M. O. Formando técnicos e mobilizando aliados: a trajetória do politécnico da saúde. In: EPSJV. Formação de Pessoal de Nível Médio para a Saúde: desafios e perspectivas. Rio de Janeiro: Fiocruz, 1996.

ORGANIZAÇÃO MUNDIALDA SAÚDE/FUNDO DAS NASÇÕES UNIDAS PARAA INFÂNCIA (OMS/UNICEF). Conferência Internacional sobre cuidados primários de saúde. Relatório da Conferência Internacional Alma-Ata. Brasília, 1979.

PAIM, J. S. Desenvolvimento teórico conceitual do ensino em saúde coletiva. In: ABRASCO. Ensino da Saúde Pública, Medicina Preventiva e Social no Brasil. Rio de Janeiro: Nutes Clates, 1982.

PAIM, J. S. A formação de recursos humanos em saúde coletiva. In: PAIM, J. S. (Org.) Saúde, Crise e Reforma. Salvador: Centro Editorial e Didático da Universidade Federal da Bahia, 1986. (Coleção Monográfica Série Reitor Miguel Calmon, 2)

PAIM, J. S. Desenvolvimento teórico conceitual do ensino em saúde coletiva. In: PAIM, J. S. (Org.) Saúde, Crise e Reforma. Salvador: Centro Editorial e Didático da Universidade Federal da Bahia. 1986.

PAIM, J. S. Medicina preventiva e social no Brasil. In: PAIM, J. S. (Org.) Saúde, Crise e Reforma. Salvador: Centro Editorial e Didático da Universidade Federal da Bahia. 1986.

PAIM, J. S. Recursos Humanos em Saúde no Brasil: problemas crônicos e desafios agudos. São Paulo: Faculdade de Saúde Pública/USP, 1994.

PAIM, J. S. Bases conceituais da reforma sanitária brasileira. In: FLEURY, S. (Org.) Saúde e Democracia: a luta do Cebes. São Paulo: Lemos Editorial, 1997.

PAIM, J. S. \& NUNES, T. C. M. N. Contribuições para um programa de educação continuada. Cadernos de Saúde Pública, 8(3): 263, 1992.

PINHEIRO, T. X. Saúde pública, burocracia e ideologia: um estudo sobre o Sesp (1942-1974), 1992. Dissertação de Mestrado. Rio Grande do Norte: Centro de Ciências Sociais Aplicadas.

SANTOS, R. C. N. A história do Projeto Montes Claros. In: FLEURY, S. (Org.) A Utopia Revisitada. Rio de Janeiro: Abrasco, 1995.

SAVIANI, D. Política e Educação no Brasil. São Paulo: Cortez/Autores Associados, 1988. 
SCHRAIBER, L. B. Ciência, trabalho e trabalhador em saúde: contribuições de Ricardo Bruno Mendes Gonçalves para a compreensão da articulação entre saber, prática e recursos humanos. Revista Divulgação em Saúde para Debate, 14: 7-9, 1996.

TEIXEIRA, M. O. Relações de Parceria do Cepel com Universidades e Centros de Pesquisas: uma análise Sociotécnica, 1994. Dissertação de Mestrado. Rio de Janeiro: Coppe/ Universidade Federal do Rio de Janeiro.

TEIXEIRA, M. Algumas Considerações sobre o Papel das Relações de Parceria entre Centros de Pesquisa e a Construção de Tecnologias no Setor Energético. Rio de Janeiro, 1996. (Mimeo.)

VILAÇA, E. O processo social de distritalização da saúde. In: VILAÇA, E. (Org.) Distrito Sanitário: o processo social de mudança das práticas sanitárias no Sistema Único de Saúde. São Paulo/Rio de Janeiro: Hucitec/Abrasco, 1994. 


\title{
7. Cadernos de Saúde Pública: UMA TRAJETÓRIA DE 20 ANOS'
}

Carlos E. A. Coimbra Jr. Reinaldo Souza-Santos Ricardo Ventura Santos

\section{INTRODUÇÃO}

\begin{abstract}
A revista Cadernos de Saúde Pública (CSP) foi fundada em 1985, tendo como primeiros editores Frederico Simões Barbosa e Luiz Fernando Ferreira. No editorial de inauguração, o então diretor da Escola Nacional de Saúde Pública (Ensp), Arlindo Fábio Gómez de Sousa (1985: 4), escreveu: "Os Cadernos de Saúde Pública pretendem (...) ser um instrumento de ajuda para o trabalho dos profissionais e instituições do setor saúde, prioritariamente, visando sempre o objetivo central de contribuir, por todos os meios, para a melhoria das condições de saúde e de vida de nossas populações".

Passadas duas décadas desde seu nascimento, CSP consolidou-se como uma das principais revistas da área de saúde coletiva no Brasil e na América Latina, com a publicação de centenas de contribuições a cada ano. Nos dias atuais, CSP é um veículo de disseminação de informação em saúde que tem como público-leitor um amplo universo de profissionais, que inclui pesquisadores ligados a instituições de ensino e pesquisa, estudantes de graduação e pós-graduação e profissionais diretamente ligados aos serviços de saúde.

Um aspecto que permite aquilatar a visibilidade alcançada por CSP é sua presença entre os periódicos mais consultados através da
\end{abstract}

1 Nossos agradecimentos a Carla Alves, Carolina Krause Ribeiro, Leandro Carvalho e Márcia Pietrukowicz pelo fundamental auxílio na coleta dos dados e confecção das tabelas apresentadas neste trabalho. 
Biblioteca Científico-Eletrônica On-line, mais conhecida como Scielo (www.scielo.br), com um número próximo de um milhão de artigos acessados.

O objetivo deste artigo é apresentar um breve histórico da trajetória de CSP ao longo de suas duas décadas de existência. Além de comentários sobre aspectos mais diretamente relacionados ao plano editorial, importantes para compreender a evolução da revista, serão tecidas considerações acerca da inserção do periódico no atual contexto da saúde coletiva no Brasil.

\section{Origens e Desenvolvimento}

As origens de CSP remontam a um conjunto de textos mimeografados de circulação restrita, produzido pela Ensp no início da década de 1980. Esse material, de autoria de profissionais da própria instituição, cumpriu o importante papel de embrião do projeto da revista científica que viria nascer em 1985.

O primeiro fascículo de CSP foi lançado em janeiro de 1985 , quando aconteceu, na Ensp, a organização de seu Programa de Educação Continuada, que tinha por objetivo modernizar e implementar novas iniciativas no âmbito da instituição. Na época foram criados, além de CSP, diversos projetos editoriais na Ensp, como Reunião Análise Difusão de Informações em Saúde (Radis), os Textos de Apoio, em co-edição com a Associação Brasileira de Pós-Graduação em Saúde Coletiva (Abrasco), Memória da Saúde Pública, entre outras publicações (Sousa, 1985).

Frederico Simões Barbosa e Luiz Fernando Ferreira foram os primeiros editores de CSP, de 1985 a 1989 (do volume 1, número 1 até o volume 5, número 3). Nos períodos seguintes, atuaram como editores Paulo M. Buss e Luiz Fernando Ferreira (1989, volume 5, número 4), Sérgio Koifman (1990, volume 6) e Carlos E. A. Coimbra Jr. (de 1991 - volume 7, número 1 - até o presente). ${ }^{2}$

Como é o caso de muitas publicações lançadas por instituições de ensino e pesquisa no Brasil, CSP surgiu como um periódico de pequena circulação, que continha em suas páginas um grande número de trabalhos produzidos por pesquisadores da própria Escola. É importante mencionar, contudo, que desde o seu lançamento, como frisou Arlindo Sousa (1985: 4), “CSP esteve sempre abertos à colaboração de profissionais de quaisquer

\footnotetext{
2 No período 1998-1999, a coordenação editorial foi compartilhada por Carlos E. A. Coimbra Jr. e Luis David Castiel.
} 
instituições, nacionais ou estrangeiras, propondo-se a ser um fórum permanente de debates sobre as questões, direta ou indiretamente, ligadas à Saúde Pública”.

Por ocasião dos dez anos de publicação da revista, em 1994, seu então diretor Adauto Araújo (1994: 3) afirmou em editorial:

Nossos Cadernos (...) começaram (...) como uma publicação modesta, de circulação restrita... mas com enorme interesse por parte do público especializado (...). Foi somente quando começaram a chegar artigos de pesquisadores de todo o Brasil e do exterior que a revista conquistou seu lugar como publicação fundamental no campo da Saúde Pública (...). A pesquisa de ponta e os novos rumos da Saúde Pública têm hoje como referencial os Cadernos de Saúde Pública, e será aqui que serão divulgados os resultados de pesquisas que influenciarão grupos emergentes que, futuramente, terão participação crucial nos cenários científico e político, nacional e internacional.

Em outro editorial, recentemente publicado, foram destacadas dimensões relativas ao crescimento e internacionalização de CSP ao longo da última década:

Durante a primeira década de publicação (...) o número médio de artigos por ano foi de cerca de 35; nos últimos três anos, alcançou 173 (...) Quanto à procedência dos autores (...) [durante] a primeira década de publicação, cerca de $48 \%$ dos autores eram externos; nos últimos volumes, chegou a $81 \%$. Outro dado significativo é que $13 \%$ dos autores que publicaram em CSP nos últimos anos são do exterior, sobretudo da América Latina, Europa, EUA e Canadá (....). (Coimbra Jr., 2004: 4)

\section{Aspectos da Trajetória de CSP}

CSP logrou consolidar uma rara trajetória dentre as revistas em saúde publicadas na América Latina. Rara porque, ao contrário de tantas outras, mantiveram-se a periodicidade e a regularidade de sua publicação, aliadas a uma busca constante por inovações de estilo, formato e conteúdo.

O aperfeiçoamento do projeto editorial de CSP ao longo de suas duas décadas foi conduzido em consonância com alguns eixos norteadores, destacando-se o processo de seleção dos trabalhos e a qualidade gráfica da publicação. Quanto ao primeiro, que se constitui em uma etapa absolutamente crucial do processo de editoração científica, buscou-se ancorá-lo rigorosamente no sistema de revisão pelos pares. Ainda no campo 
editorial, vale mencionar a linha inovadora pela qual primou CSP, ao criar espaços alternativos para a veiculação da discussão acadêmica (debates, fóruns, entrevistas, opiniões, resenhas), além da publicação de números temáticos.

CSP experimentou diversas mudanças em seu layout, seja das capas, de seu tamanho ou de seu formato (Figura 1). Estas mudanças não se deram apenas por uma questão de estética - o contínuo aprimoramento proporcionou uma organização interna mais eficiente do texto, em combinação com tabelas e figuras. Além disso, permitiu a publicação de maior número de artigos por fascículo.

Figura 1 - Formatos de capa de CPS em perspectiva, no período 19842004

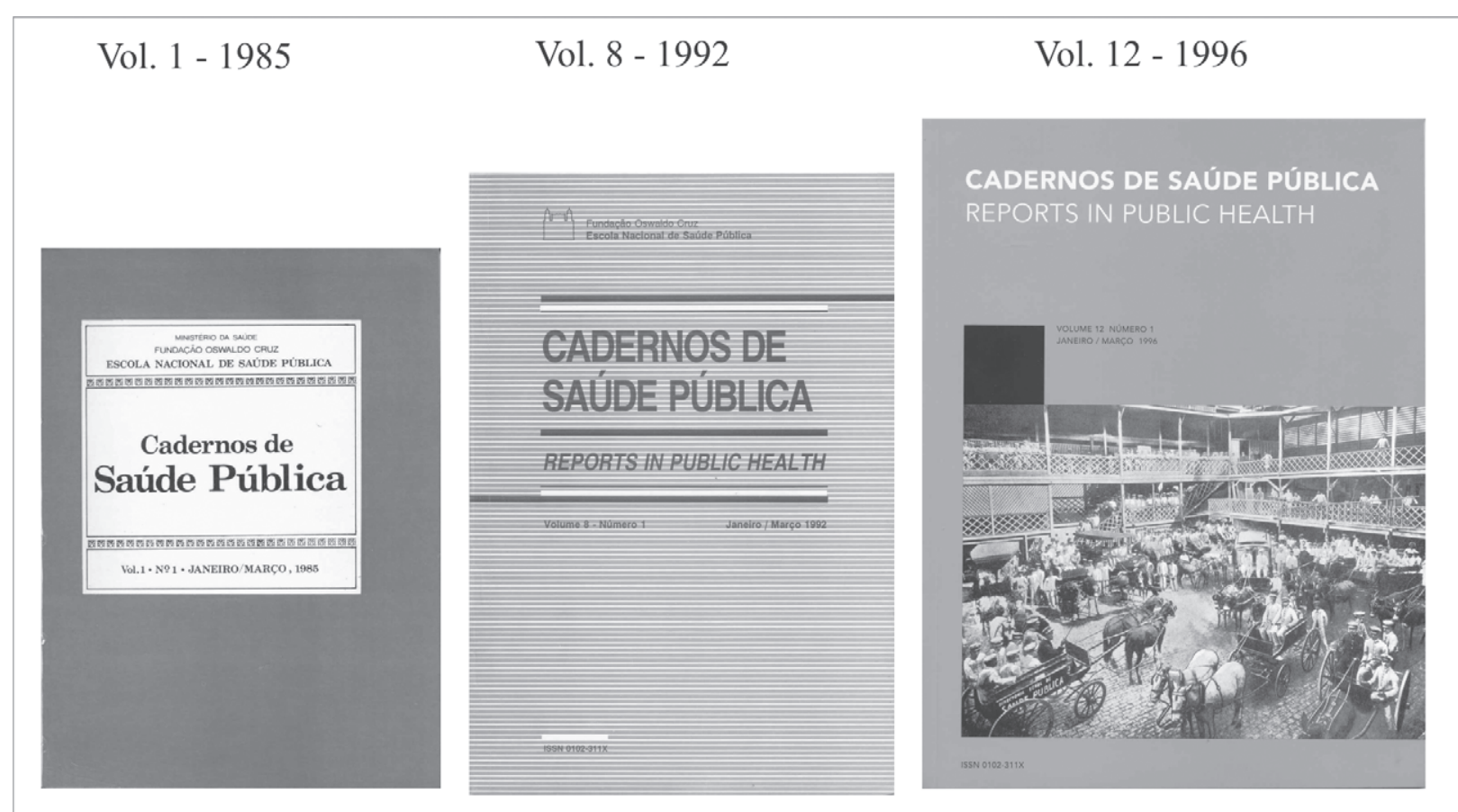

Obs.: Dimensões: volume 1 a $7-16,0$ x 23,0 cm; volume 8 a $11-18,0$ x 26,0 cm , a partir do volume $12-21,0 \times 28,0 \mathrm{~cm}$.

Uma inovação particularmente evidente de CSP aconteceu no volume 12, quando passou a ser publicada em cada capa uma fotografia. A intenção foi de que a capa se tornasse um espaço privilegiado para a veiculação de imagens, de cunho histórico, jornalístico ou documental. 
Desde então, foram publicadas dezenas de fotografias que retratam o cotidiano, as formas de organização e as condições de vida e de saúde de populações humanas. ${ }^{3}$ Tem sido comum o recebimento, na secretaria da revista, de mensagens eletrônicas de leitores comentando as imagens.

Inicialmente, CSP apresentava uma composição de quatro fascículos por volume, tendo publicado em seu primeiro ano de circulação um total de 38 artigos, totalizando 484 páginas. Em vinte anos de publicação, a tendência foi sempre na direção do aumento progressivo de páginas e artigos publicados. Em 2001, a revista tornou-se bimestral, publicando, portanto, seis fascículos por ano. Em 2003, foram publicados 232 artigos, ao longo de 2.380 páginas. Comparativamente, pode-se dizer que, desde a criação de CSP, o número de artigos publicados por ano aumentou aproximadamente seis vezes e o de páginas, cinco vezes (Gráfico 1).

Gráfico 1 - Trajetória de CSP segundo a produção anual de artigos e páginas (1985-2003)

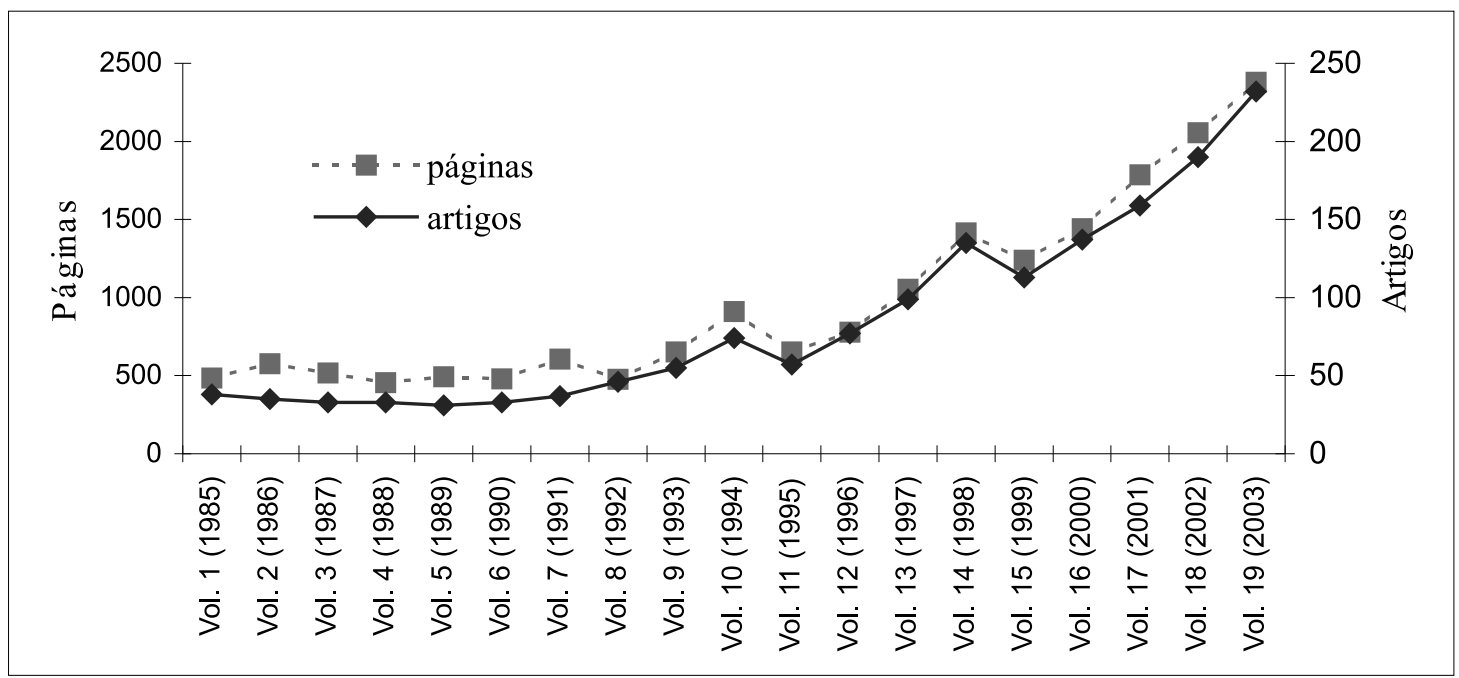

${ }^{3}$ A coleção de capas e respectivas imagens pode ser visualizada em $<$ http://ensp.fiocruz.br/csp $>$. 
Logo em seu segundo ano (1986), CSP publicou um primeiro número temático dedicado à cobertura da $8^{\text {a }}$ Conferência Nacional de Saúde (Quadro 1). No entanto, foi somente a partir do volume 9, em 1993, que a publicação números temáticos consolidou-se como parte constitutiva de sua linha editorial. Desde então, em praticamente todos os anos editaramse números temáticos, regulares e/ou suplementares, sempre sob a coordenação de um ou mais especialistas, oriundos de instituições brasileiras ou estrangeiras. Fica a cargo dos editores convidados a tarefa de estruturar o fascículo, convidando autores para enviarem contribuições. É importante frisar que todos os artigos publicados nesses números são igualmente submetidos à avaliação pelos pares. O resultado dessa política editorial traduz-se em uma ampla variedade de temas de interesse da saúde coletiva, sempre com a preocupação de oferecer o 'estado da arte' do tema abordado.

A publicação de números temáticos mostrou-se muito bemsucedida do ponto de vista editorial, de modo que, nos últimos anos, além dos seis fascículos regulares têm sido publicados de dois a três desses números. Outro indicador de sucesso é que, devido à intensa procura, em geral apresentam tiragens maiores do que os regulares, ainda assim se esgotando rapidamente.

A crescente representatividade, no plano nacional e internacional, de CSP como veículo de divulgação de conhecimentos na área da saúde coletiva pode ser avaliada pela análise da origem dos autores (Gráfico 2). Se nos primeiros anos de publicação o número de autores da Ensp e de outras unidades da Fundação Oswaldo Cruz (Fiocruz) era próximo ou ligeiramente superior ao de autores externos, percebe-se que, rapidamente, CSP tornou-se um veículo da comunidade científica mais ampla da saúde coletiva, com um incremento substancial no número de autores externos à Fiocruz. No presente, de forma majoritária, os primeiros-autores dos artigos são oriundos de instituições outras que a Fiocruz. 


\section{Quadro1 - Números e suplementos temáticos publicados por CSP (1984- 2004)}

\begin{tabular}{|c|c|c|}
\hline $\begin{array}{l}\text { Volume/ } \\
\text { ano }\end{array}$ & Título & Coordenação editorial \\
\hline $\begin{array}{l}\text { Vol. } 2(4) / \\
1986\end{array}$ & 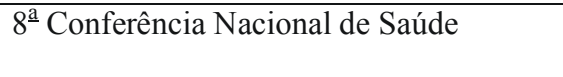 & Tânia Celeste Nunes \\
\hline $\begin{array}{l}\text { Vol. } 3(2) / \\
1987\end{array}$ & Dengue & Keyla B. F. Marzochi \\
\hline $\begin{array}{l}\text { Vol. } 7 \text { (2)/ } \\
1991\end{array}$ & Mulher e saúde & Karen M. Giffin \\
\hline $\begin{array}{l}\text { Vol. } 7(4) / \\
1991\end{array}$ & Saúde de populações indígenas & Carlos E. A. Coimbra Jr. \\
\hline $\begin{array}{l}\text { Vol. } 9(3) / \\
1993\end{array}$ & Abordagens antropológicas em saúde & $\begin{array}{l}\text { Maria Cecília S. Minayo, Carlos E. A. } \\
\text { Coimbra Jr. }\end{array}$ \\
\hline $\begin{array}{l}\text { Vol. } 9 \\
\text { (Sup. 1)/ } \\
1993\end{array}$ & $\begin{array}{l}\text { Crescimento e desenvolvimento físico da } \\
\text { criança brasileira }\end{array}$ & $\begin{array}{l}\text { Ricardo Ventura Santos, Luis Antonio dos } \\
\text { Anjos }\end{array}$ \\
\hline $\begin{array}{l}\text { Vol. } 10 \\
\text { (Sup. 1)/ } \\
1994\end{array}$ & $\begin{array}{l}\text { O impacto da violência social sobre a } \\
\text { saúde }\end{array}$ & Maria Cecília S. Minayo \\
\hline $\begin{array}{l}\text { Vol. } 10 \\
\text { (Sup. 2)/ } \\
1994\end{array}$ & $\begin{array}{l}\text { Investigação epidemiológica de } \\
\text { endemias no Brasil }\end{array}$ & Maria Fernanda Lima-Costa \\
\hline $\begin{array}{l}\text { Vol. } 12 \\
\text { (Sup. 1)/ } \\
1996\end{array}$ & $\begin{array}{l}\text { Saúde materno-infantil em pelotas, Rio } \\
\text { Grande do Sul, Brasil, 1982-1993: uma } \\
\text { década de transição }\end{array}$ & Fernando C. Barros, Cesar G. Victora \\
\hline $\begin{array}{l}\text { Vol. } 12 \\
\text { (Sup. 2)/ } \\
1996\end{array}$ & $\begin{array}{l}\text { Epidemiologia e avaliação de serviços de } \\
\text { saúde }\end{array}$ & $\begin{array}{l}\text { Luiz A. B. Camacho, Zulmira M. A. Hartz, } \\
\text { Moisés Goldbaum, H. M. D. Novaes }\end{array}$ \\
\hline $\begin{array}{l}\text { Vol. } 13 \\
\text { (Sup. 1)/ } \\
1997\end{array}$ & $\begin{array}{l}\text { Epidemiologia do câncer de estômago no } \\
\text { Brasil }\end{array}$ & Sergio Koifman \\
\hline $\begin{array}{l}\text { Vol. } 13 \\
\text { (Sup. 2)/ } \\
1997\end{array}$ & $\begin{array}{l}\text { Novas perspectivas em saúde do } \\
\text { trabalhador }\end{array}$ & $\begin{array}{l}\text { Carlos Minayo-Gomez, Francisco A. C. } \\
\text { Lacaz }\end{array}$ \\
\hline $\begin{array}{l}\text { Vol. } 14 \\
\text { (Sup. 1)/ } \\
1998\end{array}$ & Saúde reprodutiva na América Latina & Ellen E. Hardy \\
\hline $\begin{array}{l}\text { Vol. } 14 \\
(\text { Sup. 2)/ } \\
1998\end{array}$ & $\begin{array}{l}\text { Participação popular e controle de } \\
\text { endemias }\end{array}$ & Victor V. Valla \\
\hline $\begin{array}{l}\text { Vol. 14 } \\
\text { (Sup. 3)/ } \\
1998\end{array}$ & $\begin{array}{l}\text { Câncer ambiental e ocupacional na } \\
\text { América Latina }\end{array}$ & Sergio Koifman \\
\hline $\begin{array}{l}\text { Vol. } 15 \\
\text { (Sup. 1)/ } \\
1999\end{array}$ & Bioética & Fermin R. Schramm, Luis D. Castiel \\
\hline Vol. 15 & Educação em saúde: novas perspectivas & Virgínia T. Schall, Miriam Struchiner \\
\hline
\end{tabular}


Gráfico 2 - Trajetória de CPS segundo procedência do primeiro-autor dos artigos - da Ensp, da Fiocruz e externos à Fiocruz (1984-2004)

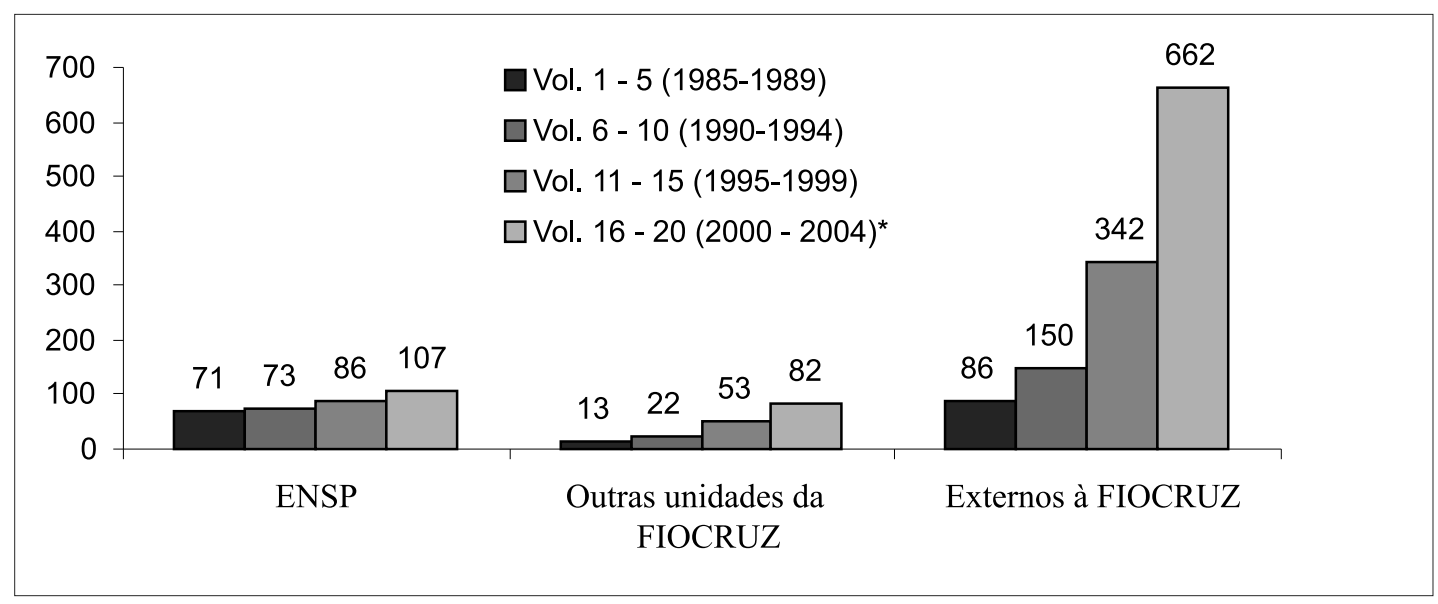

* No caso do volume 20, os dados referem-se até o número 4 (julho-agosto/2004).

Além do aumento de autores externos à Fiocruz, nota-se, ao longo da trajetória de CSP, uma tendência à maior presença de autores das várias regiões do país (Gráfico 3). Assim, ao compararmos os cinco primeiros volumes (referentes a 1985-1989) com os mais recentes (referentes a 20002004), percebemos que aumentou significativamente a presença de autores das várias regiões, sobretudo da Nordeste e Sul.

Gráfico 3 - Trajetória de CSP segundo procedência do primeiro-autor dos artigos por região do Brasil (1985-2004)

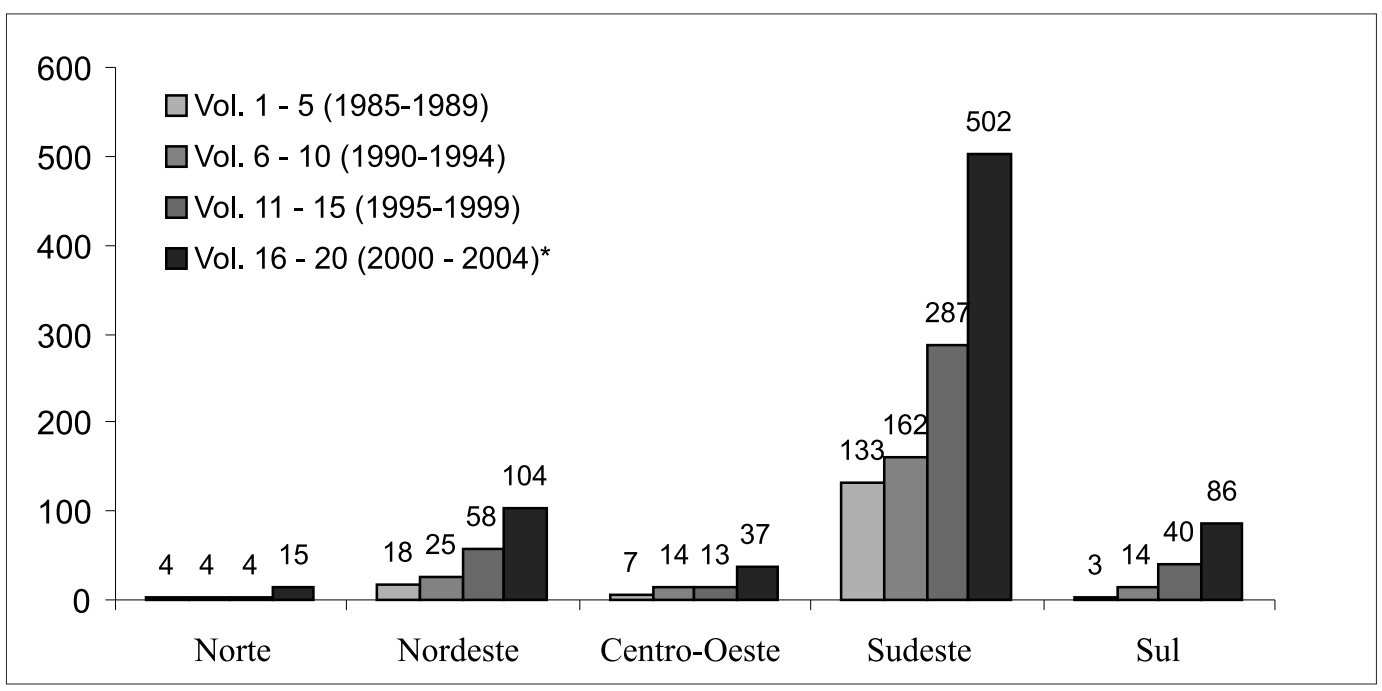

* No caso do volume 20, os dados referem-se até o número 4 (julho-agosto/2004). 
Gráfico 4 - Trajetória de CSP segundo língua de publicação dos artigos (1984-2004)

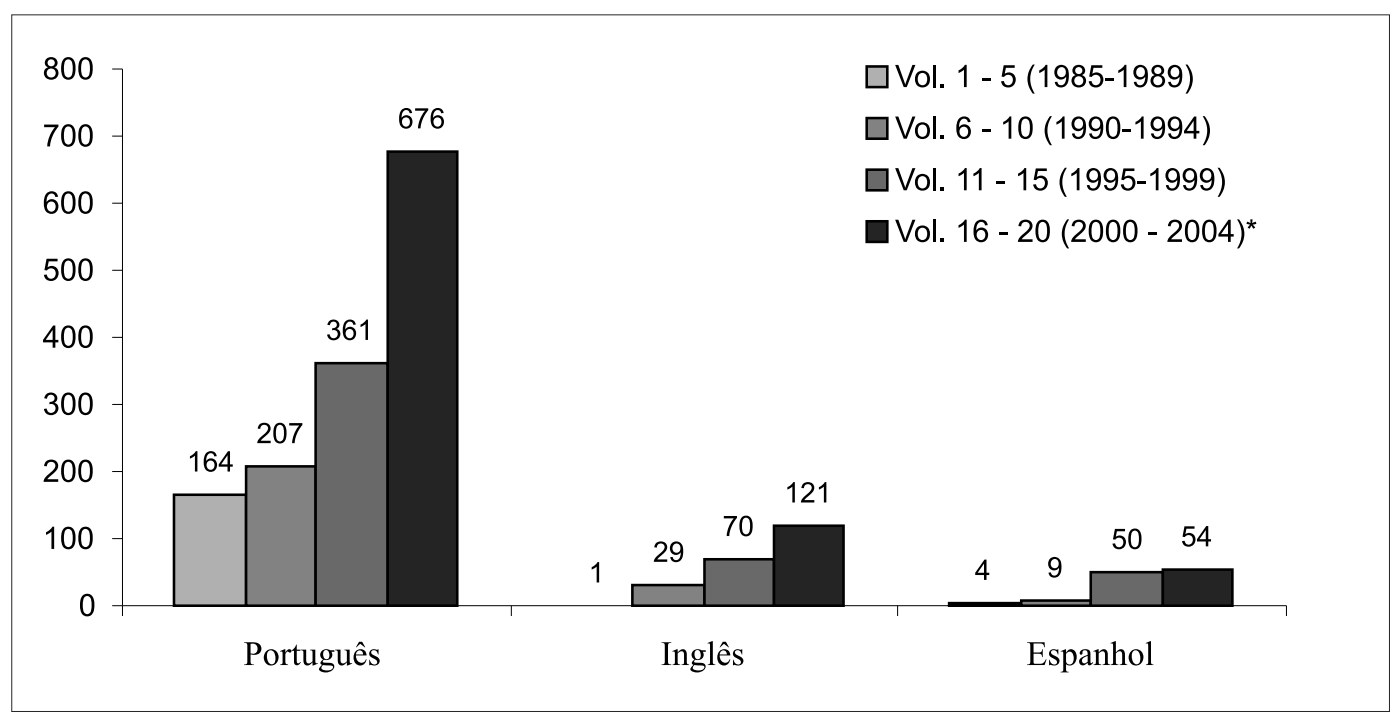

* No caso do volume 20, os dados referem-se até o número 4 (julho-agosto/2004).

Se no âmbito nacional foi ampliada a participação de autores das várias regiões do país, CSP também experimentou uma notável internacionalização ao longo de sua trajetória (Gráfico 4). Sobretudo a partir de meados da década de 1990, aumentou significativamente o número de artigos em outras línguas além do português, mais especificamente o inglês e espanhol. Este crescimento veio associado, em especial a partir de 1997, ao aumento no número de artigos publicados por autores de vários países da América Latina, América do Norte e Europa (Gráfico 5). O fato de autores estrangeiros estarem optando pelas páginas de CSP para publicarem suas idéias e os resultados de suas pesquisas sinaliza que a revista passou a ser conhecida e a gozar de reputação para além das fronteiras nacionais. 
Gráfico 5 - Trajetória de CPS segundo procedência do primeiro-autor por região do mundo (1984-2004)

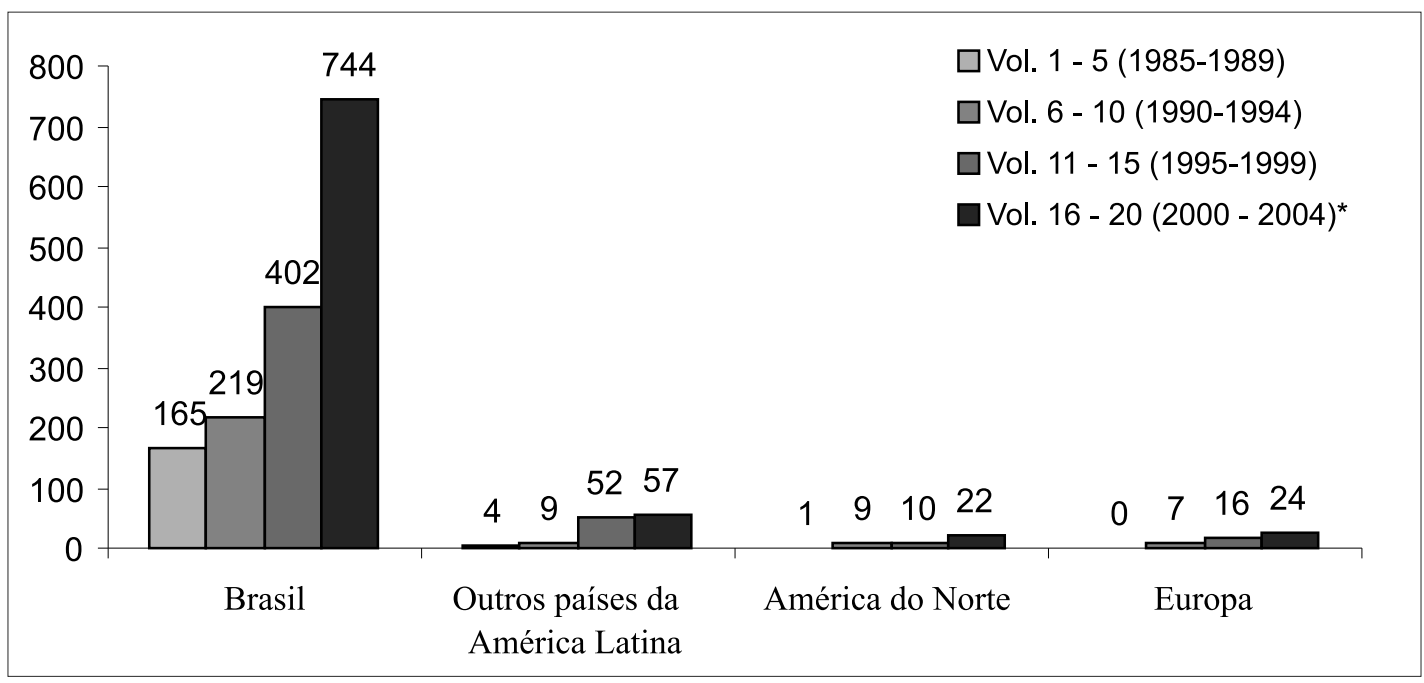

* No caso do volume 20, os dados referem-se até o número 4 (julho-agosto/2004).

Vale destacar dois aspectos que reiteram a bem-sucedida trajetória de CSP. Em 2003, o Departamento de Ciência e Tecnologia (Decit) da Secretaria de Ciência, Tecnologia e Insumos Estratégicos do Ministério da Saúde conferiu pela primeira vez o Prêmio de Incentivo em Ciência e Tecnologia para Sistema Único de Saúde (SUS), em uma concorrência de âmbito nacional. Do total de cinco prêmios conferidos na categoria Artigos Publicados, três haviam sido veiculados por CSP. Igualmente significativos são os resultados das análises de Golbaum \& Barata (2003), que indicam os periódicos em que se publicam mais freqüentemente os trabalhos dos bolsistas de produtividade do Conselho Nacional de Desenvolvimento Científico e Tecnológico (CNPq) na área da saúde coletiva. Os autores demonstram que, dentre os 486 trabalhos publicados no período 20002002 em 12 periódicos, 41,6\% concentraram-se em CSP. Além disso, para todas as categorias de bolsistas (1A, 1B, 1C, 2A, 2B e 2C), CSP desponta como o periódico no qual mais trabalhos foram publicados. 


\section{DISSEMINAÇÃO DE CSP}

Sobre a indexação da literatura científica, pode-se afirmar que:

Do ponto de vista dos usuários imediatos das revistas, isto é, autores e leitores, as bases de indexação são os meios mais eficientes de disseminação de resultados de pesquisas e de realização de levantamentos bibliográficos. (...) Já para os editores, a indexação de um periódico nas principais bases de dados internacionais representa muito mais do que um veículo de disseminação de informação científica. A inclusão de revistas em determinadas bases consideradas como de maior prestígio tem sido percebida por número crescente de profissionais (tanto pesquisadores como aqueles ligados a atividades de fomento) como parâmetro indicativo da qualidade de um periódico e, por extensão, dos artigos neste publicados, gerando acirrada competição entre editores, autores e instituições financiadoras de pesquisa. (Coimbra Jr., 1999: 883)

Em um mundo em que coexistem quase 100 mil revistas acadêmicas, a mera existência de um título não assegura a sua leitura (Coimbra Jr., 1999). Nesse contexto, A indexação internacional de CSP foi um dos principais passos na busca de maior visibilidade, tendo sido crucial sua inclusão no Index Medicus-Medline em 1998, a base mais consultada mundialmente na área da saúde. Mais recentemente, tem sido ampliada a indexação de CSP nesta base, com a inclusão retroativa de artigos publicados até 1994.

Também em 1998, a disponibilização integral dos fascículos publicados na Internet, por meio do sistema Scientific Electronic Library Online (Scielo), integrado ao sistema de busca bibliográfica do Medline, colocou CSP em um seleto conjunto de revistas científicas publicadas na América Latina, com efetivas possibilidades de maior disseminação para outras regiões do mundo.

Além dessas bases, a revista é indexada em: Sociological Abstracts; Social Planning/Policy \& Development; Protozoological Abstracts; Helminthological Abstracts; Rural Development Abstracts; Review of Medical and Veterinary Mycology; Veterinary Bulletin; Literatura LatinoAmericana e do Caribe em Ciências da Saúde (Lilacs); CAB Abstracts; Nutrition Abstracts and Reviews. Series A: human and experimental; Abstracts on Hygiene and Communicable Diseases; Tropical Diseases Bulletin; e Red Panamericana de Información y Documentación en Ingeniería Sanitaria y Ciencias del Ambiente (Repidisca).

Pode-se afirmar com segurança que CSP figura atualmente entre as revistas científicas mais lidas no país. Segundo estatísticas recentes da 
Scielo, do total de revistas que integram a base (127 periódicos em agosto de 2004), foi CSP que apresentou o maior número de downloads de artigos, com uma cifra próxima de um milhão (893.929 em 20/8/2004). Do total de downloads de artigos de todos os periódicos presentes na base, a revista alcançou $6,4 \%$, a mais elevada porcentagem entre os mais de 100 periódicos.

Em reconhecimento ao seu papel na disseminação das pesquisas em saúde coletiva, CSP é classificada como Qualis Internacional A (categoria máxima) no sistema Capes/Qualis, utilizado para fins da avaliação da produção dos docentes ligados aos programas de pós-graduação (mestrado e doutorado) em saúde coletiva no país.

Vale destacar outra dimensão acoplada à disseminação, que assume grande relevância no contexto da Ensp e da Fiocruz: estamos nos referindo às permutas que a biblioteca da Ensp vem estabelecendo com bibliotecas e instituições nacionais e estrangeiras. Em agosto de 2004, além de 105 permutas nacionais, CSP era permutada com outras 134 publicações das mais diversas partes do mundo (Gráfico 6). Tais permutas, que incluem importantes periódicos como o American Journal of Epidemiology e o International Journal of Epidemiology, não somente têm contribuído sobremaneira para o enriquecimento do acervo da biblioteca da Escola, como também funcionam como via de disseminação adicional de CSP, já que seus exemplares são incorporados aos acervos de centenas de bibliotecas no Brasil e em outros países.

Gráfico 6 - Procedência das permutas de revistas estrangeiras com CSP (2004)

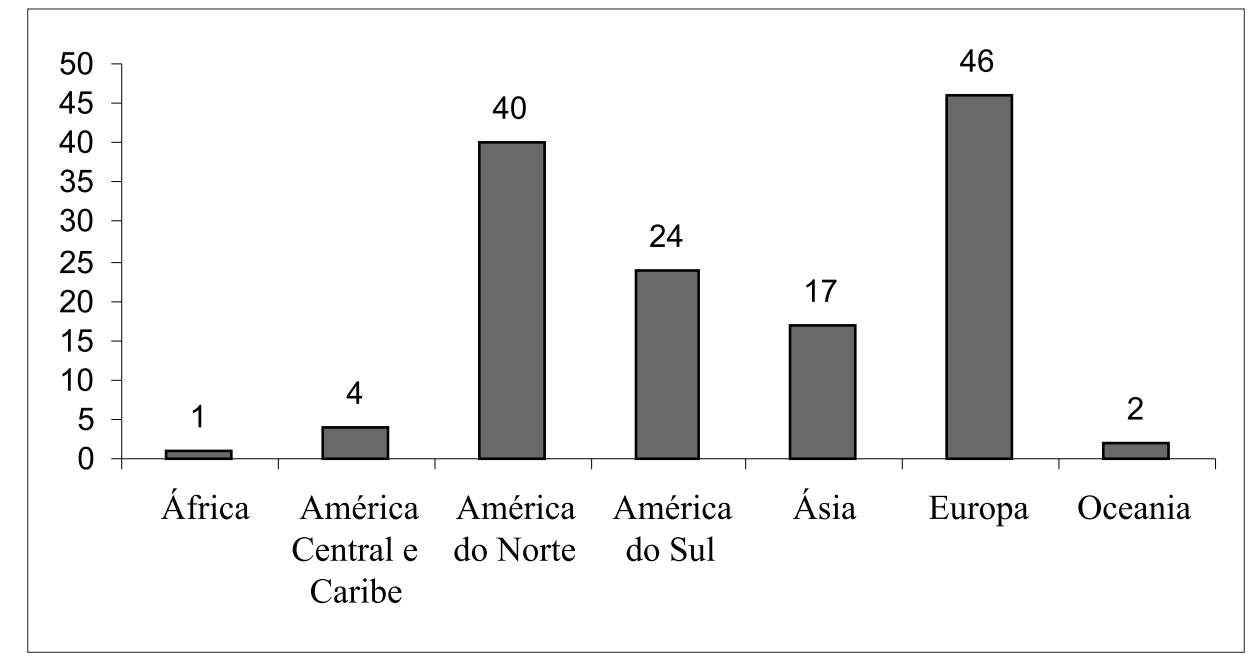




\section{COMENTÁRIOS FinaIS}

Em um artigo recente, Moisés Goldbaum e Rita Barata (2003:

1863) observaram que:

Enquanto campo científico, a Saúde Coletiva constitui um conjunto de teorias e práticas que se organiza e se diferencia para compreender, explicar e modificar o processo saúde-doença, em seus aspectos materiais e não materiais, na dimensão coletiva, assim como as formas de respostas socialmente organizadas para o enfrentamento das necessidades de saúde (...). Tomando esses aspectos da realidade como objeto de trabalho, no Brasil, a Saúde Coletiva experimentou crescimento considerável na última década, expresso no aumento do número e ampliação da distribuição de programas de pós-graduação, constituição de grupos de pesquisa, número de pesquisadores qualificados e consolidação da produção científica, retratados, por exemplo, em recente levantamento sobre a pesquisa em Epidemiologia no Brasil.

Inquestionavelmente, como demonstra a análise desses autores, CSP está intimamente associada à expansão e à consolidação da saúde coletiva no Brasil nas últimas décadas. Em suas páginas, ao longo desses 20 anos, foram publicadas centenas de contribuições que, em intenso sinergismo, foram moldadas pelo vibrante campo da saúde coletiva no país, ao mesmo tempo que contribuíram para consolidá-lo.

O ano de 2004 marca os 20 anos de publicação de CSP. Deve-se destacar a raridade de uma trajetória como a de CSP no meio editorialcientífico latino-americano, marcado pelo grande número de títulos de periódicos interrompidos precocemente ou que são irregulares. $\mathrm{O}$ apoio dos dirigentes e da comunidade da Ensp tem sido fundamental para a permanência e o crescimento de CSP.

Contribuiu para o êxito de CSP, além do esforço daqueles mais diretamente envolvidos em sua produção, o apoio do grande público potencialmente usuário das revistas científicas no país, em especial pesquisadores, profissionais de saúde e estudantes. Atualmente, tal diversidade reflete-se nas páginas de CSP: são autores e leitores com perfis extremamente variados, identificados com o largo espectro das profissões de saúde, inclusive setores das ciências sociais e da biologia. Altamente significativo é o fato de CSP ter-se constituído como uma das principais pontes entre as esferas acadêmico-científicas e os serviços de saúde.

A sustentação de um projeto de tamanha envergadura é realização de muitos, cujos nomes seria impossível listar sem incorrer em injustiças. A Ensp tem sido a principal financiadora da revista, que também conta 
com importante apoio financeiro do $\mathrm{CNPq}$, além do suporte de outras instituições, sobretudo no custeio dos suplementos temáticos. As centenas de autores que têm confiado os resultados de suas pesquisas às páginas de CSP, e os milhares de leitores que buscam na revista informação em saúde de ponta e de qualidade seriam presença obrigatória em uma longa lista de agradecimentos. Também as centenas de consultores ad hoc (em 2003, por exemplo, foram 388), cujos nomes aparecem listados em seção especial do último fascículo de CSP a cada ano, prestam valiosíssimo serviço à revista. Por fim, o reconhecimento à 'equipe da casa', que inclui os editores associados, editores assistentes e todo o pessoal de secretaria e apoio, essenciais na orquestração de um projeto cujo número de artigos novos recebidos anualmente é da ordem das centenas. ${ }^{4}$

A trajetória de CSP foi marcada pela ênfase na concomitância, nem sempre fácil, entre consolidação e renovação. É desta interação que resulta a vitalidade de um veículo de disseminação de conhecimento científico. Não podemos perder de perspectiva que a vitalidade não é fruto apenas do trabalho de editores e consultores; pelo contrário, ela se nutre do amadurecimento, da produtividade e da constante efervescência da comunidade acadêmica imediata na qual a revista está inserida. Os 20 anos de CSP e os 50 anos da Ensp significam muito mais do que marcos temporais arbitrários. Constituem um momento de pausa para ouvir, refletir e propor novos caminhos. Cadernos de Saúde Pública é um projeto coletivo, transcendendo limites institucionais específicos, sendo produto do dinamismo da comunidade científica em saúde pública brasileira como um todo.

\section{REFERÊNCIAS BibLIOGRÁFICAS}

ARAÚJO, A .J .G. Editorial. Cadernos de Saúde Pública, 10(1): 3-4, 1994.

COIMBRA JR., C. E. A. Produção científica em saúde pública e as bases bibliográficas internacionais. Cadernos de Saúde Pública, 15(4): 883-888, 1999.

COIMBRA JR., C. E. A. Cadernos de Saúde Pública: 20 anos. Cadernos de Saúde Pública, 20(1): 4-5, 2004.

GOLDBAUM, M. \& BARATA, R. B. Perfil dos pesquisadores com bolsa de produtividade em pesquisa do CNPq da área de saúde coletiva. Cadernos de Saúde Pública, 19(6): 1863-1876, 2003.

SOUZA, A. F. G. Editorial. Cadernos de Saúde Pública, 1(1): 4, 1985.

\footnotetext{
4 A partir de 2002, foi implementada uma reorganização do trabalho editorial de CSP, com a maior participação dos editores associados no processo de avaliação e seleção dos manuscritos.
} 


\section{BiBLIOgRAFIA}

CASTIEL, L. D. \& COIMBRA JR., C. E. A. Cadernos de Saúde Pública: rumo ao ano 2000. Cadernos de Saúde Pública, 15(4): 670-671, 1999.

CASTIEL, L. D. \& COIMBRA JR., C. E. A. Mudanças em Cadernos de Saúde Pública. Cadernos de Saúde Pública, 16(1): 4-5, 2000.

COIMBRA JR., C. E. A. Editorial. Cadernos de Saúde Pública, 7(1): 5, 1991.

COIMBRA JR., C. E. A. Editorial. Cadernos de Saúde Pública, 8(1): 3-4, 1992.

COIMBRA JR., C. E. A. Dez anos dos Cadernos de Saúde Pública. Cadernos de Saúde Pública, 10(4): 423-424, 1994.

COIMBRA JR., C. E. A. Editorial. Cadernos de Saúde Pública, 12(1): 4-5, 1996.

COIMBRA JR., C. E. A. Editorial. Cadernos de Saúde Pública, 14(3): 462-463, 1998.

COIMBRA JR., C. E. A. 2002. Dezoito anos de Cadernos de Saúde Pública. Cadernos de Saúde Pública, 18(1): 4-5.

CONSELHO EDITORIAL DE CSP. Editorial. Cadernos de Saúde Pública, 9(1): 3, 1993.

KOIFMAN, S. Editorial. Cadernos de Saúde Pública, 6(1): 3, 1990. 


\section{O Perfil dos Egressos da Pós- Graduação Stricto Sensu da Ensp: HIPÓTESES, TENDÊNCIAS E PROPOSTA PARA UMA AVALIAÇÃO INSTITUCIONAL}

\section{INTRODUÇÃO}

A criação e o desenvolvimento do Programa de Pós-Graduação stricto sensu da Escola Nacional de Saúde Pública, da Fundação Oswaldo Cruz (Ensp/Fiocruz), em meados da década de 1970, integrou o processo de organização e expansão da pós-graduação no Brasil, da qual a Coordenação de Aperfeiçoamento de Pessoal de Nível Superior (Capes) foi agente privilegiado.

Uma avaliação do perfil dos egressos do Programa de PósGraduação stricto sensu da Ensp deve ser, portanto, inserida no contexto de organização da pós-graduação em nosso país, levando em consideração as instituições, concepções e os atores envolvidos. Em seguida, faremos uma apresentação e análise sumária dos primeiros dados obtidos no levantamento desenvolvido na Secretaria Acadêmica da Ensp, ${ }^{1}$ complementado com informações obtidas na Plataforma Lattes da Capes. Esta pesquisa permitiu que fossem elaborados diferentes perfis dos egressos. Gênero, origem profissional e geográfica foram alguns dos parâmetros utilizados para desenhar este perfil. Foram incluídos nesta análise tanto os dados dos alunos que concluíram quanto os dos que não terminaram os cursos de mestrado e doutorado. Os egressos que fizeram mestrado e doutorado na Ensp mereceram atenção especial. Os 'filhos' da Ensp complementam nosso estudo.

\footnotetext{
Agradecemos a participação de Renata Rufino e Júlia Bertolini - bolsistas do Programa de Vocação Científica (Provoc) da Escola Politécnica de Saúde Joaquim Venâncio - na construção e organização do Banco de Dados sobre os Egressos da Ensp, que serviu de base para a redação deste artigo. Agradecemos, ainda, ao sociólogo Luciano Cerqueira e ao programador Elcio Novis Cardozo, que nos ajudaram na indexação dos dados.
} 
Os dados coletados e sistematizados e as tabelas permitem a apresentação de hipóteses explicativas para o perfil obtido e indicam tendências para os próximos anos. Este artigo visa ainda enfatizar a importância de uma análise permanente que avalie e acompanhe o egresso. Os resultados fornecidos por esta pesquisa e sua continuidade podem ser incorporados ao conjunto de indicadores utilizados na avaliação institucional da Ensp.

\section{CAPES: UMA HISTÓRIA EM CINCO TEMPOS ${ }^{2}$}

Marieta de Moraes Ferreira e Regina da Luz Moreira (2002) coordenaram uma equipe de pesquisadores e organizaram uma obra recorrendo a depoimentos orais com alguns dos atores sociais que participaram da criação e do desenvolvimento da Capes desde sua origem - 1951 - até os dias atuais. Com base nas entrevistas e nas leituras realizadas, propuseram uma periodização para a história desta agência de fomento, dividindo-a em cinco momentos.

O primeiro foi denominado por elas de 'A Capes em tempos de Anísio Teixeira' (1951-1964). Inicialmente denominada Campanha Nacional de Aperfeiçoamento de Pessoal de Nível Superior, a Capes foi criada com o objetivo oficial de assegurar a existência de pessoal especializado em quantidade e qualidade suficientes para atender às necessidades dos empreendimentos públicos e privados que visam ao desenvolvimento do país.

A organização dessa entidade ocorreu durante o segundo governo Vargas, quando a questão da construção de uma nação desenvolvida e independente estava na ordem do dia. A administração pública, a industrialização e o setor de serviços assumiam uma abrangência inédita e careciam de pessoal especializado de nível superior. Com propósito análogo e/ou atendendo a demandas semelhantes, foram criados, nos anos 1950, o Banco de Desenvolvimento Econômico e Social (BNDES), o Conselho Nacional de Pesquisas (CNPq), a Escola Brasileira de Administração Pública (Ebap) e a Escola Nacional de Saúde Pública (Ensp). A criação da Capes não foi, portanto, um fato isolado; atendeu, antes de mais nada, a uma visão estratégica sobre o lugar da formação profissional no exercício das atividades públicas, no pleno funcionamento do Estado e na incursão do país no mundo desenvolvido.

\footnotetext{
2 Neste trecho, incorporamos livremente boa parte das idéias expostas por Ferreira e Moreira (2002).
} 
Nesse primeiro momento, a presença do educador Anísio Teixeira à frente da Capes foi fundamental, não só como idealizador da agência, mas também como responsável por sua configuração institucional. No primeiro caso, entendia como necessária a formação de mão-de-obra de nível superior para enfrentar os desafios do desenvolvimento. No segundo, concebeu um órgão vinculado, ao mesmo tempo, simultaneamente ao Ministério da Educação e à Presidência da República. Esta estruturação dotou a Capes de prestígio e agilidade administrativa em seus primeiros anos de vida.

A direção executiva da instituição foi entregue, em 1954, a Almir de Castro. Em depoimento publicado Ferreira e Moreira (2002), este médico sanitarista, diretor do Serviço de Grandes Endemias do Instituto Oswaldo Cruz, afirmou que a Capes de Anísio Teixeira criou centros regionais de treinamento e preocupou-se com a qualidade do corpo docente. Além disso, foram feitos vários levantamentos descritivos das faculdades, universidades e instituições de pesquisa do Brasil. Anualmente, 120 pessoas eram contempladas com bolsas de estudo no exterior. Almir Castro revelou a inexistência de entrosamento e a duplicação de funções existentes entre a Capes e o CNPq e denunciou, ainda, o fato de o $\mathrm{CNPq}$ receber, na época, dez vezes mais recursos do que a Capes.

Os tempos de Anísio Teixeira como secretário-geral da Capes (1951-1964) foram de estruturação, organização e composição do corpo de funcionários da agência. Foram tempos de conceder bolsas de estudo, ainda que de modo restrito, e de estabelecer os primeiros convênios internacionais com instituições congêneres, como a Fundação Ford e a Rockfeller. Em abril de 1964, os militares assumiram o poder e deram fim ao primeiro momento da história da Capes, exonerando Anísio Teixeira e Almir de Castro de suas funções.

O segundo período (1964-1974) foi considerado por Ferreira e Moreira (2002) de "instabilidade e redefinição institucional". A turbulência administrativa foi de tal ordem que o fechamento da agência foi cogitado. A redefinição institucional começou a ser operada desde 1964. Durante aquele ano, a Capes passou a estar, cada vez mais, subordinada ao ministro da Educação, que tinha autoridade para regulamentar as atividades da agência e aprovar seu regimento interno. Aos poucos, a Capes passou a ser responsável pela execução dos planos do Ministério da Educação. A instabilidade pôde ser observada pelo fato de seis diretores executivos terem se sucedido no poder e de a agência ter tido muita dificuldade para implementar, efetivamente, uma política de apoio e aperfeiçoamento do 
pessoal do ensino superior. Para Ferreira e Moreira (2002), a posse e o mandato de Celso Barroso Leite (1969-1974) na direção da Capes interrompeu este 'ciclo'. A reforma universitária de 1968 e a ideologia do 'milagre econômico' dotaram a pós-graduação de enorme relevância.

Com Celso Barroso Leite, nos anos de 1970, a Capes passou a ter maior autonomia em relação ao Ministério da Educação e Cultura (MEC). Suas funções, entretanto, confundiam-se, cada vez mais, com as do $\mathrm{CNPq}$ e as do Departamento de Assuntos Universitários (DAU), do MEC. Em depoimento, recuperado por Ferreira e Moreira, Barroso Leite afirmou: "Sempre considerei que havia certa superposição de tarefas entre a Capes e o CNPq; então um cuidado que tive foi trazer a Capes mais para o aperfeiçoamento do corpo docente, que era sua função" (Barroso Leite apud Ferreira \& Moreira, 2002: 59).

Em junho de 1970, foi oficializada a presença da área acadêmica no Conselho Deliberativo da Capes. Durante sua gestão, Barroso Leite conseguiu retomar o processo de reestruturação da agência, reforçando a racionalização e padronização dos processos administrativos. Ele se considerava um executor, um administrador. "A política mais geral já chegava pronta para nós, formulada pela DAU. Eu procurava, então, adaptála às rotinas da casa, seguindo sempre as instruções - tinha que seguir", afirmou (Barroso Leite apud Ferreira \& Moreira, 2002: 63).

A periodização proposta pelas autoras integra a história da Capes à história política do país. Se o movimento militar de 1964 dificultou a sobrevivência da Capes segundo o modelo criado e dirigido por Anísio Teixeira, a distensão política 'lenta' e 'gradual', promovida pelo general Geisel a partir de 1974, mudou outra vez o curso dos acontecimentos da agência. Durante o seu governo, a lógica do planejamento e da racionalidade da coisa pública, que já dominava a agenda política da elite do poder pós1964, passou a receber apoio ainda mais explícito.

O terceiro período dessa história institucional circunscreve-se entre o início do governo Geisel (1974) e a posse de Collor na presidência da República (1990), quando foi imputado à Capes um papel estratégico na organização da pós-graduação no país. Para Ferreira e Moreira (2002), enquanto que o período anterior assistiu à criação de mecanismos de financiamento, neste momento houve o 'desabrochar' da pós-graduação no Brasil, conseqüência da implementação dos três Planos Nacionais de Desenvolvimento, do Plano Setorial de Educação e Cultura e do Plano Básico de Desenvolvimento da Ciência e Tecnologia. Diretamente vinculados aos objetivos estratégicos da Capes, foram elaborados o Plano 
Nacional de Pós-Graduação e o Conselho Nacional de Pós-Graduação. Esta instância deliberativa reunia representantes das principais instituições responsáveis pelo Sistema Nacional de Ciência e Tecnologia e pelo Sistema Universitário Brasileiro. Aos poucos, foram sendo ampliadas as responsabilidades da Capes na implementação, no acompanhamento e na avaliação dos programas de capacitação docente e de recursos humanos.

Segundo as autoras, a partir do governo Geisel,

se redefiniram e compatibilizaram as funções e responsabilidades de cada uma das instituições envolvidas com o sistema de pós-graduação, de modo a eliminar as indefinições, as sobreposições e os conflitos de interesse e, assim, não apenas garantir uma ação integrada e cooperativa, mas também evitar a repetição de um processo de crescimento espontâneo e desordenado, marcado pela duplicação de esforços. (Ferreira \& Moreira, 2002: 21)

Para atender à nova e grande responsabilidade, a Capes teve de se reformular internamente. Foram contratados e treinados novos funcionários para trabalhar na sede em Brasília, recém-inaugurada. Sob a direção de Darcy Closs (1974-1979), passou a ser dotada de autonomia administrativa e financeira. Suas diretrizes acompanhavam o Plano Nacional de Pós-Graduação. A participação de membros da comunidade acadêmica na análise de solicitações, na avaliação de cursos, na implementação de políticas definidas pela agência, assim como nas demais decisões a cargo da Capes, passou a ser cada vez mais freqüente.

A esse respeito, o professor Closs afirmou: "Progressivamente, os Comitês de Assessores por área de conhecimento foram sendo ampliados em número. Com a seleção de professores de acordo com as indicações da comunidade científica” (Darcy Closs apud Ferreira \& Moreira, 2002: 73).

Os dados disponíveis na Capes revelam um crescimento notável do número de cursos de pós-graduação no Brasil durante a gestão Closs. Aos 561 cursos de mestrado existentes em 1976 foram acrescidos outros 142 até 1979. Criaram-se, portanto, 35 cursos de mestrado, em média, por ano no Brasil, no período. Darcy Closs atribui à Financiadora de Estudos e Projetos (Finep), sob a direção de José Pelúcio, boa parte das responsabilidades desse crescimento. Naquele momento, a Capes ultrapassava o CNPq em número de bolsas, consolidando-se como agência de pósgraduação, ao passo que o $\mathrm{CNPq}$ concentrava suas atenções no fomento a grupos, núcleos e linhas de pesquisa. A rápida e expressiva expansão dos programas de pós-graduação trouxe consigo a preocupação com a preservação da qualidade e a avaliação das atividades por eles desenvolvidas. 
Darcy Closs foi sucedido por Cláudio Moura e Castro (1979-1982), que consolidou o processo iniciado por seu antecessor. A velocidade de crescimento dos cursos de mestrado foi ligeiramente limitada nesse período. Em quatro anos foram criados 57 novos cursos de mestrado: praticamente a metade do quadriênio anterior. ${ }^{3}$ A questão agora passava a ser descentralizar os procedimentos de modo a garantir a continuidade da atuação da agência. Segundo Ferreira \& Moreira (2002: 23), sob a gestão de Moura e Castro (1979/1982) "foi estabelecido todo um processo de transferência, para as universidades e programas, da responsabilidade de selecionar, acompanhar, pagar e avaliar o desempenho dos alunos bolsistas, cabendo à agência apenas a função de promover a mais ampla avaliação dos programas e dos alunos".

Os dois últimos momentos da história da Capes, sugeridos por Ferreira e Moreira (2002), foram denominados "ameaça" (1990-1992) e de "novos desafios" (1992 até hoje). No primeiro deles, a agência e o país viveram o interregno autoritário capitaneado pelo então presidente Fernando Collor. A reestruturação da administração pública por ele perpetrada promoveu a extinção da Capes. Um misto de perplexidade e revolta tomou conta da comunidade acadêmica. $\mathrm{O}$ fim da Capes não perdurou: em janeiro de 1992, sendo ministro da Educação e Cultura José Goldemberg, a agência foi transformada em uma fundação pública.

Conforme consta na lei:

A fundação Capes terá como finalidade subsidiar o Ministério da Educação na formulação de políticas para a área de pós-graduação, coordenar e avaliar os cursos desse nível no País e estimular, mediante bolsas de estudo, auxílios e outros mecanismos, a formação de recursos humanos altamente qualificados para a docência de grau superior, a pesquisa e o atendimento da demanda dos setores públicos e privado. (Brasil, 2002)

A partir de 1992, as sucessivas direções da Capes trataram de implementar, sobretudo, um novo sistema de avaliação que fosse capaz de dotar os programas de pós-graduação de algum estímulo para a elevação da qualidade, em níveis internacionais.

Essa breve retrospectiva nos permitiu perceber que a história da Capes desenvolveu-se à sombra das alterações políticas e institucionais dos diversos governos e modelos de desenvolvimento que dominaram a cena política brasileira dos últimos 50 anos. Apesar disso, a instituição seguiu

\footnotetext{
Ver a Tabela 6 - Evolução do número de alunos matriculados e titulados na pós-graduação (mestrado, doutorado e profissionalizante) 1987-2000, em Ferreira e Moreira (2002: 323).
} 
ampliando seu poder de credenciamento e avaliação dos programas de pós-graduação do país, sobretudo a partir de 1974. A iniciativa cerceadora perpetrada nos primeiros anos do governo Collor, por exemplo, não foi suficientemente efetiva para inibir essa trajetória. Como pode ser observado na evolução do número de cursos de pós-graduação no Brasil entre 1976 e 2000, apesar da extinção formal da agência, os cursos de pós-graduação continuaram a ser criados no início dos anos de 1990. Outro aspecto digno de nota foi a reiterada preocupação, evidente tanto na configuração legislativa de 1951 quanto na de 1992, de que a formação de pós-graduação atenda às necessidades dos empreendimentos públicos e privados.

A criação da primeira turma de mestrado (1977) e de doutorado (1980) da Ensp ocorreu em meio a todo este contexto político e institucional.

\section{A Pós-Graduação Stricto Sensu da Ensp: procedimentos METODOLÓGICOS DESTA PESQUISA}

Antes de apresentarmos alguns resultados do levantamento realizado e desenharmos o perfil do egresso dos cursos de pós-graduação stricto sensu da Ensp, faremos uma breve exposição dos métodos utilizados na coleta dos dados.

Trata-se de um levantamento quantitativo. Para que fosse realizado, elaborou-se uma ficha nominal para cada aluno(a), indexando-se as informações, por turma, em três grandes campos distintos. No primeiro deles, foram registrados os dados pessoais do estudante, tais como o nome completo, sexo, data e local de nascimento e endereço residencial. Estes dados foram discriminados para que se pudesse acompanhar a questão de gênero na formação do sanitarista, a faixa etária em que se realizou o ingresso no programa e o poder de atração que a Escola desempenhou sobre os profissionais oriundos de outras unidades da federação. Um desdobramento possível desta investigação seria verificar se o número de egressos de outros estados diminuiu com a criação de cursos de pósgraduação de saúde pública nesses locais.

No segundo campo constam informações relacionadas à formação universitária e à atuação profissional do egresso. Foram incluídas informações sobre o curso de graduação realizado pelo egresso: qual o título obtido; ano de conclusão; unidade da federação em que se localiza; nome da universidade e sua condição de instituição pública ou privada. Além disso, registra o local e o nome da instituição em que o ex-aluno trabalhava quando ingressou no mestrado e/ou doutorado e sua condição 
de organização pública ou privada. Nosso objetivo, ao criarmos tais índices, foi verificar como evoluiu a presença de indivíduos com diferentes formações universitárias e inserções profissionais nos cursos de pósgraduação stricto sensu da Ensp. No caso dos alunos que ingressaram no doutorado, constam ainda informações sobre o local, a instituição, o ano de conclusão e a especialidade do mestrado. Um desdobramento possível desta pesquisa seria verificar as relações entre o local de trabalho do egresso e a opção pelos cursos da Ensp.

No terceiro campo incluímos informações sobre o desempenho do egresso na Ensp: a área ou linha de pesquisa de sua dissertação/tese; data de defesa; grau obtido; nome do orientador e do coordenador da pósgraduação; e título do trabalho. Com isso, pretendíamos verificar o tempo que o aluno levou para concluir o curso, as relações que desenvolveu com orientadores e coordenadores e a avaliação que seu trabalho teve. Um desdobramento possível desta pesquisa seria verificar se a dissertação ou tese foi editada ou não sob a forma de artigo ou livro.

Os anos de recorte de nosso levantamento foram os seguintes: para o mestrado, 1977 e 2000; para o doutorado, 1980 e 1998. As datas do início do levantamento correspondem, respectivamente, ao início das primeiras turmas de mestrado e doutorado da Ensp. Os outros dois marcos indicam as duas turmas que deveriam ter defendido sua dissertação e tese, uma vez que o diploma de mestre é obtido com dois anos e o de doutor com quatro anos de estudo.

A maioria das informações que integram esse banco de dados foram coletadas nos arquivos da Secretaria Acadêmica da Ensp. Outras foram resgatadas no banco de currículos da Plataforma Lattes da Capes. As tabelas que integram este texto foram organizadas por nós com base nos dados obtidos nesse levantamento.

\section{O Ingresso e a Evasão do Aluno: HIPÓTESES E AGENDA DE PESQUISA}

Um primeiro dado que salta aos olhos de quem examina este acervo de informações relaciona-se com o volume de alunos que entraram nos dois programas de pós-graduação stricto sensu da Ensp nos últimos anos.

A Tabela 1 apresenta o movimento de ingresso nos programas da Ensp no mestrado e no doutorado e revela alguns dados dignos de nota. 
Tabela 1 - Movimento de ingresso no mestrado e doutorado da Ensp (1977-2000)

\begin{tabular}{|c|c|c|}
\hline Ano & Mestrado & Doutorado \\
\hline 1977 & 17 & \\
\hline 1978 & 7 & \\
\hline 1979 & 8 & \\
\hline 1980 & 10 & 5 \\
\hline 1981 & & 7 \\
\hline 1982 & 9 & \\
\hline 1983 & 5 & 1 \\
\hline 1984 & 12 & \\
\hline 1985 & 11 & 3 \\
\hline 1986 & 16 & 4 \\
\hline 1987 & 20 & 7 \\
\hline 1988 & 19 & \\
\hline 1989 & 20 & \\
\hline 1990 & 20 & \\
\hline 1991 & 24 & 24 \\
\hline 1992 & 39 & 31 \\
\hline 1993 & 31 & 15 \\
\hline 1994 & 49 & 14 \\
\hline 1995 & 55 & 23 \\
\hline 1996 & 47 & 18 \\
\hline 1997 & 50 & 26 \\
\hline 1998 & 56 & 23 \\
\hline 1999 & 73 & \\
\hline 2000 & 80 & \\
\hline Total & 678 & 201 \\
\hline
\end{tabular}

Em primeiro lugar, constatamos que, no caso do mestrado, o número de alunos foi igual ou inferior a 20 até a turma de 1990. A partir de então este número foi aumentando de maneira irregular, até atingir o patamar de 80 alunos na seleção de 2000. No doutorado, o movimento foi semelhante, em menores proporções. Até 1990 o número de alunos admitidos anualmente não chegava a dez. Depois deste ano, o número de estudantes de doutorado foi sempre superior a uma dezena, chegando a 
ultrapassar a barreira das duas dezenas diversas vezes e atingir a cifra de 31 alunos em 1992.

Uma das hipóteses que pode explicar esse crescimento diz respeito ao fato de o plano de carreira em ciência e tecnologia e no magistério de nível superior estar associado à titulação formal em mestrado e doutorado, o que resulta em ganhos reais na remuneração. Tal vinculação foi instituída pela Constituição de 1989; antes dela, a titulação não representava ganho real no salário do servidor público de formação acadêmica. Outro aspecto que não pode ser negligenciado é o fato de a Ensp ter crescido muito durante os anos 1980. Os departamentos e linhas de pesquisa já desenvolviam trabalhos de reconhecida consistência, e seus quadros eram integrados por professores com doutorado.

Tal crescimento, evidenciado na Tabela 1, pode ser, ainda, comparado às tendências nacionais. Segundo consta nos dados da Capes, havia, em 1987, cerca de 29 mil alunos de mestrado no Brasil. Em 2000, este número atingiu a casa dos 61 mil. Ou seja, em linhas gerais, este número duplicou. No caso do doutorado, em 1987, havia cerca de oito mil alunos inscritos no Brasil, contra 26 mil em 1998. Ou seja, um aumento de pouco mais de três vezes. ${ }^{4}$ Seguindo o mesmo parâmetro, podemos verificar que até 1987 a Ensp havia inscrito 115 alunos no mestrado e 27 no doutorado. O número de alunos aprovado na seleção da Ensp entre 1988 e 2000 foi cinco vezes maior do que os que estavam matriculados até 1987.

A Tabela 1 revela também que em alguns anos não houve seleção para os programas de pós-graduação da Ensp. Uma pesquisa, que contemplasse entrevistas com os coordenadores do programa seria uma alternativa para desvendar as razões que levaram à não-abertura dessas turmas.

De qualquer forma, entre 1977 e 2000, 678 alunos foram selecionados e se matricularam no mestrado da Ensp. Entre 1980 e 1998, 201 ingressaram no doutorado da instituição. Foram feitas, portanto, 879 matrículas. Os dados presentes na Secretaria Acadêmica da Ensp comprovam que nem todos esses 879 alunos matriculados concluíram o curso e obtiveram o título nesta instituição.

Na Tabela 2 constam os números de formandos e de evasão do mestrado da Ensp, em valores absolutos e percentuais.

\footnotetext{
4 Ver a Tabela 6 - Evolução do número de alunos matriculados e titulados na pós-graduação (mestrado, doutorado e profissionalizante) 1987-2000, em Ferreira e Moreira (2002: 323).
} 
Tabela 2 - Formados e evasão do mestrado da Ensp (1977-2000): valores absolutos e percentuais

\begin{tabular}{|c|c|c|c|c|c|}
\hline Ano & Matriculados & Formados & $\%$ & Evasão & $\%$ \\
\hline 1977 & 17 & 10 & $59 \%$ & 7 & $41 \%$ \\
\hline 1978 & 7 & 4 & $57 \%$ & 3 & $43 \%$ \\
\hline 1979 & 8 & 5 & $63 \%$ & 3 & $38 \%$ \\
\hline 1980 & 10 & 5 & $50 \%$ & 5 & $50 \%$ \\
\hline 1982 & 9 & 7 & $78 \%$ & 2 & $22 \%$ \\
\hline 1983 & 5 & 5 & $100 \%$ & 0 & $0 \%$ \\
\hline 1984 & 12 & 10 & $83 \%$ & 2 & $17 \%$ \\
\hline 1985 & 11 & 9 & $82 \%$ & 2 & $18 \%$ \\
\hline 1986 & 16 & 10 & $63 \%$ & 6 & $38 \%$ \\
\hline 1987 & 20 & 16 & $80 \%$ & 4 & $20 \%$ \\
\hline 1988 & 19 & 16 & $84 \%$ & 3 & $16 \%$ \\
\hline 1989 & 20 & 17 & $85 \%$ & 3 & $15 \%$ \\
\hline 1990 & 20 & 18 & $90 \%$ & 2 & $10 \%$ \\
\hline 1991 & 24 & 20 & $83 \%$ & 4 & $17 \%$ \\
\hline 1992 & 39 & 31 & $79 \%$ & 8 & $21 \%$ \\
\hline 1993 & 31 & 26 & $84 \%$ & 5 & $16 \%$ \\
\hline 1994 & 49 & 41 & $84 \%$ & 8 & $16 \%$ \\
\hline 1995 & 55 & 51 & $93 \%$ & 4 & $7 \%$ \\
\hline 1996 & 47 & 40 & $85 \%$ & 7 & $15 \%$ \\
\hline 1997 & 50 & 46 & $92 \%$ & 4 & $8 \%$ \\
\hline 1998 & 56 & 42 & $75 \%$ & 14 & $25 \%$ \\
\hline 1999 & 73 & 59 & $81 \%$ & 14 & $19 \%$ \\
\hline 2000 & 80 & 49 & $61 \%$ & 31 & $39 \%$ \\
\hline Total & 678 & 537 & $79 \%$ & 141 & $21 \%$ \\
\hline
\end{tabular}

Podem ser identificados quatro momentos na história desse mestrado. No primeiro, compreendido entre 1977 e 1982, os índices de conclusão e evasão aproximam-se bastante, até igualarem-se em 1982. Esta situação talvez possa ser explicada pelo fato de a pós-graduação, então em seus primórdios, estar em fase de organização e não dispor ainda de um programa consolidado de bolsas de estudo, o que favoreceria a evasão de muitos profissionais que não eram liberados de seus serviços 
para fazer o curso, realizado em tempo integral. De qualquer forma, estas são hipóteses que uma pesquisa com os alunos que evadiram e os formados poderá ou não confirmar.

A partir de 1982 houve um sensível incremento dos índices de conclusão, chegando estes à casa dos $80 \%$. O processo de seleção mais rígido e o acompanhamento mais detido do aluno são elementos que podem explicar esta tendência de queda nos índices de evasão.

Em 1986, observa-se uma queda percentual. Um hiato. Os que concluíram chegam a $63 \%$ e os que evadiram atingem a marca de $38 \%$. Esta aproximação, verificada em uma turma específica, pode ser melhor compreendida se forem entrevistados todos os alunos que a integraram. Quem dá aulas sabe que existem diferenças sensíveis entre as turmas dentro de um mesmo estabelecimento de ensino.

O terceiro momento, situado entre 1987 e 1997, caracteriza-se por uma relativa estabilidade. Os índices de conclusão giram em torno de $80 \%$ e os de evasão aproximam-se da casa dos $20 \%$.

Em 1988 os níveis de evasão do mestrado voltam a subir, chegando atingir a 39\% em 2000. Se levarmos em consideração os números absolutos apresentados na Tabela 2, verificamos que, na última turma investigada, 31 alunos, abandonaram o curso de mestrado da Ensp antes de defender a dissertação. Outros 49 conseguiram concluir e obter seu diploma. Os números são grandes e despertam a atenção, se comparados aos primeiros anos do programa. Naquele tempo, os índices de evasão giravam também em torno de $40 \%$. Entretanto, em termos absolutos, em 1980, por exemplo, cinco alunos concluíram mestrado e cinco não o conseguiram. Naquela época, uma dissertação de mestrado podia ser equiparada, em abrangência e profundidade, a uma atual tese de doutorado, o que talvez explique os elevados índices de evasão dos primeiros anos. Mas como justificar a reemergência desta tendência a partir de 1988? O rigor no cumprimento do prazo de dois anos para a conclusão do curso, determinado pela Capes, talvez responda a esta questão.

Observemos agora como a relação entre formados e evasão evoluiu entre os alunos de doutorado. A Tabela 3 apresenta uma configuração diferente da anterior. 
Tabela 3 - Formados e evasão do doutorado da Ensp (1980-1998): valores absolutos e percentuais

\begin{tabular}{c|c|c|c|c|c}
\hline Ano & Matriculados & Formados & $\%$ & Evasão & $\%$ \\
\hline 1980 & 5 & 2 & $40 \%$ & 3 & $60 \%$ \\
\hline 1981 & 7 & 4 & $57 \%$ & 3 & $43 \%$ \\
\hline 1983 & 1 & 1 & $100 \%$ & 0 & $0 \%$ \\
\hline 1985 & 3 & 2 & $67 \%$ & 1 & $33 \%$ \\
\hline 1986 & 4 & 2 & $50 \%$ & 2 & $50 \%$ \\
\hline 1987 & 7 & 2 & $29 \%$ & 5 & $71 \%$ \\
\hline 1991 & 24 & 20 & $83 \%$ & 4 & $17 \%$ \\
\hline 1992 & 31 & 22 & $71 \%$ & 9 & $29 \%$ \\
\hline 1993 & 15 & 12 & $80 \%$ & 3 & $20 \%$ \\
\hline 1994 & 14 & 12 & $86 \%$ & 2 & $14 \%$ \\
\hline 1995 & 23 & 20 & $87 \%$ & 3 & $13 \%$ \\
\hline 1996 & 18 & 14 & $78 \%$ & 4 & $22 \%$ \\
\hline 1997 & 26 & 18 & $69 \%$ & 8 & $31 \%$ \\
\hline 1998 & 23 & 17 & $74 \%$ & 6 & $26 \%$ \\
\hline TOTAL & 201 & 148 & $74 \%$ & 53 & $26 \%$ \\
\hline
\end{tabular}

A Tabela 3 apresenta em números absolutos e percentuais a evasão no curso de doutorado da Ensp, de 1980 a 1998. Neste caso, os índices de evasão chegaram a superar, por duas vezes, os de conclusão do curso. Tal tendência, indesejada, talvez explique as razões que levaram à suspensão temporária da seleção para o doutorado em 1987, só retomada quatro anos depois. A partir de 1992, os índices de conclusão mantiveram-se em torno de $80 \%$ e os de evasão não chegaram à casa dos $20 \%$, excetuando-se o ano de 1997, quando este índice atingiu a marca de $31 \%$.

A tabela relativa aos doutorandos revela uma tendência diferente daquela observada entre os mestrandos. No primeiro caso, o percentual de alunos que abandonam o curso apresenta um movimento descendente, enquanto que no segundo o movimento é ascendente. O aluno de doutorado, em geral, já tem sua inserção acadêmica definida e uma significativa maturidade intelectual, obtida inclusive durante o mestrado. Estas características poderiam explicar os baixos índices de evasão do doutorado, quando comparados aos observados do mestrado. 
Uma hipótese, muitas vezes aventada, é a de que o aluno que sai do curso de mestrado ou de doutorado da Ensp torna a se inscrever nele anos depois. A partir dos dados fornecidos pela Plataforma Lattes do CNPq, chegamos à conclusão de que poucos alunos reingressaram no programa de pós-graduação da Ensp. Este foi o caso de apenas duas das 53 pessoas que não concluíram doutorado e cinco dos 141 alunos que abandonaram o curso sem ter obtido o diploma de mestrado. Cabe ressaltar que oito alunos que haviam evadido se inscreveram e concluíram doutorado em outra instituição.

No caso do mestrado, apenas um aluno concluiu o curso em outra instituição. A maioria dos ex-alunos de mestrado e doutorado que evadiram não tem currículo na Plataforma Lattes ou, se o tem, não consta que tenham concluído a pós-graduação em outra instituição. $O$ trauma que a nãoconclusão de um curso de pós-graduação causa em um ex-aluno talvez explique este quadro.

Um item que poderia compor a agenda de pesquisa sobre a qualidade dos cursos oferecidos nos programas de pós-graduação da Ensp seria a análise das razões que levaram esses alunos a abandonar o curso, sem ter obtido o almejado diploma. Questionários com perguntas abertas e fechadas e entrevistas poderiam ser feitos para tentar identificar as razões que levaram à evasão.

Sobre o tema, algumas questões podem ser desde já formuladas. $\mathrm{O}$ que fez esses alunos abandonarem o curso antes de concluí-lo? A falta de estímulo e/ou contrapartida institucional de onde trabalhavam podem justificar os altos índices de evasão? Além disso, não se deve esquecer que muitos alunos são requisitados pelo mercado de trabalho vendo-se forçados a abandonar o curso para atender a essas demandas. De qualquer forma, não pode ser descartada a possibilidade de alguns alunos terem desistido do curso por não poderem se dedicar a ele em tempo integral bem como por insatisfação com o programa ou desentendimento com o orientador e/ou algum professor. Óbito, gravidez, problemas de saúde, nascimento de filho(s) e complicações familiares como separação ou falecimento de parentes são razões de cunho privado que igualmente não podem ser esquecidas.

Uma pesquisa com os alunos que evadiram mereceria ser feita, para que o programa de pós-graduação conseguisse avaliar as razões de seu insucesso parcial. Afinal, foi feito um investimento grande em cada um desses alunos. O que chama a atenção nos alunos que evadiram é que todos se submeteram a uma rigorosa seleção para ingressar nos programas de pós-graduação da Ensp. Considerando-se os critérios classificatórios de seleção, ao serem aprovados esses candidatos ocuparam a vaga de outros 
que, uma vez admitidos, poderiam ter concluído o curso, defendendo sua dissertação ou tese no prazo previsto. Verificar as razões que levaram um aluno a não concluir seu curso de pós-graduação pode oferecer elementos para que a coordenação do programa de pós-graduação tome atitudes preventivas que inibam esta tendência e potencializem o investimento público nesse tipo de formação profissional.

Passaremos a analisar, a seguir, os 537 alunos que concluíram mestrado e os 148 que defenderam tese de doutorado na Ensp, definindo seu perfil.

\section{O Perfil dos Egressos na Ensp: MULHER, NÃO-MÉDICA E FLUMINENSE}

Três dimensões compõem o perfil do egresso da Ensp que organizamos: gênero, profissão e origem geográfica. A primeira teve a intenção de identificar se houve ou não um crescimento da presença feminina entre os sanitaristas. Na segunda, os dados foram organizados de modo a podermos verificar como evoluiu a participação dos graduados em medicina nos cursos de pós-graduação da Ensp ao longo do tempo. Finalmente, com a terceira, pretendemos analisar até que ponto a Escola de Saúde Pública da Fundação Oswaldo Cruz foi 'nacional', ou seja, até que ponto ela atraiu alunos oriundos de outras unidades da federação, além daqueles nascidos no estado do Rio de Janeiro.

A Tabela 4 refere-se à evolução da presença feminina entre os egressos da Ensp.

Em relação aos egressos do mestrado da Ensp, pelo menos duas explicações, combinadas, justificam uma tendência favorável à hegemonia feminina. Por um lado, não deve ser negligenciado o aumento da presença feminina no meio universitário, sobretudo na área da saúde. Por outro, algumas carreiras, como a enfermagem, a psicologia, o serviço social e a nutrição - dominadas pelo gênero feminino -, passaram a ocupar um lugar de destaque, cada vez maior, nos cursos de pós-graduação de saúde pública no Brasil.

Em relação aos egressos do doutorado o quadro é semelhante, com algumas diferenças que merecem destaque. No doutorado houve, até o início dos anos de 1990, uma sensível oscilação entre as maiorias feminina e masculina. Depois de 1993, evidenciou-se um crescimento progressivo da hegemonia feminina, que chegou a atingir os 82\% em 1998 - último ano inventariado nesta investigação. 
Tabela 4 - Distribuição dos alunos da Ensp quanto aos gêneros masculino e feminino: valores absolutos e percentuais

\begin{tabular}{|c|c|c|c|c|c|}
\hline \multicolumn{6}{|c|}{ Mestres } \\
\hline Ano & Homem & $\%$ & Mulher & $\%$ & Total \\
\hline 1977 & 4 & $40 \%$ & 6 & $60 \%$ & 10 \\
\hline 1978 & 0 & $0 \%$ & 4 & $100 \%$ & 4 \\
\hline 1979 & 2 & $40 \%$ & 3 & $60 \%$ & 5 \\
\hline 1980 & 1 & $20 \%$ & 4 & $80 \%$ & 5 \\
\hline 1982 & 3 & $43 \%$ & 4 & $57 \%$ & 7 \\
\hline 1983 & 4 & $80 \%$ & 1 & $20 \%$ & 5 \\
\hline 1984 & 5 & $50 \%$ & 5 & $50 \%$ & 10 \\
\hline 1985 & 5 & $56 \%$ & 4 & $44 \%$ & 9 \\
\hline 1986 & 1 & $10 \%$ & 9 & $90 \%$ & 10 \\
\hline 1987 & 7 & $44 \%$ & 9 & $56 \%$ & 16 \\
\hline 1988 & 7 & $44 \%$ & 9 & $56 \%$ & 16 \\
\hline 1989 & 6 & $35 \%$ & 11 & $65 \%$ & 17 \\
\hline 1990 & 4 & $22 \%$ & 14 & $78 \%$ & 18 \\
\hline 1991 & 6 & $30 \%$ & 14 & $70 \%$ & 20 \\
\hline 1992 & 11 & $35 \%$ & 20 & $65 \%$ & 31 \\
\hline 1993 & 7 & $27 \%$ & 19 & $73 \%$ & 26 \\
\hline 1994 & 10 & $24 \%$ & 31 & $76 \%$ & 41 \\
\hline 1995 & 17 & $33 \%$ & 34 & $67 \%$ & 51 \\
\hline 1996 & 14 & $35 \%$ & 26 & $65 \%$ & 40 \\
\hline 1997 & 11 & $24 \%$ & 35 & $76 \%$ & 46 \\
\hline 1998 & 16 & $38 \%$ & 26 & $62 \%$ & 42 \\
\hline 1999 & 18 & $31 \%$ & 41 & $69 \%$ & 59 \\
\hline 2000 & 14 & $29 \%$ & 35 & $71 \%$ & 49 \\
\hline
\end{tabular}

Doutores

\begin{tabular}{l|c|c|c|c|c}
\hline Ano & Homem & $\%$ & Mulher & $\%$ & Total \\
\hline 1980 & 0 & $0 \%$ & 2 & $100 \%$ & 2 \\
\hline 1981 & 2 & $50 \%$ & 2 & $50 \%$ & 4 \\
\hline 1983 & 1 & $100 \%$ & 0 & $0 \%$ & 1 \\
\hline 1985 & 1 & $50 \%$ & 1 & $50 \%$ & 2 \\
\hline 1986 & 0 & $0 \%$ & 2 & $100 \%$ & 2 \\
\hline 1987 & 2 & $100 \%$ & 0 & $0 \%$ & 2 \\
\hline 1991 & 11 & $55 \%$ & 9 & $45 \%$ & 20 \\
\hline 1992 & 7 & $32 \%$ & 15 & $68 \%$ & 22 \\
\hline 1993 & 6 & $50 \%$ & 6 & $50 \%$ & 12 \\
\hline 1994 & 5 & $42 \%$ & 7 & $58 \%$ & 12 \\
\hline 1995 & 8 & $40 \%$ & 12 & $60 \%$ & 20 \\
\hline 1996 & 6 & $43 \%$ & 8 & $57 \%$ & 14 \\
\hline 1997 & 6 & $33 \%$ & 12 & $67 \%$ & 18 \\
\hline 1998 & 3 & $18 \%$ & 14 & $82 \%$ & 17 \\
\hline
\end{tabular}


O aumento do contingente feminino na pós-graduação da Ensp traduz, em parte, o progressivo processo de inclusão da mulher no sistema produtivo e nas esferas decisórias em nosso país. Para os objetivos que orientam este trabalho, cabe destacar que a Ensp está formando cada vez mais mulheres sanitaristas e que esta tendência é ainda mais evidente entre os doutorandos.

Outra perspectiva que compõe o perfil dos egressos é a origem profissional dos estudantes. Afinal, que profissional procura a Ensp para se tornar um sanitarista pós-graduado?

As diferentes formações profissionais, presentes nas fichas de matrícula dos alunos, foram agrupadas em quatro categorias diferentes. Em 'medicina' colocamos exclusivamente os médicos graduados. Em 'saúde', reunimos todos os profissionais que fizeram graduação na área, como os enfermeiros, dentistas, fisioterapeutas, terapeutas ocupacionais, fonoaudiólogos, nutricionistas, farmacêuticos e biólogos. Em 'ciências humanas e sociais', reunimos os filósofos, jornalistas, sociólogos, historiadores, arqueólogos, biblioteconomistas, economistas, pedagogos, psicólogos e assistentes sociais. Em 'outras', agrupamos os engenheiros, zootecnistas, veterinários, químicos, agrônomos, geólogos, programadores de computação, arquitetos e estatísticos, dentre outros.

As Tabelas 5 e 6 apresentam o quadro de egressos da Ensp segundo a formação na graduação. Para melhor visualizar a evolução da presença de médicos entre os egressos da Ensp, agrupamos todas as demais profissões na categoria 'não' e contrastamos este conjunto com a profissão médica.

Os dados nos mostram que, exceto 1979, até 1991 o número de alunos médicos no mestrado era igual ou superior à soma de todos os demais alunos que haviam se graduado em outras áreas do conhecimento. Depois desse período, o quadro mudou. A tendência que passou a se evidenciar foi de predomínio das carreiras não-médicas com formação de sanitarista na Ensp. A partir de 1966 cerca de 80\% dos alunos de mestrado da Ensp não eram médicos. 
Tabela 5 - Origem profissional dos mestrandos da Ensp (1977-2000): valores absolutos e percentuais

\begin{tabular}{|c|c|c|c|c|c|c|c|c|c|c|c|}
\hline Ano & Medicina & $\%$ Medicina & Saúde & & C H.S & & Outras & & Não & & TOTAL \\
\hline 1977 & 8 & $80 \%$ & 1 & $10 \%$ & & $0 \%$ & 1 & $10 \%$ & 2 & $20 \%$ & 10 \\
\hline 1978 & 1 & $25 \%$ & 3 & $75 \%$ & & $0 \%$ & & $0 \%$ & 3 & $75 \%$ & 4 \\
\hline 1979 & 2 & $40 \%$ & & $0 \%$ & 3 & $60 \%$ & & $0 \%$ & 3 & $60 \%$ & 5 \\
\hline 1980 & 3 & $60 \%$ & 1 & $20 \%$ & 1 & $20 \%$ & & $0 \%$ & 2 & $40 \%$ & 5 \\
\hline 1982 & 5 & $71 \%$ & 2 & $29 \%$ & & $0 \%$ & & $0 \%$ & 2 & $29 \%$ & 7 \\
\hline 1983 & 5 & $100 \%$ & & $0 \%$ & & $0 \%$ & & $0 \%$ & 0 & $0 \%$ & 5 \\
\hline 1984 & 8 & $80 \%$ & 1 & $10 \%$ & 1 & $10 \%$ & & $0 \%$ & 2 & $20 \%$ & 10 \\
\hline 1985 & 5 & $56 \%$ & 1 & $11 \%$ & 1 & $11 \%$ & 2 & $22 \%$ & 4 & $44 \%$ & 9 \\
\hline 1986 & 5 & $50 \%$ & 4 & $40 \%$ & 1 & $10 \%$ & & $0 \%$ & 5 & $50 \%$ & 10 \\
\hline 1987 & 12 & $75 \%$ & 2 & $13 \%$ & 2 & $13 \%$ & & $0 \%$ & 4 & $25 \%$ & 16 \\
\hline 1988 & 10 & $63 \%$ & 3 & $19 \%$ & 3 & $19 \%$ & & $0 \%$ & 6 & $38 \%$ & 16 \\
\hline 1989 & 11 & $65 \%$ & 4 & $24 \%$ & 2 & $12 \%$ & & $0 \%$ & 6 & $35 \%$ & 17 \\
\hline 1990 & 12 & $67 \%$ & 5 & $28 \%$ & 1 & $6 \%$ & & $0 \%$ & 6 & $33 \%$ & 18 \\
\hline 1991 & 10 & $50 \%$ & 3 & $15 \%$ & 4 & $20 \%$ & 3 & $15 \%$ & 10 & $50 \%$ & 20 \\
\hline 1992 & 13 & $42 \%$ & 8 & $26 \%$ & 7 & $23 \%$ & 3 & $10 \%$ & 18 & $58 \%$ & 31 \\
\hline 1993 & 9 & $35 \%$ & 9 & $35 \%$ & 5 & $19 \%$ & 3 & $12 \%$ & 17 & $65 \%$ & 26 \\
\hline 1994 & 10 & $24 \%$ & 11 & $27 \%$ & 14 & $34 \%$ & 6 & $15 \%$ & 31 & $76 \%$ & 41 \\
\hline 1995 & 21 & $41 \%$ & 12 & $24 \%$ & 12 & $24 \%$ & 6 & $12 \%$ & 30 & $59 \%$ & 51 \\
\hline 1996 & 8 & $20 \%$ & 13 & $33 \%$ & 12 & $30 \%$ & 7 & $18 \%$ & 32 & $80 \%$ & 40 \\
\hline 1997 & 7 & $15 \%$ & 6 & $13 \%$ & 21 & $46 \%$ & 12 & $26 \%$ & 39 & $85 \%$ & 46 \\
\hline 1998 & 7 & $17 \%$ & 12 & $29 \%$ & 19 & $45 \%$ & 4 & $10 \%$ & 35 & $83 \%$ & 42 \\
\hline 1999 & 10 & $17 \%$ & 18 & $31 \%$ & 22 & $37 \%$ & 9 & $15 \%$ & 49 & $83 \%$ & 59 \\
\hline 2000 & 12 & $24 \%$ & 13 & $27 \%$ & 18 & $37 \%$ & 6 & $12 \%$ & 37 & $76 \%$ & 49 \\
\hline TOTAL & 194 & $36 \%$ & 132 & $25 \%$ & 149 & $28 \%$ & 62 & $12 \%$ & 343 & $64 \%$ & 537 \\
\hline
\end{tabular}

No caso do doutorado o quadro é bem distinto. A Tabela 6 sintetiza as informações obtidas a este respeito, entre os egressos do doutorado. Depois dos primeiros anos de soberania oscilante entre as duas categorias, passou-se algum tempo de equilíbrio, seguido de hegemonia não-médica. Os dados de 1988 revelam uma tendência ao equilíbrio, como demonstrado na mesma tabela. 
Tabela 6 - Origem profissional dos doutorandos da Ensp (1980-1998): valores absolutos e percentuais

\begin{tabular}{c|c|c|c|c|c|c|c|c|c|cc}
\hline Ano & Med & & Saúde & & C H.S & & Outras & & Não Med & \multicolumn{2}{|c}{ TOTAL } \\
\hline 1980 & & $0 \%$ & 2 & $100 \%$ & & $0 \%$ & & $0 \%$ & 2 & $100 \%$ & 2 \\
\hline 1981 & 2 & $50 \%$ & & $0 \%$ & 2 & $50 \%$ & & $0 \%$ & 2 & $50 \%$ & 4 \\
\hline 1983 & 1 & $100 \%$ & & $0 \%$ & & $0 \%$ & & $0 \%$ & 0 & $0 \%$ & 1 \\
\hline 1985 & 1 & $50 \%$ & 1 & $50 \%$ & & $0 \%$ & & $0 \%$ & 1 & $50 \%$ & 2 \\
\hline 1986 & & $0 \%$ & 1 & $50 \%$ & 1 & $50 \%$ & & $0 \%$ & 2 & $100 \%$ & 2 \\
\hline 1987 & 1 & $50 \%$ & & $0 \%$ & 1 & $50 \%$ & & $0 \%$ & 1 & $50 \%$ & 2 \\
\hline 1991 & 11 & $55 \%$ & 2 & $10 \%$ & 4 & $20 \%$ & 3 & $15 \%$ & 9 & $45 \%$ & 20 \\
\hline 1992 & 13 & $59 \%$ & 3 & $14 \%$ & 3 & $14 \%$ & 3 & $14 \%$ & 9 & $41 \%$ & 22 \\
\hline 1993 & 2 & $17 \%$ & 3 & $25 \%$ & 6 & $50 \%$ & 1 & $8 \%$ & 10 & $83 \%$ & 12 \\
\hline 1994 & 3 & $25 \%$ & 3 & $25 \%$ & 2 & $17 \%$ & 4 & $33 \%$ & 9 & $75 \%$ & 12 \\
\hline 1995 & 10 & $50 \%$ & 5 & $25 \%$ & 4 & $20 \%$ & 1 & $5 \%$ & 10 & $50 \%$ & 20 \\
\hline 1996 & 5 & $36 \%$ & 5 & $36 \%$ & 3 & $21 \%$ & 1 & $7 \%$ & 9 & $64 \%$ & 14 \\
\hline 1997 & 5 & $28 \%$ & 7 & $39 \%$ & 4 & $22 \%$ & 2 & $11 \%$ & 13 & $72 \%$ & 18 \\
\hline 1998 & 7 & $41 \%$ & 3 & $18 \%$ & 6 & $35 \%$ & 1 & $6 \%$ & 10 & $59 \%$ & 17 \\
\hline TOTAL & 61 & $41 \%$ & 35 & $24 \%$ & 36 & $24 \%$ & 16 & $11 \%$ & 87 & $59 \%$ & 148 \\
\hline
\end{tabular}

A ampliação da presença de outros profissionais que não o médico, na formação de sanitarista, parece traduzir uma tendência favorável à ampliação da base cognitiva da profissão. Importa assinalar que, entre os mestres, depois de 1997, houve uma dominação de profissionais oriundos das áreas humanas e sociais. Somados aos profissionais graduados em outras áreas, o quantitativo atinge a metade do número de egressos. Entre os doutores o quadro é semelhante, com uma diferença significativa. O percentual de médicos doutores foi inferior a 30\% apenas em 1993 e 1997. Nas demais turmas, o número foi sempre superior ao verificado entre os mestrandos.

Uma análise detida poderia relacionar a questão de gênero e de origem profissional às áreas e linhas de pesquisa que compõem o programa de pós-graduação da Ensp. Esta é uma possibilidade interessante, que pode desvendar novas questões e hipóteses. Para os objetivos que regem este artigo, convém ressaltar que a Ensp está formando cada vez menos médicos como sanitaristas e que o número de sociólogos, psicólogos e assistentes sociais tem crescido de maneira inédita, sobretudo entre os mestres.

E de onde vieram os alunos da Ensp? Neste caso, nos interessa perceber se a Escola foi ou não 'nacional'. Para identificar a origem geográfica do mestrando e doutorando, nos baseamos nos registros sobre 
a naturalidade do aluno, imaginando que ele tenha se transferido para o Rio de Janeiro para fazer sua pós-graduação.

Nas Tabelas 7 e 8 agrupamos os egressos em quatro categorias distintas. Na primeira, denominada 'Rio', reunimos os alunos naturais de diferentes municípios do estado do Rio de Janeiro. Na segunda, Sudeste, agrupamos os naturais dos estados de São Paulo, Minas Gerais e Espírito Santo. Em 'Brasil', os estudantes nascidos nas demais regiões do país. Em 'estrangeiro', incorporamos aqueles nascidos em outros países, entre os quais se destacam os latino-americanos e africanos. Na categoria não-Rio reunimos todos os egressos naturais de outras regiões do país e os estrangeiros. Como no caso da origem profissional, reunimos diferentes registros de origens regionais sob o mesmo rótulo. Nosso objetivo foi o de facilitar a visualização e identificar tendências. A Ensp seria 'nacional' se a soma das diferentes origens geográficas fosse superior ao número de estudantes naturais do estado do Rio de Janeiro.

Analisando a Tabela 7, podemos constatar que o curso de mestrado da Ensp chegou a ser uma referência nacional até 1991, quando o índice de não-fluminenses atingiu o patamar de 55\%. Depois, este percentual oscilou em torno de $30 \%$, excetuando-se 1996, quando atingiu $48 \%$. Uma análise detida dos integrantes dessa turma, sob o ponto e vista de origem regional também poderia ser interessante. A queda verificada depois de 1991 pode ser explicada pela criação de novos cursos de mestrado em outras unidades da federação, muitos deles estimulados pela Ensp ou por muitos de seus professores.

No caso dos egressos do doutorado, a Tabela 8 guarda algumas diferenças com o observado anteriormente.

Como foi observado entre os mestres, no doutorado houve uma oscilação de hegemonia entre fluminenses e não-fluminenses até 1991. Depois, a tendência da presença de alunos de doutorado de fora do Rio de Janeiro atingiu a faixa dos 45 ou $50 \%$. Com isso podemos constatar que o curso de doutorado é bem mais 'nacional' que o de mestrado. Tal fato pode ser explicado pela criação de bolsas de estudo para doutorado específicas para docentes que estimulam esta formação em uma unidade da federação diferente daquela em que atuam profissionalmente. Além disso, o número de cursos de mestrado em saúde coletiva cresceu mais que o de doutorados na mesma área. Hoje, no Brasil, existem 17 cursos de mestrado e 11 de doutorado reconhecidos pela Capes. Destes últimos, apenas cinco tem a nota 5, entre os quais o da Ensp. A qualidade e a notoriedade que o curso detém no Brasil exercem, sem dúvida, um papel de atração 
sobre os pesquisadores de todo o país, fazendo com que o curso de doutorado seja ainda uma referência nacional na área.

Se existem os alunos que abandonaram e não concluíram o curso, há aqueles que fizeram o mestrado e o doutorado na Ensp. Estes serão denominados por nós 'filhos' da Ensp. A análise dos 42 'filhos' da Ensp auxiliará na compreensão das tendências verificadas até aqui.

Tabela 7 - Origem geográfica dos mestrandos da Ensp (1977-2000): valores absolutos e percentuais ${ }^{5}$

\begin{tabular}{|c|c|c|c|c|c|c|c|c|c|c|c|}
\hline Ano & Rio & $\%$ & Sudeste & $\%$ & Brasil & $\%$ & Estrang. & $\%$ & Não-Rio & & TOTAL \\
\hline 1977 & 2 & $22 \%$ & & $0 \%$ & 6 & $67 \%$ & 1 & $11 \%$ & 7 & $78 \%$ & 9 \\
\hline 1978 & & $0 \%$ & 2 & $50 \%$ & 2 & $50 \%$ & 0 & $0 \%$ & 4 & $100 \%$ & 4 \\
\hline 1979 & 1 & $25 \%$ & 1 & $25 \%$ & 2 & $50 \%$ & 0 & $0 \%$ & 3 & $75 \%$ & 4 \\
\hline 1980 & 4 & $80 \%$ & 1 & $20 \%$ & 0 & $0 \%$ & 0 & $0 \%$ & 1 & $20 \%$ & 5 \\
\hline 1982 & 3 & $43 \%$ & 2 & $29 \%$ & 2 & $29 \%$ & 0 & $0 \%$ & 4 & $57 \%$ & 7 \\
\hline 1983 & 2 & $50 \%$ & 1 & $25 \%$ & 0 & $0 \%$ & 1 & $25 \%$ & 2 & $50 \%$ & 4 \\
\hline 1984 & 5 & $50 \%$ & 2 & $20 \%$ & 1 & $10 \%$ & 2 & $20 \%$ & 5 & $50 \%$ & 10 \\
\hline 1985 & 4 & $44 \%$ & 1 & $11 \%$ & 2 & $22 \%$ & 2 & $22 \%$ & 5 & $56 \%$ & 9 \\
\hline 1986 & 4 & $40 \%$ & 4 & $40 \%$ & 2 & $20 \%$ & 0 & $0 \%$ & 6 & $60 \%$ & 10 \\
\hline 1987 & 8 & $50 \%$ & 1 & $6 \%$ & 4 & $25 \%$ & 3 & $19 \%$ & 8 & $50 \%$ & 16 \\
\hline 1988 & 8 & $50 \%$ & 1 & $6 \%$ & 6 & $38 \%$ & 1 & $6 \%$ & 8 & $50 \%$ & 16 \\
\hline 1989 & 7 & $41 \%$ & 5 & $29 \%$ & 3 & $18 \%$ & 2 & $12 \%$ & 10 & $59 \%$ & 17 \\
\hline 1990 & 10 & $56 \%$ & & $0 \%$ & 4 & $22 \%$ & 4 & $22 \%$ & 8 & $44 \%$ & 18 \\
\hline 1991 & 9 & $45 \%$ & 6 & $30 \%$ & 4 & $20 \%$ & 1 & $5 \%$ & 11 & $55 \%$ & 20 \\
\hline 1992 & 17 & $55 \%$ & 4 & $13 \%$ & 5 & $16 \%$ & 5 & $16 \%$ & 14 & $45 \%$ & 31 \\
\hline 1993 & 16 & $62 \%$ & 2 & $8 \%$ & 7 & $27 \%$ & 1 & $4 \%$ & 10 & $38 \%$ & 26 \\
\hline 1994 & 28 & $68 \%$ & 4 & $10 \%$ & 6 & $15 \%$ & 3 & $7 \%$ & 13 & $32 \%$ & 41 \\
\hline 1995 & 31 & $63 \%$ & 4 & $8 \%$ & 9 & $18 \%$ & 5 & $10 \%$ & 18 & $37 \%$ & 49 \\
\hline 1996 & 21 & $53 \%$ & 10 & $25 \%$ & 8 & $20 \%$ & 1 & $3 \%$ & 19 & $48 \%$ & 40 \\
\hline 1997 & 31 & $69 \%$ & 5 & $11 \%$ & 7 & $16 \%$ & 2 & $4 \%$ & 14 & $31 \%$ & 45 \\
\hline 1998 & 29 & $69 \%$ & 4 & $10 \%$ & 7 & $17 \%$ & 2 & $5 \%$ & 13 & $31 \%$ & 42 \\
\hline 1999 & 36 & $67 \%$ & 9 & $17 \%$ & 6 & $11 \%$ & 3 & $6 \%$ & 18 & $33 \%$ & 54 \\
\hline 2000 & 30 & $65 \%$ & 10 & $22 \%$ & 3 & $7 \%$ & 3 & $7 \%$ & 16 & $35 \%$ & 46 \\
\hline TOTAL & 306 & $59 \%$ & 79 & $15 \%$ & 96 & $18 \%$ & 42 & $8 \%$ & 217 & $41 \%$ & 523 \\
\hline
\end{tabular}

\footnotetext{
5 Em 14 fichas de alunos inscritos no mestrado da Ensp não consta a naturalidade.
} 
Tabela 8 - Origem geográfica dos doutorandos da Ensp (1980-1998): valores absolutos e percentuais ${ }^{6}$

\begin{tabular}{c|c|c|c|c|c|c|c|c|c|cc}
\hline Ano & Med & & Saúde & & C H.S & & Outras & & Não Med & \multicolumn{2}{|c}{ TOTAL } \\
\hline 1980 & & $0 \%$ & 2 & $100 \%$ & & $0 \%$ & & $0 \%$ & 2 & $100 \%$ & 2 \\
\hline 1981 & 2 & $50 \%$ & & $0 \%$ & 2 & $50 \%$ & & $0 \%$ & 2 & $50 \%$ & 4 \\
\hline 1983 & 1 & $100 \%$ & & $0 \%$ & & $0 \%$ & & $0 \%$ & 0 & $0 \%$ & 1 \\
\hline 1985 & 1 & $50 \%$ & 1 & $50 \%$ & & $0 \%$ & & $0 \%$ & 1 & $50 \%$ & 2 \\
\hline 1986 & & $0 \%$ & 1 & $50 \%$ & 1 & $50 \%$ & & $0 \%$ & 2 & $100 \%$ & 2 \\
\hline 1987 & 1 & $50 \%$ & & $0 \%$ & 1 & $50 \%$ & & $0 \%$ & 1 & $50 \%$ & 2 \\
\hline 1991 & 11 & $55 \%$ & 2 & $10 \%$ & 4 & $20 \%$ & 3 & $15 \%$ & 9 & $45 \%$ & 20 \\
\hline 1992 & 13 & $59 \%$ & 3 & $14 \%$ & 3 & $14 \%$ & 3 & $14 \%$ & 9 & $41 \%$ & 22 \\
\hline 1993 & 2 & $17 \%$ & 3 & $25 \%$ & 6 & $50 \%$ & 1 & $8 \%$ & 10 & $83 \%$ & 12 \\
\hline 1994 & 3 & $25 \%$ & 3 & $25 \%$ & 2 & $17 \%$ & 4 & $33 \%$ & 9 & $75 \%$ & 12 \\
\hline 1995 & 10 & $50 \%$ & 5 & $25 \%$ & 4 & $20 \%$ & 1 & $5 \%$ & 10 & $50 \%$ & 20 \\
\hline 1996 & 5 & $36 \%$ & 5 & $36 \%$ & 3 & $21 \%$ & 1 & $7 \%$ & 9 & $64 \%$ & 14 \\
\hline 1997 & 5 & $28 \%$ & 7 & $39 \%$ & 4 & $22 \%$ & 2 & $11 \%$ & 13 & $72 \%$ & 18 \\
\hline 1998 & 7 & $41 \%$ & 3 & $18 \%$ & 6 & $35 \%$ & 1 & $6 \%$ & 10 & $59 \%$ & 17 \\
\hline TOTAL & 61 & $41 \%$ & 35 & $24 \%$ & 36 & $24 \%$ & 16 & $11 \%$ & 87 & $59 \%$ & 148 \\
\hline
\end{tabular}

\section{Os 'Filhos' da EnsP: um PeRfil QUe MereCe Respeito}

Dos 148 egressos que concluíram o doutorado na Ensp, 41 haviam feito mestrado na mesma instituição. Este seleto grupo compõe a Tabela 9. Na coluna 'ano' nos referimos ao da turma de ingresso no doutorado. Para preservar a privacidade dos alunos, na coluna 'nome' registramos apenas um número. Na coluna intitulada ' $G$ ' está indicado o gênero; em 'formação' consta o curso de graduação realizado pelo ex-aluno. Este breve levantamento encerra-se com a identificação de sua condição de ex-aluno de curso de especialização e seu local de trabalho atual. As quatro primeiras informações foram obtidas na Secretaria Acadêmica da Ensp; as duas últimas, na Plataforma Lattes.

6 Em uma ficha de aluno inscrito no doutorado da Ensp não consta a naturalidade. 
Tabela 9 - 'Filhos' da Ensp

\begin{tabular}{|c|c|c|c|c|c|}
\hline ANO & ALUNO & G & FORMAÇÃO & ESP. & TRABALHO ATUAL \\
\hline 1980 & 1 & $\mathrm{~F}$ & ENFERMAGEM & Não & USP - RP \\
\hline 1991 & 2 & $\mathrm{M}$ & MEDICINA & Fio & ENSP - FIOCRUZ \\
\hline 1991 & 3 & $\mathrm{~F}$ & MEDICINA & Fio & ENSP - FIOCRUZ \\
\hline 1992 & 4 & $\mathrm{~F}$ & MEDICINA & Não & UEM - MARINGÁ \\
\hline 1992 & 5 & F & MEDICINA & Fio & UFRJ \\
\hline 1992 & 6 & $\mathrm{~F}$ & PSICOLOGIA & Fio & ENSP - FIOCRUZ \\
\hline 1992 & 7 & $\mathrm{M}$ & MEDICINA & Fio & ENSP - FIOCRUZ \\
\hline 1992 & 8 & $\mathrm{~F}$ & MEDICINA & Fio & ENSP - FIOCRUZ \\
\hline 1992 & 9 & $\mathrm{~F}$ & MEDICINA & Sim & OMS - BRASILIA \\
\hline 1992 & 10 & F & MEDICINA & Fio & ENSP - FIOCRUZ \\
\hline 1992 & 11 & F & MEDICINA & Fio & UFPA - PARÁ \\
\hline 1994 & 12 & F & NUTRIÇÃO & & SEM LATTES \\
\hline 1994 & 13 & $\mathrm{~F}$ & (SEM INFO) & Fio & ENSP - FIOCRUZ \\
\hline 1994 & 14 & F & MEDICINA & Fio & UFRJ \\
\hline 1994 & 15 & $\mathrm{~F}$ & MEDICINA & Fio & ENSP - FIOCRUZ \\
\hline 1995 & 16 & $\mathrm{M}$ & MEDICINA & Fio & UFMG - MG \\
\hline 1995 & 17 & F & MEDICINA & Fio & SMS - RJ \\
\hline 1995 & 18 & $\mathrm{M}$ & SEM LATTES & & SEM LATTES \\
\hline 1995 & 19 & $\mathrm{M}$ & MEDICINA & Fio & UFRJ \\
\hline 1995 & 20 & $\mathrm{M}$ & MEDICINA & Fio & ENSP - FIOCRUZ \\
\hline 1995 & 21 & $\mathrm{~F}$ & ENFERMAGEM & Sim & UNIJUI - RS \\
\hline 1995 & 22 & F & NUTRIÇÃO & $\operatorname{sim}$ & UFPEL - RS \\
\hline 1996 & 23 & $\bar{M}$ & MEDICINA & Fio & UNIRIO \\
\hline 1996 & 24 & $\mathrm{~F}$ & NUTRIÇÃO & $\operatorname{sim}$ & UFRJ \\
\hline 1996 & 25 & $\mathrm{~F}$ & ENG. SANITÁRIA & Fio & ENSP - FIOCRUZ \\
\hline 1996 & 26 & F & NUTRIÇÃO & Fio & UERJ \\
\hline 1996 & 27 & $\mathrm{~F}$ & SERVIÇO SOCIAL & Fio & FIOCRUZ \\
\hline 1997 & 28 & $\bar{M}$ & SEM LATTES & & SEM LATTES \\
\hline 1997 & 29 & $\mathrm{~F}$ & ENFERMAGEM & Fio & HEC - FIOCRUZ \\
\hline 1997 & 30 & F & ENFERMAGEM & Fio & UERJ \\
\hline 1997 & 31 & $\mathrm{~F}$ & PSICOLOGIA & Fio & UFRJ \\
\hline 1997 & 32 & $\mathrm{~F}$ & (SEM INFO) & Fio & ENSP - FIOCRUZ \\
\hline 1997 & 33 & F & SOCIOLOGIA & Não & IFF - FIOCRUZ \\
\hline 1998 & 34 & $\mathrm{~F}$ & PSICOLOGIA & Fio & UFF \\
\hline 1998 & 35 & $\mathrm{M}$ & MEDICINA - PERU & Fio & INCA \\
\hline 1998 & 36 & $\mathrm{~F}$ & PSICOLOGIA & Fio & ENSP - FIOCRUZ \\
\hline 1998 & 37 & $\mathrm{~F}$ & PEDAGOGIA & Fio & UFF \\
\hline 1998 & 38 & F & PSICOLOGIA & Fio & UNC - ST. CATARINA \\
\hline 1998 & 39 & $\mathrm{~F}$ & MEDICINA & Fio & HEC - FIOCRUZ \\
\hline 1998 & 40 & F & MEDICINA & Fio & UNIR - RONDONIA \\
\hline 1998 & 41 & $\mathrm{~F}$ & ENFERMAGEM & Fio & IELUSC - ST. CATARINA \\
\hline
\end{tabular}


Os dados obtidos revelam a supremacia feminina: Entre os 41 'filhos' da Ensp encontramos apenas nove homens, dois dos quais não têm currículo na Plataforma Lattes. Este fato pode significar que não tenham seguido carreira acadêmica, universitária ou de pesquisa. Em termos de formação profissional, na graduação a incidência maior é de médicos. Dezenove dos 41 'filhos' da Ensp fizeram graduação em medicina. Este número parece ser ainda maior até a turma de 1995. Até então haviam 22 'filhos' da Ensp, dos quais 15 eram médicos. A partir de 1996 esta tendência inverteu-se. Dos 19 restantes, apenas quatro haviam feito medicina na graduação. A proliferação de origens profissionais predomina, sobretudo a partir desta data, quando foi observada a presença significativa de enfermeiras e psicólogas, em maior número, e de assistentes sociais, nutricionistas, pedagogas, engenheiras e sociólogas. Todas mulheres.

$\mathrm{O}$ aspecto que mais nos chamou a atenção, na análise dos currículos destes 41 doutores da Ensp, é que quase todos haviam feito cursos de especialização na própria Fundação Oswaldo Cruz. A impressão que se tem é que estes cursos serviram como porta de entrada para a pós-graduação stricto sensu. Entre os 'filhos' da Ensp, há quem tenha feito o curso básico ou de especialização de saúde pública, de epidemiologia das doenças endêmicas, de saúde mental, de malariologia, de programação e gerência de sistemas ou de pneumologia sanitária. Alguns não fizeram sua especialização na Fundação Oswaldo Cruz. Apenas membros desse grupo não fizeram, antes do mestrado, um curso de especialização.

No que se refere à atuação profissional posterior à conclusão do doutorado, a endogenia parece ter predominado, sobretudo até 1995. Até aquele ano, nove dos 22 'filhos' da Ensp permaneceram trabalhando na mesma instituição onde fizeram sua formação de mestrado e doutorado. Depois, esta tendência diminuiu. Os 'filhos' da Ensp espalharam-se pelo país, concentrando-se a maioria no Rio de Janeiro. No entanto, cabe assinalar que nos estados de São Paulo, Minas Gerais, Paraná, Santa Catarina, Rio Grande do Sul, Brasília, Pará e Rondônia existem 'filhos' da Ensp, todos desempenhando papel de destaque na pesquisa e formação de novos sanitaristas e/ou atuando na gestão e planejamento de serviços de saúde.

$\mathrm{O}$ refinamento da pesquisa que estes dados traduzem indicam a predominância das tendências verificadas no conjunto da amostra. Os profissionais com graduação em medicina prevaleceram nos primeiros anos, mas vêm perdendo espaço para os graduados em outras áreas, sobretudo os de enfermagem e psicologia. Os homens, que na amostra geral já eram 
em número menor do que as mulheres, perdem sua participação no contingente de 'filhos' da Ensp.

Neste estudo não foi verificada a origem geográfica de cada 'filho' da Ensp, mas observou-se seu destino. A maioria deles veio a trabalhar no Rio de janeiro, sobretudo na Fundação Oswaldo Cruz, particularmente na própria Ensp. Não é desprezível, entretanto, o número de profissionais que atuam nos mais diferentes cantos do país, em importantes instituições de ensino e pesquisa. Este dado revela o impacto que os 'filhos' da Ensp podem ter na formulação de políticas públicas, na produção acadêmica e na formação de futuros sanitaristas.

\section{CONSIDERAÇÕES FINAIS}

Nos últimos anos houve um crescente reconhecimento da necessidade de institucionalização da prática da avaliação nos cursos de graduação e pós-graduação. Uma das razões que justificam este esforço está relacionada com a legítima reivindicação de diversos segmentos da sociedade civil, que clamam pela verificação do uso e do retorno social do investimento público em educação.

O modelo de avaliação da Capes é indicador relevante quanto ao credenciamento e à qualidade dos cursos de pós-graduação. Não fosse assim, haveria a pletora de cursos sem qualidade e controle que se observa na graduação, onde o ensino parece caminhar a passos largos para a mercantilização.

A avaliação que a Capes desenvolve e que a transformou em uma agência respeitada em todo o país combina componentes objetivos e subjetivos. Por um lado, introduziu um sistema de informações quantificáveis bastante completo, com número de professores, linhas de pesquisa, trabalhos publicados e dissertações e/ou teses defendidas, entre outros dados. Por outro lado, a agência organiza visitas periódicas aos programas de pós-graduação, procurando introduzir critérios subjetivos em sua análise. No final, os programas são pontuados com uma nota que traduz, em linhas gerais, a qualidade do curso, a atividade do corpo docente e a qualidade da produção acadêmica de alunos e professores.

Simon Schwartzman (1982) vem analisando os critérios utilizados pela Capes nas avaliações que esta agência desenvolve junto aos programas de pós-graduação do país. O Núcleo de Pesquisas sobre Ensino Superior (Nupes) da Universidade de São Paulo (USP) tem feito esforço semelhante. Em geral, os pesquisadores que tratam do tema são unânimes em ratificar 
a importância das avaliações desenvolvidas pela Capes, tecendo alguns comentários que visam a torná-la ainda mais completa e adequada a cada área do conhecimento e região deste imenso país.

Nosso intuito com este artigo foi, em primeiro lugar, apresentar um perfil dos egressos dos cursos de pós-graduação stricto sensu da Ensp; um perfil ainda incompleto e que pode ser aperfeiçoado, se prosseguirem as investigações sobre as questões e hipóteses aqui assinaladas.

Sugerimos, também, à comunidade de professores, pesquisadores, alunos, ex-alunos e amigos da Ensp que seja feita uma avaliação permanente e sistemática de seus egressos. Uma avaliação que monitore suas expectativas e (in)satisfações, que acompanhe sua trajetória fora da Ensp, que verifique se os ideais de Anísio Teixeira sobrevivem - ou seja, se os cursos de pós-graduação da Ensp têm assegurado a existência de pessoal especializado em quantidade e qualidade suficientes para atender às necessidades dos empreendimentos públicos e privados que visam ao desenvolvimento do país. A impressão que temos, ao conhecermos os 'filhos' da Ensp, é de que este sonho se tornou, em boa parte, realidade. Cabe entrar em contato com os egressos, sofisticar a amostragem, cruzar os dados e pensar novas hipóteses e questões.

No mesmo sentido, a lei que criou a Capes em 1992 propunha que instituições como a Ensp formassem recursos humanos altamente qualificados para a docência de grau superior, a pesquisa e o atendimento da demanda dos setores público e privado. A avaliação e o acompanhamento de seus egressos contribuem também para fazer com que a Ensp se assegure ainda mais do papel central que desempenha no processo de profissionalização do sanitarista no Brasil, seja como gestora de serviços de saúde, formadora de pesquisadores e professores e mesmo formador de outras ou de gerações de sanitaristas.

A avaliação e o acompanhamento do egresso podem servir, finalmente, para analisar e intervir nas tendências predominantes, reformatando o objetivo e o planejamento estratégico da unidade. Os dados fornecidos por esta pesquisa e por seu prosseguimento, bem como pelo acompanhamento do egresso podem ser incorporados ao conjunto de indicadores utilizados na avaliação institucional da Escola.

Está na hora de ser feita uma avaliação que leve em consideração o desempenho dos egressos? No nosso entender toda hora é hora de avaliar o fruto de nosso esforço. O momento das comemorações dos 50 anos da Ensp parece ainda mais propício para que seja iniciado tal empreendimento. 


\section{REFERÊNCIAS BIBLIOGRÁFICAS}

BRASIL. Legislação e Normas da Pós-Graduação. 2.ed. Brasília: Funadesp, 2002.

FERREIRA, M. M. \& MOREITA, R. L. Capes/50 Anos: depoimentos ao CPDOC. Brasília: Capes, 2002.

SCHWARTZMAN, S. Avaliando a pós-graduação: a prática da teoria. Iuperj, 10 dez. 1982. (Trabalho apresentado na reunião com a coordenação de programas de pós-graduação). Friburgo, 20 a 22 de outubro de 1982. (Série Estudos, 10)

\section{BIBLIOGRAFIA}

CASTRO, M. H. M. A pós-graduação em zoom. Três casos revisitados. Núcleo de Pesquisas sobre Ensino Superior (Nupes) Universidade de São Paulo. Documento de Trabalho 6/91, 1991 (Mimeo.)

DURHAN, E. \& SCHWARTZMAN, S. Avaliação do Ensino Superior. São Paulo: Edusp. 1992.

MEDEIROS, G. K. et al. Formação profissional versus mercado de trabalho no vale do Itajaí: um estudo avaliatório. Revista Brasileira de Estudos Pedagógicos, 73(174): 361-379, maio-ago., 1992.

MORAES FERREIRA, M. \& LUZ MOREIRA, R. Capes/50 Anos: depoimentos ao CPDOC. Brasília: Capes, 2002.

PENA, M. D. C. Acompanhamento dos egressos no âmbito educacional brasileiro: análise da situação profissional dos diplomados nos cursos de Engenharia Industrial - Elétrica e Mecânica do CEFET-MG, no período de 1983 a 1994, 2000. Dissertação de Mestrado. Belo Horizonte: Centro Federal de Educação Tecnológica de Minas Gerais.

THOME, E. G. da R. O egresso do curso e enfermagem da Unisinos e sua situação ocupacional, 1991. Dissertação de Mestrado. Porto Alegre: PUC-RS. 


\title{
9. Escola Nacional de Saúde Pública Sergio Arouca: UMA REFLEXão PESSOAL
}

\author{
Jorge Antonio Zepeda \\ Bermudez
}

\section{INGRESSANDO NA ENSP: 1974}

Ao ingressar na Escola Nacional de Saúde Pública (Ensp) para aqui iniciar minhas atividades profissionais como técnico de laboratório de nível superior, senti um profundo respeito, admiração e uma imensa alegria. Posso dizer que essas mesmas emoções me acompanham enquanto escrevo estas palavras, muitos anos depois. Posso afirmar, também, com muito orgulho que, pelo fato de ter ingressado nesta casa nos idos de 1974, exatamente em $1^{\circ}$ de novembro daquele ano, e por ter passado aqui exatos 30 anos, tive a oportunidade de acompanhar de perto mais da metade de sua história, desses 50 anos que marcaram o Brasil. Ao longo desse período em que atuo na escola, além de técnico de laboratório de nível superior, fui auxiliar de ensino, professor assistente (por concurso em 1976) e, hoje, sou pesquisador titular, além de ter ocupado diversos cargos, dentro e fora da Ensp e da própria Fundação Oswaldo Cruz (Fiocruz).

Naqueles idos dos dias iniciais, em plena época da repressão militar, a Ensp era palco de uma efervescência de idéias, debates, ideais e propostas para avançar cada vez mais nas questões sociais no Brasil. Os debates contagiantes logo me entusiasmaram, pois vinha eu de uma área, embora mais clínica, também envolvida na discussão dos problemas sociais que afligiam o país.

Recém-egresso da Faculdade de Medicina da Universidade Federal do Rio de Janeiro (UFRJ), ao entrar no curso de mestrado em Medicina Tropical - localizado no Pavilhão Carlos Chagas, nos fundos do Hospital São Francisco de Assis na à Avenida Presidente Vargas -, tive meus primeiros contatos com a virologia médica no Departamento de Ciências Biológicas 
(DCB) da Ensp, departamento então chefiado por nosso atual pesquisador emérito Luiz Fernando Ferreira. Nesse departamento, estabeleci minha base de interlocução, de debate e de embates, de discussão de propostas, de luta institucional, de efetivo pertencimento. Lembro-me nitidamente que o DCB delimitava, como campos de trabalho e de debates, as áreas de helmintologia, com o próprio Luiz Fernando; protozoologia, com Sérgio Coutinho e Carlos Maurício de Andrade; bacteriologia, com Jarbas Andrade e Maria Diana Lacerda; e virologia, com Hermann Shatzmayr e Akira Homma. É interessante observar que três desses pesquisadores ocupariam mais tarde, em períodos e em circunstâncias absolutamente diferentes entre si, a presidência da Fiocruz.

\section{Antes da Abertura Democrática: PRé-1985}

Na segunda metade da década de 1970, a Ensp fervilhava de com novas propostas. Participamos da gestão colegiada do curso básico de saúde pública, acompanhamos o ingresso de novas lideranças, as discussões do Programa de Estudos Socioeconômicos em Saúde (Peses) e do Programa de Estudos Populacionais e Epidemiológicos (Peppe). Recordo-me com clareza, pois na época participava do Conselho de Ensino, Pesquisa e Extensão da Escola (Consepe/Ensp). No mesmo período houve uma iniciativa de fortalecimento das atividades de pesquisa biomédica no Instituto Oswaldo Cruz (IOC), parcialmente às custas do esvaziamento de atividades que vinham sendo implementadas na Ensp, o que poderia ser considerado um paralelismo entre ambas as unidades. Com um caminhão de mudanças estacionado na porta da Ensp, o martelar da retirada de bancadas e de divisórias ecoando pelos corredores do prédio, e do sexto andar sendo retirados equipamentos e aparelhagem, que migravam, junto com profissionais, para novos departamentos no IOC, a direção se recusava a colocar o assunto em discussão por não ter recebido nenhuma comunicação formal da presidência da Fiocruz.

Era a esquizofrenia, a permanente visão de jovens contestadores, às vezes referidos como os 'agitadores de esquerda' em conflito com a tecnocracia instalada na presidência da Fiocruz, e pesados investimentos financeiros acoplados a tentativas de delimitar espaços de atuação no campo da saúde. Tendo como ministro da Saúde Paulo de Almeida Machado, São Paulo recebia altos investimentos nessa área, e a reação do Rio de Janeiro 
era, muitas vezes, entendida como uma contestação ao regime militar - e efetivamente assim o era.

A reforma do Ministério da Saúde em 1976 e as novas diretrizes impressas na saúde a partir de 1979, com Waldyr Arcoverde como ministro da Saúde, levaram um grupo de profissionais do então Serviço Especial de Saúde Pública (Sesp) a assumir a área de controle de doenças do ministério, colocada na estrutura como Secretaria Nacional de Ações Básicas de Saúde, sendo indicado para o cargo de secretário João Baptista Risi Junior. Ao explicitar que, nessa área, precisava do apoio da Fundação Oswaldo Cruz, meu nome foi indicado para a direção da Divisão Nacional de Laboratórios de Saúde Pública. Tais atividades se concentravam até então no Instituto Adolpho Lutz (IAL), de São Paulo, na época reputado o único laboratório de referência para o sistema. Não que fôssemos desconsiderar a excelência do IAL no apoio laboratorial para o controle de doenças, mas trouxemos a discussão para o interior da Fiocruz e reaparelhamos o DCB da Ensp, assumindo, junto ao juntamente com o IAL e um total de cinco instituições de excelência, o papel de Laboratório Nacional de Saúde Publica. Regionalizamos o país, e ficou o DCB responsável pela supervisão e assessoria aos laboratórios nos estados da Bahia, de Minas Gerais, do Espírito Santo e Rio de Janeiro.

Considerando que, além da atuação em âmbito nacional do DCB/Ensp, identificamos e credenciamos também como centros de referência diversas estruturas da Fiocruz, houve, durante vários anos, envolvimento considerável de profissionais da instituição nas atividades de apoio laboratorial ao controle de doenças, água e alimentos nas ações de vigilância sanitária.

Ao também coordenar as atividades ainda incipientes de controle de vacinas para a estratégia de campanhas e dias nacionais de vacinação, estabelecemos as bases para as atividades hoje incluídas no Instituto Nacional de Controle de Qualidade em Saúde (INCQS). Com o apoio da Organização Pan-Americana da Saúde, da Organização Mundial da Saúde (Opas/OMS), inicialmente por intermédio de um grupo de trabalho, incorporamos na rotina as atividades de controle da qualidade dos imunobiológicos utilizados pelo Programa Nacional de Imunização (PNI). O embate político com o setor produtivo, a verificação da qualidade de produtos levaram ao fechamento das atividades da empresa Syntex no Brasil e à crise decorrente de desabastecimento de soros antipeçonhentos e me trouxeram de volta à Fiocruz, cada vez com maior espírito de luta. 


\section{A Nova República: Arouca na presidência}

Não me caberia discorrer, nesta oportunidade, a respeito das qualidades de Sergio Arouca ou de minha convivência com ele. Apenas quero compartilhar algumas palavras sobre o que significou, como dizem no jargão, 'tomar o Castelo com ele em 1985', logo após o convite que recebeu do ministro Carlos Santana, por telefone, para comparecer a Brasília, cuja ligação ele atendeu na sala da direção da Ensp, ao cair daquela tarde imortalizada na fotografia que Christina Tavares, da assessoria de imprensa da presidência, redistribuiu no início do ano passado. $\mathrm{O}$ delírio coletivo e contagiante esteve sempre presente em todas as suas atividades, sempre sonhando para o bem.

Foi pelas mãos de Arouca que tive meu primeiro contato com a área das políticas de medicamentos, que abracei desde que ele me instigou a assumir a direção de Far-Manguinhos em 1985, sem ter tido qualquer contato anterior com a área farmacêutica, paixão súbita que me conduziu em uma trajetória profissional nunca premeditada. Assumi também a presidência do Instituto Vital Brazil em 1987, com Arouca na Secretaria Estadual de Saúde e em uma coalizão de forças políticas nas quais sempre tive nele um interlocutor do mais elevado nível. É o Arouca pensador, humanista, político!

Ainda hoje, chego a considerar que minhas passagens por FarManguinhos, pelo Instituto Vital Brazil e também na gestão central do Ministério da Saúde nunca me afastaram da Ensp. Pelo contrário; sempre a considerei como uma trincheira de idéias e pensamentos capazes de nutrir o Sistema Único de Saúde (SUS) com a formulação de políticas setoriais e de alternativas inovadoras.

De fato, foi efetivamente na Ensp que encontrei sempre o referencial para nortear a luta política por uma assistência farmacêutica integral e pela busca da eqüidade; foi na Ensp que dei início a uma aglutinação de profissionais que, pensando a assistência farmacêutica no SUS, geraram o Centro Colaborador da Opas/OMS em políticas farmacêuticas, assim credenciado a partir de 1998, e hoje, sem lugar para dúvidas, um dos mais produtivos centros de discussão dessa área temática no mundo.

Arouca, na presidência da Fiocruz, representou o fortalecimento da presença marcante da instituição nos mais diversos foros nacionais e internacionais; a consolidação do processo de democracia interna, com a 
eleição de gestores e o estabelecimento do Conselho Deliberativo; a $8^{\mathrm{a}}$ Conferência Nacional de Saúde e a luta pelo capítulo de seguridade social da Constituição de 1988, com a premissa de saúde como direito; a criação de novas unidades e a captação de mais recursos; a incorporação de contingentes de força de trabalho. Foi um período absolutamente fértil em idéias, propostas e realizações.

O ano de 2003 ficou marcado pela perda de Sergio Arouca, que partiu precocemente no dia 2 de agosto, após nos deixar encerrar o Congresso de Saúde Coletiva da Abrasco sem causar a comoção que sabia que iria ocasionar. Não saberia dizer se existe também sabedoria no momento de partir. Existe sabedoria na chegada. A chegada de Arouca à presidência da Fiocruz, em 1985, no bojo da Nova República, mudou os rumos da instituição e sua dinâmica, como já foi decantado em todos os eventos recentes. Sua partida, sem dúvida, deixou um vazio em todos aqueles que tiveram o privilégio, em maior ou menor intensidade, de conviver com ele. Nossa Escola Nacional de Saúde Pública passou a incorporar para sempre o nome de Arouca.

\section{A DÉCADA DE 1990}

A década de 1990 foi extremamente rica em propostas, inovações e parcerias por parte da Ensp. A retomada do doutorado acadêmico e o ingresso da primeira turma em 1990 foram emblemáticos do elevado nível que esse doutorado assumiria. A investida nos cursos descentralizados; o mestrado interinstitucional; a implementação de bases sólidas na educação a distância; a discussão acerca da consolidação, na estrutura organizacional, de uma coordenação de escola de governo em saúde; as primeiras discussões para a criação de uma fundação de apoio que pudesse dar resposta às novas demandas geradas no âmbito das relações com as três esferas de governo que compõem o SUS; as discussões de uma nova modalidade de curso que privilegiasse os serviços e as relações entre os setores acadêmicos e o SUS; a maior interação com as esferas estadual e municipal; e as atividades de efetiva implementação do controle social, por intermédio da capacitação dos integrantes dos conselhos de saúde, são algumas das principais abordagens que estiveram presentes e que nortearam decisões de relevância para a Ensp, a Fiocruz e o conjunto da saúde pública no Brasil. 


\section{A INSERÇÃo dA ENSP NA SAÚdE}

Fazemos sempre questão de assegurar, no discurso e na prática, a inserção da Ensp em todas as iniciativas, nacionais e internacionais, no âmbito da atenção e da promoção à saúde. Em uma das primeiras reuniões do Conselho Deliberativo da Fiocruz, em 2002 - ao comparecer Otávio Mercadante, então chefe de gabinete do ministro e depois secretário executivo do Ministério da Saúde, para apresentar a Agenda Nacional de Saúde 2001, regulamentada por portaria em março de 2001 e definindo seis eixos prioritários de intervenção -, asseguramos que nossa Escola, tanto na prestação direta de serviços à comunidade como na implementação de ações de referência, já atuava e contribuía em todos os eixos de intervenção então deliminados.

Diversas publicações elaboradas pelo Ministério da Saúde, pelo Conselho Nacional de Saúde e por organismos internacionais, nas quais são discutidos temas de elevada relevância, nos informam sobre a atuação efetiva da Ensp em praticamente todos os temas abordados.

Da mesma maneira, a Ensp esteve presente na $8^{\underline{a}}, 9^{\underline{a}}, 10^{\mathrm{a}}, 11^{\mathrm{a}}$ e $12^{\mathrm{a}}$ conferências nacionais de saúde e nas diversas conferências específicas, contribuindo, seus pesquisadores, nas discussões prévias, com documentos e propostas, apoiando, questionando, mas sempre ressaltando o controle social como imperativo e fundamental para a consolidação do SUS. É assim que vemos a potencialização da capacidade da Ensp na formulação de políticas setoriais e estratégias de intervenção e, ao mesmo tempo, assegurando excelência a todos os serviços prestados diretamente à população.

No contexto internacional, o Brasil enfrenta o processo de globalização e as ineqüidades existentes no acesso aos serviços de saúde, a concentração de renda, a exclusão social, monopólios e oligopólios e a dependência tecnológica.

Da mesma maneira que hoje abrigamos o Centro Colaborador da Opas/OMS em Políticas Farmacêuticas, estamos discutindo outras áreas de excelência, entre as quais destacamos saúde e ambiente, junto com a Presidência da Fiocruz e a Opas; controle de doenças não-transmissíveis com a OMS; acesso à atenção para pessoas vivendo com HIV/Aids, junto com Unaids. Estamos, dessa maneira, preparando a Ensp que se integra para se integrar cada vez mais no ao cenário internacional, no desenvolvimento dos sistemas de saúde, mas sempre privilegiando conjuntamente atividades acadêmicas. 
Temos também recebido visitas internacionais de delegações, de intercâmbio, de missões internacionais, de cursos de pós-graduação. Tenho certeza de que, hoje, a Ensp projeta-se para além das fronteiras nacionais, ao estreitar sua interação com a Opas e OMS, bem como com outras agências internacionais.

\section{A Ensp no CONTEXto da Fiocruz}

Desde a primeira reunião do Conselho Deliberativo da Ensp, em 2001, fizemos questão de que todos os chefes de departamento recebessem uma cópia do Plano Quadrienal da Fiocruz, documento de respaldo para a definição de nossas prioridades e inserção em todos os programas institucionais. Conforme explicitado anteriormente, atualiza-se o papel da Fiocruz como instituição estratégica de suporte ao Ministério da Saúde na interface com a ciência e tecnologia e, portanto, de natureza pública e estatal. Os programas institucionais se constituem em marcos de referência para a definição de ações e prioridades.

Uma série de compromissos de gestão e de luta marca nossa equipe de direção, que trabalha de maneira colegiada. Com vistas a uma maior definição de espaços institucionais, interlocução e parcerias, propusemos e colocamos em prática a estrutura atual da direção, com o gabinete e três coordenações: Escola de Governo em Saúde, pós-graduação e Desenvolvimento Institucional e Gestão.

Nossa excelência acadêmica representa compromisso coletivo da equipe de direção. Nesse sentido, estamos envidando todos os esforços e rigor no processo de avaliação trienal da Fundação Coordenação de Aperfeiçoamento de Pessoal de Nível Superior (Capes) e temos certeza absoluta de que estamos no caminho certo. Os elogios à maneira como vem sendo tratada a informação, de acordo com o coordenador da área de saúde coletiva, bem como as avaliações parciais, reforçam a convicção de que estamos caminhando etapa por etapa na busca da excelência. Tudo está sendo feito em nome desse compromisso, assumido desde o primeiro dia de nossa gestão.

Entendemos também a importância da renovação das parcerias e das demandas, geradas por praticamente todos os órgãos do Ministério da Saúde para a capacitação dos quadros dirigentes, seja por intermédio de cursos de especialização, como vem sendo feito com diversos órgãos do ministério, seja com os mestrados profissionais, implementados igualmente 
em parceria com órgãos ministeriais e com a própria Fiocruz. Toda esta demanda está sendo analisada, e as ações implementadas, em conjunto com a Presidência da Fiocruz, para seu atendimento consideram sua complexidade e seus reflexos na avaliação de nosso mestrado acadêmico, sob a égide de nossa Coordenação de Pós-Graduação.

A Escola de Governo em Saúde representa um espaço institucional de articulação dos serviços e produtos de apoio imediato ao SUS, respondendo a demandas geradas pelas necessidades das três esferas de governo. Uma série de frentes de trabalho e oficinas vem sendo executada nesse sentido, entre as quais destacamos a promoção da saúde, o programa de saúde da família e a vigilância sanitária, entre outros de igual importância.

Temos investido no Desenvolvimento Institucional e Gestão com propostas de reformulação completa da estrutura, com uma política interna de recursos humanos que se tornou evidente na organização do último concurso público, capacitação interna de nosso pessoal, programa de modernização da gestão e dos processos administrativos, adequação de infra-estrutura e equipamentos, bem como com uma política de informação e comunicação institucional.

\section{A Ensp de Hoje e o Novo Milênio}

Somos uma Escola de Saúde Pública de grande porte e de grande projeção, não apenas nacional, mas também internacional. Estamos inseridos definitivamente no SUS e no Sistema Nacional de Ciência, Tecnologia e Inovação. Temos, portanto, uma responsabilidade enorme pela frente. Por nossas salas de aula passaram alunos que hoje ocupam cargos da maior relevância no Brasil e também em outros países.

Cabe deixar muito claro que nunca atuamos de forma isolada; pelo contrário, constatamos que a fortaleza da Ensp reside, em grande parte, na capacidade de gerar alianças e parcerias, trabalhar em redes e compartilhar responsabilidades. Instituições sólidas como a nossa são capazes de estabelecer parcerias igualmente sólidas e duradouras. É no trabalho em rede que visualizamos uma abrangência territorial compatível com nossas demandas e com a necessidade de capacitação de recursos humanos que este novo milênio nos traz.

Posso afirmar, também, que a reformatação da estrutura do Ministério da Saúde nos facilitou uma interlocução profícua com o primeiro escalão, fortalecida desde a transição de governo. Temos trabalhado de 
modo integral com todas as secretarias, agências reguladoras e com a Fundação Nacional de Saúde (Funasa). Além da renovação e reestruturação do Ministério da Saúde, também acompanhamos de perto os processos de renovação na Opas, em Washington, e na OMS, em Genebra.

Atuamos na saúde pública com o SUS, mas também temos parcerias e atividades conjuntas na região das Américas e, em escala mundial, com a OMS e outros organismos das Nações Unidas. Destaco, em especial, a área de saúde e ambiente com a Opas; o Centro Colaborador da Opas/OMS em políticas farmacêuticas; cooperação com o Canadá, envolvendo a Abrasco, em promoção da saúde; cooperação com França e Chile em gestão hospitalar; cooperação envolvendo o Japão com saúde do trabalhador; com o Centers for Disease Control and Prevention (CDC) dos EUA em avaliação e HIV/Aids; e em diversas áreas com os Países Africanos de Língua Oficial Portuguesa (Palops).

Reafirmo que nossa excelência acadêmica representa o compromisso coletivo da equipe de direção. Consideramos também como absolutamente prioritárias as parcerias e as demandas geradas por praticamente todos os órgãos do Ministério da Saúde para a capacitação de seus quadros dirigentes, seja por intermédio de cursos de especialização, ou mestrados profissionais.

Esta é a nossa Ensp: a instituição que se faz presente em todos os grandes eventos relacionados com a saúde, dentre eles os congressos no Brasil e no exterior, os eventos internacionais e, da mesma maneira, as conferências nacionais de saúde e as conferências temáticas específicas, bem como outros grandes eventos, como a Assembléia Mundial da Saúde.

Temos muito orgulho do nosso papel e das atividades que aqui se realizam. Temos orgulho de nossos cursos, das nossas publicações. Quero destacar os 20 anos dos Cadernos de Saúde Pública, e seu editor, Carlos Coimbra, e a visão de futuro que tiveram Frederico Simões Barbosa, falecido este ano, e Luiz Fernando Ferreira, nosso pesquisador emérito.

Orgulhamo-nos, sobretudo, de ser a Ensp parte da Fiocruz. Temos, entretanto, ainda muitos desafios pela frente: colaborar na implementação das funções essenciais da saúde pública na região das Américas; contribuir à exaustão com as metas do Plano Quadrienal da Fundação Oswaldo Cruz, com o Plano Pluri-Anual de Governo e com o Plano Nacional de Saúde, sem esquecer o compromisso social com as atividades de ensino, pesquisa e prestação de serviços de referência. A Ensp deve exercer papel efetivo na geração e disseminação do conhecimento, na formulação, implementação 
e avaliação de políticas setoriais no campo da saúde e na capacitação de recursos humanos para o SUS.

Olhar o passado vivendo o presente e pensando o futuro. Ousar e implementar esse delírio coletivo que Arouca sempre mencionava. Estas devem ser as diretrizes a nortear nossas ações, nossa prática, nossos compromissos. A Ensp, essa construção coletiva de 50 anos que marcou o Brasil, nos coloca perante o desafio de lutar sempre, ousar cada vez mais e jamais abandonar a utopia. 
MEMÓRIA FOTOGRÁFICA 

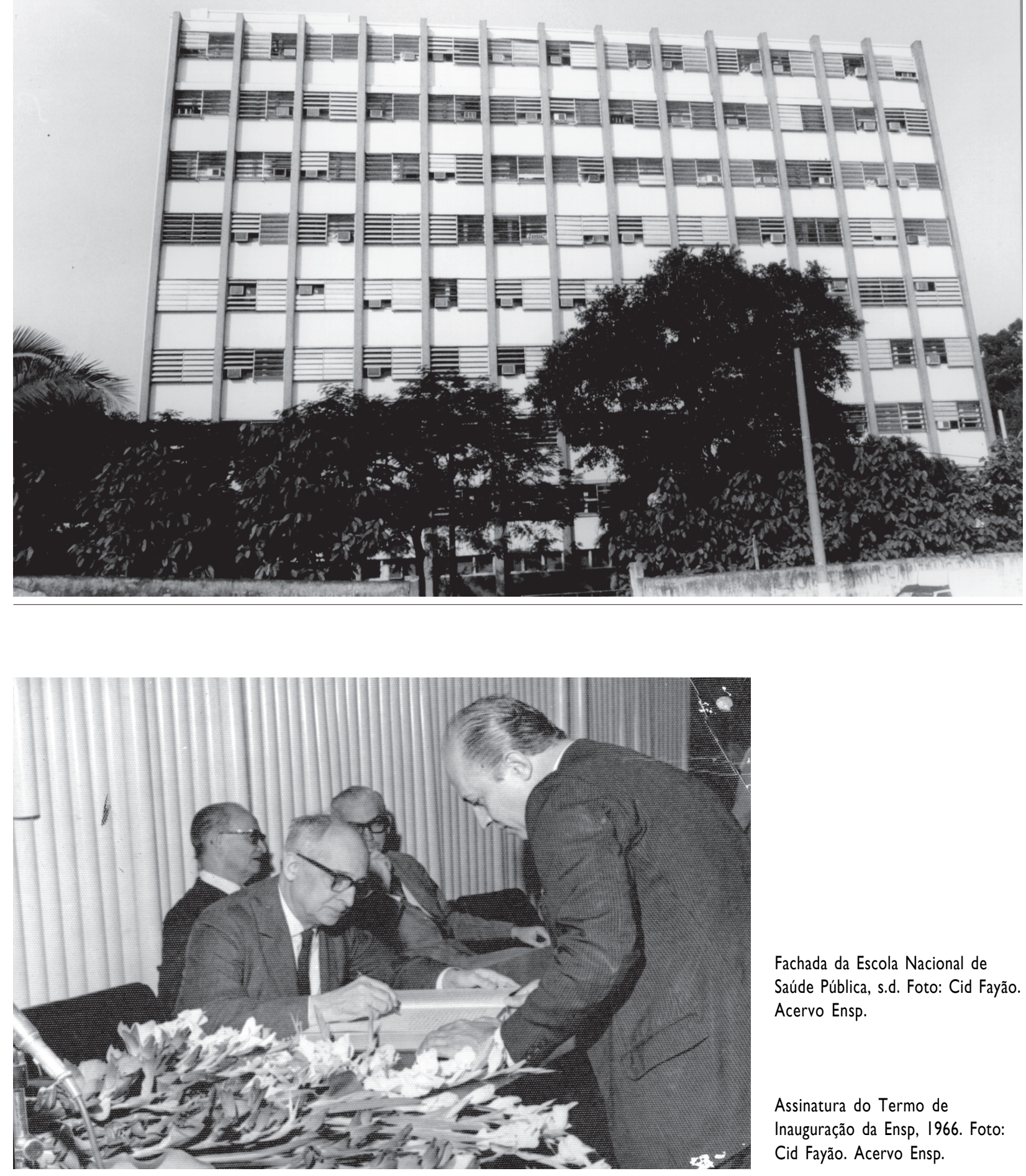

Fachada da Escola Nacional de Saúde Pública, s.d. Foto: Cid Fayão. Acervo Ensp.

Assinatura do Termo de Inauguração da Ensp, 1966. Foto: Cid Fayão. Acervo Ensp. 
Garagem da Ensp, 1967. Foto: Cid Fayão Acervo Ensp.

Turma de Mestrado em Saúde Pública, 1968. Foto: Cid Fayão. Acervo Ensp.
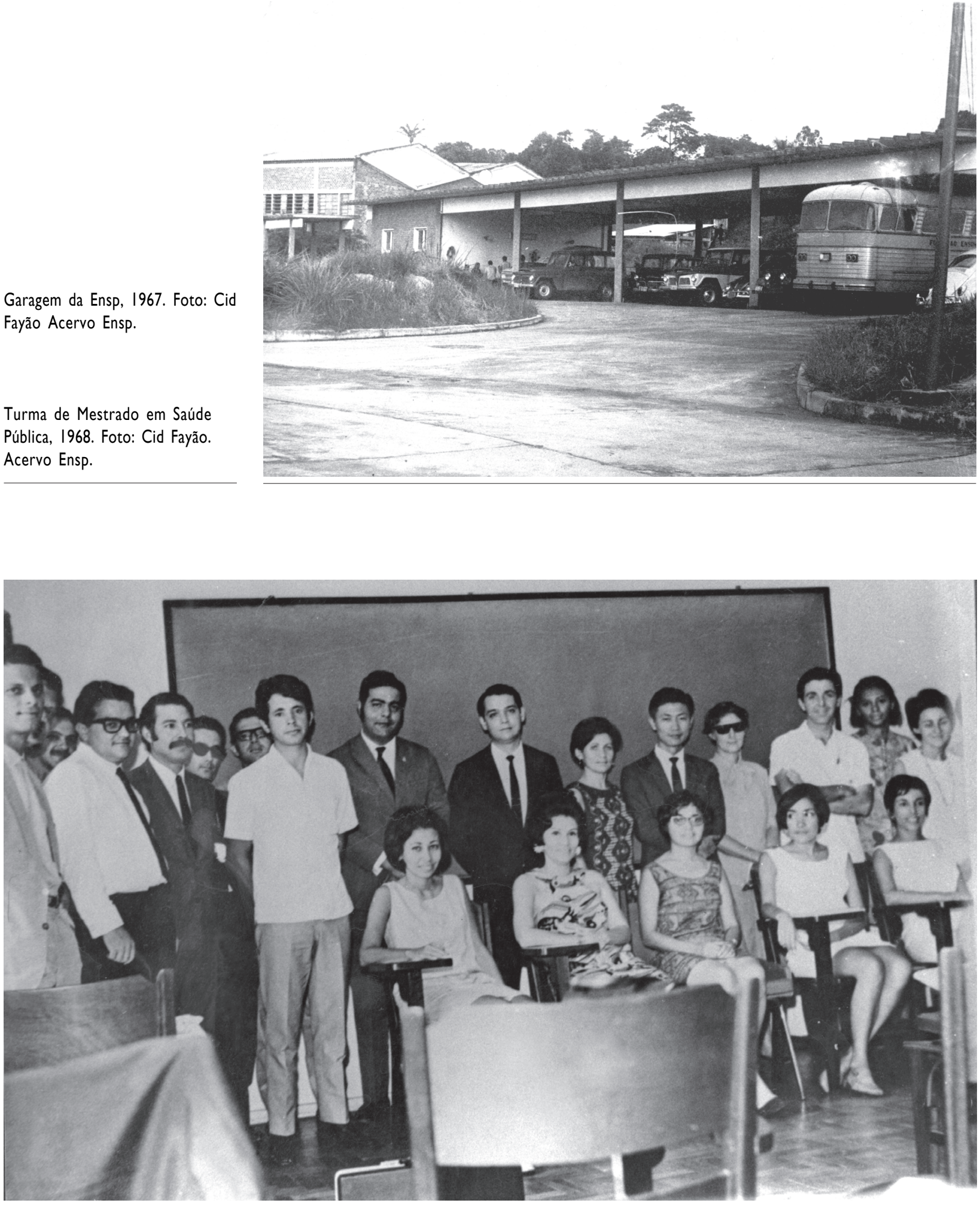

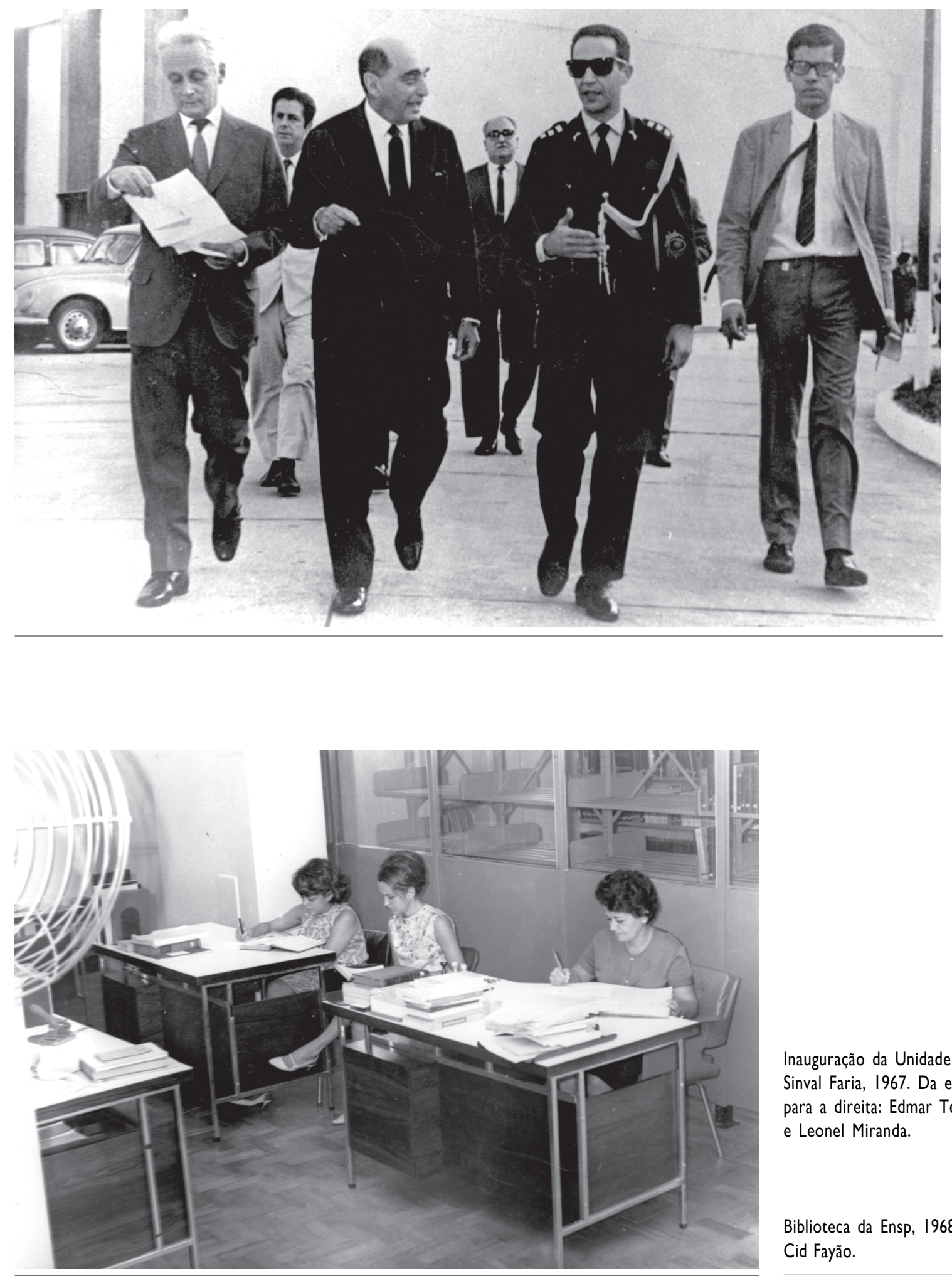

Inauguração da Unidade Germano Sinval Faria, 1967. Da esquerda para a direita: Edmar Terra Blois e Leonel Miranda.

Biblioteca da Ensp, 1968. Foto: Cid Fayão. 


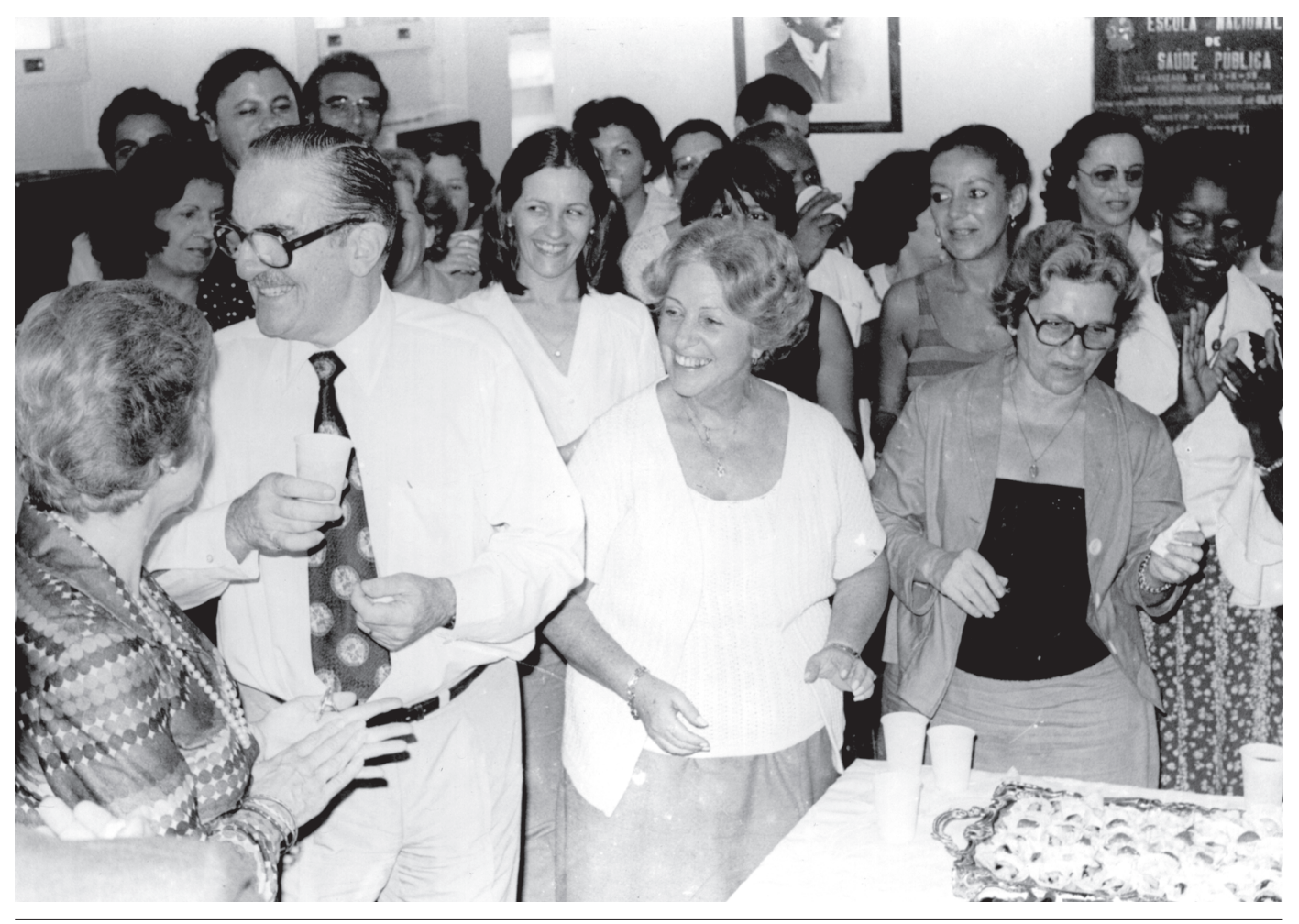

Aniversário de Ernani Braga, s.d. Foto: Cid Fayão. Acervo Ensp.

Aniversário do dr. Maneco Ferreira. Equipe Planificação, Avaliação, Pesquisa e Programas Especiais (Pappe), 1977. Da esquerda para a direita: Antonio Jorge de Almeida, Fernando Leitão, Maneco Ferreira, Zelina, Ernani Braga, Henrique Maia Penido, não identificado e Mário Hamilton. Acervo Particular Fernando Leitão.

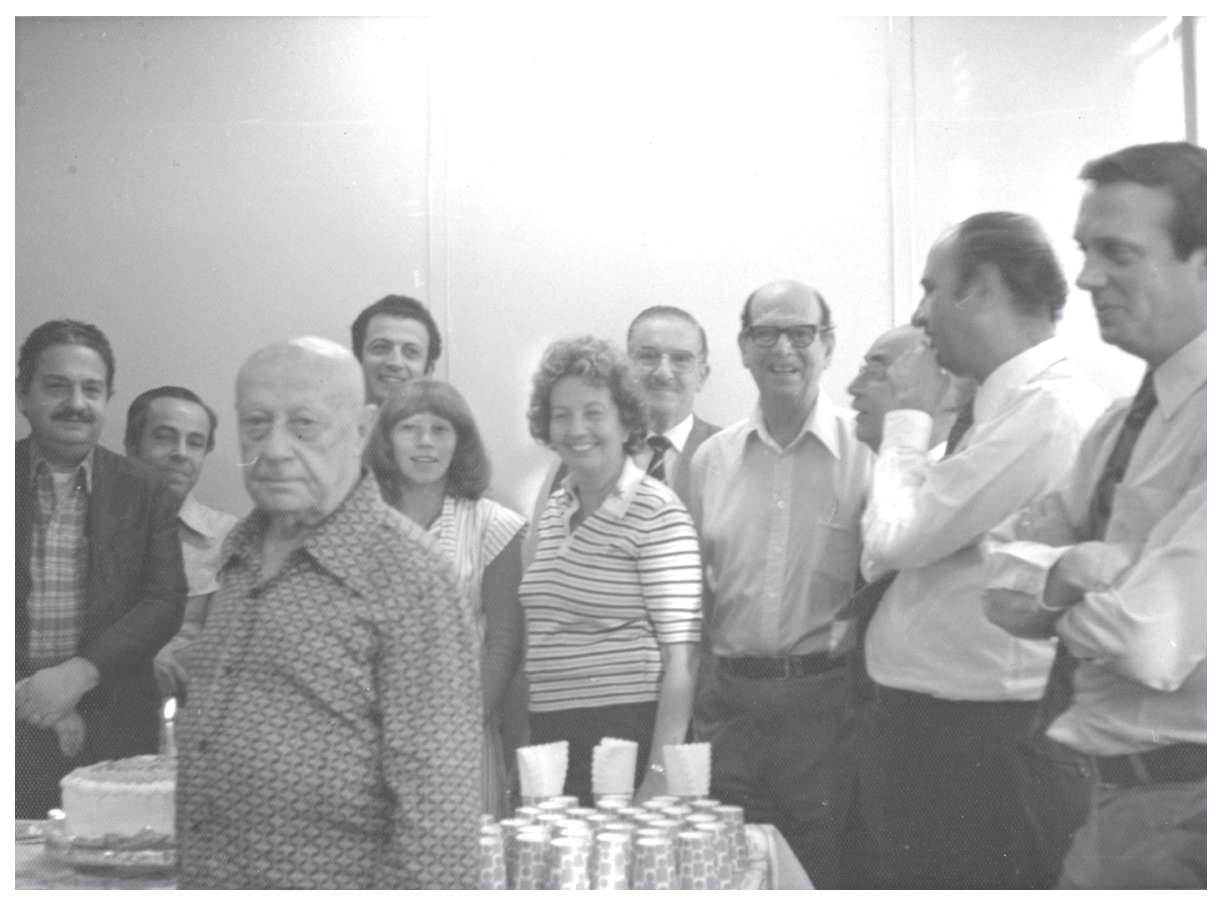



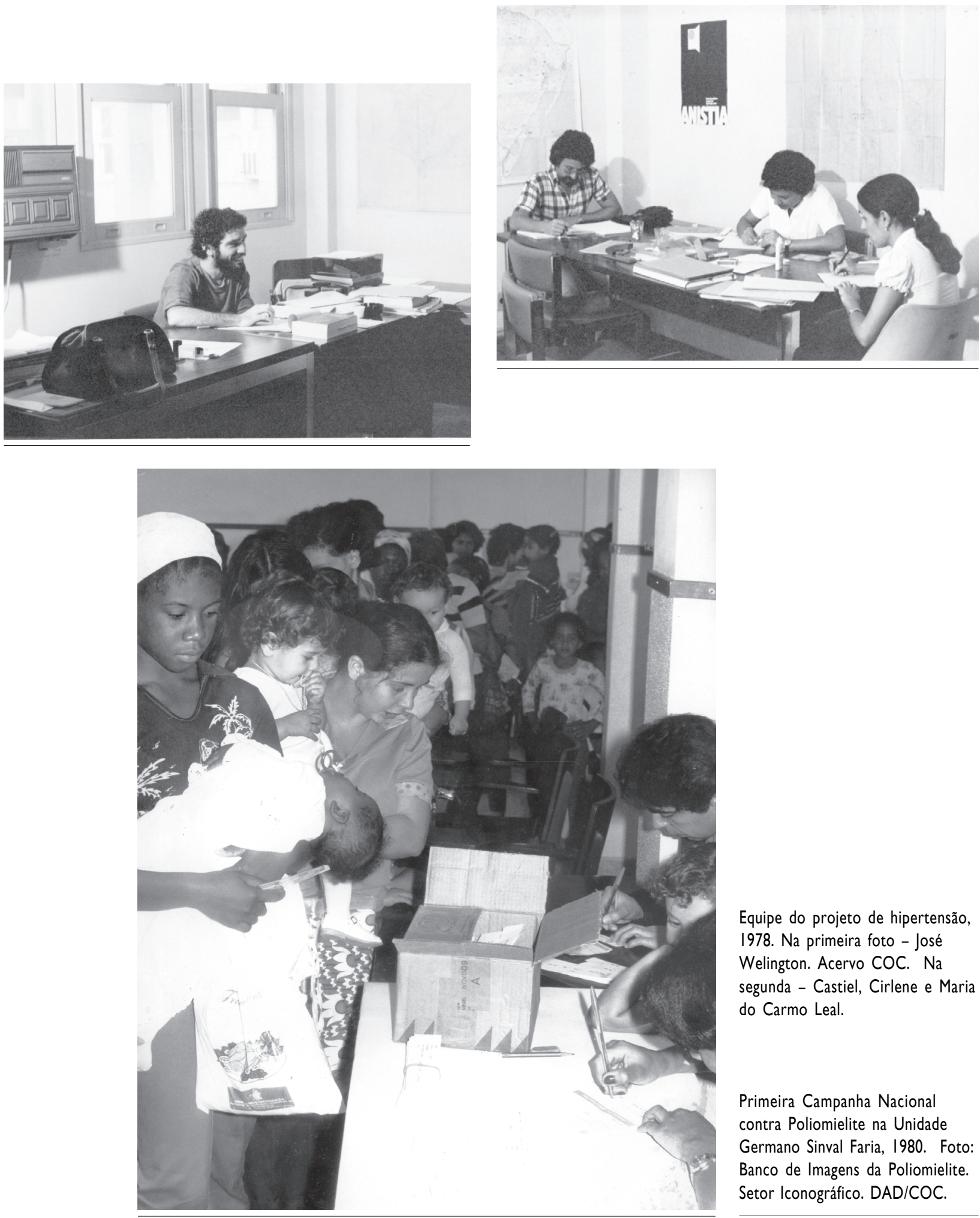

Equipe do projeto de hipertensão, 1978. Na primeira foto - José Welington. Acervo COC. Na segunda - Castiel, Cirlene e Maria do Carmo Leal.

Primeira Campanha Nacional contra Poliomielite na Unidade Germano Sinval Faria, 1980. Foto: Banco de Imagens da Poliomielite. Setor Iconográfico. DAD/COC. 


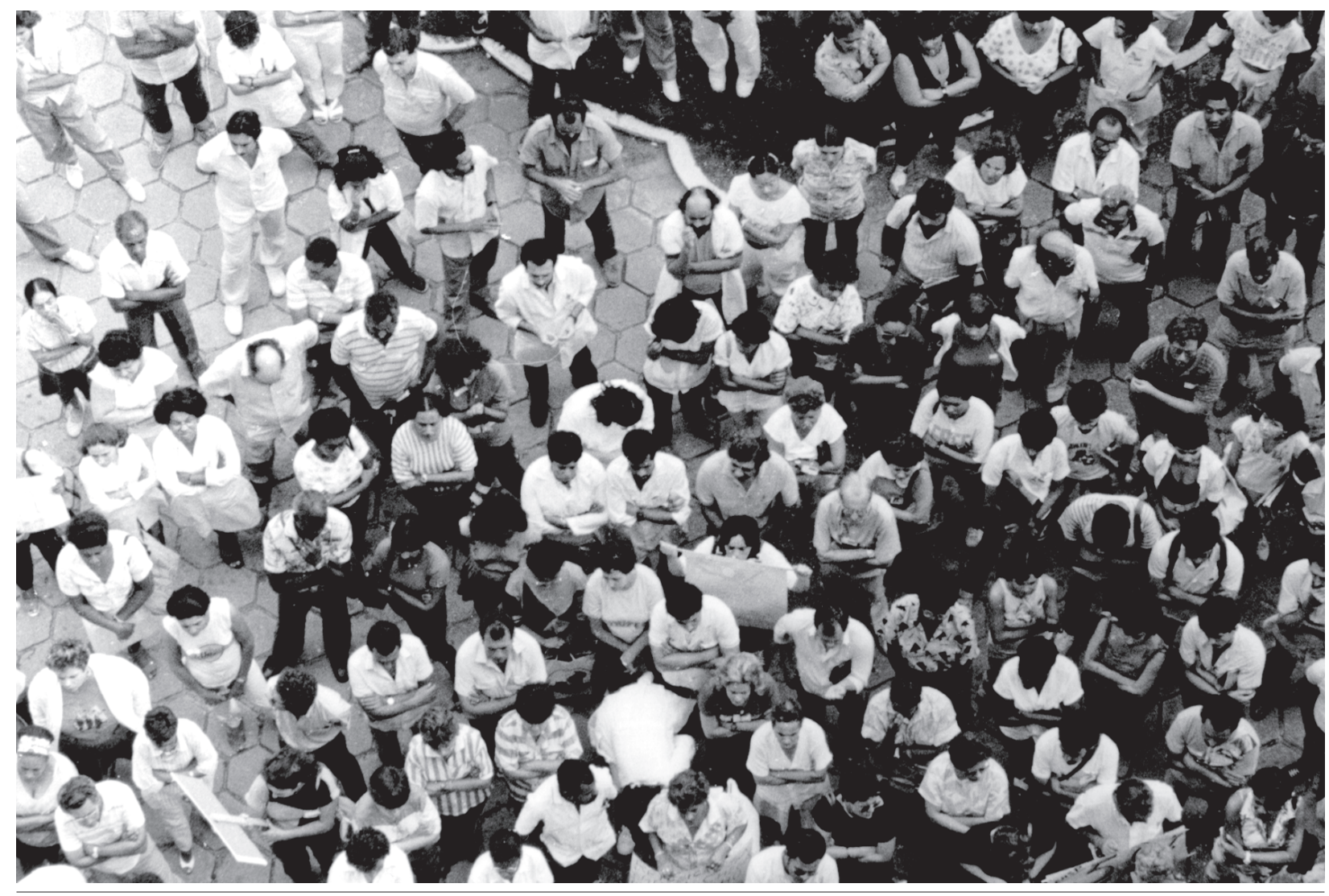

Assembléia na Portaria da Ensp, s.d. Foto: Cid Fayão. Acervo Ensp.

Ministro da Saúde Alcenir Guerra, em visita à Fiocruz, recebe reivindicações dos dirigentes da Asfoc, 1990.

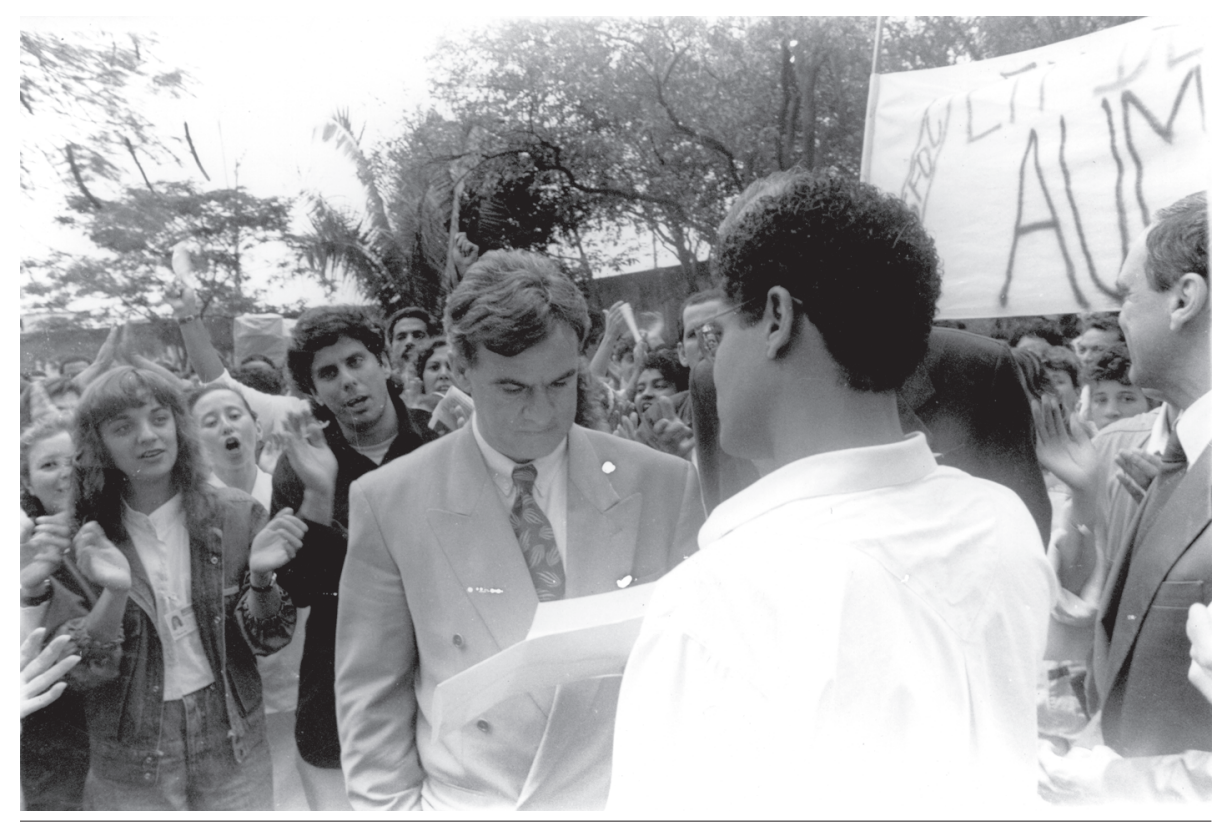




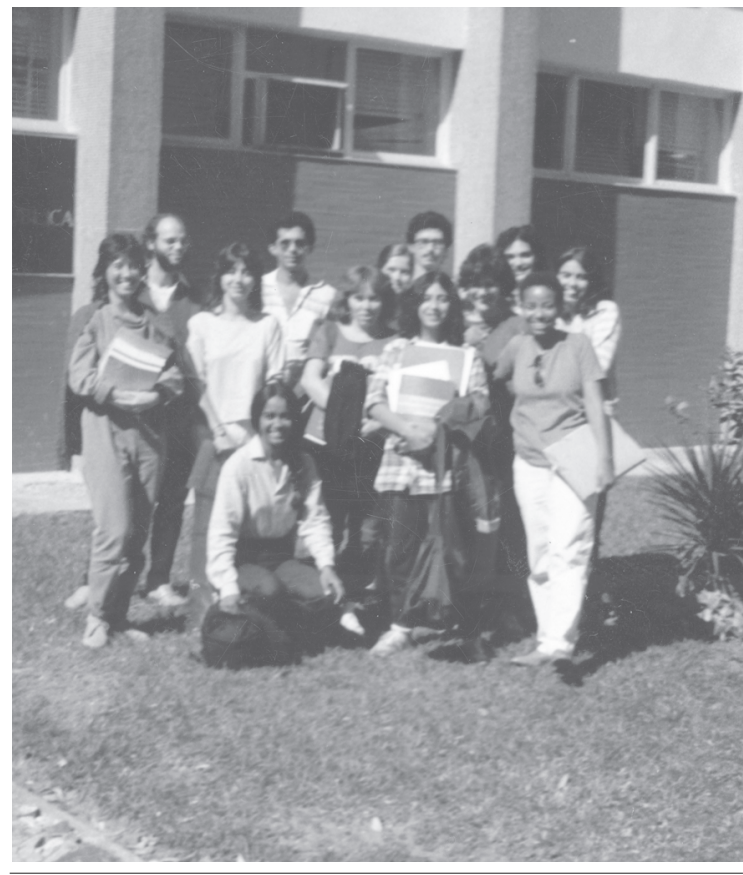

Turma da Residência em 1986.

Acervo Particular José Wellington.

Turma de Biologia, 1972. Foto: Cid Fayão. Acervo Ensp.

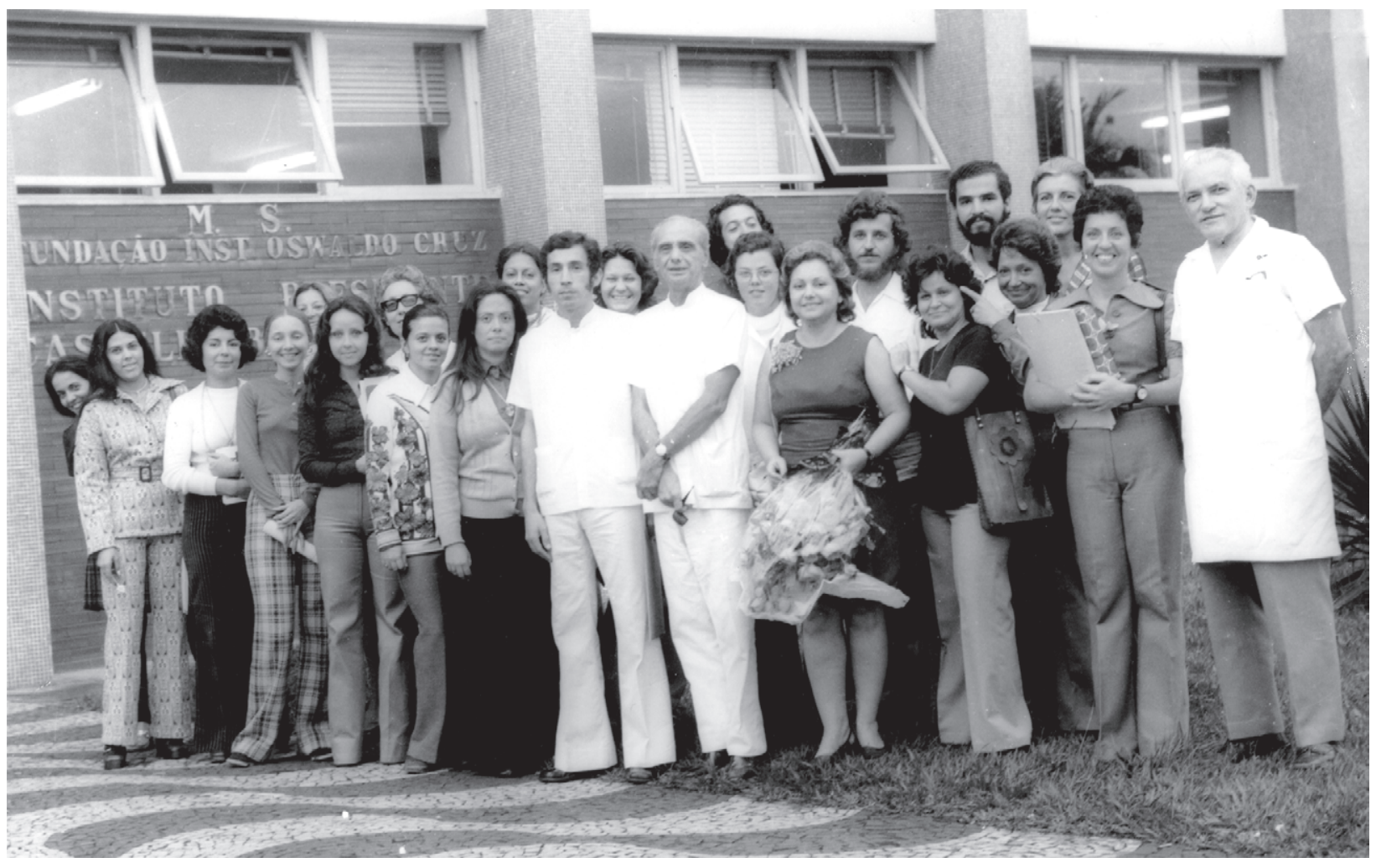




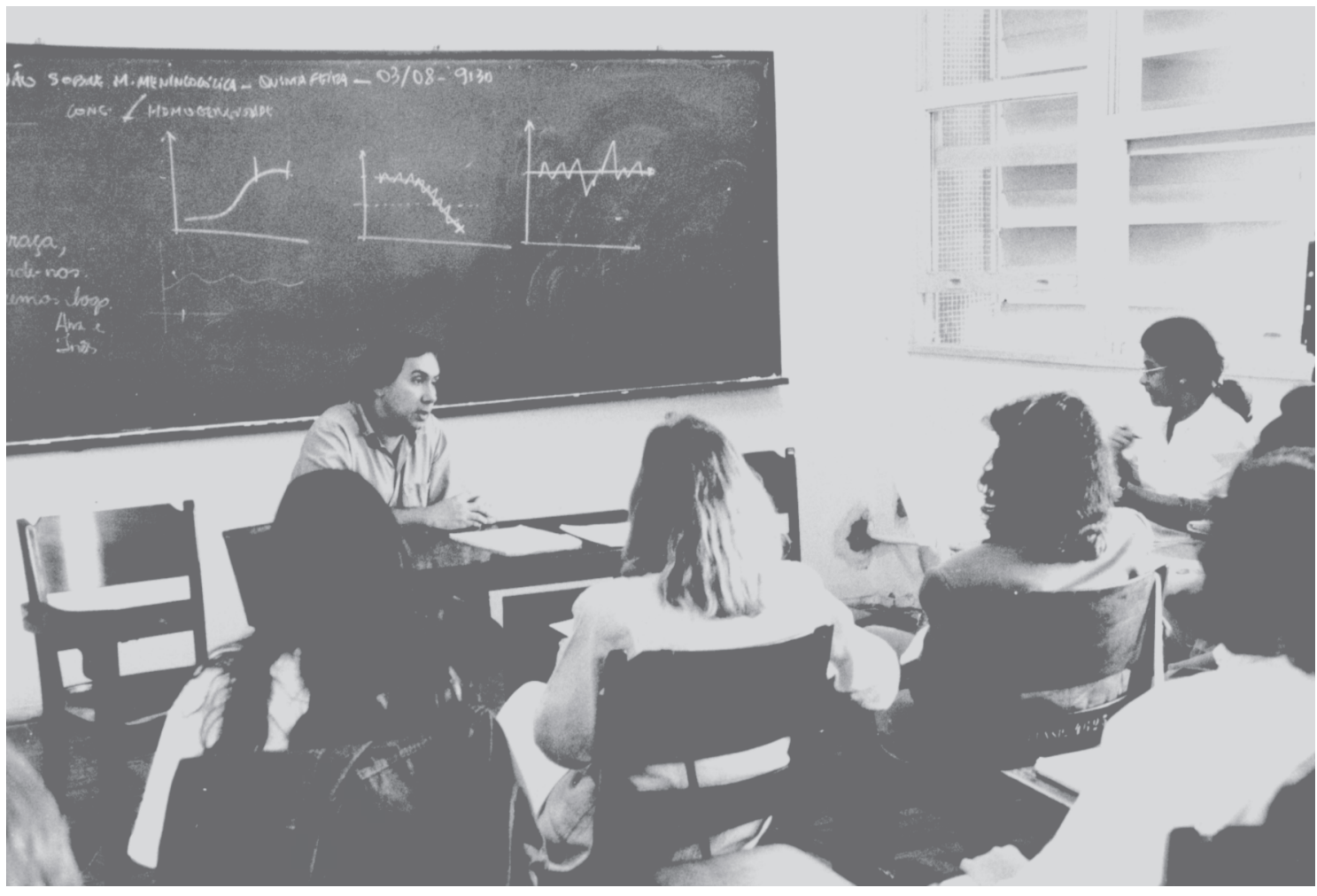

Professor Paulo Sabroza em sala de aula, s.d. Foto: Cid Fayão. Acervo Ensp.

Homenagem a Frederico Simões Barboza. Da esquerda para a direita: Luiz Fernando Ferreira, Paulo Buss, Frederico Simões Barboza e Ulysses Coutinho, março de 1991. Acervo Frederico Simões Barboza/COC.

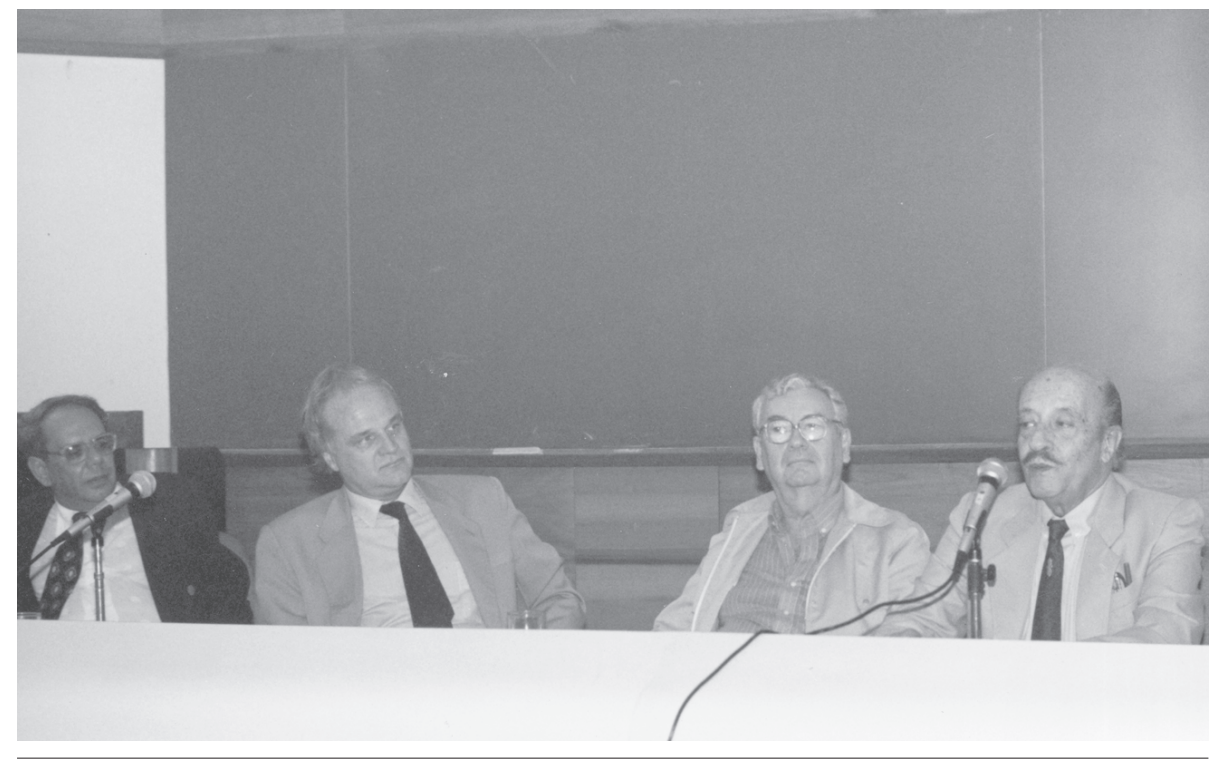




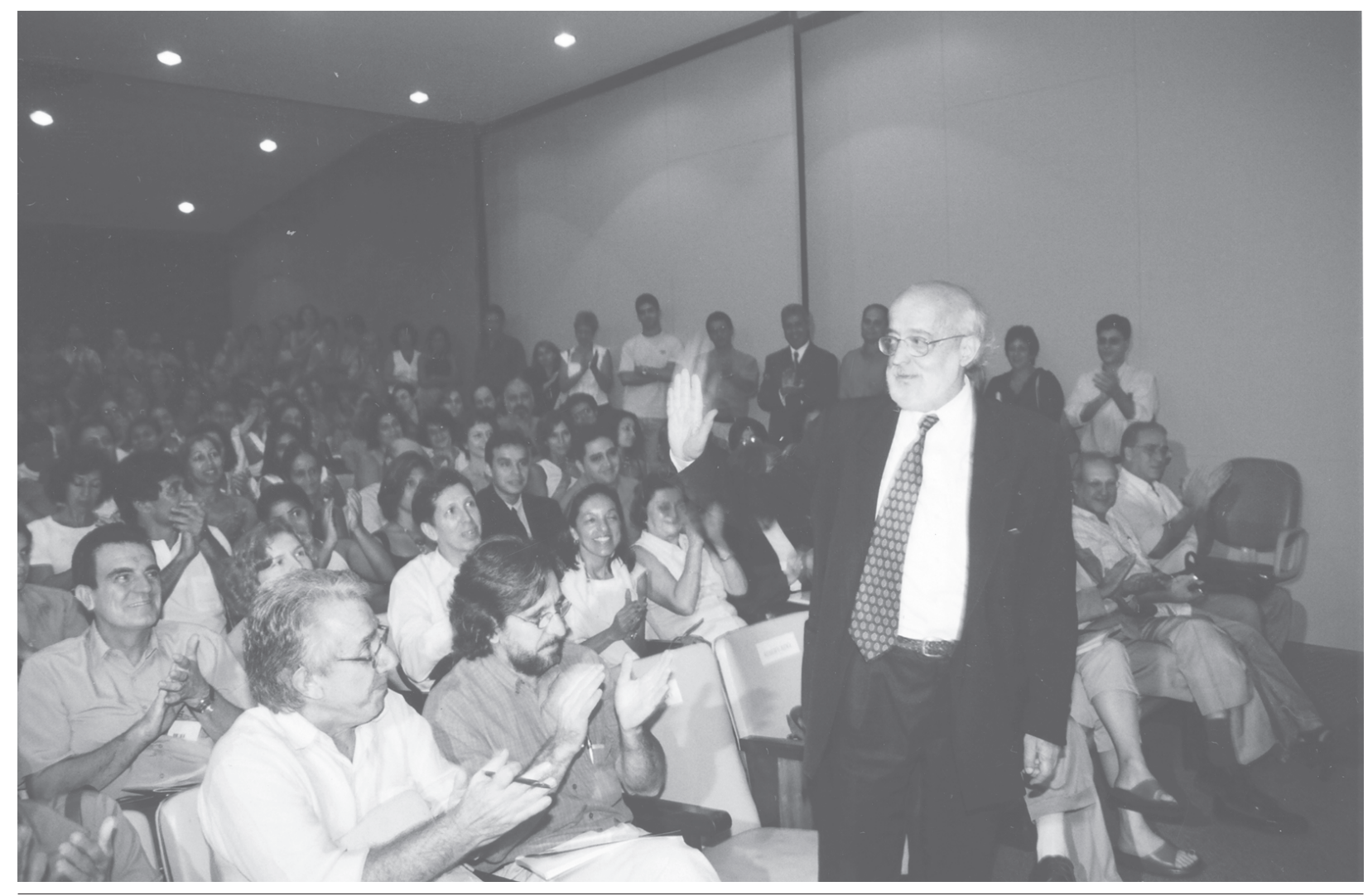

Abertura do ano acadêmico. Aula inaugural de Antonio Sergio Arouca, março de 2003. Foto: Peter Illiciev. Acervo Particular Arlindo Fábio Gómez de Sousa.

Digitalização e tramento de imagens: Roberto Jesus Oscar e Vinícius Pequeno 


\author{
Formato: 21 x $26 \mathrm{~cm}$ \\ Tipologia: Times New Bambara e Gill Sans \\ Papel: Printmax $90 \mathrm{~g} / \mathrm{m}^{2}$ (miolo) \\ Cartão supremo $250 \mathrm{~g} / \mathrm{m}^{2}$ (capa) \\ Fotolito: Grafitipo Gráfica e Editora Ltda.(capa) \\ Fotolitos: ACE Digital (miolo) \\ Impressão e acabamento: Imprinta Gráfica e Editora Ltda. \\ Rio de Janeiro, setembro de 2004. \\ Não encontrando nossos títulos em livrarias, contactar a EDITORA FiocruZ: \\ Av. Brasil, 4036 - Térreo - sala 112 - Manguinhos - 21040-361 \\ Rio de Janeiro - RJ. \\ Tel.: (21) 3882-9039 e 3882-9041 - Telefax: (21) 3882-9006 \\ http://www.fiocruz.br/editora \\ e-mail: editora@fiocruz.br
}

